\title{
Sector-Specific Issues and Reporting Methodologies Supporting the General Guidelines for the Voluntary Reporting of Greenhouse Gases under Section 1605(b) of the Energy Policy Act of 1992
}

\section{Volume II}

Part 4 - Transportation Sector

Part 5 - Forestry Sector

Part 6 - Agricultural Sector

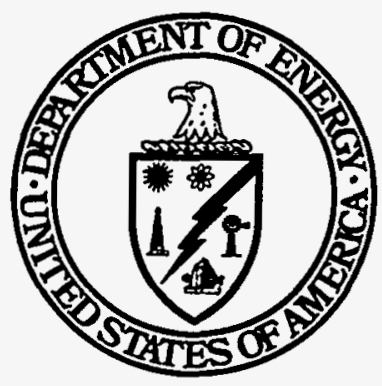

October 1994

United States Department of Energy

Washington, DC 20585 


\section{DISCLAIMER}

This report was prepared as an account of work sponsored by an agency of the United States Government. Neither the United States Government nor any agency thereof, nor any of their employees, make any warranty, express or implied, or assumes any legal liability or responsibility for the accuracy, completeness, or usefulness of any information, apparatus, product, or process disclosed, or represents that its use would not infringe privately owned rights. Reference herein to any specific commercial product, process, or service by trade name, trademark, manufacturer, or otherwise does not necessarily constitute or imply its endorsement, recommendation, or favoring by the United States Government or any agency thereof. The views and opinions of authors expressed herein do not necessarily state or reflect those of the United States Government or any agency thereof. 


\section{DISCLAIMER}

Portions of this document may be illegible in electronic image products. Images are produced from the best available original document. 


\section{Volume II}

Sector-Specific Issues and Reporting Methodologies Supporting the General Guidelines for the Voluntary Reporting of Greenhouse Gases under Section 1605(b) of the Energy Policy Act of 1992

Part 4: Transportation Sector

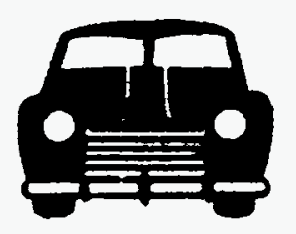

Part 5: Forestry Sector

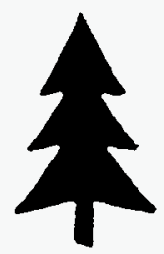

Part 6: Agricultural Sector

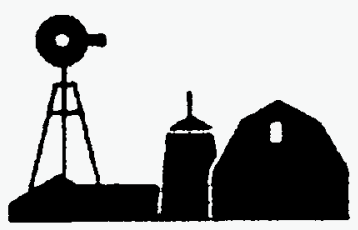



. 


\section{Contents of Volume II}

This volume, the second of two such volumes, contains sector-specific guidance in support of the General Guidelines for the voluntary reporting of greenhouse gas emissions and carbon sequestration. This voluntary reporting program was authorized by Congress in Section 1605(b) of the Energy Policy Act of 1992.

The General Guidelines, bound separately from this volume, provide the overall rationale for the program, discuss in general how to analyze emissions and emission reduction/carbon sequestration projects, and address programmatic issues such as minimum reporting requirements, time parameters, international projects, confidentiality, and certification. Together, the General Guidelines and the guidance in these supporting documents will provide concepts and approaches needed to prepare the reporting forms.

This second volume of sector-specific guidance covers the transportation sector, the forestry sector, and the agricultural sector. The first volume contains guidance for the electricity supply sector, the residential and commercial buildings sector, and the industrial sector. If you need copies of the General Guidelines or Volume I, contact the United States Department of Energy, 1000 Independence Avenue, SW, Washington, DC 20585.

Reporting forms are available at the following address: United States Department of Energy, Energy Information Administration, 1000 Independence Avenue, SW, Washington, DC 20585. 


\section{Contents}

Part 4 - Transportation Sector $\ldots \ldots \ldots \ldots \ldots \ldots \ldots \ldots \ldots \ldots \ldots \ldots$

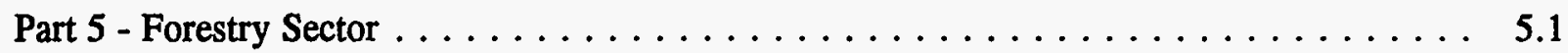

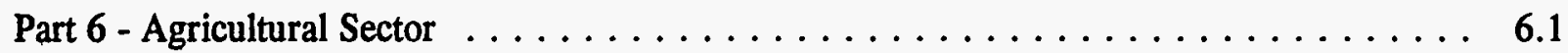

Appendix A - Conversion Factors for Standard Units $\ldots \ldots \ldots \ldots \ldots \ldots$. . . . . . .

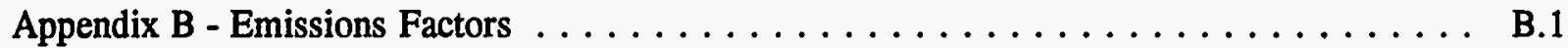

Appendix C - Adjusted Electricity Emissions Factors by State . . . . . . . . . . C.1

Appendix D - Conversion of Carbon to Carbon Dioxide Emissions . . . . . . . . . . D.1

Appendix E - Reportable Greenhouse Gases for Which Global Warming Potentials

Have Been Developed $\ldots \ldots \ldots \ldots \ldots \ldots \ldots \ldots$. . . . . . . . . . . 



\section{Acronyms}

\begin{tabular}{|c|c|c|c|}
\hline AFV & alternative fueled vehicle & IPP & independent power producer \\
\hline ARB & California Air Resources Board & IRP & integrated resource planning \\
\hline ARC & Assessment Recommendation Code & $\mathrm{kW}$ & kilowatt \\
\hline ASM & Annual Survey of Manufactures & $\mathrm{kWh}$ & kilowatt/hour \\
\hline BDT & Best Demonstrated Technology & LEPA & low energy precision application \\
\hline bf & board feet & MCFM & thousand cubic feet per minute \\
\hline BMP & Best Management Practice & MECS & Manufacturing Energy \\
\hline CAA & Clean Air Act & & Consumption Survey \\
\hline CARE & Cost and Return Evaluator & MOU & Memorandum Of Understanding \\
\hline $\mathrm{CE}$ & current efficiency & MPO & metropolitan planning organization \\
\hline CEM & continuous emissions monitoring & MSHA & Mining Safety and Health \\
\hline CFC & chlorofluorocarbon & & Administration \\
\hline CFM & cubic feet per minute & MSW & municipal solid waste \\
\hline $\mathrm{CM}$ & Census of Manufactures & MT & metric ton \\
\hline CRP & Conservation Reserve Program & MWh & megawatt hour \\
\hline CVP & Conservation Verification Protocols & $\mathrm{N}$ & nitrogen \\
\hline DOE & Department of Energy & NMOC & nonmethane organic compound \\
\hline DOT & Department of Transportation & OPS & Office of Pipeline Safety \\
\hline DSM & demand-side management & $\mathrm{VA}^{\prime}$ & Organic Vapor Analyzer \\
\hline EIA & Energy Information Administration & PEC & portable evacuation compressors \\
\hline EPA & Environmental Protection Agency & PFC & perfluorocarbon \\
\hline EPAct & Energy Policy Act & PJ & petajoule \\
\hline \multirow[t]{2}{*}{ EPIC } & Erosion Productivity Index & ROG & reactive organic gas \\
\hline & Calculator & RTECS & Residential Transportation Energy \\
\hline EPRI & Electric Power Research Institute & & Consumption Survey \\
\hline ESCO & energy service company & SCS & Soil Conservation Service \\
\hline FFV & flexible-fueled vehicle & SI & Standard International \\
\hline $\mathrm{Gg}$ & gigagram & SOC & soil organic carbon \\
\hline GJ & gigajoule & SPUR & Simulation of Production and \\
\hline HAP & hazardous air pollutant & & Utilization of Rangeland \\
\hline $\mathrm{HCFC}$ & hydrochlorofluorocarbon & ST & short ton \\
\hline $\mathrm{HFC}$ & hydrofluorocarbon & SWCD & soil and water conservation district \\
\hline HVF & heating value factor & $\mathrm{T} \& \mathrm{D}$ & transmission and distribution \\
\hline $\mathrm{I} / \mathrm{M}$ & inspection and maintenance & USDA & U.S. Department of Agriculture \\
\hline IPCC & $\begin{array}{l}\text { Intergovernmental Panel on Climate } \\
\text { Change }\end{array}$ & VOC & volatile organic compound \\
\hline
\end{tabular}




\section{Transportation Sector}

Part 4 of 6 Supporting Documents

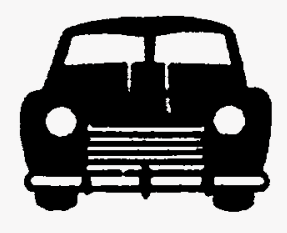

Sector-Specific Issues and Reporting Methodologies

Supporting the General Guidelines for the Voluntary Reporting of Greenhouse Gases under Section 1605(b) of the Energy Policy Act of 1992 



\section{Transportation Sector}

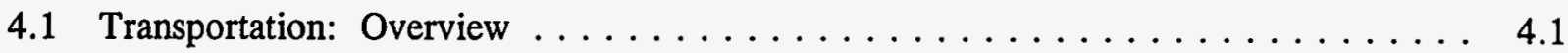

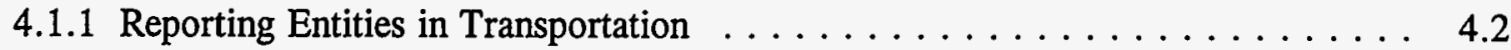

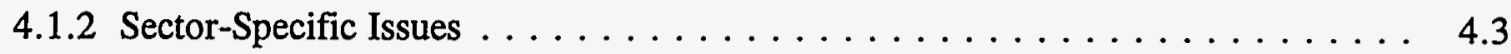

4.2 Organization of This Supporting Document $\ldots \ldots \ldots \ldots \ldots \ldots$

4.3 Estimating and Reporting Greenhouse Gas Emissions . . . . . . . . . . . 4.5

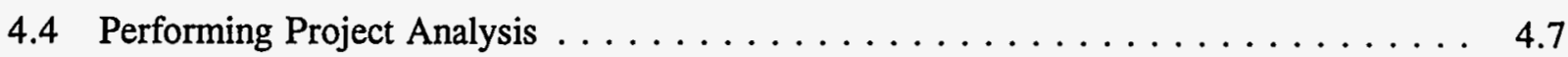

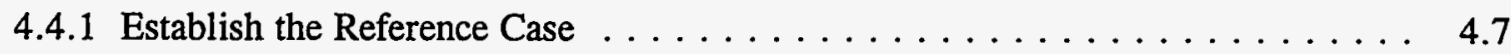

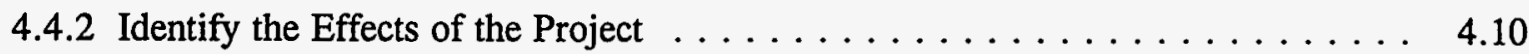

4.4.3 Estimate Emissions for the Reference Case and the Project . . . . . . . . 4.12

4.5 Estimation Methods for Fuel Consumption, Vehicle Use, and Emissions $\ldots \ldots \ldots 4.13$

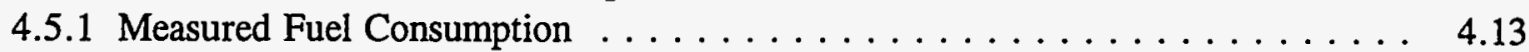

4.5 .2 Estimated Fuel Consumption and Vehicle Use . . . . . . . . . . 4.13

4.5.3 Translating Fuel Consumption and Vehicle Use into Emissions . . . . . . . 4.16

4.6 Estimating the Effects of Marketing Vehicles With Lower Emissions $\ldots \ldots \ldots .22$

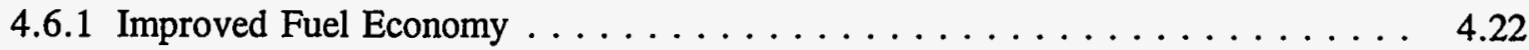

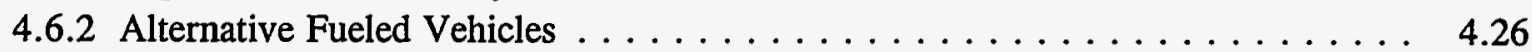

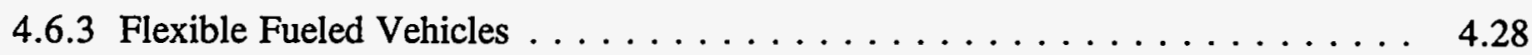

4.6 .4 Equipment that Improves Fuel Economy $\ldots \ldots \ldots \ldots \ldots \ldots \ldots \ldots .28$

4.7 Estimating the Effects of Operating or Maintaining a Vehicle Fleet to Reduce Emissions 4.30

4.7 .1 Data Sources for Service Suppliers $\ldots \ldots \ldots \ldots \ldots \ldots \ldots \ldots . \ldots \ldots \ldots$

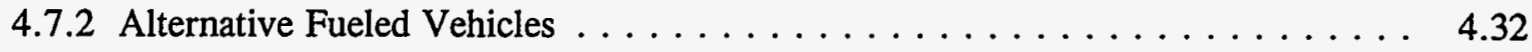

4.8 Estimating the Effects of Modifying Demand and Infrastructure $\ldots \ldots \ldots \ldots . \ldots . \ldots 33$

4.8 .1 Demand Modification . . . . . . . . . . . . . . . 4.33

4.8.2 Improvements in Infrastructure and Transportation System Efficiency . . . . . . 4.36

4.9 Estimating the Effects of Accelerating Vehicle Scrappage $\ldots \ldots \ldots \ldots \ldots . \ldots . \ldots 47$

4.10 References $\ldots \ldots \ldots \ldots \ldots \ldots \ldots \ldots \ldots \ldots \ldots \ldots \ldots \ldots \ldots$ 


\section{Examples}

4.1 Modified Reference Case . . . . . . . . . . . . . . . . . . . . 4.9

4.2 Identifying the Effects of the Project $\ldots \ldots \ldots \ldots \ldots \ldots \ldots \ldots \ldots \ldots$

4.3 Estimating Emissions Reductions Resulting from Improved Fuel Economy . . . . . . . 4.25

\section{Figures}

4.1 Computing Emissions Reductions for Light-Duty Vehicles . . . . . . . . . . . . 4.14

\section{Tables}

4.1 Where to Find Guidance for Reporting Transportation-Related Emissions Reductions . . 4.5

4.2 Emissions Factors for Miles Driven by Automobiles and Light Trucks Using Gasoline and Alternative Fuels . . . . . . . . . . . . . . . . . . 4.19

4.3 Emissions Factors for Use of Gasoline and Alternative Fuels in Automobiles and Light Trucks . . . . . . . . . . . . . . . . . . . . . . 4.19

4.4 Emissions Factors for Distance Driven by Heavy Trucks Using Diesel Fuel

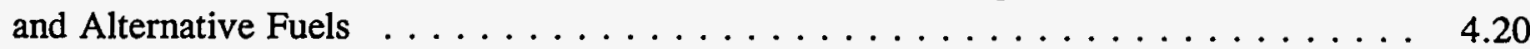

4.5 Emissions Factors for Use of Diesel Fuel and Alternative Fuels in Heavy Trucks . . . 4.20

4.6 Emissions Factors for Electric Vehicles by State and Region . . . . . . . . . . 4.21 


\subsection{Transportation Sector}

This document supports and supplements the General Guidelines for reporting greenhouse gas information under Section 1605(b) of the Energy Policy Act (EPAct) of 1992. The General Guidelines provide the rationale for the voluntary reporting program and overall concepts and methods to be used in reporting. Before proceeding to the more specific discussion contained in this supporting document, you should read the General Guidelines. Then read this document, which relates the general guidance to the issues, methods, and data specific to the transportation sector. Other supporting documents address the electricity supply sector, the residential and commercial buildings sector, the industrial sector, the forestry sector, and the agricultural sector.

The General Guidelines and supporting documents describe the rationale and processes for estimating emissions and analyzing emissions-reducing and carbon sequestration projects. When you understand the approaches taken by the voluntary reporting program, you will have the background needed to complete the reporting forms.

The General Guidelines and supporting documents address four major greenhouse gases: carbon dioxide, methane, nitrous oxide, and halogenated substances. Although other radiatively enhancing gases are not generally discussed, you will be able to report nitrogen oxides $\left(\mathrm{NO}_{x}\right)$, nonmethane volatile organic compounds (NMVOCs), and carbon monoxide (CO) after the second reporting cycle (that is, after 1996). The transportation sector is a significant source of these emissions.

The Department of Energy (DOE) has designed this voluntary reporting program to be flexible and easy to use. For example, you are encouraged to use the same fuel consumption or energy savings data that you may already have compiled for existing programs or for your own internal tracking. In addition, you may use the default emissions factors and stipulated factors that this document provides for some types of projects to convert your existing data directly into estimated emissions reductions. The intent of the default emissions and stipulated factors is to simplify the reporting process, not to discourage you from developing your own emissions estimates.

Whether you report for your whole organization, only for one project, or at some level in between, you will find guidance and overall approaches that will help you in analyzing your projects and developing your reports. If you need reporting forms, contact the Energy Information Administration (EIA) of DOE, 1000 Independence Avenue, SW, Washington, DC 20585.

\subsection{Transportation: Overview}

This supporting document provides technical guidance on reporting greenhouse gas emissions and emissions reductions in the transportation sector. Transportation activities give rise to the emission of three of the greenhouse gases treated in detail in these guidelines: carbon dioxide $\left(\mathrm{CO}_{2}\right)$, methane $\left(\mathrm{CH}_{4}\right)$, and nitrous oxide $\left(\mathrm{N}_{2} \mathrm{O}\right)$. This document provides guidance for reporting activities that reduce

Transportation Sector-Page 4.1 
the emissions of these gases by reducing emissions from individual vehicles, improving the overall efficiency (and associated emissions levels) of vehicle fleets, and influencing the level and type of demand for transportation.

Activities that may be undertaken to reduce transportation-related emissions include the following:

- Marketing more fuel-efficient vehicles, vehicles that use cleaner fuels, and equipment (such as tires) that makes vehicles more fuel efficient

- Operating or maintaining a vehicle fleet more efficiently (including the purchase and use of vehicles that use cleaner fuels)

- Reducing or modifying demand for transportation (for example, through telecommuting, reduced travel, or increased bus ridership) and modifying infrastructure to reduce fuel consumption (for example, through modifying signalization to improve traffic flow $)^{(a)}$

- Accelerating scrappage of older, less efficient vehicles.

All of these types of activities have the potential to reduce emissions and can be reported under the EPAct Section 1605(b) program. Note, however, that you may report any type of project that reduces greenhouse gas emissions so long as you are able to perform a credible project analysis. You are not restricted to reporting only those projects mentioned explicitly in this document. For example, some transportation-related emissions originate from vehicles, such as hydraulic-assisted boom trucks for use in working on utility lines, that operate primarily in idling mode. While specific emissions factors for this type of operation are not provided in this document, if you have the necessary data you can compute and report emissions and emissions reductions associated with using these vehicles.

This document provides technical assistance and illustrative examples to support each of the steps involved in estimating emissions and emissions reductions for the transportation sector. Note that each example is provided for illustrative purposes only; other appropriate ways to evaluate the hypothetical projects may exist.

\subsubsection{Reporting Entities in Transportation}

A typical reporting entity in transportation could be a vehicle manufacturer, tire manufacturer, airline, railroad, delivery firm, rental fleet operator, public transit agency, or local government planning agency.

(a) In reporting infrastructure modification projects, you should take care to ensure that reductions actually occur, as some infrastructure modifications can have the effect of increasing emissions. 
Transportation activities are conducted or influenced by the following five groups:

- Infrastructure suppliers: organizations or government agencies that supply or manage transportation infrastructure (such as highways and railways)

- Vehicle suppliers: the manufacturers and sellers of vehicles

- Fuel suppliers: organizations that manufacture and sell transportation fuel

- Service suppliers: those who use vehicles and fuel to move passengers or goods (such as households, delivery firms, rental car agencies, airlines, and railways)

- Users: those who demand the movement of people or goods.

These groups may each take actions to reduce transportation-related emissions or may be affected by the actions of the other groups. Except for fuel suppliers, these groups are referred to throughout this supporting document. Reductions in emissions from the fuel manufacturing process are discussed in the supporting document for the industrial sector.

\subsubsection{Sector-Specific Issues}

A key issue in the transportation sector is the complex network of interactions among potential reporters in transportation activities. Opportunities for third-party reporting and multiple reporting are particularly numerous in this sector. Similarly, you may find your analysis of possible unintended and off-site effects of projects to be difficult.

You may choose to report through a third party, which could aggregate the emissions reductions for a group of entities with similar characteristics. The third party could ease the reporting burden on individual companies and use aggregate data to inform the public of their group's accomplishments toward reducing greenhouse gas emissions. A third party may provide an additional layer of confidentiality, since the contributions of any individual entity would not need to be identified in the report. (You should familiarize yourself with the confidentiality discussion in the General Guidelines.) A third party may also provide technical assistance in conducting the emissions-reducing projects and reporting. In this case, the emissions reductions might be reported jointly. Possible third parties include industry trade associations, electric utilities, gas utilities, and government agencies responsible for air quality.

A third party reporter would be responsible for developing aggregated reports and tracking the individual contributions of reporting entities. The third party would not be responsible for verification or certification; that responsibility remains with you as the reporting entity. If you report your emissions through a third party, you should retain in your files the information you used to compute your emissions and emissions reductions.

\section{Transportation Sector-Page 4.3}


You may report activities undertaken jointly with others. If you do so, you need to identify other potential reporters of the same activity so that the voluntary reporting program can account for multiple reports of the same activities. (You may further wish to make prior arrangements with these other potential reporters, in the form of contracts or sales agreements.) Similarly, if you are providing data on emissions reductions to several third parties-for example, two trade associations of which you are a member-you should identify those parties in your report to track possible multiple reporting.

Joint activities in transportation primarily involve transactions that take place repeatedly between manufacturers and consumers where negotiated contracts generally are not involved. For example, the use of high-efficiency automobiles may be considered a joint activity. On the one hand, the purchaser of a high-efficiency car makes the ultimate decision to reduce emissions related to personal transportation. On the other hand, the automobile manufacturers who shifted their sales fleet composition are enabling the automobile owners to obtain more efficient automobiles. In another example, a utility company could be involved in an electric vehicle program that reduces overall emissions when power plant emissions are compared with tailpipe emissions.

It may be particularly difficult to identify all the effects of a transportation project, since vehicle use, market shares, infrastructure conditions, and other factors play sometimes pivotal roles in determining the effects of any given project on emissions. Many of these factors may be beyond your control, though they may affect your project. Thus, even when you can identify all possible effects, you may not be able to quantify them.

\subsection{Organization of This Supporting Document}

As described in the General Guidelines, EPAct Section 1605(b) addresses the reporting of annual emissions as well as emissions reductions and carbon sequestration. Section 4.3 provides guidance on reporting emissions, especially at the whole-entity level. Section 4.4 builds on the discussion of project analysis in the General Guidelines and provides a framework for understanding how your emissions reduction project relates to the reference cases, project effects, and estimation approaches described in the General Guidelines. Section 4.5 provides general guidance on methods for estimating reductions in transportation fuel use and on translating fuel use into emissions. Tables with emissions factors for transportation fuels are located in Section 4.5.

The remainder of this chapter is organized by type of emissions-reducing activity. Sections 4.6 through 4.9 provide guidance on analyzing projects and estimating emissions for the four types of activities mentioned in Section 4.1. The specific locations of guidance for these activities are listed in Table 4.1. 
Table 4.1. Where to Find Guidance for Reporting Transportation-Related Emissions Reductions

\begin{tabular}{||c|c||}
\hline \multicolumn{1}{|c|}{ Emissions-Reducing Activity } & Location \\
\hline \hline $\begin{array}{l}\text { Marketing Vehicles and Equipment } \\
\text { - more fuel efficient vehicles } \\
\text { - vehicles that use cleaner fuels } \\
\text { - equipment (primarily tires) that makes } \\
\text { vehicles more fuel efficient }\end{array}$ & Section 4.6 .1 \\
Sections $4.6 .2,4.6 .3$ \\
Operating or Maintaining a Vehicle Fleet More Efficiently & Section 4.6 .4 \\
\hline Modifying Transportation Demand or Infrastructure & Section 4.7 \\
\hline Accelerating Vehicle Scrappage & Section 4.8 \\
\hline
\end{tabular}

Except as noted, all data sources cited by name in Sections 4.5 to 4.9 can be found summarized in the Transportation Energy Data Book sponsored by the U.S. Department of Energy, Office of Transportaion Technologies and updated annually by Oak Ridge National Laboratory.

\subsection{Estimating and Reporting Greenhouse Gas Emissions}

The General Guidelines (Section GG-4, "What is Involved in Reporting Emissions?") explain that reporting information on greenhouse gas emissions for the baseline period of 1987 through 1990 and for subsequent calendar years on an annual basis is considered an important element of this program. If you are able to report emissions information for your entire organization, you should consider providing a comprehensive accounting of such emissions so that your audience can gain a clear understanding of your overall activities. As noted in the General Guidelines, some users of the database may find your reported estimates of emissions reductions more credible when accompanied by data on your organization's total emissions for the year of the reduction and for the baseline period of 1987 through 1990 and for subsequent years. You may wish to report this information for all or as much of your organization as possible, particularly if it would be important to users of your report.

Your emissions report should include all emissions you control, whether or not they are related to transportation, plus those indirect, off-site emissions attributable to your use of electricity. Typically, not all the emissions you control directly will be related to transportation. You will usually have other, non-transportation emissions; if you are able to estimate these emissions, you should include them in your emissions report. For example, vehicle manufacturers would have industrial emissions arising from the vehicle production process. Many other transportation entities consume energy in office buildings that have associated greenhouse gas emissions, both direct (from the use of fuel) and indirect (from the use of electricity). Guidance for estimating such non-transportation emissions is found in other supporting documents. Those for the electricity supply, residential and commercial buildings, and industrial sectors may be particularly relevant to reporters of transportation-related emissions. In general terms, to report direct non-transportation emissions, you should compute direct emissions 
from fuel use data and the emissions factors in Appendix B (or your own, more site-specific emissions factors). To report indirect emissions from electricity use (other than that used for electric vehicles), you may use the default state level emissions factors in Appendix $\mathrm{C}$ or calculate utility-specific factors using the guidance provided in the supporting document for Electricity Supply.

To compute transportation-related emissions, you should determine the amount and type of fuel and electricity you consume for transportation purposes and translate that fuel and electricity use into emissions. Section 4.5 provides specific guidance on estimating vehicle fuel use and translating it into emissions. You should use the emissions factors provided in Section 4.5 to compute emissions unless you have specific information on the emissions rate for your vehicle(s) or electricity supplier. If you use different emissions factors from those in Section 4.5, you should document the values and the basis for them in your report.

Many entities maintain and report data that can be used to estimate their total emissions. For example:

- Airlines and major railroads are likely to maintain accurate records of fuel consumption for internal purposes and for required reporting to the Federal Aviation Administration or the Interstate Commerce Commission. In addition, you may have utility bills or summaries for office and vehicle support functions (e.g, refueling stations, refueling trucks, and baggage handling equipment operated by airlines).

- If you lease vehicles, you record odometer readings at the beginning and end of lease periods but are likely to have only limited information about fuel consumption. If you have EPA fuel economy ratings (discussed in Section 4.5) for your vehicles, you may estimate fuel consumption by dividing the miles each vehicle is driven by its fuel economy rating. A conservative approach to the estimate would use the urban fuel economy rating, unless you can provide supporting information that the combined or highway ratings are more representative of your vehicle use patterns. As noted in Section 4.5, the combined fuel economy rating should be divided by 1.15 (or a specific factor for your vehicle) before use in these calculations.

- If you are an infrastructure supplier, you may record information about your own energy consumption, which includes that from operating construction equipment, maintenance equipment (for example, street sweeping, snow plowing), and service equipment (for example, fueling equipment and baggage handling equipment when operated by airport authorities rather than the airlines). Infrastructure facilities themselves can consume energy; for example, electricity is used in inland waterways to operate locks, in road systems for illumination and control signals, in rail systems for control signals, in airports for control towers and terminal space conditioning, and in bus and truck depots for maintenance and refueling. Many infrastructure agencies also operate and maintain offices that use energy.

To compute your total emissions, you should add your transportation emissions to other emissions (for example, from industrial or building energy use) computed as described elsewhere in these supporting documents. You should report a total emissions level (in physical units such as pounds or metric tons)

\section{Transportation Sector-Page 4.6}


for each gas you emit. You do not need to separate transportation emissions from other emissions in your emissions report, although you may wish to do so if your total transportation emissions will also constitute a reference case for a particular emissions-reducing activity being reported.

\subsection{Performing Project Analysis}

Your project may consist of a single, discrete action (for example, improved maintenance or routing that reduces the fuel consumption of a delivery fleet without reducing service); several activities, perhaps as part of an energy efficiency program (for example, a program at an auto manufacturing plant to reduce energy and fuel use for vehicle manufacture, in-plant transportation, and vehicle shipping); or your entire organization, where you report the change in total emissions for your organization.

The analysis of emissions reduction projects in the transportation sector follows the process described in the general guidance provided in the General Guidelines:

1. Establish the reference case as a basis for comparison with the project.

2. Identify the effects of the project.

3. Estimate emissions for the reference case and the project.

The General Guidelines describe two categories of reports: standard project reports and reporterdesigned project reports. Standard project reports are those that use only default values-specifically, emissions factors (emissions per unit energy or fuel) and stipulated factors (standard energy or fuel savings or emissions reduction values for specific types of projects). No standard projects exist for the transportation sector at this time. Most reports will use emissions factors together with fuel and energy savings estimates, but you will need to develop these estimates on a case-by-case basis. Thus, the rest of this supporting document discusses only reporter-designed project reports.

\subsubsection{Establish the Reference Case}

As described in the General Guidelines, under this program you may choose a basic or a modified reference case (see Section GG-5.1, "What Should I Compare the Project To?"). You should be thoroughly familiar with that discussion before proceeding with project analysis.

If you are a vehicle manufacturer, your reference case and project case should be based on the vehicles sold in a calendar year. Although your "model year" may not correspond to the calendar year, if possible you should define the reference case and project case based on the calendar year. If the data needed to compute project effects on a calendar year basis are not available, you can use a model year basis for your report. However, you should be aware that users of the EPAct 1605(b) database will

\section{Transportation Sector-Page 4.7}


find your report more useful if it is based on the actual vehicles sold in a calendar year. Your report must specify which type of reporting year you used.

A basic reference case uses only historical emissions data as a basis for comparison with project emissions. Depending on the nature of and circumstances associated with your reporting, a basic reference case may provide a suitable and appropriate benchmark against which to compare project emissions. Some users of the EPAct 1605(b) database may have more confidence in reports that use a basic reference case than in reports that use a modified reference case.

In some cases, you may determine that a modified reference case is most appropriate. If so, you may choose to also report the emissions change using a basic reference case, to enable users of the database to evaluate U.S. efforts to reduce emissions with respect to an historic baseline.

The remainder of this section discusses one type of modified reference case that is based on emissions per unit of activity. If you do not need this information, you can skip to Section 4.4.2.

A form of modified reference case that may be of particular interest to reporters of transportation projects is a reference case that accounts for changes in the level of activity over time. An organization can take steps to improve the efficiency of its transportation activities but experience increases in the demand for its goods or services that cause total emissions to increase, even though emissions per unit activity (for example, emissions per ton-mile) are decreasing. In such a situation, you may wish to use a modified reference case based on the level of activity.

In simple terms, you could compute emissions per unit of activity production before the emissionsreducing project is conducted, and then determine what emissions would have been if the higher level of activity had been conducted at the "old" emissions rate. This value is the modified reference case. Current emissions are compared to the reference emissions to determine the reportable reduction.

If you develop a modified reference case, you may use only physical measures of activity (for example, miles driven, passenger-miles flown, ton-miles carried) to compute emissions per unit of activity. Dollar values (for example, sales figures) cannot be used as the unit of activity. You may calculate emissions per unit of activity for your entire entity or for discrete projects, taking care to account for all project effects within and outside of your organization. 
Example 4.1 - Modified Reference Case

Note: This example illustrates only one approach to analyzing a project; your analysis,
methods, and calculations will vary depending on your particular circumstances,
the geographic location of the project, and other factors.

A small trucking firm that carries 250 million ton miles per year computed that it produced emissions of $0.02 \mathrm{lb} \mathrm{CO}_{2}$ per ton mile. The firm instituted an efficiency program that involved rerouting and driver training, and achieved reductions of $10 \%$ in unit emissions, such that emissions were $0.018 \mathrm{lb} \mathrm{CO}_{2}$ per ton mile. At the same time the firm experienced an increase in business of 50 million ton miles per year.

Before the project and the increase in business, total annual emissions were as follows (the basic reference case, bref):

$$
\begin{aligned}
\text { Emissions }_{\text {bref }} & =250 \text { million ton miles } \bullet 0.02 \mathrm{lb} \mathrm{CO}_{2} / \text { ton mile } \\
& =5 \times 10^{6} \mathrm{lb} \mathrm{CO}_{2} .
\end{aligned}
$$

To compute the modified reference case (mref) for $\mathrm{CO}_{2}$ emissions, the firm determined what the annual emissions would have been in the absence of the project using the "old" emissions rate and the new activity level.

$$
\begin{aligned}
\text { Emissions }_{\text {mref }} & =300 \text { million ton miles } \bullet 0.02 \mathrm{lb} \mathrm{CO}_{2} \text { /ton mile } \\
& =6 \times 10^{6} \mathrm{lb} \mathrm{CO}_{2} . \\
\text { Emissions }_{\text {proj }} & =300 \text { million ton miles } \bullet 0.018 \mathrm{lb} \mathrm{CO}_{2} \text { /ton mile } \\
& =5.4 \times 10^{6} \mathrm{lb} \mathrm{CO}_{2} . \\
\text { Emissions Reduction } & =\text { Emissions } \\
& =6 \times 10^{6} \mathrm{lb} \mathrm{CO}_{2}-5.4 \times 10^{6} \mathrm{lb} \mathrm{CO}_{2} \\
& =6 \times 10^{5} \mathrm{lb} \mathrm{CO}_{2}=300 \text { short tons. }
\end{aligned}
$$

Thus, in the absence of other effects, the firm could report an annual emissions reduction relative to the modified reference case of 300 short tons $\mathrm{CO}_{2}$, even though total emissions increased by 200 short tons relative to the basic reference case. 


\subsubsection{Identify the Effects of the Project}

Your report should address all the identifiable effects of your project, as described in the General Guidelines (see Section GG-5.2, "What Effects Did the Project Have?"). You should quantify these effects whenever possible. You should identify all potential effects, even if you are not able to quantify all of them.

Projects in the transportation sector run the gamut from discrete, well-defined projects to projects that can have both reinforcing and antagonistic effects within and outside of a reporting entity. When projects begin to interact such that the effects of each project cannot clearly be separated, you should consider reporting your total emissions reduction rather than the emissions reduction associated with individual projects. For example, you may wish to compute the emissions associated with your total energy use (for transportation alone or for all activities) before and after the project. After accounting for project effects outside the entity (for example, increased off-site emissions associated with outsourcing), you can report the reduction in total emissions. If you choose to report in this way, you must identify the specific projects or, at a minimum, categories of projects you undertook to reduce emissions, even if you are not able to determine the fraction of your total emissions reduction associated with each project.

You may account for some unintended effects by defining your project to include them. For example, if you are a vehicle manufacturer, you can capture the effects of shifts in your sales mix by defining your project to include sales of all of your vehicles. In fact, some users of the 1605(b) database may find your report more credible if you report for your entire sales rather than for specific models. By also including emissions from manufacturing, you can capture changes in emissions resulting from changes in production processes as well as those resulting from changes in what is sold. Other types of effects, such as the way that vehicle purchasers use the vehicles, or changes in your market share, are essentially beyond your control, although in some cases you may be able to estimate their magnitude.

Projects to influence the demand for transportation or to modify infrastructure to reduce fuel consumption have perhaps more potential for unintended effects. For example, an increase in carpooling or telecommuting means that more vehicles are left at home during the day, where other household members have the opportunity to use them. Where an urban area has severe traffic congestion, adding highway capacity has the potential to improve traffic flow and reduce fuel consumption, but also to attract additional traffic. Additional congestion during capacity reconstruction or expansion can offset subsequent reductions in congestion and emissions. If you are an infrastructure planner, you probably estimate the size of some of these effects already and should report them if you do. 
Example 4.2 - Identifying the Effects of the Project

Note: This example illustrates only one approach to analyzing a project; your analysis,
methods, and calculations will vary depending on your particular circumstances,
the geographic location of the project, and other factors.

A vehicle manufacturer modified the engine in one of its models (Model A) in a way that improved vehicle efficiency, and wished to determine whether a reportable emissions reduction existed. The company needed to identify the potential effects of the project and determine their magnitude. To do this, the manufacturer looked at each stage of the automobile's life that influences emissions: vehicle manufacture, sale, use, and scrappage. Because the model is a redesign and replacement of a previous model with no change in interior space, statistics on the previous model could be used to determine the reference case. In this situation, the manufacturer chose a modified reference case, computed by determining what the emissions would have been if the cars sold that calendar year had been the original Model A rather than the improved version.

The most important effect of the project was reduced emissions from use of the more efficient vehicle rather than the previous model. Other potential effects are evaluated below.

1. Manufacture. The vehicle manufacture did not result in any change in manufacturing-related energy use or emissions, nor had any changes been made in the supply of parts (that is, no increase or decrease in outsourcing), relative to the reference case.

2. Sales. Sales of improved Model A decreased slightly relative to the reference case; however, the sales appeared to have shifted to a similar model in this manufacturer's sales fleet (Model B). No overall change in sales relative to competitors' models appeared to have occurred.

3. Use. A survey of vehicle purchasers revealed that users of the improved Model A were driving an average of $5 \%$ farther per year than had been the case for the reference case model. However, other use characteristics (for example, maintenance) appeared unchanged.

4. Scrappage. The improved engine had no effect on the extent to which the vehicle can be recycled or on vehicle lifetime.

Therefore, the manufacturer determined that project effects had occurred in the sales and use stages, and was able to quantify the effects. ${ }^{(a)}$ Using EPA combined fuel economy values (adjusted by a factor of 1.15 in accordance with the guidance in Section 4.5) and its own data on miles driven, it computed the reference case emissions, the emissions from the use of the improved Model A (adjusted for the $5 \%$ increase in driving), and the emissions from the incremental increase in sales of Model B and reported the net emissions reduction for each greenhouse gas. The calculations are shown in Example 4.3. (If the manufacturer had not had access to a survey on driving characteristics, it would have used national aggregate statistics on vehicle use but adjusted the miles driven as described in Section 4.6.1.)

(a) Note that if the manufacturer had not been able to quantify these effects, the emissions reduction report may have lost credibility with some users of the 1605 (b) database. To address this, the manufacturer could define the project to include all of its sales rather than just one model.

Transportation Sector-Page 4.11 


\subsubsection{Estimate Emissions for the Reference Case and the Project}

Your analysis of emissions for the reference case and project and your report must meet the minimum reporting requirements described in the General Guidelines (see Section GG-6, "What Are the Minimum Reporting Requirements?"). Your report will lose credibility if you do not use analytic and estimating practices commonly acceptable in the professional community. You may want to review the guidance provided in Sections 4.5 through 4.9 that describes procedures for estimating fuel savings and emissions reductions for several types of emissions-reducing measures. Section 4.3 describes examples of data you may already maintain that could be used to estimate some reference case and project emissions.

The guidelines recognize three categories of data:

Physical Data. This is information that describes the activities involved in your project and must be included in every report. For example, what types of operational and maintenance improvements did you undertake to improve the efficiency of your vehicle fleet? In what portion of your total vehicle production did you install more efficient engines? What fraction of your fleet did you convert to alternative fuels or replace with high-efficiency vehicles? The specific actions that you undertook should be identified clearly in your report.

Default Data. As noted previously, the primary category of default data applicable to the transportation sector is emissions factor data. These data are provided in Section 4.5.3. Stipulated factors (average fuel savings or emissions reductions for specific types of projects) can be used only when there are standard emissions-reducing activities and widespread agreement on how much they reduce emissions. These conditions are not applicable to the transportation sector at this time.

Reporter-Generated Data. These are data you develop for estimating the effects of your project. There are two categories of reporter-generated data:

- Measured Data. These are data collected directly from the project that you use in estimating your project's accomplishments. For example, you may monitor fuel gauges, odometers, or electricity used to charge electric vehicle batteries, or you may keep detailed fuel purchase records. Direct measurement of greenhouse gas emissions is not feasible for projects in the transportation sector.

- Engineering Data. These are data that you derive from various sources such as manufacturer's equipment specifications, surveys, reports, academic literature, and professional judgment.

Your choice of estimation methods will be constrained by the availability of data. For example, you may combine metered or measured values with emissions factors, physical data, and other parameters to determine the emissions reductions associated with your project. Using several methods and comparing the results may increase the confidence that database users have in your estimations. 
Specific estimation methods for fuel consumption, vehicle use, and emissions are described in Section 4.5 .

\subsection{Estimation Methods for Fuel Consumption, Vehicle Use, and Emissions}

Analysis of transportation-related emissions and emissions reductions requires information on how the type and amount of fuel used and the distance traveled (vehicle use) have changed between the reference case and the project case. This section provides guidance on estimating fuel consumption and vehicle mileage and translating them into emissions values. The process for performing these calculations for light-duty vehicles is illustrated in Figure 4.1.

\subsubsection{Measured Fuel Consumption}

In general, if you supply transportation services to yourself or others, you can use information from vehicle fuel gauges or fuel purchase records to determine actual fuel consumption. Measured data, of course, would be the most accurate data, and you should use them if you collect them. However, you may not find direct collection of this information cost effective but have other procedures to collect information that will support estimates of fuel consumption.

If you manufacture vehicles and components, you may measure fuel consumption directly via sensors or microprocessors, perhaps on a sample basis. You may aggregate partial or sample information collected during vehicle servicing and project it to all vehicles of that model sold during the year to allow a fairly direct estimation of fuel consumption for vehicles sold in a given year. You may be able to account for systematic differences between the characteristics of vehicles serviced at dealerships and those serviced elsewhere. A more indirect method would be asking vehicle purchasers to report their fuel consumption to you.

\subsubsection{Estimated Fuel Consumption and Vehicle Use}

You may estimate emissions and reductions using information on vehicle fuel economy and the characteristics of vehicle use (annual distance traveled). You may estimate fuel consumption by dividing vehicle use (for example, miles) by vehicle fuel economy (for example, miles per gallon). Data sources for these two pieces of information are discussed below.

Fuel Economy. You may use several sources of fuel economy data. Manufacturers of light-duty highway vehicles (cars, pickup trucks, and light vans) are now required to have production vehicles tested for fuel economy and emissions using the EPA Federal Test Procedure (FTP) and are required to report their fuel economy test results, vehicle sales, and the sales-weighted average fuel economy to determine compliance with the Corporate Average Fuel Economy (CAFE) program. Emissions testing does not address specific greenhouse gases, such as methane and nitrous oxide, but categories of gases

Transportation Sector-Page 4.13 
Measured Fuel Use

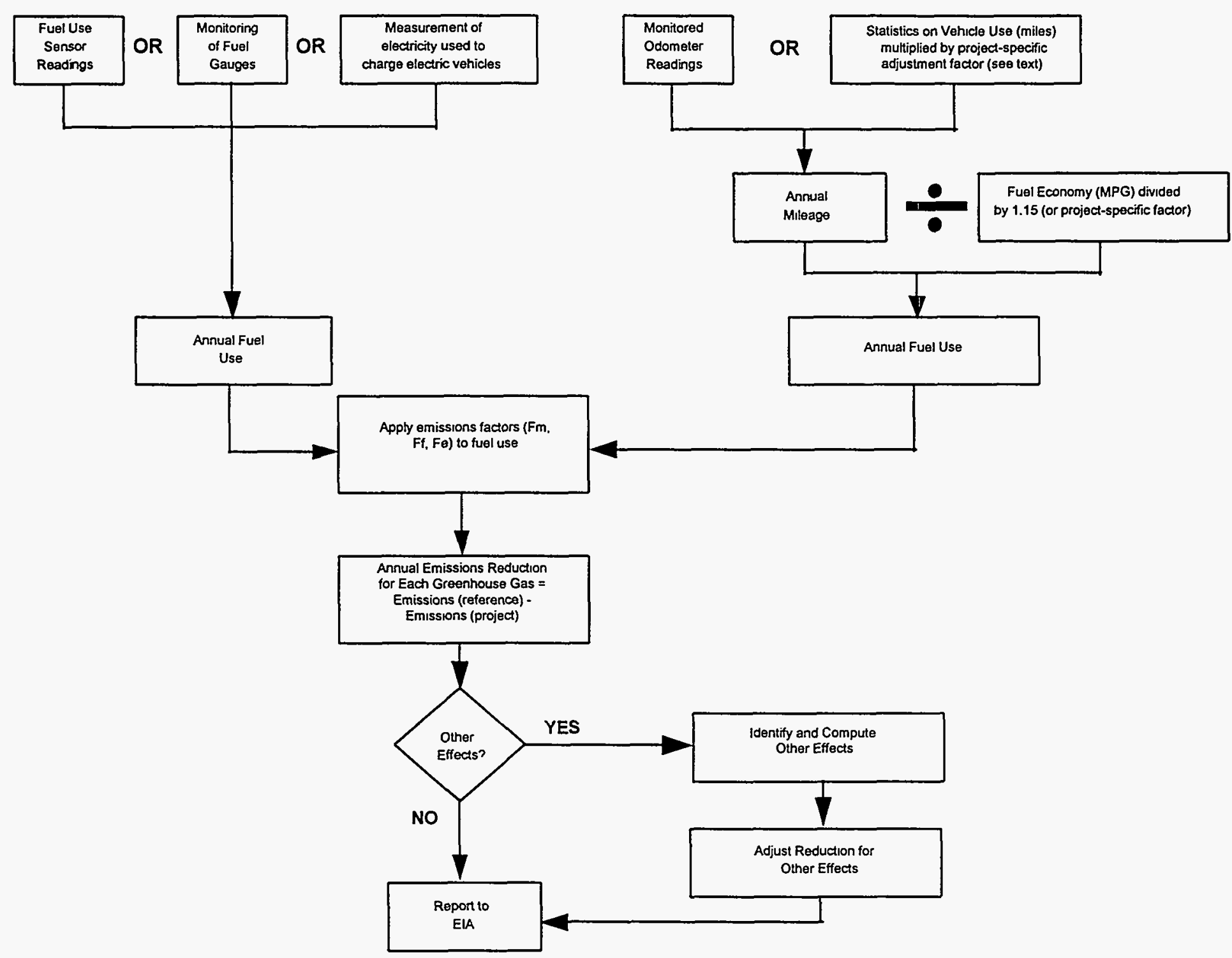

Figure 4.1. Computing Emissions Reductions for Light-Duty Vehicles 
that include them. Because the information needed to separate the emissions of greenhouse gases from those of other gases in these categories does not exist at this time, the FTP emissions values cannot be reported directly to the EPAct Section 1605(b) reporting program; rather, the fuel economy data should be used along with vehicle use data to estimate emissions and emissions reductions.

The test procedure provides two measures of fuel economy: urban and highway. A combined urban/ highway value also is reported for use in the CAFE program. You should use the combined value divided by a factor of 1.15 to account for the difference between the CAFE value and what the average driver actually achieves. Alternatively, if you have specific information for your vehicle(s) indicating that a different adjustment factor should be used, you can use this value instead. You should document the value used and the basis for it in your report. Except when specifically noted in the discussion of alternative fueled vehicles, any mention of a fuel economy rating in this guidance should be interpreted to mean the combined MPG rating adjusted as above.

Note that, as described in Section 4.6.2, if you are computing emissions reductions associated with electric vehicles or other alternative fueled vehicles, you should use the urban fuel economy rating instead of the combined value. You can use the urban values directly; no adjustments to the FTP values are needed.

Vehicle Use. If you are not the user of the vehicle(s) included in your project, you will need to obtain information on vehicle use (annual distance traveled) to determine vehicle fuel consumption. You will also need this information to compute emissions for light-duty vehicles other than electric vehicles. You can obtain vehicle use information in several ways. For example:

1. Surveys. You can conduct surveys of vehicle owners to collect odometer readings. (Note that odometer readings recorded at specified intervals are considered more accurate than self-reporting of mileage driven over a similar interval.)

2. Data Collection During Vehicle Service. You can record odometer readings during scheduled vehicle service, adjusted if necessary to reflect any systematic differences in vehicle use between users whose data you collect and users who have their vehicles serviced elsewhere.

3. Statistics. You can use statistics on light-duty vehicle use, which are available in the form of national, fleet-wide averages. The Energy Information Administration (EIA) uses the Residential Transportation Energy Consumption Survey (RTECS) to collect data on odometer readings and to determine the average number of miles driven by vehicle age for automobiles. The Transportation Energy Data Book (Davis and Strang 1993) provides information on light-duty truck use. Analysis of the effects of improved fuel economy on driving shows a small aggregate tendency to drive farther as vehicle fuel economy increases, reducing overall fuel savings by 5 to 15 percent from what they would be if the additional driving did not occur. Given current fuel price and fuel economy trends, a decrease in fuel savings of 10 percent is a reasonable assumption.

\section{Transportation Sector-Page 4.15}


However, as detailed in Section 4.6.1, to compute transportation emissions based on vehicle use statistics, you will need to know the specific miles driven in the project case. Therefore, you will need to convert the assumed reduction in fuel savings into the corresponding change in miles traveled. To do this, you will need to compute a project-specific adjustment factor that you can apply to the reference case miles traveled to obtain the miles traveled in the project case. The procedure for doing this is described in Section 4.6.1.

Note that these national statistics will generally better reflect sales of a diversified manufacturer's complete product line than of a portion of it. Also, in some cases, such as alternative-fueled vehicles, the characteristics of the vehicle affect its use, such that aggregate national statistics should not be used (see Section 4.6.2). In such situations, estimates of emissions and reductions should use estimates of vehicle use, fuel use, and transportation demand based on modeling, surveys, or other sources.

If you have other data for specific vehicles, you may use that information in estimating emissions and emissions reductions. For example, you may perform your own fuel economy testing on heavy trucks, locomotives, and aircraft, which are not subject to industry-wide fuel economy testing and reporting. Aggregate fleet estimates of vehicle use may be unavailable for these types of vehicles. If you cooperate closely with others in maintenance, troubleshooting, and other activities, you may be able to acquire information on vehicle use and/or fuel consumption. (For example, a vehicle manufacturer may cooperate with a fleet operator in maintaining the fleet.) You should use any such data you have in estimating your emissions and emissions reductions.

\subsubsection{Translating Fuel Consumption and Vehicle Use into Emissions}

Fuel consumption and vehicle use should be translated into emissions using the emissions factors in Tables 4.2 through 4.6. The emission factors for use in computing emissions for light-duty vehicles (Tables 4.2 and 4.3) and heavy trucks (Tables 4.3 and 4.4) are given in two parts: a factor per mile driven and a factor per unit of fuel placed into the car. The effects of these two factors are additive, so that total emissions for each greenhouse gas are computed as follows:

$$
\text { Annual Emissions } \mathrm{i}_{\mathrm{i}, \mathrm{j}}=\text { Annual Mileage } \bullet \mathrm{Fm}_{\mathrm{i}, \mathrm{j}}+\text { Annual Fuel Use } \bullet \mathrm{Ff}_{\mathrm{i}, \mathrm{j}}
$$

where $\mathrm{Fm}_{\mathrm{i}, \mathrm{j}}=$ emissions factor per mile driven for greenhouse gas $\mathrm{i}$ and fuel $\mathrm{j}$

$\mathrm{Ff}_{\mathrm{i}, \mathrm{j}}=$ emissions factor per unit of fuel used for greenhouse gas $\mathrm{i}$ and fuel $\mathrm{j}$.

The reason that both factors must be used is that, for each greenhouse gas, the two emissions factors address different types of emissions, as explained below.

Fm, the emissions factor per mile driven, is given in Tables 4.2 and 4.4. It addresses the following emissions: 
$\mathrm{CH}_{4}$ : tailpipe emissions-based on tailpipe emissions standards for criteria pollutants

$\mathrm{N}_{2} \mathrm{O}$ : tailpipe emissions-based on tailpipe emissions standards for criteria pollutants

$\mathrm{CO}_{2}$ : emissions from unintentional burning of oil in vehicle engines.

Because these factors are based on emissions standards and unintentional burning of oil, they are valid over a broad range of vehicle fuel economy values. Also, because the emissions standards are given in metric units, the factors in Tables 4.2 through 4.6 are also given in these units.

Ff, the emissions factor per unit of fuel placed into the vehicle, is given in Tables 4.3 and 4.5 . It addresses the following emissions:

$\mathrm{CH}_{4}$ : upstream emissions (from fuel extraction, processing, delivery, and storage)

$\mathrm{N}_{2} \mathrm{O}$ : upstream emissions (from fuel extraction, processing, delivery, and storage)

$\mathrm{CO}_{2}$ : tailpipe emissions and upstream emissions (from fuel extraction, processing, delivery, and storage).

Note that, for heavy trucks, Fm is given in terms of brake-horsepower hours rather than miles.

The factors in Tables 4.2 through 4.6 are derived from an analysis of full fuel-cycle emissions (ANL 1991, ANL 1993). The analysis estimates energy consumption and other sources of greenhouse gas emissions associated with extracting fossil fuels, moving them to refineries, power plants, or other conversion facilities, converting them to final form, moving the products to fueling points, and placing fuel into vehicles. Thus, for petroleum-based fuels, these emissions include leakages of methane associated with crude petroleum; energy spent in extracting crude petroleum and products; energy consumed in refining; energy required for pumping into and out of storage at petroleum terminals; energy used to move product by rail, barge, and truck; and energy used in pumping product into retailers' tanks and pumping out of retailers' tanks into vehicles. The analysis identifies similar kinds of operations and estimates emissions for other types of fuels, including electricity. These "upstream" emissions are important when comparing the effects of switching fuels, because a fuel that has few or no emissions of $\mathrm{CO}_{2}, \mathrm{CH}_{4}$, or $\mathrm{N}_{2} \mathrm{O}$ in the vehicle can have much larger "upstream" emissions than a fuel that has higher emissions in the vehicle. Although the published analysis reported emissions in terms of global warming potentials rather than emissions of individual gases, the default factors provided in Tables 4.2 through 4.6 use unaggregated emissions factors obtained from the author of the published reports.

More details on the emissions factors included in Tables 4.2 through 4.5 may be found in Section 4.6.2, "Alternative Fueled Vehicles." If you have specific emissions factors for your project, you should use those values in computing your emissions reductions. This is especially important for alternative fuels, because the emissions from these fuels can vary significantly depending on the feedstocks and processes used to produce them (see Section 4.6.2). If you use factors other than those in Tables 4.2 through 4.5 , you must document the values you use and their basis in your report. 
Only one emissions factor is used for electric vehicles. You should compute emissions for electric vehicles by multiplying the $\mathrm{kWh}$ used to charge the vehicles by the appropriate emissions factor $(\mathrm{Fe})$ from Table 4.6 or by the specific emissions factor for your project.

$$
\text { Annual Emissions } \text { electric vehicles }^{=} \text {Annual Electricity Use } \bullet \mathrm{Fe}_{\mathrm{i}}
$$

where $\mathrm{Fe}_{\mathrm{i}}=$ emissions factor per $\mathrm{kWh}$ for greenhouse gas $\mathrm{i}$.

Thus, if you are a vehicle manufacturer, you could determine the distribution of your fleet or sales among the states and use state-specific emissions factors for the appropriate fractions of your fleet. If you have more specific emissions factors for the utilities that supply your electricity, you are encouraged to use those factors. You must document the values you use and their basis in your report. 
Table 4.2. Emissions Factors for Miles Driven by Automobiles and Light Trucks Using Gasoline and Alternative Fuels (grams/mile driven)

\begin{tabular}{||l|c|c|c||}
\hline \multicolumn{1}{||c|}{ Fuel Type } & $\mathbf{N}_{2} \mathbf{0} / \mathbf{M i l e}$ & $\mathbf{C H}_{4} / \mathbf{M i l e}$ & $\mathbf{C O}_{2} / \mathbf{M i l e}$ \\
\hline \hline Gasoline & 0.05 & 0.05 & 2.0 \\
Reformulated gasoline & 0.05 & 0.05 & 2.0 \\
Ethanol from corn & 0.05 & 0.03 & 1.5 \\
LPG & 0.05 & 0.05 & 2.0 \\
Methanol from natural gas & 0.05 & 0.03 & 2.0 \\
Compressed natural gas & 0.05 & 1.00 & 1.0 \\
\hline \hline
\end{tabular}

Source: Computed from coefficients based on ANL (1991) and ANL (1993). See text for discussion of methodology used.

Table 4.3. Emissions Factors for Use of Gasoline and Alternative Fuels by Automobiles and Light Trucks (grams/unit of fuel placed into the vehicle)

\begin{tabular}{|c|c|c|c|c|c|}
\hline Fuel Type & Fuel Unit & $\begin{array}{l}\text { Btu per } \\
\text { Fuel Unit }\end{array}$ & $\begin{array}{l}\mathrm{N}_{2} \mathrm{O} \text { per } \\
\text { Fuel Unit }\end{array}$ & $\begin{array}{l}\mathrm{CH}_{4} \text { per } \\
\text { Fuel Unit }\end{array}$ & $\begin{array}{c}\mathrm{CO}_{2} \text { per } \\
\text { Fuel Unit }\end{array}$ \\
\hline $\begin{array}{l}\text { Gasoline } \\
\text { Reformulated gasoline } \\
\text { Ethanol from corn } \\
\text { LPG } \\
\text { Methanol from natural gas } \\
\text { Compressed natural gas }\end{array}$ & $\begin{array}{l}\text { gallon } \\
\text { gallon } \\
\text { gallon } \\
\text { gallon } \\
\text { gallon } \\
\text { standard } \\
\text { cubic foot }\end{array}$ & $\begin{array}{l}1.25 \times 10^{5} \\
1.22 \times 10^{5} \\
8.46 \times 10^{4} \\
8.93 \times 10^{4} \\
6.45 \times 10^{4} \\
\\
1.03 \times 10^{3}\end{array}$ & $\begin{array}{c}0.175 \\
0.171 \\
7.88 \\
3.57 \times 10^{-2} \\
8.39 \times 10^{-2} \\
\\
5.00 \times 10^{-4}\end{array}$ & $\begin{array}{c}8.67 \\
8.47 \\
32.8 \\
1.65 \\
8.30 \\
\\
0.15\end{array}$ & $\begin{array}{c}1.10 \times 10^{4} \\
1.05 \times 10^{4} \\
7.48 \times 10^{3} \\
6.23 \times 10^{3} \\
5.92 \times 10^{3} \\
64.6\end{array}$ \\
\hline
\end{tabular}

Transportation Sector-Page 4.19 
Table 4.4. Emissions Factors for Distance Driven by Heavy Trucks Using Diesel Fuel and Alternative Fuels (grams/brake-horsepower hour)

\begin{tabular}{||l|c|c|c|}
\hline \multicolumn{1}{|c|}{ Fuel Type } & $\mathbf{N}_{2} \mathbf{0} / \mathbf{b h p}-\mathbf{h r}$ & $\mathbf{C H}_{4} / \mathrm{bhp}-\mathrm{hr}$ & $\mathrm{CO}_{2} / \mathrm{bhp}-\mathbf{h r}$ \\
\hline \hline Diesel & 0.06 & 0.10 & 4.0 \\
Ethanol from corn & 0.06 & 0.05 & 4.0 \\
LPG & 0.06 & 0.10 & 3.0 \\
Methanol from natural gas & 0.06 & 0.05 & 4.0 \\
Compressed natural gas & 0.06 & 3.0 & 2.0 \\
\hline \hline
\end{tabular}

Source: Computed from coefficients based on ANL (1991) and

ANL (1993). See text for discussion of methodology used.

Table 4.5. Emissions Factors for Use of Diesel Fuel and Alternative Fuels by Heavy Trucks

(grams/unit of fuel placed into the vehicle)

\begin{tabular}{||l|l|c|c|c|c||}
\hline \multicolumn{1}{|c|}{ Fuel Type } & Fuel Unit & $\begin{array}{c}\text { Btu per } \\
\text { Fuel Unit }\end{array}$ & $\begin{array}{c}\mathbf{N}_{2} \mathbf{0} \text { per } \\
\text { Fuel Unit }\end{array}$ & $\begin{array}{c}\mathrm{CH}_{4} \text { per } \\
\text { Fuel Unit }\end{array}$ & $\begin{array}{c}\mathrm{CO}_{2} \text { per } \\
\text { Fuel Unit }\end{array}$ \\
\hline \hline Diesel & gallon & $1.39 \times 10^{5}$ & 0.139 & 8.61 & $1.17 \times 10^{4}$ \\
Ethanol from corn & gallon & $8.46 \times 10^{4}$ & 7.88 & 32.8 & $7.48 \times 10^{3}$ \\
Liquefied petroleum gas & gallon & $8.93 \times 10^{4}$ & $3.57 \times 10^{-2}$ & 1.65 & $6.37 \times 10^{3}$ \\
Methanol from natural gas & gallon & $6.45 \times 10^{4}$ & $8.39 \times 10^{-2}$ & 8.30 & $6.05 \times 10^{3}$ \\
Compressed natural gas & standard & & & \\
& cubic foot & $1.03 \times 10^{3}$ & $5.00 \times 10^{4}$ & 0.15 & 66.1 \\
\hline \hline Source: Computed from coefficients based on ANL (1991) and ANL (1993). See text for discussion of \\
methodology used.
\end{tabular}


Table 4.6.Emissions Factors For Electric Vehicles by State and Region ${ }^{(a)}$ (grams $/ \mathrm{kWh}$ )

\begin{tabular}{|c|c|c|c|c|c|c|c|}
\hline State & $\mathrm{N}_{\mathbf{2}} \mathrm{O}$ & $\mathrm{CH}_{4}$ & $\mathrm{CO}_{2}$ & State & $\mathrm{N}_{2} \mathrm{O}$ & $\mathrm{CH}_{4}$ & $\mathrm{CO}_{2}$ \\
\hline $\begin{array}{l}\text { New England } \\
\text { Connecticut } \\
\text { Maine } \\
\text { Massachusetts } \\
\text { New Hampshire } \\
\text { Rhode Island } \\
\text { Vermont }\end{array}$ & $\begin{array}{l}0.027 \\
0.028 \\
0.042 \\
0.029 \\
0.035 \\
0.014\end{array}$ & $\begin{array}{l}0.496 \\
0.258 \\
1.05 \\
0.582 \\
1.15 \\
0.087\end{array}$ & $\begin{array}{l}3.82 \times 10^{2} \\
1.85 \times 10^{2} \\
7.67 \times 10^{2} \\
3.72 \times 10^{2} \\
6.43 \times 10^{2} \\
5.25 \times 10^{1}\end{array}$ & $\begin{array}{l}\text { South Atlantic } \\
\text { Delaware } \\
\text { District of Columbia } \\
\text { Florida } \\
\text { Georgia } \\
\text { Maryland } \\
\text { North Carolina } \\
\text { South Carolina } \\
\text { Virginia } \\
\text { West Virginia }\end{array}$ & $\begin{array}{l}0.053 \\
0.041 \\
0.043 \\
0.039 \\
0.041 \\
0.041 \\
0.027 \\
0.036 \\
0.054\end{array}$ & $\begin{array}{l}1.63 \\
1.21 \\
1.20 \\
1.18 \\
1.21 \\
1.23 \\
0.672 \\
0.985 \\
1.83\end{array}$ & $\begin{array}{l}1.06 \times 10^{3} \\
7.29 \times 10^{2} \\
7.84 \times 10^{2} \\
6.69 \times 10^{2} \\
7.28 \times 10^{2} \\
6.92 \times 10^{2} \\
3.82 \times 10^{2} \\
5.65 \times 10^{2} \\
1.03 \times 10^{3}\end{array}$ \\
\hline $\begin{array}{l}\text { Mid Atlantic } \\
\text { New Jersey } \\
\text { New York } \\
\text { Pennsylvania }\end{array}$ & $\begin{array}{l}0.029 \\
0.033 \\
0.040\end{array}$ & $\begin{array}{l}0.749 \\
0.821 \\
1.20\end{array}$ & $\begin{array}{l}4.32 \times 10^{2} \\
5.42 \times 10^{2} \\
6.83 \times 10^{2}\end{array}$ & $\begin{array}{l}\text { East-South Central } \\
\text { Alabama } \\
\text { Kentucky } \\
\text { Mississippi } \\
\text { Tennessee }\end{array}$ & $\begin{array}{l}0.041 \\
0.054 \\
0.037 \\
0.041\end{array}$ & $\begin{array}{l}1.28 \\
1.83 \\
1.11 \\
1.25\end{array}$ & $\begin{array}{l}7.21 \times 10^{2} \\
1.03 \times 10^{3} \\
6.32 \times 10^{2} \\
7.08 \times 10^{2}\end{array}$ \\
\hline $\begin{array}{l}\text { East-North Central } \\
\text { Illinois } \\
\text { Indiana } \\
\text { Michigan } \\
\text { Ohio } \\
\text { Wisconsin }\end{array}$ & $\begin{array}{l}0.032 \\
0.056 \\
0.046 \\
0.051 \\
0.045\end{array}$ & $\begin{array}{l}0.880 \\
1.93 \\
1.49 \\
1.69 \\
1.450\end{array}$ & $\begin{array}{l}5.06 \times 10^{2} \\
1.09 \times 10^{3} \\
8.41 \times 10^{2} \\
9.49 \times 10^{2} \\
8.16 \times 10^{2}\end{array}$ & $\begin{array}{l}\text { West-South Central } \\
\text { Arkansas } \\
\text { Louisiana } \\
\text { Oklahoma } \\
\text { Texas }\end{array}$ & $\begin{array}{l}0.038 \\
0.040 \\
0.047 \\
0.044\end{array}$ & $\begin{array}{l}1.17 \\
1.27 \\
1.59 \\
1.45\end{array}$ & $\begin{array}{l}6.61 \times 10^{2} \\
7.13 \times 10^{2} \\
8.92 \times 10^{2} \\
8.16 \times 10^{2}\end{array}$ \\
\hline $\begin{array}{l}\text { West-North Central } \\
\text { Iowa } \\
\text { Kansas } \\
\text { Minnesota } \\
\text { Missouri } \\
\text { Nebraska } \\
\text { North Dakota } \\
\text { South Dakota }\end{array}$ & $\begin{array}{l}0.052 \\
0.048 \\
0.045 \\
0.050 \\
0.039 \\
0.058 \\
0.032\end{array}$ & $\begin{array}{l}1.76 \\
1.56 \\
1.43 \\
1.64 \\
1.18 \\
2.0 \\
0.912\end{array}$ & $\begin{array}{l}9.91 \times 10^{2} \\
8.78 \times 10^{2} \\
8.08 \times 10^{2} \\
9.26 \times 10^{2} \\
6.67 \times 10^{2} \\
1.12 \times 10^{3} \\
5.13 \times 10^{2}\end{array}$ & $\begin{array}{l}\text { Mountain } \\
\text { Arizona } \\
\text { Colorado } \\
\text { Idaho } \\
\text { Montana } \\
\text { Nevada } \\
\text { New Mexico } \\
\text { Utah } \\
\text { Wyoming }\end{array}$ & $\begin{array}{l}0.036 \\
0.055 \\
0.015 \\
0.044 \\
0.051 \\
0.057 \\
0.055 \\
0.058\end{array}$ & $\begin{array}{l}1.05 \\
1.88 \\
0.046 \\
1.38 \\
1.73 \\
1.95 \\
1.86 \\
1.99\end{array}$ & $\begin{array}{c}5.93 \times 10^{2} \\
1.05 \times 10^{3} \\
7.98 \\
7.77 \times 10^{2} \\
9.81 \times 10^{2} \\
1.10 \times 10^{3} \\
1.04 \times 10^{3} \\
1.12 \times 10^{3}\end{array}$ \\
\hline $\begin{array}{l}\text { Pacific Contiguous } \\
\text { California } \\
\text { Oregon } \\
\text { Washington }\end{array}$ & $\begin{array}{l}0.026 \\
0.016 \\
0.017\end{array}$ & $\begin{array}{l}0.645 \\
0.187 \\
0.249\end{array}$ & $\begin{array}{l}3.59 \times 10^{2} \\
1.03 \times 10^{2} \\
1.38 \times 10^{2}\end{array}$ & $\begin{array}{l}\text { Pacific Non- } \\
\text { Contiguous } \\
\text { Alaska } \\
\text { Hawaii }\end{array}$ & $\begin{array}{l}0.019 \\
0.045\end{array}$ & $\begin{array}{l}0.287 \\
0.732\end{array}$ & $\begin{array}{l}2.16 \times 10^{2} \\
9.16 \times 10^{2}\end{array}$ \\
\hline \multicolumn{8}{|c|}{$\begin{array}{l}\text { (a) Values are grams/kWh delivered to the vehicle, based on the average kilowatt-hour generated in the state in } 1992 . \\
\text { Values are computed from coefficients based on ANL (1991) and ANL (1993) and are consistent with the electricity } \\
\text { generation fuel mixes and technologies underlying the emissions factors in Table C.1. The values include emissions from } \\
\text { the power plant and emissions upstream from the power plant to extract, process, and deliver the fuel. They account for } \\
\text { electricity losses in transmission and distribution, and the production of } \mathrm{N}_{2} \mathrm{O} \text { from transmission lines. They do not account } \\
\text { for the transfer of electricity across state lines. }\end{array}$} \\
\hline
\end{tabular}

Transportation Sector-Page 4.21 


\subsection{Estimating the Effects of Marketing Vehicles with Lower Emissions}

This class of project encompasses three general types of actions:

- Marketing vehicles that are more fuel efficient

- Marketing vehicles that use cleaner fuels

- Marketing components (primarily tires) that make vehicles more fuel efficient.

Specifics on estimating fuel use and emissions reductions resulting from these actions are discussed below.

\subsubsection{Improved Fuel Economy}

You may define a project based on the average fuel economy for all of the vehicles you sell or for a selected portion of your sales (for example, introducing a new model with high fuel economy). You should identify the specific actions you took to improve the fuel economy of your model(s) or sales fleet.

Your project should be based on the number of vehicles sold in a calendar year. Although most manufacturers use a "model year" that doesn't coincide with the calendar year, if possible you should define the reference case and the project based on the calendar year. If the data needed to compute the project effects on a calendar year basis are not available, you can use a model year basis for your report. However, you should be aware that users of the EPAct 1605(b) database will find your report more useful if it is based on the actual vehicles sold in a calendar year. Your report should specify which type of reporting year you used.

Defining a project to cover only a portion of your fleet could result in internal project effects if the models selected take or lose market share from the remainder of your sales fleet. You may use internal marketing research to assess effects between model lines. If the model included in your project is a redesign and replacement of a previously existing model, sales data for the previous model can be used to assess these effects. You could also choose to expand the definition of your project to include all effects that occur within your organization-for example, expand a project from a single vehicle model to all vehicles in your fleet. You must still be sure to identify and, where possible, quantify effects that occur outside your organization.

If your project covers only a portion of the vehicles you sell, the vehicle use characteristics for this portion may differ from the national averages in the RTECS and the Transportation Energy Data Book. If you have specific data for the vehicles covered by your project, you should use these data in your report, documenting the values used and the method you used to estimate them. 
Your reference case emissions would be computed by determining the fuel economy and average use for all of the vehicles covered by your project that were sold in the reference case year(s). If your project covers only selected models (as opposed to your entire sales fleet), the models used to estimate the reference case should be comparable in performance and interior volume to the new or improved models that constitute your project.

As noted earlier, analyses show that (1) automobile and truck users tend to drive farther as fuel economy increases, reducing expected fuel savings by 5 to 15 percent, with 10 percent a reasonable assumption given current fuel price and fuel economy trends, and (2) the EPA combined fuel economy ratings tend to be about 15 percent higher than the fuel economy that is actually achieved. Thus, if you based your calculation of fuel use reductions on combined fuel economy statistics or vehicle use statistics rather than specific data for your vehicle, you should (1) divide the combined fuel economy values by a factor of 1.15 before computing fuel consumption and savings and (2) determine the increase in miles traveled that corresponds to the 10 percent decrease in fuel savings using the following equation:

$$
\frac{\text { miles }_{\text {proj }}}{\text { miles }_{\text {ref }}}=t\left(\frac{\mathrm{mpg}_{\text {proj }}-\mathrm{mpg}_{\text {ref }}}{\mathrm{mpg}_{\mathrm{ref}}}\right)+1
$$

where miles $_{\text {proj }}=$ miles traveled in the project case

miles $_{\text {ref }}=$ miles traveled in the reference case

$\mathrm{t}=$ assumed reduction in fuel savings (default value $=0.1$ )

$\mathrm{mpg}_{\text {proj }}=$ fuel economy (miles per gallon) in the project case

$\mathrm{mpg}_{\mathrm{ref}}=$ fuel economy (miles per gallon) in the reference case.

For example, if the statistic for miles driven in the reference case is 10,000 miles, and the fuel economy in the project and reference cases is $40 \mathrm{mpg}$ and $30 \mathrm{mpg}$, respectively, the project-specific adjustment factor is as follows:

$$
\begin{gathered}
\frac{\text { miles }_{\text {proj }}}{\text { miles }_{\text {ref }}}=0.1\left(\frac{40-30}{30}\right)+1=1.033 \\
\text { miles }_{\text {proj }}=1.033 \bullet \text { miles }_{\text {ref }}=1.033 \bullet 10,000=10,330 \text { miles. }
\end{gathered}
$$

If you have data indicating that some other factor should be used to adjust the vehicle use or fuel economy data for your specific project, or if you have data on the actual miles driven or the fuel economy of your vehicles under their actual conditions of use, you should use this information instead. You should document the data you use and the basis for them in your report.

Because a vehicle with improved fuel economy continues to save fuel beyond the year in which it is sold and first used, you may wish to report emissions reductions in future years from the continued use 
of the vehicles in your project. You may report these reductions on an annual basis, after the emissions reductions for the year have taken place. For consistency, these reductions should be reported using the same reference case as the original project report. Reports of such continuing reductions should be reported separately from new projects. For continuing reductions, the number of vehicles in the project should be reduced over time. Scrappage and survival rates for automobiles and light trucks are reported in the Transportation Energy Data Book and should be used in computing your future reductions unless you have specific data on the scrappage and survival rates for your project. You should document the basis for any values you use that differ from those in the Transportation Energy Data Book.

Fuel economy also tends to decline slightly with vehicle age because of deterioration and limited maintenance. For continuing projects, you should also reduce the fuel economy of the vehicles in your project and the associated emissions reductions over time. However, no published information exists that could be used to adjust fuel economy ratings for vehicle age. Vehicle service departments and state-mandated vehicle inspection programs might collect data related to fuel economy in older vehicles, but they do not measure fuel economy directly. If you have information about the effect of age on fuel economy for your own vehicles, you should use it to calculate emissions reductions in continuing projects. If you do not have such data, you should assume no decline in fuel economy over time. 


\title{
Example 4.3 - Estimating Emissions Reductions Resulting from Improved Fuel Economy
}

\author{
Note: This example illustrates only one approach to analyzing a project; your analysis, \\ methods, and calculations will vary depending on your particular circumstances, \\ the geographic location of the project, and other factors.
}

The vehicle manufacturer in Example 4.2 redesigned and replaced its Model A with a version with improved fuel economy. In calendar year 1991, the year before the project, the manufacturer sold 5,000 of the original Model $\mathrm{A}$ vehicles. In calendar year 1992, the year of the project, the manufacturer sold 4,500 of the improved Model A vehicles and 500 additional Model B vehicles (which are similar to the original Model A but with lower fuel economy). No changes appear to have occurred in overall market share relative to competitors. All vehicles are fueled with gasoline.

The combined fuel economy values from the EPA Federal Test Procedure are $25 \mathrm{mpg}$ for the original Model A, $30 \mathrm{mpg}$ for the improved Model A, and $23 \mathrm{mpg}$ for Model B. These values must be adjusted by a factor of 1.15 in computing fuel use.

The manufacturer chose a basic reference case based on what the emissions would have been in the absence of the project, assuming that sales of the original Model A would have been the same in calendar year 1992 as in 1991-that is, 5,000 vehicles would have been sold at a fuel economy of $25 \mathrm{mpg}$.

The manufacturer had data on odometer readings for the reference and project cases recorded during scheduled vehicle service. This information indicated that the original Model A was driven 10,000 miles per year and that the improved Model A was driven slightly farther-10,500 miles per year. Model B was driven 9,500 miles per year. ${ }^{(2)}$

\section{Total Mileage}

Reference case: Total Mileage $=5,000$ vehicles $\bullet 10,000$ miles $/$ vehicle $=5.0 \times 10^{7}$ miles

Project case: $\quad$ Total Mileage $=(4,500$ vehicles $\bullet 10,500$ miles/vehicle $)+(500$ vehicles $\bullet 9,500$ miles $/$ vehicle $)$ $=4.7 \times 10^{7}$ miles $+4.8 \times 10^{6}$ miles $=5.2 \times 10^{7}$ miles

\section{Total Fuel Use}

Total fuel use was computed as follows:

$$
\text { Fuel Use }=\frac{\text { Mileage }}{\text { Fuel Economy /1.15 }}
$$

Reference case: Total Fuel Use $=\left(5.0 \times 10^{7} \mathrm{miles}\right) /(25 \mathrm{mpg} / 1.15)=2.3 \times 10^{6}$ gallons

Project case: $\quad$ Total Fuel Use $=\left(4.7 \times 10^{7}\right.$ miles $) /(30 \mathrm{mpg} / 1.15)+\left(4.8 \times 10^{6} \mathrm{miles}\right) /(23 \mathrm{mpg} / 1.15)$

$$
=2.04 \times 10^{6} \text { gallons }
$$

Emissions

$$
\text { Annual Emissions }=\text { Annual Mileage }-\mathrm{Fm}_{\text {gasoline }}+\text { Annual Fuel Use }-\mathrm{Ff}_{\text {gasoline }}
$$

Emissions were computed using the emissions factors from Tables 4.2 and 4.3.

\section{Reference Case Emissions}

$\mathrm{N}_{2} \mathrm{O}$ Emissions =

$\mathrm{CH}_{4}$ Emissions $\quad=$

$\mathrm{CO}_{2}$ Emissions $=$

Project Case Emissions

$\mathrm{N}_{2} \mathrm{O}$ Emissions =

$\mathrm{CH}_{4}$ Emissions =

$\mathrm{CO}_{2}$ Emissions $=$

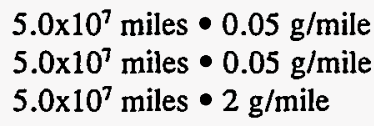

$+2.3 \times 10^{6} \mathrm{gal} \cdot 0.175 \mathrm{~g} / \mathrm{gal}$

$+2.3 \times 10^{6} \mathrm{gal} \bullet 8.67 \mathrm{~g} / \mathrm{gal}$

$+2.3 \times 10^{6} \mathrm{gal} \cdot 1.1 \times 10^{4} \mathrm{~g} / \mathrm{gal}$

$=2.9 \times 10^{6} \mathrm{~kg}$ $=2.24 \times 10^{7} \mathrm{~kg}$ $=2.54 \times 10^{10} \mathrm{~kg}$

$5.2 \times 10^{7}$ miles $\bullet 0.05 \mathrm{~g} / \mathrm{mile}$

$5.2 \times 10^{7}$ miles $\bullet 0.05 \mathrm{~g} / \mathrm{mile}$

$5.2 \times 10^{7}$ miles $\bullet 2 \mathrm{~g} / \mathrm{mile}$ $+\quad 2.04 \times 10^{6} \mathrm{gal} \cdot 0.175 \mathrm{~g} / \mathrm{gal}$
$+\quad 2.04 \times 10^{6} \mathrm{gal} \cdot 8.67 \mathrm{~g} / \mathrm{gal}$
$+\quad 2.04 \times 10^{6} \mathrm{gal} \cdot 1.1 \times 10^{4} \mathrm{~g} / \mathrm{gal}$

$=2.96 \times 10^{6} \mathrm{~kg}$

$=2.03 \times 10^{7} \mathrm{~kg}$

$=2.25 \times 10^{10} \mathrm{~kg}$

\section{Transportation Sector-Page 4.25}




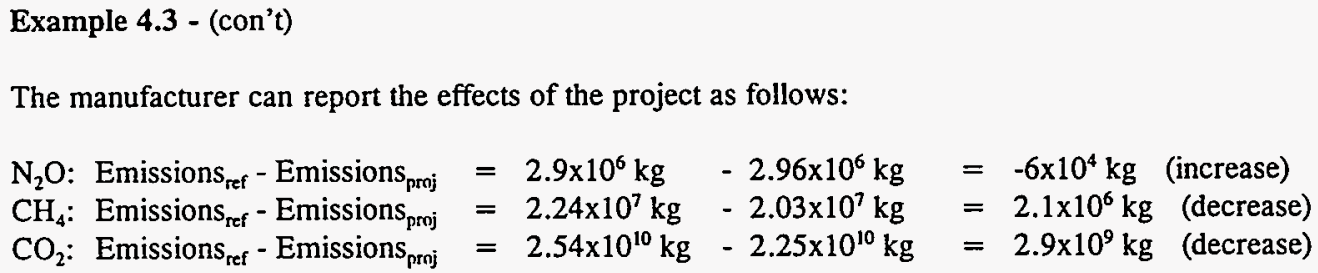

(a) If the manufacturer had not had data on miles driven, statistics on vehicle use could have been used for the reference case but the adjustment described in Section 4.6.1 would have been required to compute project case emissions.

\subsubsection{Alternative Fueled Vehicles}

Alternative fueled vehicles (AFVs), which include electric vehicles, present a number of challenges to estimating emissions and emissions reductions. In general, the calculation of emissions reductions requires estimating the amount of alternative fuel used, the amount of gasoline that would have been used but for the project, the emissions from each, and the difference.

If you do not measure fuel consumption directly, you will need to compute it from information on vehicle fuel economy and vehicle use. AFVs are expected to have different performance and shorter driving ranges between refuelings, so vehicle purchasers probably will use AFVs somewhat differently from conventional vehicles. However, at present there are too few AFVs in use and too little experience with these vehicles to project how they will be used, although the number of AFVs is expected to increase during the next 6-10 years as various state, local, and federal mandates take effect. If you are a vehicle manufacturer and have or can obtain use characteristics for a representative sample of the AFVs you sell, you should use this information in computing your emissions reduction. If you do not have such information, you should assume that the average AFV is driven as far as the average petroleum-fueled vehicle.

In reporting emissions reductions associated with the sale of AFVs, you should consider whether the vehicles sold actually replace other vehicles. For example, if an electric vehicle is purchased and used as a supplemental vehicle for short trips where the owner previously walked or took public transportation, overall emissions could increase.

To construct a credible reference case and comparable data for both the reference and project cases, you need to account for two factors:

- Differences in use. Given that AFVs are expected to have more limited driving ranges and to be used primarily in urban markets, you should use the gasoline-equivalent fuel economy for the urban (not combined) driving cycle in these calculations.

- Equivalence between gasoline and any alternative fuel used. Details of fuel economy testing for production AFVs will remain uncertain until such vehicles are routinely submitted for testing. Until a fuel economy rating is assigned, you need to estimate fuel economy using your

\section{Transportation Sector-Page 4.26}


own data and express that estimate in terms of gasoline equivalence (that is, as the miles per gallon that would be achieved if the fuel were gasoline). Thus, multiplying the fuel economy by the estimated distance driven for a new vehicle and by the number of vehicles sold would yield the reference case gasoline consumption. Then you should estimate the factor needed to convert the fuel economy to equivalent mileage per unit of the alternative fuel in order to estimate fuel consumption for the project case.

If you have fuel economy data expressed in terms of units of the alternative fuel per distance driven, then the reference case should be calculated using the fuel economy for the urban driving cycle for a conventionally fueled model with comparable interior volume. Multiplying the fuel economy for the alternative vehicle by the distance driven and the number of vehicles would yield the project case.

Another consideration in reporting is the type of alternative fuel used and its source. Some alternative fuels have low or even zero emissions of greenhouse gases if measured at the vehicle tailpipe, but higher emissions than conventional fuels when the production of the fuel is taken into consideration. Reporting emissions reductions for alternative fuels should reflect the production as well as the use of the fuel. Unfortunately, analysts do not agree about which alternative fuels, feedstocks, and production processes yield reductions of greenhouse gas emissions relative to gasoline in a comparable vehicle; for those alternative fuels where there is agreement that reductions occur, differences exist on the magnitude of the reductions.

If you wish to report reductions from the sale of AFVs, you should report the alternative fuel type and quantity as well as emissions and emissions reductions. Tables 4.2 through 4.6 in Section 4.5 contain estimated emissions per unit of alternative fuel based on a large, comprehensive study using consistent assumptions and using wide bounds on the fuel cycle to account for all effects of fuel switching on emissions. You may wish to base your calculations on this study. You should be aware that the reporting program may recalculate emissions reductions based on subsequent studies if results warrant, especially after more experience is gained with producing, marketing, and using alternative fuels. If you have specific information on the emissions for your vehicles and fuels, you should use these data instead. You should document the values used and the basis for them in your report.

The choice of a feedstock also can affect the life-cycle emissions-that is, the total of emissions for every step in making a fuel. For example, methanol made from coal is estimated to yield more emissions than gasoline, while methanol from natural gas is expected to yield slightly less than gasoline. Electricity from coal-fired steam-turbine power plants (used to charge electric vehicle batteries) is estimated to yield more emissions than gasoline, although electricity from other plants is expected to yield fewer emissions (ANL 1991). Ethanol from corn, contrary to many expectations, is estimated to yield higher emissions because the fermentation process requires energy that, at present, is typically supplied by burning coal. Thus, a vehicle manufacturer wishing to report emissions reductions from marketing AFVs must ascertain what share of the fuel market is being supplied from which feedstock in order to determine whether the use of this fuel actually reduces emissions.

Transportation Sector-Page 4.27 
In the future, as alternative fuels gain market share, it is likely that information about sources and production processes will be collected and reported by DOE, the Alternative Fuels Data Center at the National Renewable Energy Laboratory, or other organizations. Again, reporting should include estimated fuel quantities as well as emissions, to permit recalculating of reductions if subsequent information suggests revising those that have been reported. In the meantime, you should assume that methanol comes from natural gas and electricity from the state-specific fuel mixes that underlie the emissions factors in Table 4.6. A vehicle manufacturer should determine what fraction of its electric vehicle market is located in each state and use these data together with the emissions factors in Table 4.6 or your own utility-specific data to compute emissions reductions associated with electric vehicles.

\subsubsection{Flexible Fueled Vehicles}

Flexible-fueled vehicles (FFVs), which can use varying mixtures of gasoline and methanol or gasoline and other fuels, could perform very similarly to vehicles that use only gasoline, although FFVs aren't optimized for either fuel so some deterioration of performance could occur. Average use statistics could be used for these vehicles, although project-specific information would be more accurate. Estimating the emissions reductions requires information on how much of the alternative fuel was substituted for gasoline in these vehicles. In these cases, you may wish either to survey a sample of customers to determine actual fueling choices or, if FFV sales are concentrated among public or commercial fleets, to request information from fleet operators. This information also could be collected by sensors in the FFV fuel system and retrieved during regularly scheduled vehicle maintenance by the manufacturer's service outlets. If you have such data, you should use them in computing your emissions and emissions reductions.

\subsubsection{Equipment that Improves Fuel Economy}

This section provides guidance on reporting emissions reductions resulting from the use of tires that reduce vehicle fuel consumption. If you wish to report emissions reductions associated with other types of equipment, you should follow the same general guidance as that discussed for tires.

Reduced rolling resistance by tires would reduce vehicles' fuel consumption. However, very little data exist on the extent of improved fuel economy. Under the Climate Change Action Plan, a testing and rating program for rolling resistance by tires will be developed. Until tires are rated, emissions reduction projects that involve improved rolling resistance can only be analyzed using your own data.

In general, reporting will require the same kind of information on vehicle fuel use that vehicle manufacturers would have to estimate to report the projects described in Section 4.6.1, adjusted for the effects of tires. However, the estimation problem is compounded by the number of potential reporters, each with partial information: the tire manufacturer, the vehicle manufacturer, the consumers who use vehicles equipped with the tires, and (possibly) tire dealers who replace tires. 
The tire testing and rating is anticipated to allow calculation of the effects of improved rolling resistance as a percentage of fuel economy (for example, a tire model used on all four wheels of a car results in a 3 percent increase in MPG). A tire manufacturer who has a contract to supply tires for a manufacturer's new vehicles should be able to obtain from the vehicle manufacturer the number, fuel type, and fuel economy ratings of vehicles using the tires as standard equipment. The tire manufacturer then can estimate vehicle use and calculate fuel consumption with the project and reference case tires. Tire and vehicle manufacturers who report should each indicate the other as other possible reporting entities.

As with vehicle sales, the project case for tires may best be based on the number and type of tires sold. For consistency and credibility, the reference case should be based on the same testing program as the project case. Thus, the reference case should be based on tires sold during the first year of the testing and labeling program, and projects reported for the second and subsequent years of the testing program. Again as for vehicles, if you are a tire manufacturer, defining a project based on part of your sales increases the potential for unintended project effects and inaccuracies from using national vehicle use statistics. Given the other complexities in reporting emissions reductions from tire sales, your report's credibility will be enhanced by reporting for your entire sales to new vehicles, rather than portions of your product line.

Second-and-subsequent-year reports could be submitted on emissions reductions from the cohort of vehicles supplied with the tires, but you must account for scrappage rates of the vehicles and scrappage rates of the tires. Because average vehicle mileage reflects a range of use, and because scrappage can be influenced by equipment damage as well as normal wear, tire scrappage rates cannot be calculated directly from average vehicle use and expected tire mileage. You may wish to (1) reanalyze the Residential Transportation Energy Consumption Survey (RTECS) to estimate variation in mileage and expected tire scrappage rates or (2) survey vehicle purchasers, or (3) collaborate with vehicle manufacturers if they survey vehicle purchasers.

Emissions reductions from tires purchased as replacement equipment are much more difficult to estimate accurately. You may not be recording or have access to information on the age and make of car on which replacement tires are installed. You may wish to develop reporting systems to begin gathering this information from retailers, or you may wish to develop customer surveys or other methods of sampling to estimate tire-vehicle combinations or even vehicle or fuel use. Lacking this information, you may wish instead to calculate fuel consumption using the Energy Information Administration's (EIA's) reported average fuel economy for the nation's automobile fleet (published with a year's delay) and the RTECS to estimate average mileage for the fleet; these values can be used to calculate average fuel consumption in the reference and project cases for replacement tires. Unfortunately the EIA fleet average is for passenger cars only; it does not include light trucks. A comparable series probably can be constructed, at some cost, for light trucks using published information on yearly sales and average fuel economy for light trucks.

If you submit continuing reports on reductions from both tire sales for new vehicles and sales of replacement tires, you need to adjust average fleet fuel economy used in replacement sales to avoid 
reporting the same reduction twice. (Some of the fleet average fuel economy would be based on tires purchased as original equipment on new vehicles.) You may use the average fleet fuel economy of several years prior to the year of actual replacement tire sale, based on estimates of tire scrappage rates or expected lifetimes for the tires on new vehicles. Second-and-subsequent-year projects for replacement tires will become increasingly less reliable.

\subsection{Estimating the Effects of Operating or Maintaining a Vehicle Fleet to Reduce Emissions}

A transportation service supplier or fleet operator may reduce greenhouse gas emissions in a number of ways, including the following:

- purchasing and using high-MPG vehicles

- purchasing and using alternative fueled vehicles

- improving the maintenance of existing vehicles to reduce fuel consumption

- improving operating practices (for example, acceleration, braking, idling) to reduce fuel consumption

- improving routing to reduce distances traveled

- matching equipment to tasks to reduce fuel consumption

- changing vehicle dispatching or other practices to improve fleet fuel economy.

Some growing service suppliers may be able to report reductions in aggregate emissions resulting from large increases in efficiency that more than offset the effect of growth in the demand for service. (See the discussion of modified reference cases based on unit of service in Section 4.4.) These suppliers are encouraged to report, taking account of activity shifting, outsourcing, and other possible project effects.

Audits of operations, maintenance, vehicle stock, and routing for service delivery fleets using highway vehicles have identified potential reductions in fuel consumption of up to 34 percent, with reductions of 20 percent considered actually achievable (Erkut and MacLean 1992). Improved routing alone has allowed rural school districts to reduce school bus mileage by up to 20 percent (Graham 1993). Vehicle operating practices also can affect fuel consumption. For example, increasing the operating speed of an automobile above 55 miles per hour can increase fuel consumption 5-30 percent, depending on the vehicle (Holcomb et al. 1987). Idling the engine of a heavy truck during cold weather keeps fuel warm but uses 10-20 times as much diesel fuel as a fuel heater that accomplishes the same thing (Transport Topics 1988). Short-term training of vehicle operators has been shown to change behavior 
and reduce fuel consumption by 10 percent in the short term (Greene 1986), although some of this reduction may not persist in the long term.

You can undertake any of the activities listed above by itself or in concert with other activities, for your entire fleet or for part of it. If you undertake activities for part of the fleet, you must consider the possibility of additional project effects within the fleet. For example, partial replacement of a fleet with AFVs could result in changes in how they or other vehicles in the fleet are used, assigned, or routed to compensate for different characteristics (for example, limited range between refuelings) of the new vehicles.

Another possible project effect results from outsourcing, defined here as contracting with another firm to provide some of the transportation service. If your sole action to reduce emissions is to contract out for service, you have not reduced emissions (unless the supplier operates at a lower level of emissions), and you should not report a reduction under this program. If the supplier operates at a lower level of emissions and you can compute these emissions, you could report a new reduction if no other effects offset the reduction.

Unlike vehicle manufacturers, service suppliers are in a position to monitor actual fuel consumption for individual vehicles in their fleets and for the fleets themselves. Vehicles such as aircraft monitor fuel consumption directly, while consumption in other vehicles can be monitored by recording quantities used during refueling. Some trucking firms are beginning to install extensive vehicle monitoring equipment that includes distance and fuel consumption monitoring.

If you report for part of a fleet, estimating emissions reductions can become complicated, because additional project effects become more likely. Similarly, reporting can become complicated if you try to estimate the magnitudes of reductions resulting from each of several simultaneous projects (for example, a public transportation agency or a delivery company might purchase alternative fueled vehicles for use on selected routes, improve routing, improve vehicle maintenance, and improve operator behavior). In the latter situation, you may wish to report the total reduction in emissions for your organization, your fleet, or part of your fleet. You need not undertake detailed analysis to determine how much of the reduction in emissions resulted from each of these measures. However, to facilitate the process of learning how to reduce emissions, the project description should include information about the various measures undertaken and some rough assessment of the relative importance of each in achieving the reductions reported.

If you organize your fleet into distinct territorial or other divisions with relatively little interaction between division boundaries, a project might be implemented and reported for only one or a few divisions. Where divisional boundaries are loose, so that a change in activities in one division affects those in another, the project can have effects on emissions in other divisions, and expanding the project definition to encompass all of the interacting divisions would capture more of the project effects. 


\subsubsection{Data Sources for Service Suppliers}

Many transportation service suppliers already measure their fuel consumption directly for required reporting to federal agencies or for their own business purposes.

Airlines presently are required to report fleet fuel consumption, revenue ton-miles, and revenue passenger miles to the Federal Aviation Administration's Office of Airline Statistics (Form 41, required under 14 CFR Part 241). An airline may report a reference case as fleet fuel consumption and fuel consumption per revenue ton-mile in a specific year (by converting revenue passenger miles to revenue ton-miles as now done to complete the form), define a project to reduce fuel consumption per revenue ton-mile, and report emissions reductions calculated as the difference in fuel consumption per ton-mile in the specific and project years, multiplied by the ton-miles in the project year. The calculations should include both scheduled and non-scheduled service to account for all project effects.

Class I railroads presently are required to report fleet fuel consumption and freight ton miles to the Interstate Commerce Commission (Schedule 750, lines 4 and 6; Schedule 755, line 14). A Class I railroad may report a reference case as fleet fuel consumption and fuel consumption per ton-mile in a specific year, define a project to reduce fuel consumption per ton-mile, and report emissions reductions calculated as the difference in fuel consumption per ton-mile in the reference and project years, multiplied by the ton-miles in the project year. The present form collects information only on diesel fuel. A railroad that uses fuels other than diesel fuel should include consumption of the other fuels as well.

Other transportation service suppliers are not now required to report levels of fuel consumption and services supplied. However, they are likely to collect and analyze this information for their own business purposes and may report in a manner similar to those noted above.

\subsubsection{Alternative Fueled Vehicles}

If you report emissions reductions involving shifting the mix of vehicles in your fleet by operating alternative fueled vehicles (AFVs), several issues arise. Significant uncertainties exist in developing AFV programs and in life-cycle emissions data. Some of these are addressed in Section 4.6.2. This section focuses on potential reporters who purchase and operate, rather than market, AFVs.

First, several Federal and state mandates for large fleets to purchase AFVs have been enacted but have not yet taken effect. The Federal programs and probably the state programs will require record keeping and reporting about these purchases, but the reporting requirements for these programs have not yet been finalized. These reporting requirements are likely to include some information that can be used in EPAct Section 1605(b) reports.

Second, as in the case of AFV manufacturers, service suppliers wishing to report reductions from AFV use face uncertainty about which alternative fuels actually reduce greenhouse gas emissions and by how 
much. For this reason, an organization that reports reductions from the use of AFVs should report fuel consumption for each fuel in the reference and project cases as well as emissions reductions.

AFVs using two types of alternative fuels-electricity and natural gas-can be refueled from facilities that use these fuels for other purposes (for example, lighting, office equipment, space conditioning). You do not have to establish separately metered fueling stations in order to report reductions from using alternative fuels, but where multiple uses are metered jointly you must estimate the proportion of transportation uses (or you may define the project to include all other functions using the same fuel or energy sources as well as vehicle operations). This can be done by recording fuel supplied using an inline meter as the vehicle is filled or by measuring fuel in the vehicle before and after each refueling in order to establish the magnitude of the fill. A less reliable and more cumbersome approach would be to estimate historic consumption of the alternative fuels prior to the purchase of the AFVs, adjust it as needed for fluctuations in weather-related space conditioning or other variables, and subtract it from total fuel consumption after the AFVs entered service.

You can use the factors in Table 4.6 to estimate emissions and emissions reductions associated with electric vehicles. However, if you have more specific information for your project, such as the emissions rate from your electricity supplier and the time of day that vehicle charging takes place, you are encouraged to use this information in computing your emissions and emissions reductions. You must document any such data you use and their basis in your report.

\subsection{Estimating the Effects of Modifying Demand and Infrastructure}

This section provides guidance on reporting emissions reductions resulting from demand modification and infrastructure improvements. A number of programs and activities are designed to manage demand for transportation or reduce travel-related emissions. The most prominent of these are mandated employer programs to reduce commuting and encourage telecommuting. Both types of programs are intended to reduce the number of cars and light trucks driven to work each day by employees. At the same time, some improvements in infrastructure are designed to improve the operating efficiency of the vehicles that use it.

\subsubsection{Demand Modification}

The Clean Air Act Amendments of 1990 (CAAA) require states and metropolitan areas that violate ambient air quality standards to enact legislation mandating that large employers increase vehicle occupancy rates among their commuting employees. Emissions reductions achieved through these or other demand-reduction programs can be reported to the 1605(b) program.

Transportation Sector-Page 4.33 
The general approach ${ }^{(a)}$ to implementing the CAAA involves three steps. First, employees are surveyed to establish a reference case of commuting behavior. The employer then develops and implements a plan for achieving targeted increases in vehicle occupancy rates or other measures of performance specified in the legislation. Third, the employer resurveys the employees after a year to determine if the targets have been met.

This type of program puts into place several features that can be used to report emissions reductions from these mandates, but the information may be insufficient to report the project. The first survey in the program establishes a reference case, and subsequent surveys allow calculation of project cases. Annual reporting of survey results to an administering agency can provide aggregated results while protecting confidentiality and reducing the reporting burden for individual employers.

Unfortunately the survey instruments that have been used to date often do not need to request information that could be used to calculate fuel consumption or mileage driven of individual employees or employers. Information about distance driven by employees or the make and type of vehicle driven often is unnecessary to achieving the specific program objectives. Adding questions about this information increases the reporting burden, and, if such questions are added after the initial survey, comparison with the reference case becomes difficult. In addition, the largest reductions in commuting driving are expected in the early years of these programs, so using a subsequent year as the reference case may yield few reductions in fuel consumption and emissions. If you anticipate becoming subject to travel reductions under the 1990 Clean Air Act Amendments, you may wish to add questions on vehicle type and distance driven to your initial and follow-up surveys.

Given an estimate of the number of single-occupant vehicle commuting trips eliminated and information about how the affected commuters are now getting to work (for example, carpooling, or public transportation), several data sources can be used to estimate fuel consumption, as follows:

- Many metropolitan planning organizations (MPOs) have survey information that can be used to estimate average commuting distance, sometimes for employers located in different parts of the metropolitan area.

- The National Personal Transportation Survey, administered periodically by the Federal Highway Administration, has been analyzed to estimate national averages for commuting distances.

- In the absence of information about the vehicles used for commuting, the average fuel economy for the nation's automobile fleet can be used to estimate fuel economy; the Truck Inventory and Use Survey, which is conducted by the Bureau of the Census, has been analyzed to estimate fuel economy for the nation's light truck fleet. Information on the fuel economy of the combined fleet is not available in public form.

(a) The approach described here is what has been used prior to the 1990 Clean Air Act Amendments; a similar process will likely be implemented under the Amendments. 
Although these estimates will be rough, they will allow reporting. More accurate information can be acquired only by increasing the survey burden.

Carpooling and vanpooling eliminate some vehicle trips but do so at the expense of some extra travel to collect and disperse the participants at their various residences. Again, information on the magnitude of this offsetting distance may be available from MPOs. Otherwise, unless you have survey data, adjustments to the distance can only be approximate, which will decrease the accuracy of a report.

Public transit trips are more problematic, as the routes and distances traveled are unlikely to be the same for any individual commuter. You may assume a bus trip of the same distance as the car trip eliminated. If the local public transit agency collects and makes them available, local estimates of fuel consumption per passenger mile are probably more accurate than national aggregates of this information, which must be computed from data collected by the Federal Highway Administration and the American Transit Association. These national computations, in Btus per passenger mile, are published in the Transportation Energy Data Book and can be converted to diesel fuel using conversion factors published there. The national estimates again will be rough but, absent local surveys conducted by MPOs or local transit agencies, cannot be improved without substantial cost and burden.

Little information exists on unintended effects of telecommuting. Studies of telecommuting have found that at least in the early years among early adopters of telecommuting, household travel behavior does not adjust to offset reductions in commuting behavior. The phenomenon is too recent for any longterm effects to have been measured, and it remains unknown whether early adopters and later adopters will behave similarly. Telecommuting does lead to a slight increase in building energy use which appears to be quite small in comparison with the energy saved by not commuting. Until more households are equipped with meters that allow households to develop real-time or activity-based indications of their rates of energy consumption, information on this will not be readily collected by the telecommuter. In addition, consumption rates will vary with local climate and cannot be estimated well from national statistics should they become available in the future. Generally, these effects cannot be readily estimated given presently available data, and telecommuting should be regarded as eliminating a commuting trip entirely. However, if you have more specific data on the effects of your project, you should use this information in your report.

Many of these estimates may be made more easily by the agency that administers the program, both because it can perform the estimates once using aggregate data from many employers, and because it may have better access to data from the local MPO. If you wish to report reductions on your own to the voluntary reporting program, you should agree with the administering agency on how to identify or avoid multiple reporting if the agency reports aggregate reductions.

Once estimated, the information above is sufficient to define a project case based on the present number of employees and a reference case based on the same number of employees commuting as they did before the project.

\section{Transportation Sector-Page 4.35}


Employers not subject to trip reduction mandates may also wish to report reductions, especially if they take actions to promote telecommuting or "cash out" employee parking as proposed under the Climate Change Action Plan. You may not need to conduct surveys to collect information if only a few targeted measures are undertaken and if management approval is required for employees to take these measures voluntarily. In these circumstances, you may request information only from those employees who participate, and you might reasonably request information on commuting distance and vehicle type that could be used to estimate fuel consumption more accurately. Some resurveying of the participating employees would be required to determine current levels of participation, as it would be relatively easy for employees to move in and out of telecommuting programs.

\subsubsection{Improvements in Infrastructure and Transportation System Efficiency}

State and local governments engage in a continual process of planning for transportation improvements, land development associated with growth, and impacts on the local economy and environment. This process involves forecasting travel activity and the effect of different changes in infrastructure, operating practices, or policies on either the level of this activity, the performance of the transportation system, or air quality. The general approach and many of the models used are well documented. You may use these tools to assess the impact of travel demand measures, usually on system performance or air quality.

These methods may be the only tools available at present for establishing reference cases and evaluating impacts for some kinds of activities, including land-use planning. However, the focus of these models on transportation congestion and local air quality limits their usefulness for the reporting program; they either must be supplemented with information on travel demand and use, or their information may be used indirectly to calculate emissions reductions.

Infrastructure improvements that might reduce traffic congestion and reduce emissions include improving the synchronization of traffic signals, installing left-turn lanes, widening roads, developing high-occupancy-vehicle lanes, and building dedicated roadways for truck access to ports or terminals. Decisions to make such improvements typically are based on measurements of traffic volumes and speeds that are used in traffic engineering models to assess the effects of improvements on traffic conditions.

The information used to identify and plan needed improvements can be used to define a reference case and project case for reporting to the EPAct Section 1605(b) program, although additional work will be required to estimate emissions and emissions reductions from model results (traffic speed, delay, and volumes) that were used in planning. Users of the database will have greater confidence in emissions reductions estimates based on measurements of traffic volumes and congestion after the improvements have been completed than they will in estimates based entirely on model projections. Your report should account for, and compute, if possible, other project effects resulting from the construction process (emissions resulting from traffic diversion or increased congestion as well as emissions from construction vehicles), increased demand for travel generated by the improved infrastructure, and any other factors. As a result, reporting of infrastructure improvement projects should be done only by

\section{Transportation Sector-Page 4.36}


metropolitan planning organizations and similar agencies that have the ability to estimate impacts on a metropolitan or regional scale and account for all project effects.

\subsection{Estimating the Effects of Accelerating Vehicle Scrappage}

Transportation service suppliers may accelerate the scrappage and replacement of inefficient vehicles in their fleets with more efficient vehicles. Guidance for this type of project is provided in Section 4.7. The guidance in this section applies to a different activity that has received recent attention, in which an entity undertakes to accelerate the scrappage of vehicles in fleets that it does not operate, as a way of improving local air quality or for some other goal. There has been relatively little experience with this type of project; the earliest and most significant project was conducted by Unocal which in 1990 paid owners of pre-1971 vehicles in Southern California to allow it to scrap the vehicles (U.S. Congress 1992).

Similar projects have been suggested as a way to improve the fuel economy of the nation's automobile fleet, possibly with some credit given under the CAFE program to automobile manufacturers who accelerate scrappage of old vehicles. If such a CAFE credit program is established for automobile manufacturers, it is likely to specify methods for calculating fuel savings, and these methods may be used to report fuel and emissions reductions under the 1605(b) reporting program.

Under the Clean Air Act Amendments of 1990, the EPA has published guidance for computing emissions reductions from accelerated scrappage programs. The publication, "Guidance for the Implementation of Accelerated Retirement of Vehicles Programs," is a technical addendum to the EPA's "Interim Guidance on the Generation of Mobile Source Emissions Reduction Credits" (58 FR 11134, February 23, 1993). You may wish to use this guidance in computing vehicle scrappage emissions reductions to be reported under the EPAct 1605(b) program. For information and copies of the technical addendum, contact the EPA Emissions Planning and Strategies Division at 2565 Plymouth Road, Ann Arbor, Michigan 48105.

The remaining discussion of this type of project is intended to be used for an accelerated scrappage project implemented without any credit under the CAFE program. Reporting requires information about the fuel consumption of the vehicle being scrapped and about what replaces it. The Unocal program subjected a sample of vehicles to the Federal Test Procedure to determine emissions of criteria pollutants, and this procedure could be used to estimate fuel economy for a sample of vehicles. Similarly, the Unocal program also surveyed drivers of the scrapped vehicles to determine their estimates of how far the vehicles had been driven.

More accurate mileage information might be collected if the state department of motor vehicles recorded odometer readings at the time of annual relicensing or taxation. Given average values derived from these data, you could calculate the fuel consumption of the vehicles scrapped. Testing a sample of vehicles and surveying the drivers would become less necessary over time if information collected

Transportation Sector-Page 4.37 
about these variables were to be made available to others, for example, as part of the educational use of the $1605(b)$ reporting program.

In the absence of testing a sample of vehicles and surveying the owners, or drawing on data collected by similar vehicle scrappage programs, fuel consumption estimates must be based on assumptions and available published information, in ways similar to projects involving the sale of new fuel efficient vehicles. The fuel economy testing program did not begin until the 1973 model year, and the CAFE program did not begin until 1978. Cars older than 1973 should probably be assumed to have the fuel economy found by Unocal, 12.1 MPG; fuel economy for those of 1973-1977 vintage can be obtained from early EPA fuel economy reports: Alternatively, fuel economy for these vehicles can be assumed to be the earliest reported combined domestic CAFE estimates (19.9 MPG for automobiles in 1978, 18.2 MPG for light trucks in 1978). Fuel economy for more recent vehicles can be taken from EPA fuel economy reports or actual CAFE values for the appropriate model year. Vehicle mileage can be estimated from the EIA's Residential Transportation Energy Consumption Survey for automobiles or the Truck Inventory and Use Survey.

Vehicles that are scrapped provided transportation service prior to scrappage, and this service usually must be continued. If the replacement has occurred prior to scrappage, surveying the vehicle owners can determine the age and type of the replacement vehicle; this can be cross-referenced with model/ year-specific or year-specific fuel economy ratings. Such a survey would be less reliable if the replacement vehicle has yet to be purchased. In this case, or in the absence of any survey at all, you should assume an average vehicle from the nation's vehicle fleet replaces the one scrapped, and use the fleet average fuel economy rating for the year in which the scrappage occurs.

The project case for vehicle scrappage is estimated as the amount of fuel estimated to be consumed by the replacement vehicles, driven the distance the scrapped vehicles would have been driven. The reference case is estimated using the fuel consumption estimated for the vehicles that have been scrapped, driven the same distance.

If the scrappage program truly accelerates the scrappage of old vehicles, then the vehicle would have been used for another few years, and second-and-subsequent-year projects might be defined, based on what the lifetime of the vehicle would have been had it not been scrapped. Very little information is publicly available on the survival rates and expected use of very old vehicles. You may use vehicle survival rates for the fleet in the Transportation Energy Data Book; these can be used to estimate the proportion of scrapped vehicles that would have been used in the project. Mileage estimates for very old vehicles probably are best based on the mileage obtained by surveying the owners of scrapped vehicles. Some states may record vehicle odometer mileage as part of vehicle registration or taxation, and average values based on this information might be used to estimate mileage for very old vehicles.

In addition to the EPA guidance noted earlier, you may wish to consult the Office of Technology Assessment report, Retiring Old Cars: Programs to Save Gasoline and Reduce Emissions, Report OTA-E-536, on which the discussion above draws heavily. The report contains sample calculations of fuel savings from accelerated scrappage projects. 


\subsection{References}

Argonne National Laboratory (ANL). 1991. Emissions of Greenhouse Gases from the Use of Transportation Fuels and Electricity, Volume 1, ANL/ESD/TM-22, Argonne, IL.

Argonne National Laboratory (ANL). 1993. Emissions of Greenhouse Gases from the Use of Transportation Fuels and Electricity, Volume 2, ANL/ESD/TM-22, Argonne, IL.

Davis, S.C. and S.G. Strang. 1993. Transportation Energy Data Book: Edition 13. ORNL-5198, Oak Ridge National Laboratory, Oak Ridge, TN.

Energy Information Administration (EIA). 1988. Residential Transportation Energy Consumption Survey, public use tapes, Office of Energy Markets and End Use, Energy End Use Division, Washington, DC.

Erkut, E. and D. MacLean. 1992. "Alberta's Energy Efficiency Branch Conducts Energy Audits, Interfaces, 22(3), pp. 15-21.

Graham, D.S. 1993. "A GIS for Bus Routing Saves Money, Worry in North Carolina," Geo Info Systems, 3(5), pp. 39-43.

Greene, D.L. 1986. Driver Energy Conservation Awareness Training: Review and Recommendations for a National Program. ORNL/TM-9897, Oak Ridge National Laboratory, Oak Ridge, TN.

Holcomb, M.C., S.D. Floyd, and S.L. Cagle. 1987. Transportation Energy Data Book: Edition 9. ORNL-6325, Oak Ridge National Laboratory, Oak Ridge, TN.

Transport Topics. 1988. "Unnecessary Idling Shortens Engine Life, Wastes Fuel," Transport Topics, March 21, p. 9.

United States Congress. 1992. Retiring Old Cars: Programs to Save Gasoline and Reduce Emissions, OTA-E-536, Office of Technology Assessment, Washington, DC.

United States Department of Commerce (DOC). 1990. Truck Inventory and Use Survey, 1987 Census of Transportation public use tapes, Bureau of the Census, Washington, DC.

Transportation Sector-Page 4.39 


\section{Forestry Sector}

Part 5 of 6 Supporting Documents

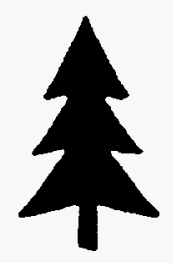

Sector-Specific Issues and Reporting Methodologies

Supporting the General Guidelines for the Voluntary

Reporting of Greenhouse Gases under Section 1605(b)

of the Energy Policy Act of 1992 



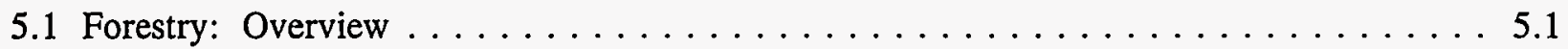

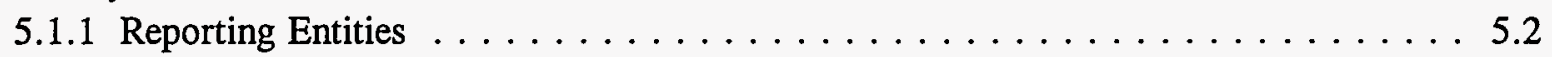

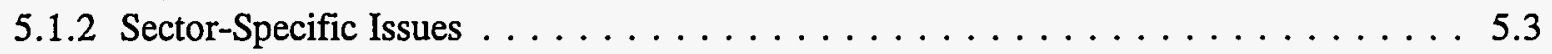

5.1 .3 Organization of This Supporting Document . . . . . . . . . . . 5.4

5.2 Estimating Annual Carbon Flows $\ldots \ldots \ldots \ldots \ldots \ldots \ldots \ldots \ldots \ldots \ldots \ldots \ldots \ldots \ldots \ldots$

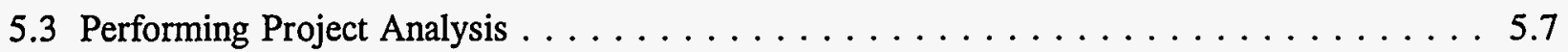

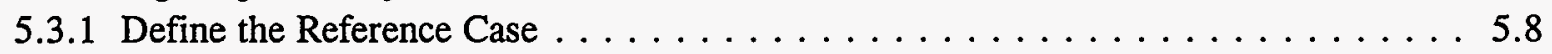

5.3.2 Identify Effects of the Project . . . . . . . . . . . . . . . 5.9

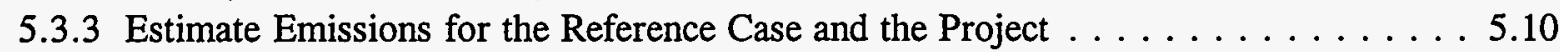

5.3 .4 Reporting Procedures . . . . . . . . . . . . . . . 5.13

5.4 Estimating Carbon Flow Effects for Forestry Activities . . . . . . . . . . . . . . 5.19

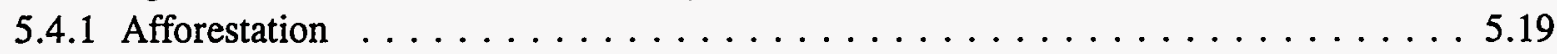

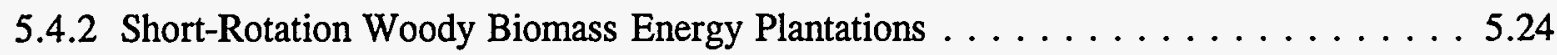

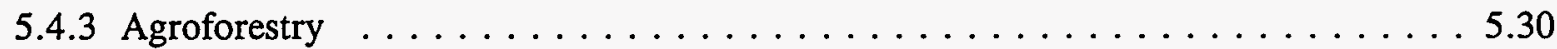

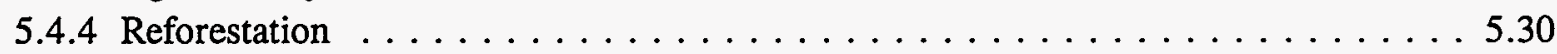

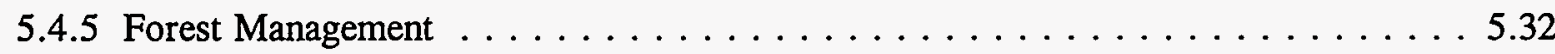

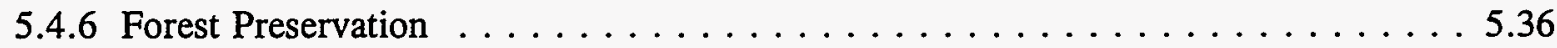

5.4 .7 Wood Products . . . . . . . . . . . . . . . . . . . . 5.37

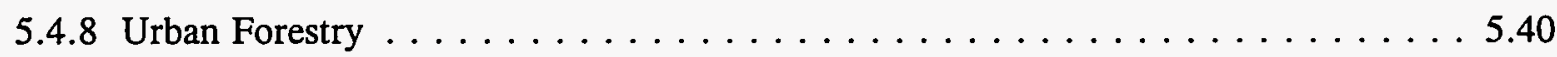

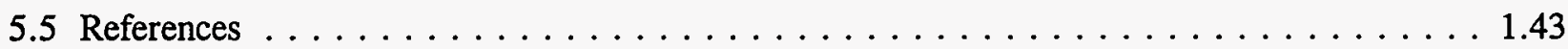

Appendix 5.A - Tables for Standard Projects $\ldots \ldots \ldots \ldots \ldots \ldots \ldots \ldots \ldots \ldots \ldots \ldots \ldots \ldots \ldots \ldots$ A.1 


\section{Examples}

5.1 Reporting Entity-Wide Carbon Flows $\ldots \ldots \ldots \ldots \ldots \ldots \ldots \ldots \ldots .7$

5.2 Project Analysis and Reporting $\ldots \ldots \ldots \ldots \ldots \ldots \ldots \ldots \ldots \ldots \ldots \ldots .12$

5.3 Afforestation: Analyzing a Project on an Inventory Basis $\ldots \ldots \ldots \ldots \ldots \ldots . .22$

5.4 Afforestation: Analyzing a Project on a Flow Basis $\ldots \ldots \ldots \ldots \ldots \ldots \ldots .23$

5.5 Afforestation: Analyzing a Standard Project $\ldots \ldots \ldots \ldots \ldots \ldots \ldots \ldots \ldots .24$

5.6 Short Rotation Woody Biomass Crops $\ldots \ldots \ldots \ldots \ldots \ldots \ldots \ldots \ldots \ldots . .27$

5.7 Reforestation: Analyzing a Standard Project $\ldots \ldots \ldots \ldots \ldots \ldots \ldots \ldots \ldots .3 .31$

5.8 Reforestation: Reclamation of Mined Lands $\ldots \ldots \ldots \ldots \ldots \ldots \ldots \ldots \ldots .5 .32$

5.9 Modified Forest Management $\ldots \ldots \ldots \ldots \ldots \ldots \ldots \ldots \ldots \ldots \ldots \ldots .34 \ldots \ldots \ldots \ldots$

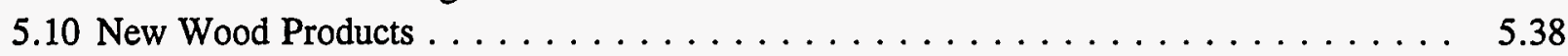

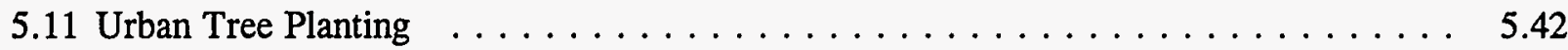

Figures

5.1 Geographic Regions Used to Estimate Carbon Storage $\ldots \ldots \ldots \ldots \ldots \ldots \ldots$

Tables

5.1 Carbon Flows for BFDI's Biomass Energy Project $\ldots \ldots \ldots \ldots \ldots \ldots \ldots .29$ 


\subsection{Forestry Sector}

This document supports and supplements the General Guidelines for reporting greenhouse gas information under Section 1605(b) of the Energy Policy Act (EPAct) of 1992. The General Guidelines provide the rationale for the voluntary reporting program and overall concepts and methods to be used in reporting. Before proceeding to the more specific discussion contained in this supporting document, you should read the General Guidelines. Then read this document, which relates the general guidance to the issues, methods, and data specific to the forestry sector. Other supporting documents address the electricity supply sector, the residential and commercial buildings sector, the industrial sector, the transportation sector, and the agricultural sector.

The General Guidelines and supporting documents describe the rationale and processes for estimating emissions and analyzing emissions-reducing and carbon sequestration projects. When you understand the approaches taken by the voluntary reporting program, you will have the background needed to complete the reporting forms.

The General Guidelines and supporting documents address four major greenhouse gases: carbon dioxide, methane, nitrous oxide, and halogenated substances. Although other radiatively enhancing gases are not generally discussed, you will be able to report nitrogen oxides $\left(\mathrm{NO}_{x}\right)$, nonmethane volatile organic compounds (NMVOCs), and carbon monoxide (CO) after the second reporting cycle (that is, after 1996).

The Department of Energy (DOE) has designed this voluntary reporting program to be flexible and easy to use. For example, you are encouraged to use the same fuel consumption or energy savings data that you may already have compiled for existing programs or for your own internal tracking. In addition, you may use the default emissions factors and stipulated factors that this document provides for some types of projects to convert your existing data directly into estimated emissions reductions. The intent of the default emissions and stipulated factors is to simplify the reporting process, not to discourage you from developing your own emissions estimates.

Whether you report for your whole organization, only for one project, or at some level in between, you will find guidance and overall approaches that will help you in analyzing your projects and developing your reports. If you need reporting forms, contact the Energy Information Administration (EIA) of DOE, 1000 Independence Avenue, SW, Washington, DC 20585.

\subsection{Forestry: Overview}

The forestry sector affects a broad range of potential greenhouse gas emissions sources, emissions reductions activities and carbon sequestration activities. Examples include, but are not limited to, the following:

Forestry Sector-Page 5.1 
- Afforestation of agricultural land can lead to large increases in carbon capture and storage by the treated area.

- Reforestation of harvested forestland can accelerate the natural regeneration process and encourage establishment of fast-growing species.

- Agroforestry can decrease requirements for fossil energy and energy-intensive chemicals in the production of food and fuel.

- Short-rotation woody biomass energy plantations can provide fuel that displaces fossil fuels in the electricity production process.

- Low-impact harvesting methods can decrease the emissions from soil disturbance and biomass decay that often follow timber harvest.

The emissions reductions and carbon sequestration projects in the forestry sector range from those that are relatively easy to evaluate (such as construction of wooden bridges) to those with more difficult-toestimate effects (such as agroforestry projects). Some of the most cost-effective forestry projects may also be the most difficult to evaluate.

\subsubsection{Reporting Entities}

You can report forestry activities to the EPAct 1605(b) database if you own, control, financially support, or participate in operations that affect forestry-related greenhouse gas emissions, emissions reductions, or carbon sequestration. Reportable activities could include tree planting, forest preservation, biomass energy plantation establishment, use of natural or plantation forests to displace fossil fuels, agroforestry, marketing of new wood products, and introduction of improved forest management practices.

You may choose to report your organization's net emissions on an entity-wide basis and derive your emissions reductions/carbon sequestration accomplishments directly from that report. You may choose to report your net emissions separately from your project accomplishments, or you may opt to not report entity-wide emissions at all, concentrating instead on the accomplishments of your individual projects.

If your company has multiple subsidiaries, you might choose to aggregate some or all of your projects in a single report or to have the subsidiaries report separately. The decision to report on an entity-wide basis or separately should be based on the types of emissions reduction activities, keeping in mind that your report should identify all significant effects of a project. (See the General Guidelines, "What Are the Minimum Reporting Requirements?") 


\subsubsection{Sector-Specific Issues}

The supporting documents for the electricity supply, residential and commercial buildings, and the industrial and transportation sectors, address only emissions and emissions reductions activities. The forestry sector must also deal with emissions and emissions reductions. However, unlike activities in other sectors, forestry (and agricultural) sector activities can also remove carbon from the atmosphere and store it, a process known as carbon sequestration.

Carbon sequestration is a two-step process: carbon dioxide is first withdrawn from the atmosphere through the photosynthetic process, and then carbon is stored in organic materials over a period of time. The sequestration process ends when the carbon is released back to the atmosphere principally as carbon dioxide, through either combustion or decay processes. In this sense, carbon sequestration is completely defined by net flows of carbon between forests and the atmosphere. Carbon sequestration in forests is increasing when the amount of carbon withdrawal from the atmosphere exceeds the release of carbon to the atmosphere.

Carbon can also be removed from the forest as trees are harvested. However, some of the carbon might not be returned directly to the atmosphere. If the trees are used to make wood products, a portion of the carbon sequestered over the growth period will remain in solid form up to several decades. If the harvested trees are used to produce energy, carbon will be released through combustion. This could offset carbon that would have been released through the burning of fossil fuels. Both cases demonstrate the variety of effects that forestry activities may have on carbon flows.

This supporting document focuses on measuring these net flows of carbon as accurately as is practical. Accuracy clearly depends on accounting for all positive flows (emissions) of carbon from forests and negative flows (capture) of carbon to forests. By focusing on flows of carbon (rather than simple inventories of carbon stocks), this forestry guidance is consistent and directly comparable with estimates of emissions described in supporting documents for other sectors.

Reporting the effects of forestry activities may prove especially challenging. Nearly every action undertaken in the management of forests causes changes in stocks of biomass-and therefore in flows of carbon. Tree planting establishes a new carbon sink; thinning forests shifts biomass to fewer, faster growing trees; harvesting removes stored carbon from the forest (but does not necessarily release all stored carbon back into the atmosphere). Even the elimination of an activity, such as stopping the clearing of forests to develop agricultural land, can influence carbon flows by allowing forest growth and other natural processes to proceed uninterrupted.

Two important issues relate to measuring the effects of forestry activities on carbon flows. The first is that forestry activities typically trigger a sequence of effects that change through time. For example, a newly established forest will take up carbon in trees at a low rate initially, then pass into a period of relatively rapid carbon capture. The uptake of carbon will then typically decline as growth is balanced against mortality in the older forest. From this point in time, tree biomass may cease to capture

Forestry Sector-Page $\mathbf{5 . 3}$ 
carbon, but evidence suggests that carbon may continue to flow into soils until the forest is removed by harvest or a natural disturbance event. Measures of carbon flows must account for these dynamic effects.

A second and related issue for measuring carbon flows in forests is the need to define the net rather than the gross effects of the activity. Forestry activities may be very effective at increasing the accumulation of biomass in commercially valuable forms-that is, in the trunks of commercial tree species. This type of accumulation is typically the focus of forest measurements. This "increased" growth may simply result from reducing competition from other types of trees, effecting a transfer of carbon uptake from one group of trees to another. In this case, the net carbon flow effects of the activity may in fact be zero when all relevant parts of the forest are measured. Defining net effects also requires an accounting for the release of carbon to the atmosphere through forest harvesting.

\subsubsection{Organization of This Supporting Document}

Section 5.2 provides guidance on reporting historical patterns of carbon flow related to forests and forestry activities. Section 5.3 builds on the discussion of project analysis in the General Guidelines and explains the two basic categories of projects: standard projects and reporter-designed projects. That section then explains the reporting procedure for either pathway. Section 5.4 provides guidance for reporting various categories of forestry activities. While the categories are neither exhaustive nor mutually exclusive, they do provide insight into the kinds of issues that must be addressed in evaluating various types of projects. Section 5.5 provides references cited in the discussion of activities in Sections 5.3 and 5.4. Appendix 5.A provides stipulated factors for certain types of projects involving tree planting in the United States. While this document focuses almost exclusively on carbon flows, you should be aware that forestry activities can also lead to emissions, and reductions of emissions, of methane and nitrous oxide.

\subsection{Estimating Annual Carbon Flows}

The General Guidelines ("What is Involved in Reporting Emissions?") explain that reporting information on greenhouse gas emissions for the baseline period of 1987 through 1990 and for subsequent calendar years on an annual basis is considered an important element of this program. If you are able to report carbon flows for your entire organization, you should consider providing a comprehensive accounting so that your audience can gain a clear understanding of your overall activities.

While this is not a prerequisite to reporting the effects of your forestry projects, a comprehensive report of net annual greenhouse gas emissions or carbon flows may increase the usefulness of your carbon flow reduction report. Because of the complexity of project analysis and the potential for unanticipated effects, users of the database may have more confidence in reports that include comprehensive accounts of the reporter's greenhouse gas emissions and carbon flows.

Forestry Sector-Page 5.4 
As with the discussion of forestry projects, this discussion of greenhouse gas flows will be limited to a discussion of carbon. All final measures of carbon flow should be expressed in the form of carbon dioxide equivalent.

Your annual flow of carbon expresses the net release of carbon to the atmosphere from the forests you control and the fossil fuels that you use. Your reports of carbon flows should include negative flows from the capture of carbon from the atmosphere and positive flows from the combustion and decay of organic matter and the use of fossil fuels. Consequently, if your forest areas and operations are capturing more carbon then they are releasing, you would report a negative flow.

Typically, carbon flows from forests and forest operations are estimated using changes in carbon inventory or stocks. The annual flow in carbon is the difference in carbon stocks in consecutive years. The general formula for calculating annual carbon flows is

$$
\text { Annual carbon flow in year } t=\left(I_{t-1}-I_{\nu}+E_{t}\right.
$$

where $I_{t}=$ carbon inventory (for example, tons) in the forest area in year $t$

$$
\begin{aligned}
& \mathrm{I}_{\mathrm{t}-1}=\begin{array}{l}
\text { carbon inventory (for example, tons) in the forest area in the year immediately } \\
\text { preceding } \mathrm{t}
\end{array} \\
& \mathrm{E}_{\mathrm{t}}=\text { carbon emissions from forestry-related fossil fuel use in year } \mathrm{t} \text {. }
\end{aligned}
$$

Few reporters will be able to measure or develop meaningful estimates of their carbon inventories every year, so it is acceptable to report average annual carbon flows. Suppose you want to report your average carbon flows for several years, say from year $s$ to year $t$. The average flow can be derived as follows:

$$
\text { Average annual carbon flow for years } s \text { to } t=\left[\left(I_{s}-I_{t}\right)+\sum_{n=(s+1)}^{t} E_{n}\right] /(t-s)
$$

where $I_{s}=$ carbon inventory in the forest area in year $s$

$I_{t}=$ carbon inventory in the forest area in year $t$

$E_{n}=$ carbon emissions from fossil fuel use for the year $n$.

Note that in both cases a negative flow implies the carbon captured by the forest is greater than the sum of the fossil fuel carbon emitted and the carbon released from the forest (that is, a negative flow indicates that carbon has been sequestered).

This approach measures the net carbon flow from the forest area. However, some carbon removed from the forest area may not flow to the atmosphere immediately. For example, carbon stored in wood

\section{Forestry Sector-Page 5.5}


products may not be released to the atmosphere for years or even decades. If you wish to account for these effects, you may want to modify this accounting process to reflect delayed releases of carbon.

There is an alternative to this inventory approach for estimating annual flows of carbon. Rather than using changes in carbon inventory to approximate carbon flows, you may directly estimate carbon flow using models of the impacts of certain forestry practices on carbon flows into and out of forest carbon sinks. These models start from an estimate of a carbon stock for a specific site, and data about the forest type and its physical characteristics. Then, based on information about forest practices, the models develop estimates of annual carbon flows.

Some models are already available for simple conditions and standard treatments, such as tree planting on agricultural land. More complex models are being developed and appear to be progressing rapidly. As they become available for different regions of the country and for a broader array of forest types and forest practices, they may be useful tools for analyzing both entity-wide carbon flows, as described in this section, and project-level accomplishments as described in Sections 5.3 and 5.4.

Example 5.1 illustrates one method for estimating and reporting carbon flows at the entity level. In this example, the reporter used models to estimate flows for five years, then corrected those reports with measured data. 


\section{Example 5.1 - Reporting Entity-Wide Carbon Flows}

\section{Note: This example illustrates only one approach to analyzing a project; your analysis, methods, and calculations will vary depending on your particular circumstances, the geographic location of the project, and other factors.}

Pacific House, Inc. (PHI) conducted inventories of its timber stands every five years. Because PHI had been expanding its holdings of timberland, primarily by planting on understocked forestland and converting marginal agricultural land, PHI's average stand age was only 10 years. This meant that the carbon inventory was expanding.

Based on extrapolations and models that used data from 1991 and 1996 inventories and knowledge about their fuel use patterns in forestry operations, PHI reported to the EPAct 1605(b) program estimated average annual carbon dioxide flows in the years 1996 to 2000 of $-348,000$ tons per year; that is, forests and forest operations were estimated to capture more carbon than they released.

In the year 2001 PHI undertook its regular 5-year inventory. Based on the field samples and fuiel use records PHI staff found the following:

carbon inventory (2001): 15.0 million tons carbon inventory (1996): 14.3 million tons carbon from fuel use and forestry operations (1996-2000): 130,000 tons.

From this information they calculated:

$$
\begin{aligned}
\text { annual average carbon flow } & =\left[\left(14.3 \times 10^{6}-15.0 \times 10^{6}\right)+130,000\right] / 5 \\
& =-114,000 \text { tons carbon. }
\end{aligned}
$$

Multiplying this by the factor for converting from carbon to carbon dioxide as described in Appendix D (3.67 tons of carbon dioxide per ton of carbon), PHI calculated a $-418,000$ ton flow of carbon dioxide per year.

PHI analysts attributed the higher-than-predicted carbon capture to the success of their innovations in forest practices that emphasized increases in carbon stock. On the basis of the measurements and calculations, they amended their reports of modeled estimates of accomplishments for the years 1996 to 2000 to reflect the actual measurements.

\subsection{Performing Project Analysis}

The analysis of carbon flow reductions in the forestry sector follows the process described in the General Guidelines, "How Should I Analyze Projects I Wish to Report?"

- Establish the reference case to use as a basis for comparison with the project.

- Identify the project effects.

- Estimate carbon flows for the reference case and the project. 
These three steps are illustrated in Example 5.2 at the end of Section 5.3.3.

As described in the General Guidelines, this voluntary program is designed to both record project accomplishments and communicate innovative approaches to reducing greenhouse gas emissions and increasing carbon sequestration. Reflecting these dual objectives, the voluntary reporting program allows two different pathways for reporting activities and their effects. Standard projects focus on activities having effects that can be estimated with data provided by this supporting document. Reporter-designed projects allow for reporting innovative activities with estimates you develop and reporting standard projects using other sources of data.

In the forestry sector, standard projects involve activities for which DOE has assembled data that can be used to estimate carbon flow effects. At this time, the only forestry activities classified as standard are tree planting projects. These standard projects are discussed later in this section and again in Section 5.4 .

Any project that does not fit the requirements of a standard project is a reporter-designed project, for which you need to develop estimates of effects. However, you are required to report several physical parameters for each activity so that estimates of effects can be accurately compared across entities. Reporting this information may also allow database users to reevaluate estimated effects in the future, as better data become available.

You may also report standard projects as reporter-designed projects. This could be the case, for example, if you wish to report the effects of your activity using a method different from the standard approach. This may encourage innovation in estimating the effects of standard projects. If you choose to report a standard project in this way, you should provide estimates of its effects using both standard and reporter-designed pathways. This will allow users of the database to evaluate differences between the two approaches.

\subsubsection{Define the Reference Case}

For both categories of projects the basic structure of reporting is the same. Defining the effects of the forestry activity starts with defining a reference case. This reference case describes the physical parameters of the activity and the carbon flows without the activity. Once the reference case is established, it serves as the basis for evaluating the effects of the reported activity (the project). In simple terms, the carbon flow reduction is defined by the carbon flows for the reference case minus the carbon flows for the project case.

Development of the reference case can be relatively simple in some cases. Where you do not expect the flows of carbon from the land area involved in the project to change from historic levels in the absence of the project, then you can evaluate the project accomplishments by comparing carbon flows in the reporting year to the historic level of carbon flows from the same area for some specified year or years. As defined in the General Guidelines, this is called the basic reference case.

\section{Forestry Sector-Page $\mathbf{5 . 8}$}


In other instances you might expect that, even in the absence of the project, the carbon flows from the project area will change because of the natural processes (for example, tree growth) or external influences (for example, harvest or other forms of clearing). When the reference case is based on an assumption that carbon flows, in the absence of the project, would have been different than in the past, it is called a modified reference case. You should be particularly careful in constructing modified reference cases. Clearly state both the methods and assumptions that you used to arrive at the reference case. The credibility of your project analysis depends a great deal on your definition of a convincing reference case to which the carbon flows for your project are compared.

\subsubsection{Identify Effects of the Project}

Your report should address as many of the effects of your project as you can identify. The General Guidelines ("What Effects Did the Project Have?") describe many types of potential effects of emissions reductions projects. You should quantify as many of the effects as possible, using best professional judgement as to which are important. You should identify all potential effects, even if you are not able to quantify them.

Projects in the forestry sector run the gamut from discrete, well-defined projects to projects that can have both reinforcing and antagonistic effects within and outside of a reporting entity. When projects begin to interact such that the effects of each project cannot clearly be separated, you should consider reporting your total net carbon flows rather than the reductions in flows associated with individual projects. For example, you may wish to compute the carbon flows associated with your total forestry operations before and after the projects. After accounting for effects outside your organization (for example, associated with outsourcing or market effects), you can report the reduction in total carbon flows. If you choose to report in this way, you must identify the specific projects or, at a minimum, categories of projects that you undertook to reduce carbon flows, even if you are not able to determine the fraction of your total reductions associated with each project.

Forestry activities can have a wide range of effects. For example, forest management may reduce the likelihood of natural forest fires. In addition, and perhaps of more relevance here, foresters use fire as a management tool to control competing vegetation and to prepare a site for regeneration. These activities lead to important effects on greenhouse gas emissions (including effects on nitrous oxide and methane emissions), beyond the obvious effect of increasing carbon capture in a growing forest. Other effects arise from fertilizer use, which can increase nitrous oxide emissions, and fossil fuel use in harvesting and transporting timber.

Forestry activities may also have impacts on greenhouse gas emissions from sectors other than the forestry sector. This is particularly true for urban forestry, where the principal objective is to improve the living environment of cities, especially by decreasing the extent and severity of urban heat islands. Urban forestry potentially reduces the consumption of electricity used to cool buildings, thereby reducing the emissions of greenhouse gases. The emissions reductions resulting from the additional shade created by urban tree planting is an example where the indirect effects on emissions probably outweigh the direct carbon capture effects.

Forestry Sector-Page 5.9 
Other indirect effects occur through market forces. For example, preservation of a mature forest in the United States could lead to increased harvest of timber elsewhere in the United States or overseas in order to meet market demand. Alternatively, reduction of harvesting could increase the recycling rates for paper and wood products and increase the efficiency of manufacturing and use of wood products. Similarly, the afforestation of one area could displace afforestation or deforestation in another, as competition among timber suppliers affects tree planting decisions.

The guidance for analyzing specific activities in Sections 5.4 provides some description of likely effects of each type of project. However, actual effects will be site-specific. You should carefully attempt to identify all effects and, where possible, quantify those effects.

\subsubsection{Estimate Emissions for the Reference Case and the Project}

Your report must include estimation of carbon flow effects associated with your project. For standard projects, effects can be estimated using tables of stipulated factors provided by this and other supporting documents. For all other projects you must provide your own estimation process, taking several factors into account.

\section{Carbon elements}

Carbon is stored in the trunks of trees, but it is also stored in other components of the forest. You may (if you have data) consider the effects of reported activities on the following four components (Birdsey 1992, page 23):

1. Trees = All above- and below-ground portions of all live and dead trees, including the merchantable stem; limbs, tops, and cull sections; stump; foliage; bark and root bark; and coarse tree roots (greater than $2 \mathrm{~mm}$ in diameter)

2. Soil = All organic carbon in mineral horizons to a depth of $1 \mathrm{~m}$, excluding coarse tree roots

3. Forest Floor = All dead organic matter above the mineral soil horizons, including litter, humus, and other woody debris

4. Understory vegetation $=$ All live vegetation except that defined as live trees.

\section{Emissions effects}

Carbon sequestration in forests is only one component of the total greenhouse gas regime associated with forestry. Forestry activities may also have indirect and direct effects on the emission of greenhouse gases. For example, the use of fire in site preparation results in greenhouse gas emissions. In addition, changés in the use of fossil fuels in forest management activities have implications for 
emissions. Where possible, your report should include these types of effects in carbon budgets at the time they occur for both the reference case and the project case to accurately account for total net change in carbon flows.

\section{Time frame}

Forest growth is variable through time, so that the time frame used to report effects will have an important bearing on the evaluation of activities. You must report estimates of activity effects for the year the project begins. In addition, you may report anticipated effects for any future years throughout the life of the activity. If you choose to forecast carbon flow estimates for the life of the activity, you must document how the duration of the project was defined. Although you do not need to redocument each activity every year, the program does require that you certify annually that the project appears to be performing as expected, or that you provide a revised estimate. If your revised estimates, or results from actual measurements, in later years are different from your reported anticipated effects, you should revise your past and current reports and update your estimate of future carbon flows to reflect the new information.

If you choose to stop reporting, but wish to preserve information in the EPAct Section 1605(b) database regarding the final disposition of your forestry project, you will have the option of submitting a closing report that indicates your reason for cessation of annual reporting and the expected fate of the sequestered carbon. This may help users of the database to better assess the contributions of your project.

\section{Field measurements}

While the effects of activities can often be estimated using standard tables and computer models, field measurements may also be applied and are generally preferred. When appropriately designed and executed, site-specific field studies will provide higher quality data and thus higher credibility with users of the database. If you use field measurements, your report should briefly describe the sampling scheme under the reporter-designed project pathway. Also, if you use field measurements for standard projects, estimate your accomplishments for the standard project pathway using tables and report the results of the field measurements using the reporter-designed pathway.

The following example illustrates the overall process of forestry project analysis and reporting under the EPAct 1605(b) program. The example discusses establishing a reference case, determining project effects, estimating carbon flows, and reporting over time.

Forestry Sector-Page 5.11 
Example 5.2 - Project Analysis and Reporting

Note: This example illustrates only one approach to analyzing a project; your analysis, methods, and calculations will vary depending on your particular circumstances, the geographic location of the project, and other factors.

This example illustrates how one company worked through several of the decisions related to project analysis and reporting. It builds on Case Study 4 from the General Guidelines.

\section{Project Description and Emissions Reporting}

Black Forest Cake, Inc. (BFCD) was a family-owned business that was experiencing extremely rapid growth in demand for its products, which included bakery products produced at 13 sites in five states, catering services at 10 shops in seven states, and equipment rentals in 15 stores in three states. It operated from a total of 23 sites spread across nine states.

The family members and many of their staff were environmentally conscious. While they were delighted with the increased demand for their products, they were concerned to see their energy consumption rising, particularly their natural gas consumption for baking ovens and space heating, and their gasoline use in delivery vehicles. They knew that increased energy use signaled increased greenhouse gas emissions.

At its annual business meeting, the board of directors decided to voluntarily offset some of the increase in emissions by undertaking a tree-planting (carbon sequestration) project on farmland they owned. They were not interested in receiving official recognition for their effort. They were motivated purely by their interest in environmental protection and a desire to project an image of BFCI as a "good global citizen." They did, however, want to be sure that their project actually reduced net carbon dioxide emissions, not just have appeared to do so. Therefore, BFCI decided that its project should at least meet the minimum reporting standards used by DOE in the EPAct 1605(b) voluntary reporting program.

The first decision BFCI had to make was whether to report its entire operation's emissions of greenhouse gases. The company chose not to report emissions for two reasons. First, since BFCI had operations at 23 sites and record-handling was decentralized, and, since the company emitted at least three gases covered by the program (carbon dioxide, methane, and chlorofluorocarbons), the burden of reporting emissions was considered too great for a small company. Second, since the directors were not undertaking the project out of concern for meeting agreements with the government or in anticipation of possible future legislative action, they were not concerned with the size of the carbon sequestration project relative to their total emissions.

\section{Reference Case}

The BFCI project involved conversion of agricultural land to forestland. This land had been used for a combination of crops and grazing for more than three decades and, in the absence of this project, is unlikely to have been used for any other new purpose. Therefore, BFCI used a basic reference case, using the year 1990 as its designated year.

\section{Project Effects}

BFCI quickly identified that the major effect its tree-planting project would have was to sequester, over a long period of time, carbon that would not have been captured in the absence of this project. However, BFCI wanted to be sure that its analysis was going to capture all important effects. Review by an extension forester suggested that the project might have at least two effects in addition to the obvious carbon sequestration. First, the forester said that if this agricultural land were taken out of production, other farm operations could be expanded to supply the BFCI farm's former customers. If they did this by clearing forest areas, that action would offset some of BFCI's accomplishments. Second, even though BFCI did not plan to harvest this area, other landowners who had been considering establishing new woodlots might decide not to do so because of the perceived competition from BFCl's newly established forest stand.

BFCI then went to an agricultural economist at the local college to ask him to evaluate these possibilities. After careful consideration, he reported to BFCI that, given the nature of local agricultural practices, other farms would likely meet the needs of the BFCI farm's former customers through increased productivity rates and not through expanded land area. While this might lead to some increase in emissions, for example, through increased fertilizer use, the effect would be small, and measurement of it would be speculative at best. Further, the agricultural economist observed that local decisions to convert land to forests or to replant after harvest were largely driven by factors other than financial returns to investment. Therefore, BFCI's relatively small entry would not likely discourage other tree-planting activities. 
Example 5.2 - (cont'd)

Based on this evaluation, BFCI felt that it could credibly limit its quantitative analysis to the project's intended effects. BFCI developed a worksheet that summarized the effects of its project.

\begin{tabular}{lcl}
\multicolumn{1}{c}{ Project Effects } & $\begin{array}{c}\text { Contribution } \\
\text { to Reduction }\end{array}$ & Significance \\
\hline Carbon sequestered on BFCI farm & + & Large \\
$\begin{array}{l}\text { Some forest area may be converted to agricultural } \\
\text { land to meet demand for farm produce }\end{array}$ & - & Negligible \\
People would have planted trees but did not & - & Negligible
\end{tabular}

Estimation Methods

The state forester who was advising BFCI on the project pointed out that its project coincided with one of the tree-planting projects for which this supporting document provides stipulated factors. Since using the default estimates of carbon sequestration involved so little expense and effort, when compared to carrying out field measurements, BFCI decided to take advantage of the default data and report its project as a standard project.

\section{Long-Term Project Reporting}

In its first report following the establishment of the tree stand, $\mathrm{BFCI}$ reported that it had planted the trees and reported information consistent with the guidance provided in the forestry sector supporting document. It also reported that it expected the forest to capture carbon at a rate consistent with the stipulated factors provided in Appendix 5.A of this supporting document. Each year thereafter BFCI confirmed in its report to EIA that the project appeared to continue to perform as expected.

After eight years of relying on the default stipulated factors, BFCI became engaged in a dialogue with a local environmental group. One consequence of the discussions was that $\mathrm{BFCI}$ agreed to measure the standing carbon on its project site to determine whether the project had met the expectations established by the stipulated factors. The field measurements, including random sampling of both soils and biomass, revealed that the project had actually exceeded expectations by 20 percent. This was attributed to the fact that the original soils were particularly rich in phosphorous and nitrogen.

BFCI amended its previous reports to reflect this new information by increasing the reported carbon dioxide flows to the forestland by 20 percent in each of the first ten years. BFCI also amended the projected annual carbon capture rates for the second decade to reflect the higher-than-expected performance. BFCI thus transformed its project from a standard project to a reporter-defined project.

\subsubsection{Reporting Procedures}

Regardless of the reporting pathway (standard or reporter-designed) you use, you must provide certain information to identify the reporting entity and to describe the activity. This information is listed and discussed in this section. A discussion of procedures for reporting the effects of activities using the two pathways then follows.

\section{Activity location and physical parameters}

You must provide the following information regarding the type, location, and extent of the activity:

1. County/State. If the activity extends across state or county boundaries, you must indicate the portion of the activity in place in each of these areas.

2. Zip code for each area in which an activity takes place.

\section{Forestry Sector-Page 5.13}


3. Date activity was undertaken.

4. Latitude and longitude measured as close to the center of the activity as possible.

5. Activity type(s). Valid activity types are shown in the table below:

\begin{tabular}{|l|c|}
\hline \multicolumn{1}{|c|}{ Activity Type } & Data Code \\
\hline \hline Tree planting & 1 \\
\hline $\begin{array}{l}\text { Establishing a woody-biomass plantation/forest } \\
\text { biomass energy project }\end{array}$ & 2 \\
\hline Modified forest management & 3 \\
\hline Forest preservation & 4 \\
\hline Urban forestry & 5 \\
\hline Agroforestry & 6 \\
\hline Wood product modification & 7 \\
\hline Other & 8 \\
\hline
\end{tabular}

If you select the "other" activity type, you should describe it. If you are reporting an urban forestry or wood product modification activity, the balance of this section does not apply to you. For all other types of activities, however, provide the following information:

6. Site index or site productivity. Site index is defined by site class. Site index is equal to the height of the dominant trees at 50 years of age. Specify the species of tree used to establish site index.

7. Average slope of the site.

8. Dominant aspect of the site. Aspect is simply the direction that the site faces. If the area is flat, then it has no aspect and "none" should be entered. Otherwise, the dominant aspect (north, northwest, west, southwest, south, southeast, east, northeast) should be entered.

9. Elevation of the site.

10. Area of the activity (for example; acres, hectares).

These data provide key information on the physical attributes of the activity. If the site is highly variable-for example, a portion is very steep, while the remainder is flat-then you should split the activity into two or more activities to report on relatively homogenous land units. This will more accurately reflect the effects of the activity.

To help establish reference case parameters provide, to the best of your knowledge, the following:

11. Land use one year ago.

12. Land use five years ago. 
13. Land use ten years ago.

If the previous land use does not provide an accurate description of the reference case, then provide additional information. For an example of a modified reference case, see Example 5.8.

\section{Effects of activities: standard projects}

Effects of activities are reported using either standard or reporter-designed project pathways.

Currently, standard projects are limited to the planting of certain species of trees in the United States. Appendix 5.A provides tables of stipulated factors that estimate the carbon flows associated with these activities. To access these tables, include the following information:

1. Broad region. See the map in Figure 5.1 for a definition of broad regions. Their respective codes are:

\begin{tabular}{||l|c|}
\hline \multicolumn{1}{|c|}{ Regions of the United States } & Data Code \\
\hline \hline Southeast & 1 \\
\hline South Central & 2 \\
\hline Northeast & 3 \\
\hline Mid-Atlantic & 4 \\
\hline Lake States & 5 \\
\hline Central States & 6 \\
\hline Northern Rockies & 7 \\
\hline Southern Rockies & 8 \\
\hline Pacific Coast & 9 \\
\hline
\end{tabular}

Forestry Sector-Page 5.15 


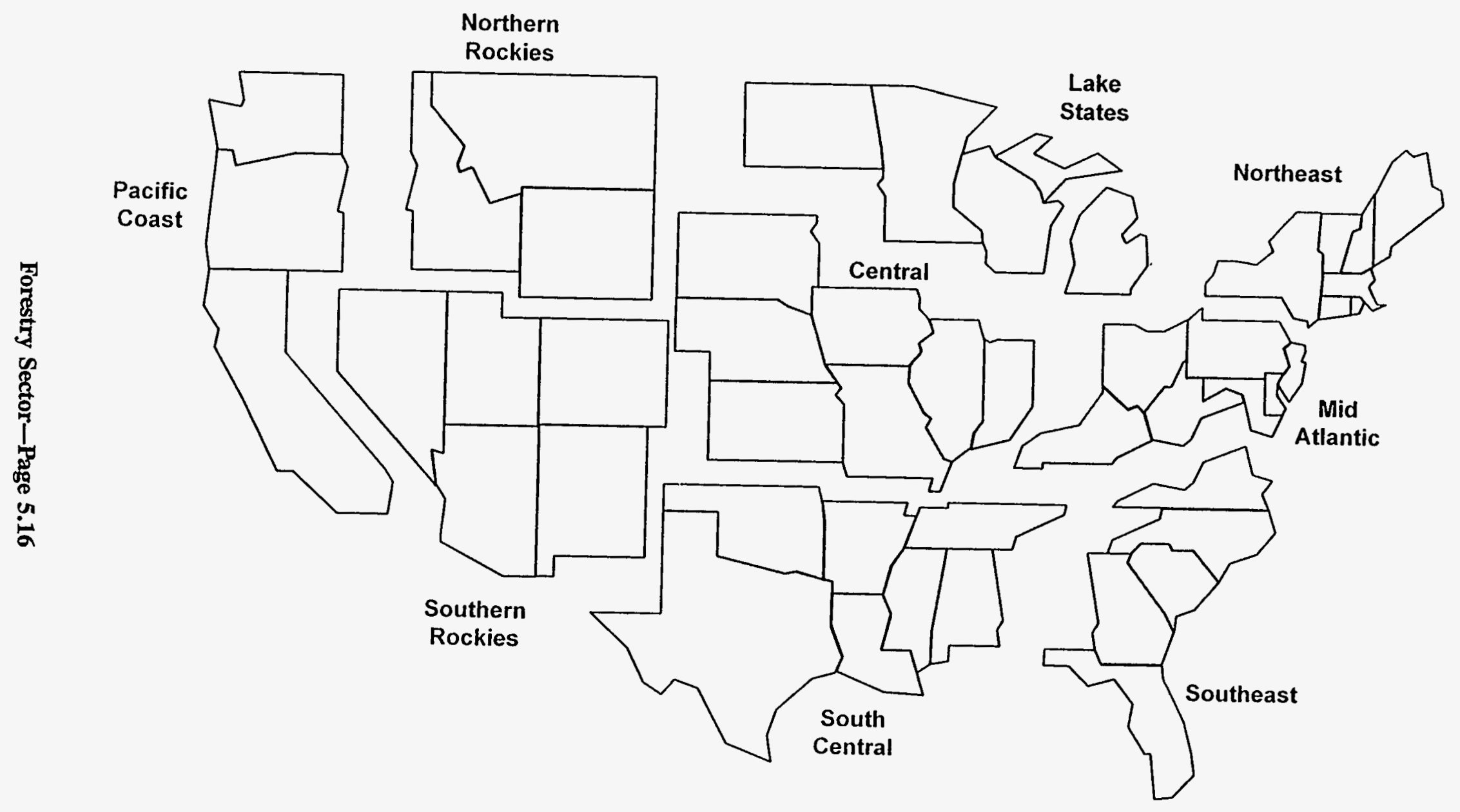

Figure 5.1. Geographic Regions Used to Estimate Carbon Storage 
2. Species or forest type. Species and forest types differ among broad regions. Codes according to forest type are provided in the following table:

\begin{tabular}{||c|c||}
\hline \multicolumn{2}{|c|}{ Standard Project Forest Types by Region } \\
\hline \hline \begin{tabular}{|} 
Southeast: \\
Southern Pine-1
\end{tabular} & $\begin{array}{c}\text { Central States: } \\
\text { White/Red Pine-1 } \\
\text { Oak/Hickory-2 }\end{array}$ \\
\hline \begin{tabular}{|l||} 
South Central: \\
Southern Pine-1
\end{tabular} & $\begin{array}{c}\text { Northern Rockies: } \\
\text { Ponderosa Pine-1 }\end{array}$ \\
\hline $\begin{array}{c}\text { Northeast: } \\
\text { White/Red Pine-1 } \\
\text { Spruce/Fir-2 }\end{array}$ & $\begin{array}{c}\text { Southern Rockies: } \\
\text { Ponderosa Pine-1 }\end{array}$ \\
$\begin{array}{c}\text { Mid Atlantic: } \\
\text { None available }\end{array}$ & $\begin{array}{c}\text { Pacific Coast: } \\
\text { Douglas Fir-1 } \\
\text { Ponderosa Pine-2 }\end{array}$ \\
\hline $\begin{array}{l}\text { Lake States: } \\
\text { White/Red Pine-1 } \\
\text { Spruce/Fir-2 }\end{array}$ & \\
\hline
\end{tabular}

If you are planting species other than those listed here or are planting outside the United States, this document does not provide data for the activity. This means that your project is not a standard project; you should develop your own analysis for a reporter-defined project.

3. Site class. Site class data should be provided for tree planting for all forest types in Southeastern and South Central regions and for the Douglas fir type in the Pacific Coast region. Codes according to site class are provided in the following table:

\begin{tabular}{|l|l|c|}
\hline \multicolumn{1}{|c|}{ Site Class } & \multicolumn{1}{c|}{ Definition } & Data Code \\
\hline \hline High & Site index of 79 feet or more ${ }^{(\mathrm{a})}$ & 1 \\
\hline Medium & Site index between 60 and 78 feet & 2 \\
\hline Not applicable & & 0 \\
\hline $\begin{array}{l}\text { (a) Site index is equal to the height of the dominant trees at 50 years } \\
\text { of age. }\end{array}$ \\
\hline
\end{tabular}

4. Land status codes are provided in the following table:

\begin{tabular}{||l|c|}
\hline \multicolumn{1}{|c|}{ Land Status } & Data Code \\
\hline \hline Clearcut Forest & 1 \\
\hline Cropland & 2 \\
\hline Pasture & 3 \\
\hline
\end{tabular}


Codes entered for categories 1-4 in this section define a four-digit access code. For example, a site in the Southeast (1) with southern pine (2), medium site class (2), and with a reference case that reflects a land status of pastureland (3), has the access code: 1123. The access code points to Table 5.A.4 in Appendix 5.A, which can be used for estimating the effects of the activity on carbon sequestration. The application of this estimation technique is illustrated by Example 5.5 in Section 5.4.

5. Management objectives. To provide users of the database with a complete picture of your project, you should also include information on the intended use of the forest. Appropriate codes are the following:

\begin{tabular}{|l|c|}
\hline \multicolumn{1}{|c|}{ Management Objective } & Data Code \\
\hline \hline Commercial timber production & 1 \\
\hline Forest preserve & 2 \\
\hline Do not know & 3 \\
\hline
\end{tabular}

6. Anticipated harvest age. If the management objective is commercial timber production, then estimate the anticipated harvest age. Age should be entered in units of years. If you cannot estimate a harvest age, then enter 0 .

7. Stocking. The tables provided in Appendix 5.A are based on a set of average yields observed for stands within a region. They are built on the assumption that the planting site will be fully stocked with trees. To allow users of the database to confirm full stocking, please enter the number of trees planted per acre and the approximate number of trees surviving to date.

\section{Effects of activities: reporter-designed projects}

Activities not listed as standard projects should be reported as reporter-designed projects. You have considerable freedom in selecting activities to report and deciding how to estimate their effects. At a minimum, however, you must meet the reporting requirements described in the General Guidelines, "What Are the Minimum Reporting Requirements?" You need to provide information on a reference case (carbon flows and greenhouse gas emissions had the activity not been undertaken) and the project case (the carbon flows and greenhouse gas emissions with the activity in place). You must identify the significant effects of the project. Finally, you must estimate the carbon flows associated with the reference case and the project, and calculate the difference between them as an estimate of your project accomplishment.

Remember that use of accepted analytical practices is important to the credibility of your report. You may want to review the guidance provided in Section 5.4 that discusses some accepted procedures for estimating the carbon flow effects for several types of forestry projects.

\section{Forestry Sector-Page 5.18}


The forms for reporting these effects will ask for information specifically on the carbon flow effects and reductions in greenhouse gas emissions associated with your project. You should maintain documentation of how these effects were derived.

\subsection{Estimating Carbon Flow Effects for Forestry Activities}

This section addresses the eight general categories of forestry activities that contribute to changes in carbon flow-afforestation on agricultural land, short rotation woody biomass plantations, agroforestry, reforestation forest management, forest preservation, wood products, and urban forestry. An overview of anticipated effects is provided. Also, several published studies that may be useful for framing your estimates are identified. However, reference to a particular study should not be construed as an endorsement of its contents by DOE.

In many situations, project evaluation will rely on a basic reference case. However, for a variety of reasons, even in the absence of an emissions reduction project, the past carbon capture and release from a given forest area might not be an adequate predictor of future carbon flows. The most dramatic example of this is when a forest area is about to be cleared to provide land for other uses. While the forest may have actually had negative flows (captured more carbon than it released) in the recent past, its positive flows in the near future are expected to be very high, at least in the short term. Therefore, a forest preservation project using a basic reference case would understate the expected flows associated with the reference case.

An impending forest harvest is an example of a change due to external influences. In addition, natural, relatively predictable changes in carbon flows such as natural regeneration and forest growth should be reflected in the reference case. Similarly, prevailing trends in forest management and wood product use should be reflected in the reference case. The credibility of your project report will be significantly enhanced if you account for these changes when you develop your reference case.

\subsubsection{Afforestation}

Forests may be established either to replace another land use such as cropland or pastureland (afforestation), or to replace trees removed by a timber harvest (reforestation, see Section 5.4.4). Afforestation of agricultural land may greatly alter the carbon storage accomplished on a site. Planting trees on nonforested land has been widely promoted as an effective tool for increasing carbon sinks globally. Accordingly, tree planting has received the most attention in the analysis of forestry's effects on global carbon cycles. There are several sources of information on the carbon sequestered and stored by forests as they develop. Published studies by Birdsey (1992a; 1992b) define carbon storage on forest sites in different ecological regions of the United States. These studies are highly detailed and distinguish among species types, the productivity class of the forest site, and the intensity of efforts. 
Tree planting activities have the benefit of producing large carbon storage gains (at least in the initial decades of tree growth) because they replace relatively low carbon storage land uses. Because of annual production cycles, agricultural land uses store comparatively little carbon.

Analyzing tree planting activities on agricultural land is relatively simple, compared to the other forestry projects discussed in the guidelines.

\section{Reference case}

In the absence of special management practices such as conservation tillage, agricultural lands, particularly those that are candidates for conversion to forests, generally do not accumulate significant amounts of carbon from one season to the next. Therefore, you can use a reference case from the year(s) immediately prior to the tree planting. That is, in the absence of information to the contrary, you can assume that the area would have remained as agricultural land, with a constant carbon stock, and no net carbon flows.

\section{Effects of the Project}

The major effect of conversion of agricultural land to forestland is to decrease net flow of carbon to the atmosphere, relative to the reference case, through capture and storage of carbon by the growing trees and the forest ecosystem. Counterproductive effects could arise if the conversion of the agricultural land had market effects that encouraged other parties to (1) convert their forestland to agricultural land, (2) avoid tree planting they might otherwise have done, or (3) harvest their existing forest stands earlier then they might otherwise have done. Other effects include biological and energy-related emissions during the planting process, and emissions resulting from the use of fertilizers. (The effects of harvesting are treated separately in Section 5.4.)

Generally, other carbon flow effects, such as market leakage and energy related emissions, are not expected to rise to a significant level compared to the effect of capturing carbon. However, if the circumstances of your project suggest otherwise, you should note all significant effects in your report and, if possible, quantify them.

\section{Estimating carbon flows for the reference case and project}

As noted above, most analyses of conversion of agricultural land to forestland assume that in the reference case, the agricultural use would capture little or no additional carbon over time. Therefore, net flows of carbon in the reference case, for all years, would be zero. However, if the converted land were under a management regime that resulted in changes in carbon stocks on the land, and hence nonzero carbon flows, you should reflect that situation in the reference case estimation-that is, you should use a modified reference case.

Net flows with the project are expected to be negative, but the level depends upon several factors, including tree species, geographic area, soil type, precipitation, slope, and aspect. You must determine 
the annual carbon exchange between your treated forest area and the atmosphere for each year you report. As described in Section 5.3, this can be done on the basis of periodic field measurements, scientific literature, computer models, or stipulated factors provided by this supporting document.

If your calculations of annual carbon flow are based on estimates of carbon inventories, then the calculation you would use for deriving annual changes in flows for the year is

$$
\text { Annual carbon flow reduction for year } t=\left(I_{t-1}^{R}-I_{t}^{R}\right)-\left(I_{t-1}^{P}-I_{t}^{P}\right)
$$

where $I_{t}^{R}=$ the reference case carbon inventory (for example, tons) at the end of year $t$

$$
\mathrm{I}_{\mathrm{t}-1}^{\mathrm{R}}=\text { the reference case carbon inventory (for example, tons) at the end of the previous }
$$$$
\text { year, } \mathrm{t}-1
$$

$I_{t}^{P}=$ the project inventory (for example, tons) at the end of year $t$

$\mathrm{I}_{\mathrm{t}-1}^{\mathrm{P}}=$ the project inventory (for example, tons) at the end of the previous year, $\mathrm{t}-1$.

If you have assumed that there is no net flow of carbon in the agricultural land use in the reference case, this becomes

Annual reduction in carbon flows in year $t=\left(\mathrm{I}_{\mathrm{t}}^{\mathrm{P}}-\mathrm{I}_{\mathrm{t}-1}^{\mathrm{P}}\right)$

If your analysis is based directly on flows of carbon rather than inventories, the expression for calculating flow reduction is

$$
\text { Annual carbon flow reduction }=\left(F^{R}-F^{P}\right)
$$

where $\mathrm{F}^{\mathrm{R}}=$ the carbon flow (for example, tons) in the reference case $\mathrm{F}^{\mathrm{P}}=$ the carbon flow (for example, tons) with the project.

For example, if $\mathrm{F}^{\mathrm{R}}$ is assumed to be zero for the afforestation project and $\mathrm{F}^{\mathrm{P}}$ is negative (that is, the project removes carbon from the atmosphere), annual flow reduction is positive.

If you are reporting an entity-level analysis of your accomplishments across many interrelated projects, then the inventory approach is probably more suited to your needs. Example 5.3 illustrates this approach. If, instead, you are analyzing a single activity with well-defined and documented effects, the carbon flow approach may be simpler. Example 5.4 illustrates project analysis on a carbon flow basis. At the same time, some simple projects will be readily analyzed in a carbon inventory context. Note, for example, that the stipulated data for tree planting activities in the United States (Appendix 5.A) are all expressed in terms of carbon inventories. Analysis of a standard project is illustrated in Example 5.5. 


\section{Example 5.3 - Afforestation: Analyzing a Project on an Inventory Basis}

\section{Note: This example illustrates only one approach to analyzing a project; your analysis, methods, and calculations will vary depending on your particular circumstances, the geographic location of the project, and other factors.}

John Fama had been practicing conservation tillage on his 40 acres of cropland for the past 10 years. He decided to convert his cropland to forestland. His reference case for the project was the land under conservation tillage. He anticipated no significant effects from the project other than carbon capture. Based on soil samples taken during his decade of farming, and just before the tree planting, he knew that the inventory of carbon was 100 tons of carbon per acre, which could have been expected to accumulate at a rate of 1 ton per acre per year.

Forest yield models for the fast growing trees that he planted indicate that the inventory of carbon was expected to grow at a rate of 3 tons per acre per year. Mr. Fama confirmed these growth rates with a field measurement of carbon stocks (including carbon in trees, litter, and soils) at the end of the fifth year of forest growth.

He used the equation described above to calculate his annual reduction in carbon flow.

$$
\text { Annual carbon flow reduction for year } t=\left(I_{t-1}^{R}-I_{t}^{R}\right)-\left(I_{t-1}^{P}-I_{t}^{P}\right)
$$

For example, in the fifth year he calculated:

Reference case inventory in the 5th year: $\quad I_{5}^{R}=105$ tons/acre

Reference case inventory in the 4th year: $\quad I_{4}^{R}=104$ tones/acre

Project case inventory in the 5th year: $\quad I_{5}^{P}=115$ tons/acre

Project case inventory in the 4 th year: $\quad I_{4}^{P}=112$ tons/acre

Annual reduction in carbon flow in year $5=(104-105)-(112-115)$

$$
\begin{aligned}
& =(-1)-(-3) \\
& =2 \text { tons/acre }
\end{aligned}
$$

That is, in the fifth year of the project there has been a 2 ton/acre reduction in carbon flow to the atmosphere, in this case achieved by removing carbon from the atmosphere.

Since Mr. Fama has 40 acres, his total reduction in carbon flow was 80 tons in the fifth year.

As described in Appendix D, the factor for converting carbon to carbon dioxide is 3.67.

$$
\text { Reduction in } \begin{aligned}
\mathrm{CO}_{2} \text { flow } & =80 \text { tons } \mathrm{C} \cdot 3.67 \text { tons } \mathrm{CO}_{2} \text { /ton } \mathrm{C} \\
& =293 \text { tons } \mathrm{CO}_{2}
\end{aligned}
$$


Example 5.4 - Afforestation: Analyzing a Project on a Flow Basis

Note: This example illustrates only one approach to analyzing a project; your analysis,
methods, and calculations will vary depending on your particular circumstances, the
geographic location of the project, and other factors.

Taking the same facts as Example 5.3, John Fama could have used the information he had to analyze his project based directly on flows of carbon. He knew that in his reference case the land was capturing one ton of carbon per acre per year, and with the project it was capturing three tons per acre per year.

Annual reduction in carbon flows in year $t=\left(I_{t}^{P}-I_{t-1}^{P}\right)$

Since he had 40 acres he could have used the above equation to calculate:

$$
\begin{aligned}
\text { Annual carbon flow reduction } & =(-1 \bullet 40)-(-3 \cdot 40) \\
& =(-40)-(-120) \\
& =80 \text { tons }
\end{aligned}
$$

That is, he reduced annual flows to the atmosphere by capturing 80 tons of carbon. Using the conversion factor for translating carbon to carbon dioxide, this was equivalent to 293 tons of carbon dioxide. 
Example 5.5 - Afforestation: Analyzing a Standard Project

$$
\begin{aligned}
& \text { Note: This example illustrates only one approach to analyzing a project; your analysis, } \\
& \text { methods, and calculations will vary depending on your particular circumstances, the } \\
& \text { geographic location of the project, and other factors. }
\end{aligned}
$$

Betty Silvan decided to plant trees on a field she had planted in soybeans for the previous 25 years. This 40 -acre tract was part of her farm outside of Durham, North Carolina. It was a relatively level and highly productive site. She planned to plant loblolly pine and intended to report the effects of her tree planting on carbon flows to the Department of Energy.

Within the EPAct Section 1605(b) reporting program, tree planting is considered a standard project, so Betty used the standard data tables to estimate the effects of her activity. To access the tables, she provided the following information:

1. Broad Region in the Southeast (code 1)

2. Forest Type is Southern Pine (code 1).

3. Site Class is High (code 1)

4. Reference Case Land Use is Cropland (code 2).

These four codes, 1112, point to Table 5.A.2 in Appendix 5.A of this document. Accessing the table, Betty reported the following net carbon storage over time, based upon planting pine trees instead of maintaining the land in crops:

$\begin{array}{ll}\text { Year } 0 & 0 \mathrm{lbs} / \mathrm{acre} \\ \text { Year } 5 & 10,000 \mathrm{lbs} / \mathrm{acre} \\ \text { Year 10 } & 22,000 \mathrm{lbs} / \mathrm{acre} \\ \text { Year 20 } & 74,000 \mathrm{lbs} / \mathrm{acre}\end{array}$

These numbers measure the net effect of the project on stocks of stored carbon. To estimate the average annual flow of carbon attributable to the project, she compared stock measures across time. For example, the annual flow of carbon for the first five years of the project was estimated as

$$
\begin{aligned}
\text { Average Annual Flow of Carbon } & =\left(I_{n}-I_{5}\right) / 5 \\
& =(0-10,000 \mathrm{lbs} / \text { acre }) /(5 \text { years })=-2000 \mathrm{lbs} / \text { acre/year. }
\end{aligned}
$$

\begin{tabular}{|c|c|c|c|}
\hline Period & Average Carbon Flow & Total Carbon Flow & Total $\mathrm{CO}_{2}$ Flow \\
\hline $1-5$ & $-2,000 \mathrm{ibs} / \mathrm{acre} /$ year & $-80,000 \mathrm{lbs} /$ year & $-293,600 \mathrm{lbs} /$ year \\
\hline $6-10$ & $-2,400 \mathrm{lbs} / \mathrm{acre} / \mathrm{year}$ & $-96,000 \mathrm{lbs} / \mathrm{year}$ & $-352,320 \mathrm{lbs} /$ year \\
\hline $11-20$ & $-5,200 \mathrm{lbs} / \mathrm{acre} / \mathrm{year}$ & $-208,000 \mathrm{lbs} / \mathrm{year}$ & $-763,360 \mathrm{lbs} /$ year \\
\hline
\end{tabular}

On the 40 acres then, a flow of $40 \times 2000=80,000 \mathrm{lbs}$ of carbon was stored each year. By applying this method to other periods, Betty derived the following schedule of carbon flows for her project:

Note that Betty should (1) annually confirm that her project appears to be forming as expected (that is, the trees are still standing and appear healthy), and (2) report the positive flow (release) of carbon that occurs when she harvests the timber she has grown.

\subsubsection{Short-Rotation Woody Biomass Energy Plantations}

The preceding discussion of afforestation anticipates a conventional view of a managed forest. That is, initial forest establishment is followed by a relatively extensive period of growth (and carbon accumulation). In contrast, biomass energy plantations occupy an intermediate position between forestry and annual agriculture. With woody biomass crops, harvesting occurs approximately every 512 years, and regeneration is accomplished by coppice methods that rely on regrowth of new stands from the root stock of the harvested stand. 
Biomass energy plantations also occupy an intermediate position between forestry and the electricity supply sector. Analysis of these projects, and particularly their reference cases, will depend upon information regarding how energy would have been supplied in the absence of the project. For purposes of reporting, you should account for emissions related to the biomass fuels and the displaced fossil fuels in the electricity supply sector, and the capture of carbon in the forestry sector.

For a discussion of the production of liquid fuels from biomass crops see Section 6.4 .7 of the supporting document for the agriculture sector.

\section{Reference case}

The reference case you adopt will be specific to your particular circumstances. In general, the reference case should account for both the carbon flows associated with the land in the absence of the project, and the emissions from the fossil fuels displaced by the biomass fuel. If the land used for the woody biomass crop was forested immediately prior to establishment of the plantation, then the reference case should reflect carbon flows appropriate for that specific forest type and age. If the plantation is established on agricultural land that has had a constant carbon stock over several years, then the reference case would reflect zero carbon flows to the land.

\section{Effects of the Project}

The principal effect of a biomass energy project is to displace fossil energy with biomass energy, thereby reducing fossil fuel carbon emissions to the atmosphere. Hence, the reference case should include an annual accounting for the positive carbon flow that would have occurred if the fossil fuel had not been displaced, and the negative carbon flow (carbon capture), if any, that would have occurred had the land area of the new plantation not been converted to a woody biomass stand. The project case should include a year-by-year accounting of negative carbon flows (carbon capture) by the new plantation, and positive carbon flows (release) from harvesting, transportation, and combustion of the biomass fuel.

You should consider other effects of this type of project. Positive effects include, for example, elimination of emissions associated with the transport of the displaced fossil fuel. Negative effects include energy-related emissions associated with the planting, management, harvest, and transport of the biomass crop; and emissions from the biological process, such as decay of litter and carbon emissions from soils due to disturbance from harvesting. These positive and negative effects may rise to a significant level and should be quantified whenever possible.

\section{Estimation of emissions}

Biomass energy defines an important cross-sectoral linkage between forestry and the electricity supply sector. Analysis of the project carbon flows should account for both increased carbon flows from the burning of biomass fuels and decreased carbon flows from displaced fossil fuels. The carbon capture resulting from woody biomass plantations can be analyzed in conventional forestry sector terms. At

Forestry Sector-Page 5.25 
the same time, the release of carbon from the combustion of biomass fuel and the displacement of emissions from fossil fuels relates more closely to activities in the electricity supply sector. You should familiarize yourself with the guidance provided in the supporting document for the electricity supply sector before analyzing this type of biomass energy project. Note, however, that it is not necessarily correct to simply assume that a ton of carbon emissions from biomass offsets a ton of fossil fuel emissions. The on-site (generation site) carbon emissions associated with the generation of a kilowatt hour of electricity may be somewhat higher for biomass fuel than for fossil fuels. The actual ratio will vary, depending upon the characteristics of the biomass fuel, the fossil fuel, and their relative combustion efficiencies.

When compared with agriculture, short rotation woody biomass plantations can increase the carbon stored upon a site. Wright et al. (1992), citing an analysis conducted by Ranney et al. (1991), report that in equilibrium the carbon increment between agriculture and short rotation woody biomass plantations can be as much as 13 to 18 tons of carbon per acre. The greatest share of this increase is stored in the soil and root components of the site. For purposes of reporting a project's effects, you need to convert this to a year-by-year estimate for the difference between the plantation and the reference case. 


\section{Example 5.6 - Short Rotation Woody Biomass Crops}

\section{Note: This example illustrates only one approach to analyzing a project; your analysis, methods, and calculations will vary depending on your particular circumstances, the geographic location of the project, and other factors.}

Biomass and Forestry Development, Inc. (BFDI) was a subsidiary of Illinois Plains Power (IPP), an independent power producer in the midwest. Most of IPP's power requirements were met with coal-fired electricity generation plants. BFDI's purpose was to find opportunities to reduce IPP's reliance on coal by establishing and operating biomass-fired electricity generation plants.

BFDI's manager decided that the most recently initiated biomass project should be treated as a pilot study on carbon dioxide emissions reductions, the results of which would be reported to the EPAct 1605(b) database. The project involved a group of small generation plants located in a rural area of the Great Lakes region. As a primary source of fuel supply, BFDI purchased a 2,000-acre farm-500 acres in mature forests and 1,500 acres that had for several decades been in cropland. The latter had recently been poorly tended and, consequently, underproductive for several years.

The management plan called for establishing one generation plant immediately, to be fueled for five years by the biomass harvested (after selective harvesting for saw timber) from the 500 acres of existing forest. The harvested forestland would be immediately replanted to short rotation woody biomass crops. The retired cropland would be planted at a rate of 300 acres per year over the same five-year period. Both the former cropland and the replanted forestland would be managed on 5-year rotations. Three new modular plants would be added to the initial plant by the end of the fifth year. Starting in the sixth year, the biomass plantations would be harvested at a rate of 400 acres (one-fifth of the total land purchased) per year to supply the four electricity generation plants.

If the cropland and forestland produced woody crops at the expected rate, BFDI's 2,000 acres of land would supply 75 percent of the biomass fuel needs of the four modular plants. The company planned to meet the balance of the fuel demand with purchases from area forestland owners and farmers. In particular, the company had one contract with farmer Jon Sven to harvest 25 acres of Sven's forestland per year for the first five years and another contract with farmer Eric Toleruth to purchase wood biomass from a 700-acre short rotation woody biomass plantation starting in the sixth year. Toleruth had expressed an interest in both participating in the voluntary reporting program and experimenting with alternative woody biomass cropping methods.

BFDI's analysis of the project involved considerable engineering work, bookkeeping, and negotiation with the participants. The project manager identified the reference case as one under which the electricity would be supplied by a new coal-fired plant, and the farmland and mature forestland continued to be managed as they had been in the recent past. The only significant carbon flows under the reference case were those from the combustion and transportation of the coal. Many more activities affected carbon flows in the project case, including the following: 
Example 5.6 - (cont'd)

BFDI's Existing Forestland

Harvest and transportation of biomass

Soil disturbance and combustion of biomass

Use of fossil fuels in site preparation for replanting

Growth of new biomass crop

\begin{tabular}{ll} 
Years $^{(2)}$ & Effect on \\
\hline & Carbon Flow
\end{tabular}

\section{BFDI's Cropland}

Use of fossil fuels in site preparation for planting biomass crop

Growth of new biomass crop

$1-5$

1-5

1-5

1-EOP

$\begin{array}{lc}1-E O P & + \\ 1-E O P & - \\ 6-E O P & + \\ 6-E O P & +\end{array}$

1-5

$1-5$

1-EOP

1-5

6-EOP

6-EOP

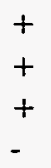

$+$

$+$

$+$

Harvest and transportation of biomass

Soil disturbance and combustion of biomass

Toleruth's Land

Use of fossil fuel in site preparation for planting biomass crop

Growth of new biomass crop

Harvest and transportation of biomass

Soil disturbance and combustion of biomass.

(a) $($ EOP $=$ end of project $)$

For the biomass plantations, BFDI considered the possibility of simply balancing the release of carbon from soil disturbance and combustion against the carbon capture from the growth of the biomass. Ultimately, these two quantities are essentially equal. However, to drop these two factors from the analysis would obscure the difference in timing of the carbon uptake and release. Since one of the purposes of the pilot analysis was to share detailed information about the performance of the project, BFDI opted for a more detailed approach.

BFDI projected the quantities associated with each of the 14 carbon flows identified above (see Table 5.1). These projections, based on expected crop yields, energy generation, and combustion efficiencies, were included in the initial report. They were updated annually to reflect actual performance for the reporting year. The project carbon flow figures were subtracted from the carbon flows for the coal-burning reference case to yield a net carbon flow reduction associated with the project. As illustrated by the last line of Table 5.1, the carbon flow reduction was translated to a carbon dioxide emission reduction for purposes of reporting to the EPAct $1605(\mathrm{~b})$ database.

For purposes of accounting and reporting, BFDI wanted to be clear with both Sven and Toleruth that the BFDI report would incorporate the biomass growth and harvest activities on their lands as well. This raised a problem with Toleruth, who had hoped to file a separate report. BFDI and Toleruth discussed several possible reporting arrangements, including (1) joint reporting where both parties would submit the same report, (2) dual reporting, where parties would submit separate overlapping reports, (3) dual reporting where Toleruth would report the capture of carbon only, and BFDI would report the release of biomass carbon and displacement of fossil carbon, and (4) dual reporting where Toleruth would report the capture and release of biomass carbon and BFDI would report the displacement of fossil carbon only. Both parties recognized that accurate and complete reporting was the most important issue, and that whatever reporting configuration was adopted must ensure that all carbon flows are reported. Ultimately, Toleruth agreed to cede all reporting rights to BFDI in return for a small increase in the price of the purchased fuel. 
Table 5.1. Carbon Flows for BFDI's Biomass Energy Project

\begin{tabular}{|c|c|c|c|c|c|c|}
\hline & \multicolumn{6}{|c|}{ Annual Carbon Flow (tons), by Year } \\
\hline & $\mathbf{1}$ & 2 & 3 & 4 & 5 & 6-EOP( \\
\hline \multicolumn{7}{|l|}{ BFDI's Existing Forestland } \\
\hline Harvest and transportation of biomass & 50 & 50 & 50 & 50 & 50 & 30 \\
\hline Soil disturbance and combustion of biomass & 4,000 & 4,000 & 4,000 & 4,000 & 4,000 & 3,500 \\
\hline Use of fossil fuel/site preparation for replanting & 10 & 10 & 10 & 10 & 10 & 5 \\
\hline Growth of new biomass crop & -700 & $-1,400$ & $-2,100$ & $-2,800$ & $-3,500$ & $-3,500$ \\
\hline Subtotal & 3,360 & 2,660 & 1,960 & 1,260 & 560 & 35 \\
\hline \multicolumn{7}{|l|}{ BFDI's Cropland } \\
\hline $\begin{array}{l}\text { Use of fossil fuels/site preparation for planting } \\
\text { biomass crop }\end{array}$ & 21 & 21 & 21 & 21 & 21 & 15 \\
\hline Growth of new biomass crop & $-2,100$ & $-4,200$ & $-6,300$ & $-8,400$ & $-10,500$ & $-10,500$ \\
\hline Harvest and transportation of biomass & 0 & 0 & 0 & 0 & 0 & 90 \\
\hline Soil disturbance and combustion of biomass & 0 & 0 & 0 & 0 & 0 & $-10,500$ \\
\hline Subtotal & $-2,079$ & $-4,179$ & $-6,279$ & $-8,379$ & $-10,479$ & 105 \\
\hline \multicolumn{7}{|l|}{ Sven's Land } \\
\hline Harvest and transportation of biomass & 15 & 15 & 15 & 15 & 15 & 0 \\
\hline Soil disturbance and combustion of biomass & 1,000 & 1,000 & 1,000 & 1,000 & 1,000 & 0 \\
\hline Subtotal & 1,015 & 1,015 & 1,015 & 1,015 & 1,015 & 0 \\
\hline \multicolumn{7}{|l|}{ Toleruth's Land } \\
\hline Use of fossil fuel/site preparation for planting & 10 & 10 & 10 & 10 & 10 & 7 \\
\hline Growth of new biomass crop & -900 & $-1,800$ & $-2,700$ & $-3,600$ & $-4,500$ & $-4,500$ \\
\hline Harvest and transportation of biomass & 0 & 0 & 0 & 0 & 0 & 60 \\
\hline Soil disturbance and combustion of biomass & 0 & 0 & 0 & 0 & 0 & 4,500 \\
\hline Subtotal & -890 & $-1,790$ & $-2,690$ & $-3,590$ & $-4,490$ & 67 \\
\hline Total project flows & 1,406 & $-2,294$ & $-5,994$ & $-9,694$ & $-13,394$ & 207 \\
\hline Reference case flows & 3,000 & 3,000 & 3,000 & 3,000 & 3,000 & 12,000 \\
\hline Carbon flow reduction & 1,594 & 5,294 & 8,994 & 12,694 & 16,394 & 11,793 \\
\hline Carbon dioxide flow reduction & $\therefore 5,845$ & 19,411 & 32,978 & 46,545 & 60,111 & 43,241 \\
\hline
\end{tabular}




\subsubsection{Agroforestry}

Agroforestry combines agriculture and silviculture on the same tract of land. Because it emphasizes the use of woody and perennial crops and biological fertilizers, it may provide agricultural products with less intensive energy uses and sequester more carbon than traditional agriculture. These agroforestry systems can be quite complex, addressing not only production of grains and fruits for human consumption, but the production of feed and forage for livestock, the production of wood fuel and building materials, and the restoration of degraded land.

Where agroforestry projects replace existing patterns of agricultural and fuel wood harvesting, it may be appropriate to use a basic reference case.

Identifying the wide range of potential effects of agroforestry projects is a difficult task. Arguably, the major effect of an agroforestry project is to remove carbon from the atmosphere through the photosynthesis process. However, this type of project can also affect energy-related emissions from farm and irrigation equipment, biological emissions from soil disturbance and livestock, emissions related to the production and use of fertilizer, and emissions related to fuel wood use.

While identifying these effects is difficult, quantifying them is still more difficult. Agroforestry projects are made up of a wide range of interdependent actions. While substantial research has been conducted to evaluate various agroforestry activities, it is not clear how much the results of the research can be generalized to provide evaluation of other projects. In the face of the difficulties with estimating project effects, you may develop a more credible report if you limit your analysis to the most certain of the effects, such as carbon capture and release by trees.

\subsubsection{Reforestation}

In contrast to afforestation, reforestation activities are used to regenerate a recently harvested or otherwise cleared forest site. In this case, the reference case would likely be natural regeneration of the forest, which leads to slower growth than managed reforestation. At the same time, the increase in carbon capture that can be attributed to the activity is likely to be considerably smaller than in afforestation, where the reference case reflects no growth of forest at all. In fact, for reforestation, the difference between the reference and activity cases may not be substantial.

It is even possible that intensifying management for the production of wood products may not result in more carbon stored upon a site when all the carbon-storing elements are considered. Birdsey (1992b) examines cases where conversion of natural stands to pine plantations would result in a net loss in carbon storage. The results depend on a number of factors, including the length of the rotation period. Examples 5.7 and 5.8 illustrate some of the considerations in analyzing reforestation projects. 
Example 5.7 - Reforestation: Analyzing a Standard Project

Note: This example illustrates only one approach to analyzing a project; your analysis, methods, and calculations will vary depending on your particular circumstances, the geographic location of the project, and other factors.

Ned Skidder, a tree farmer in South Carolina, intended, as part of his overall forest management program, to plant pine on a recently acquired 25 -acre cut-over site that had been an Oak-Hickory forest. He wanted to report the effects that this reforestation activity would have on greenhouse gases.

Tree planting for reforestation is considered a standard project. The difference between reforestation and afforestation is simply the reference case-for reforestation. The reference case is defined by natural regeneration to the original forest cover. In Ned's case, if he had not replanted the site in pine it would have regenerated to Oak-Hickory. The tables in Appendix 5.A for standard projects incorporate the effects of the reference case directly into the carbon stock figures. To access the table of stipulated factors for this forestry project, Ned provided the following information:

1. Broad Region was the Southeast (code 1)

2. Forest Type was Southern pine (code 1)

3. Site Class was High (code 1)

4. Reference Land Use was clearcut forest (code 1)

This led Ned to Table 5.A.1 in Appendix 5.A of this document. Comparing tree planting with the reference case of OakHickory in that table defined the following carbon storage effects:

$\begin{array}{ll}\text { Year } 0 & 0 \mathrm{lbs} / \mathrm{acre} \\ \text { Year } 5 & 3,000 \mathrm{lbs} / \mathrm{acre} \\ \text { Year } 10 & 10,000 \mathrm{lbs} / \mathrm{acre} \\ \text { Year } 20 & 45,000 \mathrm{lbs} / \mathrm{acre}\end{array}$

These numbers measure stocks of stored carbon. To estimate the average annual flow of carbon, he compared stock measures across time. For example, the annual flow of carbon for the first five years of the project was estimated as

$$
\begin{aligned}
\text { Average Annual Flow of Carbon } & =\left(\mathrm{I}_{0}-\mathrm{I}_{5}\right) / 5 \\
& =(0-3,000 \mathrm{lbs} / \mathrm{acre}) /(5 \text { years })=-600 \mathrm{lbs} / \text { acre/year. }
\end{aligned}
$$

On the 25 acres, a total of $25 \bullet 600=15,000 \mathrm{lbs}$ of carbon was captured each year for the first five years. By applying

\begin{tabular}{|c|c|c|c|}
\hline$\underline{\text { Period }}$ & Average Carbon Flow & Total Carbon Flow & Total $\mathrm{CO}_{2}$ Flow \\
\hline $1-5$ & $-600 \mathrm{lbs} / \mathrm{acre} / \mathrm{year}$ & $-15,000 \mathrm{lbs} /$ year & $-55,050 \mathrm{lbs} /$ year \\
\hline $6-10$ & $-1,400 \mathrm{lbs} / \mathrm{acre} / \mathrm{year}$ & $-35,000 \mathrm{lbs} / \mathrm{year}$ & $-128,450 \mathrm{lbs} / \mathrm{year}$ \\
\hline $11-20$ & $-3,500 \mathrm{lbs} / \mathrm{acre} / \mathrm{year}$ & $-87,500 \mathrm{lbs} / \mathrm{year}$ & $-321,125 \mathrm{lbs} /$ year \\
\hline
\end{tabular}
this method to other periods, the following schedule of carbon flows was derived for the project:

To this point, the project has been analyzed as a standard project. Suppose, however, that Ned planned to use fire to prepare the harvested site for regeneration. His report would need to reflect the additional carbon flow from the burning in the first year of the project. Suppose Ned's research revealed that burning under his specific conditions released $50 \mathrm{lbs}$ of carbon per acre, or $1,250 \mathrm{lbs}$ for his 25 acres. Then his first year report of carbon flow reductions would have to be revised from $55,050 \mathrm{lbs}$ down to $53,800 \mathrm{lbs}$ to reflect the effects of burning. Using the conversion factor from Appendix $\mathrm{D}$, the $53,800 \mathrm{lbs}$ of carbon is equivalent to $197.4 \times 10^{3} \mathrm{lbs}$ of carbon dioxide or 98.7 short tons of carbon dioxide.

\section{Forestry Sector-Page 5.31}


Example 5.8 - Reforestation: Reclamation of Mined Lands

Note: This example illustrates only one approach to analyzing a project; your analysis, methods, and calculations will vary depending on your particular circumstances, the geographic location of the project, and other factors.

The Piedmont Energy Association (PEA) was a coal surface mining cooperative owned by several local utilities and independent power producers. Under its past practices, PEA had met local, state, and Federal environmental regulations to reclaim mined areas as grasslands. At a board of directors meeting, one of the member companies suggested that, if recently mined areas were planted in trees rather than grasses, the cooperative could report the change as a sequestration project to the EPAct 1605(b) database. Preliminary cost studies indicated that, given the types of resources available to the cooperative and its member companies, the costs of establishing forests would be only slightly higher than the costs of establishing grasslands.

Evaluation of the project required PEA to address three critical issues: (1) identifying the appropriate reference case, (2) identifying the significant carbon flow effects of both the reference case and the project case, and (3) estimating the carbon flows associated with both cases.

PEA's first decision was whether to use a basic or modified reference case. The EPAct $1605(\mathrm{~b})$ guidelines required PEA to identify the dominant land use on the reforestation area for 1,5 , and 10 years prior to initiation of the project. Since the area had been forested before mining began ( 10 and 5 years prior to the project), some participants in the project expected that the reference case would be a forested one. However, as the project manager pointed out, the correct question to ask was, "What would have happened had the project-reforestation-not taken place?" The answer to this question, that the land area would have been in grassland in the absence of the project, indicated that a modified reference case would be most appropriate for this project.

Identifying the carbon flow effects of the reference and project cases was relatively straightforward. The reference case was assumed to have moderate negative carbon flows (that is, carbon capture) resulting from the growth of newly seeded grasslands. The project case was expected to have somewhat higher negative flows from the forest stands. Both cases would include initial emissions of greenhouse gases associated with the seeding and site preparation. Because PEA kept reclaimed areas out of other uses for 40-60 years, the project manager decided that any market effects associated with the new forestry project could be ignored.

Estimating the carbon flows associated with the reference and project cases required considerably more work. The project manager believed that the available data regarding growth rates of grasslands and timberstands on reclaimed mine sites could not credibly be applied to PEA's particular sites. Further, PEA could not translate available data for above-ground biomass to estimates of whole ecosystem carbon uptake rates. Consequently, PEA set up a carefully designed field measurement plan with both untreated (grassland) and treated (forested) plots to represent the reference and project cases. The carbon stocks on each plot were measured each year for the first 3 years and at 5 -year intervals thereafter. The estimates for years in which measurement took place were derived by linear extrapolation from previous years, and then corrected as soon as the next measurement took place.

\subsubsection{Forest Management}

The previous discussion in this supporting document has described activities that relate to the establishment or replacement of forests or trees. It may also be possible to modify the management regimes of existing forests to increase their carbon capture rates. Activities may be applied either during the period of forest growth (intermediate forest treatments) or at the time of harvest and regeneration. Intermediate treatments include the following: 
- Hardwood control

- Precommercial thin

- Commercial thin

- Firewood harvests

- Fertilization

- Prescribed fire.

These activities may increase (or decrease) carbon capture rates. While several studies have estimated the total carbon content of forests, less information exists on the effects of various forestry management regimes on carbon flows. Carbon flow effects of various treatments tend to be highly site-specific. As a consequence, fewer options exist for estimating the effects of these activities on a generalized basis, and estimation requires significant effort. However, new modeling tools are being developed to assist in this type of analysis.

Reducing the carbon flows to the atmosphere may also be possible by altering the processes used to harvest and regenerate the forest site. Logging techniques influence the amount of residual material left in the forest to decompose and the survivability of residual trees. In addition, techniques used to prepare and encourage forest regeneration can release greenhouse gases-especially through burning. Site preparation techniques include the following:

- Mechanical site preparation

- Site preparation burning

- Chemical site preparation.

As with intermediate treatments, carbon storage effects of alternative logging and site preparation methods can be difficult and costly to estimate. Defining reference cases for management regimes presents additional difficulties. Forestry research in this area is progressing rapidly. Relevant data and analytical methods may become much more accessible in the near future. Example 5.9 illustrates the use of various estimation and measurement tools in analyzing a forest management project.

Forestry Sector-Page 5.33 
Example 5.9 - Modified Forest Management

Note: This example illustrates only one approach to analyzing a project; your analysis, methods, and calculations will vary depending on your particular circumstances, the geographic location of the project, and other factors.

Lower Thiebault Bay, Limited (LTBL), a Pacific Coast power company, decided that it wanted to offset the carbon dioxide emissions from its coal-fired generating plant with a carbon sequestration project. LTBL identified that the typical management of commercial forestlands in its region was one of short-term, even-age, 40-year rotations of Douglas fir. This presented an opportunity to LTBL to increase carbon capture, since the mean annual carbon increment for Douglas fir continues to increase through the sixth to eighth decade. From a carbon sequestration standpoint, some of the most productive years are lost when harvest occurs at the end of the fourth decade.

LTBL decided to harvest a number of products from the forests under a modified forest management plan, while increasing carbon sequestration relative to the 40-year rotation regime. To confirm that the effects of its project would not be dissipated through market leakage, LTBL consulted a forest economist and the regional representative of a forest products trade association to identify what effects a change in the harvest schedule might have on wood product markets. Given the influence of the global market, recognizing the range and rapid shift of market demands for different products, and the fact that timberland owners largely make their harvest decisions based on a wide variety of issues, such as their own financial needs, it was determined that LTBL's harvest change would not make a significant difference in product availability or others' harvest patterns.

LTBL learned that commercial thinnings, which comprised part of a potential modified timber management plan, could be used for oriented strand board products. Later-harvest trees, those of 80-100 years, would provide particularly valuable larger dimension saw-timber. The company found that this kind of timber is increasingly rare; therefore, builders are substituting materials, such as steel, that have strength comparable to older timber. Steel requires considerable energy for fabrication, however, so using mature wood products could reduce the carbon dioxide emissions associated with producing alternative building materials. LTBL decided that it would not attempt to quantify the emission reductions associated with this substitution, but felt that any market leakage was more than compensated for by the displacement of steel.

LTBL contracted with a forest ecologist and a silviculturalist at the state university to design the modified forest management regime, to model the reference case and the project case, and to carry out a field measurement and monitoring program to confirm that the project performed as expected. They knew that if they did not intervene (that is, in the reference case), a clear-cut harvest was scheduled for every 40 years, to be quickly followed by replanting. Under the modified management regime that the consultants developed, commercial thins of standing inventory would occur at ages $40,60,80$ and 100 years. A harvest of 90 percent of merchantable timber would occur at age 120. The remaining 10 percent would be left to grow without haryest.

In the modeling stage the ecologist and silviculturalist drew on extensive forestry yield data, soil samples, and past field trials to assemble the data they needed to forecast expected carbon flows. The pre-project inventory for the 39-year-old stand was based on field samples from the project site. Both the reference case and project case models included as comprehensive an accounting of carbon as was feasible including components for soils; understory; coarse and fine roots; snags and stumps; and tree boles, branches and foliage. Where they relied on yield tables for model data, they used tables developed for second-growth forests, since tables developed for old growth forests do not accurately reflect second- and third-growth conditions, and therefore, carbon stores. Based on their sequestration modeling, they derived the sitespecific forecast of carbon inventories for the stand ages 40 to 120 , listed in the table below. 
Example 5.9 - (cont'd)

Carbon Stocks as Estimated for LTBL's Project

\begin{tabular}{|c|c|c|}
\hline \hline $\begin{array}{c}\text { Forest } \\
\text { stand } \\
\text { age }\end{array}$ & $\begin{array}{c}\text { Reference case carbon } \\
\text { stock (Mtc/ha) }\end{array}$ & $\begin{array}{c}\text { Project case carbon } \\
\text { stock (Mtc/ha) }\end{array}$ \\
\hline \hline 39 & 333 & 333 \\
\hline 40 & $138(\mathrm{CC})$ & $295(\mathrm{~T})$ \\
\hline 50 & 138 & 394 \\
\hline 59 & 153 & 473 \\
\hline 60 & 155 & $369(\mathrm{~T})$ \\
\hline 70 & 234 & 440 \\
\hline 79 & 333 & 493 \\
\hline 80 & $138(\mathrm{CC})$ & $407(\mathrm{~T})$ \\
\hline 90 & 138 & 456 \\
\hline 99 & 153 & 495 \\
\hline 100 & 155 & $419(\mathrm{~T})$ \\
\hline 110 & 234 & 458 \\
\hline 119 & 333 & 492 \\
\hline 120 & $138(\mathrm{CC})$ & $229(\mathrm{PC})$ \\
\hline & $\mathrm{CC}$ clear cut; T=thin; PC=partial cut. \\
\hline \hline
\end{tabular}

The carbon inventories were then converted into annual carbon flows for the reference case and the project case, and carbon flow reductions. The annual carbon flow reductions, expressed in metric tons of carbon per hectare (Mtc/ha/yr), were multiplied by both the project size (21,000 hectares) and the factor for converting carbon to carbon dioxide, 3.67 (Appendix $\mathrm{D}$ to this volume). This yielded the whole-project carbon dioxide flow reductions that would be reported to the EPAct 1605(b) program. The results of these calculations are shown in the table below. (Recall that negative flows refer to carbon capture.)

LTBL noted that the project involved some years for which there was a net increase of carbon dioxide flows in the project case relative to the reference case (years 60-79 and 100-120). However, those increases were more than outweighed by the years in which there were even greater reductions in flows. In year 120 there would be an additional 91 metric tons of carbon per hectare in storage than under the reference case, a net increase of slightly more than 7 million metric tons of carbon dioxide that would not be in the atmosphere. Equally importantly, LTBL believed, was that the large flow reductions occurred earlier than the flow increases. Because LTBL valued earlier reductions more than later reductions, this increased the value of the project from the company's perspective.

LTBL was very careful to report flows for all years, and conducted annual visual inspections and 5-year field measurements to confirm that the project was performing as predicted. The company believed that providing as comprehensive and transparent a report as possible would increase the database users' confidence in its analysis.

Forestry Sector-Page 5.35 
Example 5.9 - (cont'd)

Carbon Flows as Estimated for LTBL's Project

\begin{tabular}{|c|c|c|c|c|}
\hline $\begin{array}{l}\text { Annual } \\
\text { flow for } \\
\text { years }\end{array}$ & $\begin{array}{l}\text { Reference case carbon } \\
\text { flow (Mtc/ha/yr) }\end{array}$ & $\begin{array}{l}\text { Project case carbon } \\
\text { flow (Mtc/ha/yr) }\end{array}$ & $\begin{array}{l}\text { Flow reduction } \\
\text { (Mtc/ha/yr) }\end{array}$ & $\begin{array}{c}\text { Reportable } \\
\text { reduction in } \mathrm{CO}_{2} \\
\text { flows } \\
\left(10^{3} \mathrm{MtCO}_{2} / \mathrm{yr}\right)\end{array}$ \\
\hline 40 & 195.0 & 38.0 & 157.0 & 12,089 \\
\hline $41-50$ & 0.0 & -9.9 & 9.9 & 762 \\
\hline $51-59$ & -1.7 & -8.7 & 7.0 & 539 \\
\hline 60 & -2.0 & 104.0 & -106.0 & $-8,162$ \\
\hline $61-70$ & -7.9 & -7.1 & -0.8 & -62 \\
\hline $71-79$ & -11.0 & -5.3 & -5.7 & -439 \\
\hline 80 & 195.0 & 86.0 & 109.0 & 8,393 \\
\hline $81-90$ & 0.0 & -4.9 & 4.9 & 377 \\
\hline $91-99$ & -1.7 & -4.3 & 2.6 & 200 \\
\hline 100 & -2.0 & 76.0 & -78.0 & $-6,006$ \\
\hline $101-110$ & -7.9 & -3.9 & -4.0 & -308 \\
\hline $111-119$ & -11.0 & -3.8 & -7.2 & -554 \\
\hline 120 & 195.0 & 263.0 & -68.0 & $-5,236$ \\
\hline
\end{tabular}

\subsubsection{Forest Preservation}

Protecting existing forests from harvest and, in some cases, conversion to another land use has been proposed as a means of mitigating increases in atmospheric carbon. Carbon dioxide released in the harvesting or clearing of primary forests has contributed significantly to global increases in atmospheric carbon. Alternatively, it could be argued that conversion of existing mature forests (with high levels of stored carbon, but little net uptake of additional carbon) to intensively managed forests (with high annual uptakes of carbon) could reduce atmospheric carbon. The actual result may depend on a number of factors, including the productivity of the site, the quality and age of the existing forest, and the growth patterns of the replacement forests (Marland and Marland 1992).

The effect of forest preservation on carbon flows depends critically on how the reference case is defined. For the case where the forest would otherwise be converted to some form of managed forest, the carbon flow effects of forest preservation are questionable. If however, the credible reference case 
Another important issue is whether forest preservation actually leads to a reduction in global carbon flows-preserving one forest may simply mean that another forest will be harvested. In the case of individual projects, you might assume there are no market-level impacts on total timber harvesting. However, forest preservation may be more effective in reducing deforestation associated with land-use conversions (for example, from forests to agriculture). To be credible to users of the database, your report should clearly demonstrate that preserving a particular forest leads to a net increase in forest carbon relative to the reference case.

\subsubsection{Wood Products}

Several of the projects discussed in this supporting document could also involve the harvest of timber or pulpwood for use in wood products. Studies have indicated that the carbon contained in forest stands follows several different paths after harvest. A significant amount of carbon is released from the forest site because of soil disturbance and decay of debris. More is released during the industrial processing of the raw materials. Of the carbon that reaches wood products, some remains only for a short time (1-5 years), but a significant amount remains stored in the wood products for long periods (on the order of decades) before returning to the atmosphere.

The evaluation of projects involving timber harvest may account for this long-term storage in wood products by showing incremental releases of carbon following harvest rather than sudden release at the time of harvest. However, defining a reference case for this type of activity can be quite difficult. Presumably, had the harvesting and wood products activities not taken place in the context of the reported project, the market demand for the products would have been met by harvesting from another site. This suggests that the project may have caused forests to be preserved elsewhere. Alternatively, the fact that the forest in the project had been planted in the first place may have discouraged planting or reforestation elsewhere.

These effects can only be understood in the context of a full market model. It is difficult to argue that any individual activity will have enough price effect to shift the aggregate consumption of wood products within the market. This suggests that the most credible, and certainly the most conservative, approach is to treat carbon destined for wood products as if it is released immediately after harvest.

The one clear exception to the ambiguous effects of carbon stored in wood products is in the case of projects that develop new wood products, particularly those that substitute for non-wood products, such as steel, aluminum and cement used in construction. To be credible, the reference case would have to convincingly explain why, in the absence of the reported project, the demand would have been met using other materials. If this were accomplished, however, the project could then credibly report additional emissions reductions from foregone production of the displaced construction materials. Example 5.10 illustrates such a project.

Forestry Sector-Page 5.37 
Example 5.10 - New Wood-Products

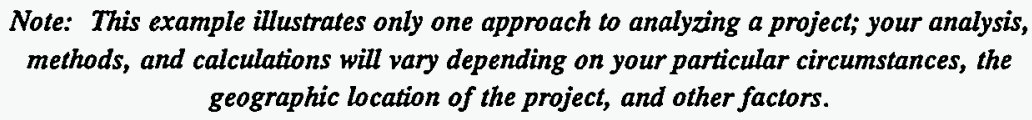

Bagley Timber Company (BTC) acquired several thousand acres of secondary mixed species forestland in the Northern Rocky Mountain Region. These timber stands were relatively mature, ranging in age from $70-90$ years. The land was acquired for the purpose of complementing an aggressive marketing plan to promote the revitalization of an old technology-wooden bridges. BTC established contracts with the State Department of Transportation (DOT) to construct 15 new bridges, in lieu of the steel, concrete, and aluminum structures the state had initially planned.

The first step in BTC's project analysis was to identify the reference case associated with the project. Since this was an introduction of a completely new activity, it was clear BTC would have to use a modified reference case. Analysis suggested that in the reference case the mature, newly purchased forests would have remained undisturbed, capturing carbon slowly and storing it primarily in soils. At the same time, the state would have constructed the bridges using energy-intensive materials such as steel, aluminum, and concrete.

In the project case, the effects of the project included the positive carbon flows in the first years associated with the initial harvesting and processing of the timber, and the negative flows in the later years resulting from the reforestation of the harvested area.

The other effects of the project were expected to be small. The decrease in purchases of the other building materials-steel, aluminum, and concrete-by the State DOT was not expected to have significant effects on the prices of these goods; hence, there would be no market leakage of the emissions reductions associated with their displacement. The construction site energy use associated with building the wooden bridge was assumed to be equal to the on-site energy use for constructing a conventional bridge. BTC identified several other minor effects, but chose not to quantify them.

To estimate the change in carbon flows associated with the construction of the wooden bridges, BTC analysts had to gather several sets of data. First, for the reference case, they had to consider the annual carbon capture (negative flow) that would have occurred on the forest sites that supplied the timber for the 15 bridges. An average of 15 acres was required for each bridge. Since the sites supported relatively mature stands, the carbon capture rates were low. BTC foresters estimated that, during the next 50 years, the harvested area would have captured 0.5 tons of carbon per acre per year. For the reference case, they estimated that, for at least 50 years, the area would have had a carbon flow rate of

$$
15 \text { acres/bridge } \bullet 15 \text { bridges } \bullet-0.5 \text { tons carbon/acre/yr }=-112.5 \text { tons carbon/yr }
$$

The second piece of data required in the reference case was the emissions that would have occurred in the manufacture of the steel, aluminum, and concrete used in conventional bridges. BTC located factors for the life-cycle emissions of each of these materials. Although those emissions might have actually occurred over two to three years, BTC considered it a reasonable approximation to treat these emissions as if they would have occurred in the first year. Engineers found that the materials required for the average conventional bridge would have led to emissions of 1,500 tons of carbon. 
Example 5.10 - (cont'd)

Thus, the reference case carbon flow was

$$
\begin{aligned}
& \text { Year 1: } \quad(1,500 \text { tons/bridge }) \bullet(15 \text { bridges })-112.5 \text { tons }=22,387.5 \text { tons } \\
& \text { Years 2-50: }-112.5 \text { tons/yr }
\end{aligned}
$$

The project case involved an initial release of carbon associated with the harvesting and processing of timber. Based on an extensive review of the technical literature and a survey of the affected land, BTC foresters estimated that for each acre harvested an average of $\mathbf{4 0}$ tons of carbon flowed to the atmosphere in the first three years of the project. This carbon flow was the result of soil disturbance and litter decay, energy used in the harvesting, transportation and timber production process, and decay of wood wastes. They approximated this effect by assuming the entire flow occurred in the first year of the project.

On this basis, they calculated a project carbon flow for this component:

$$
40 \text { tons/acre }-15 \text { acres/bridge } \bullet 15 \text { bridges }=9,000 \text { tons }
$$

Finally, BTC considered the carbon capture (negative flow) due to reforesting the harvested area with larch, a fastgrowing tree species. To estimate this effect, the foresters took advantage of the estimates provided in Table 5.A.27. Although their project was not a standard project, this information was useful for this purpose. Table 5.A.27 indicates that a larch forest planted on harvested forestland can expect to have carbon stocks of

\begin{tabular}{lr} 
Year & $\begin{array}{r}\text { Carbon s } \\
\left(10^{3} \mathrm{lbs} / \mathrm{a}\right.\end{array}$ \\
\hline 0 & 103 \\
5 & 110 \\
10 & 115 \\
20 & 131 \\
30 & 157 \\
40 & 190 \\
50 & 225
\end{tabular}

The average annual flow during the first five years was calculated using the relation

$$
\frac{I_{0}-I_{5}}{5}=\frac{103-110}{5}=-1.4
$$

For subsequent years, the average annual flow rates would be

$\begin{array}{lcc}\text { Years } & \begin{array}{l}\text { Carbon flow rate } \\ \left(10^{3} \text { bs/acre/yr) }\right.\end{array} & \begin{array}{c}\text { Project carbon flow } \\ \text { (short tons/yr) }\end{array} \\ 1-5 & -1.4 & -157.5 \\ 6-10 & -1.0 & -112.5 \\ 11-20 & -1.6 & -180.0 \\ 21-30 & -2.6 & -292.5 \\ 31-40 & -3.3 & -371.3 \\ 41-50 & -3.5 & -393.8\end{array}$


Example 5.10 - (cont'd)

Finally, the bridges themselves would eventually decay, releasing the carbon back to the atmosphere. Since the expected life of these bridges was 50 years, the release of the carbon from the structures, 400 tons per bridge, was treated as if it would all occur in that year.

Hence, the project case carbon flows were calculated as

$\begin{array}{ll}\text { Year 1: } & 9000 \text { tons }-157.5 \text { tons }=8,842.5 \text { tons } \\ \text { Years 2-5: } & -157.5 \text { tons } / y r \\ \text { Years 6-10: } & -112.5 \text { tons } / y r \\ \text { Years 11-20: } & -180.0 \text { tons } / y r \\ \text { Years 21-30: } & -292.5 \text { tons } / y r \\ \text { Years 31-40: } & -371.3 \text { tons } / y r \\ \text { Years 41-49: } & -393.8 \text { tons } / y r \\ \text { Year 50: } & 6,000-393.8=5,606.2 \text { tons }\end{array}$

BTC then calculated its reduction in carbon and carbon dioxide flows (in short tons) as follows:

\begin{tabular}{|c|c|c|c|c|}
\hline Years & Carbon Flow $_{\text {ref }}$ & Carbon Flow proj & $\begin{array}{l}\text { Annual } \\
\text { Reduction in } \\
\text { Carbon Flow } \\
\end{array}$ & $\begin{array}{c}\text { Annual } \\
\text { Reduction in } \\
\text { Carbon Dioxide Flow }\end{array}$ \\
\hline 1 & $22,387.5$ & $8,842.5$ & $13,545.0$ & $49,665.0$ \\
\hline $2-5$ & -112.5 & -157.5 & 45.0 & 165.0 \\
\hline $6-10$ & -112.5 & -112.5 & 0.0 & 0.0 \\
\hline $11-20$ & -112.5 & -180.0 & 67.5 & 247.5 \\
\hline $21-30$ & -112.5 & -292.5 & 180.0 & 660.0 \\
\hline $31-40$ & -112.5 & -371.3 & 258.8 & 948.9 \\
\hline $41-49$ & -112.5 & -393.8 & 281.3 & $1,031.4$ \\
\hline 50 & -112.5 & $5,606.2$ & $-5,718.7$ & $-20,968.6$ \\
\hline
\end{tabular}

After they had completed the construction of the wooden bridges and replanted the harvested area, BTC submitted this projected stream of carbon dioxide flow reductions with its first report to the EPAct 1605(b) program. However, the company only reported the first year carbon dioxide flow reduction of 49,665 tons as an accomplishment. In each subsequent year, BTC confirmed that the project continued to perform as expected. To do this, the company simply checked that all 15 bridges continued in service (that is, they continued to store carbon, as projected) and that the reforested area continued to grow satisfactorily.

\subsubsection{Urban Forestry}

Forest management, practiced in large contiguous blocks generally to produce wood products, is a rural activity. When forestry is practiced in an urban setting, it provides an entirely different set of benefits. The primary focus of urban forestry is on modifying the landscape and environment dominated by manmade structures. (See Sampson, Moll, and Kielbaso 1992.) 
Urban forestry can influence greenhouse gas emissions by modifying the urban environment in two ways. Trees can directly reduce summer temperatures in their immediate surroundings. They can also reduce the electricity consumed for heating and air conditioning when placed at strategic locations around buildings. In addition, tree growth can capture carbon dioxide from the air in the form of woody biomass.

Two types of urban forestry activities are relevant to EPAct Section 1605(b). Both involve tree planting, but on two different scales. On a site-specific scale, trees may be planted to influence individual buildings. The second type of activity involves tree planting on a larger, perhaps community, scale. In this case, the effects of tree planting extend beyond the effects on individual buildings to address changes in the temperature regime of large urban areas (Akbari et al. 1990).

Urban forestry activities can have two principal effects on greenhouse gas emissions and carbon capture. One is carbon capture through tree growth. As with all forestation activities, urban trees also capture and store carbon in above- and below-ground components. They may also contribute to carbon uptake in soils. However, urban trees may require maintenance efforts-such as trimming and leaf collection-that need to be factored into the carbon flow accounts.

The other principal effect is the avoidance of greenhouse gas emissions through energy conservation. Simulation models have indicated that strategically located trees may provide two kinds of effects in this regard. One is through increased shading during peak cooling periods. Deciduous trees conveniently cast a great deal of shade during the growing season and much less during the winter. The other effect results from providing a windbreak during winter heating months. This effect can often be provided by conifers. Again, the location of the trees relative to the targeted building is a critical factor. (See Huang et al. 1989.)

Efforts are underway to develop a model that applies recent research on the energy conservation effects of urban tree cover to develop a spatial model, using geographic information system technology, for assessing energy and cost savings of various tree planting strategies at the neighborhood scale. The model is currently being tested in several locations through the Cool Communities program sponsored by the Federal government. When that model is fully developed, it may facilitate the analysis of the energy effects of urban forestry projects.

The measurement of carbon storage is directly analogous to that described for forest management activities. That is, carbon stored by trees is measured as the net increase above the previous land use (for example, lawn). This should account for both above- and below-ground components and all relevant tree maintenance activities.

Estimating reductions in greenhouse gas emissions through energy conservation involves estimating energy consumed with and without the project. This can be a complicated endeavor because many factors are variable over the life of the project. One source of variation is climate; the temperature regime differs from year to year. Another source of variation is additional modifications in the building that may influence energy consumption (and the energy saving contribution of trees). These

Forestry Sector-Page 5.41 
factors are key in developing a modified reference case as discussed in the supporting document for the residential and commercial buildings sector.

\section{Example 5.11 - Urban Tree Planting}

\section{Note: This example illustrates only one approach to analyzing a project; your analysis, methods, and calculations will vary depending on your particular circumstances, the geographic location of the project, and other factors.}

The Leafy Need Tree Cooperative initiated a tree-planting program in Greenway, a small town in Georgia. The program aimed to increase the shading of homes in this area, and trees have been planted in strategic locations around 500 homes at a rate of two trees per home.

While Leafy Need intended to monitor the energy consumed to heat and cool these homes, it would report its activities to DOE in its initial report. Accordingly, Leafy Need needed to estimate the project's net effects. Because this was not a standard project-that is, DOE does not provide standard data tables-Leafy Need had to develop its own forecast of energy savings and resulting reductions in greenhouse gas emissions.

After searching the literature, Leafy Need selected a study by McPherson, Sacamanoo, and Wensman (1993) for the project's estimates. This study examined similar tree-planting programs in several U.S. cities, including Atlanta, which is relatively close to Greenway.

In the initial year of the project there was obviously no effect on energy use. However, the McPherson report shows that after ten years two well-placed trees could reduce electricity used to cool a 1,761 square foot house by about $222 \mathrm{kWh}$ per year. However, heating needs increase about $609 \mathrm{kBtu}$ per year because of the trees. According to the Leafy Need's survey of heating equipment in Greenway, this translates into an increase in electricity use of $35 \mathrm{kWh}$ per year.

The net effect of the tree planting program in year 10 was therefore calculated as

$$
\text { Energy Saved }=500 \text { houses } \bullet(222-35) \mathrm{kWh} / \text { house } / \text { year }=93,500 \mathrm{kWh} / \text { year }
$$

However, this was the annual effect in year 10. Noting that there was no effect in year 1 of the activity; Leafy Need assumed that energy savings associated with this activity would increase in a straight line manner from zero in the initial year to $93,500 \mathrm{kWh} /$ year in the 10th year. So, for example, energy savings in the seventh year would be

$$
\begin{aligned}
\text { Energy Savings in year } 7 & =7 / 10(93,500) \mathrm{kWh} / \text { year } \\
& =65,450 \mathrm{kWh}
\end{aligned}
$$

Energy savings for each year can be converted to effects on carbon dioxide emissions using the standard conversion factors provided in Appendix $\mathrm{C}$ and discussed in Section 1.7 of the supporting document for the electricity supply sector.

The carbon dioxide factor for deriving carbon dioxide emissions reductions from electricity savings in Georgia from a combined utility/nonutility source is $1,220 \mathrm{lb} / \mathrm{MWh}$.

$$
\begin{aligned}
\mathrm{CO}_{2} \text { Emissions Reductions } & =\text { (Electricity Savings) } \bullet \text { (Emission Factor) } \\
& =65.45 \mathrm{MWh} \bullet 1,220 \mathrm{lb} / \mathrm{MWh} \bullet \text { short tons } / 2,000 \mathrm{lb} \\
& =39.9 \text { short tons of } \mathrm{CO}_{2} \text { per year }
\end{aligned}
$$

To finish the calculation of net greenhouse emission effects of its program, Leafy Need next factored in the direct carbon dioxide emissions that resulted from its tree planting efforts-equal to about 25 tons of carbon dioxide. This was reported as an emission in the initial year. These resulted mainly from the truck used to haul trees and labor to planting sites. In addition, the trees required maintenance including leaf disposal and trimming. Leafy Need documented its maintenance plan and estimated the maintenance program to result in 5 tons of carbon dioxide emissions per year. Accordingly, Leafy Need estimated the effects in the seventh year of the program as a 34.9 short ton reduction in net flows of carbon dioxide. Each year, Leafy Need verified that its program continued to operate as expected, calculated its annual emissions reductions, and submitted an annual report to the EPAct $1605(\mathrm{~b})$ program. 
All of these factors need to be accounted for in estimating the effects of tree planting on energy consumption. Once this estimate has been made, the concomitant reduction in greenhouse gas emissions can be calculated as a multiple of the energy saved. The factors applied will depend on the type of fuel displaced.

Estimating the effects of large scale programs aimed at reducing the ambient temperatures of urban areas would follow the same types of methods. However, an additional layer of analysis will be required. That is, the effect of the tree planting program on average temperature levels would be estimated and then applied to all buildings in the relevant neighborhood of the project. For detailed information on how to estimate the effects of urban forestry activfties, see McPherson et al. (1993).

\subsection{References}

Akbari, H., A.H. Rosenfeld, and H. Taha. 1990. Summer heat islands, urban trees, and white surfaces. In American Society for Heating, Refrigeration, and Air-conditioning Engineers, Winter 1990, pp. 1-10.

Akbari, H. et al. 1992. Cooling our Communities: A guidebook on tree planting and light colored surfacing. U.S. Environmental Protection Agency, Office of Policy Analysis, Climate Change Division, Washington, DC.

Birch, T.W., D.G. Lewis, and H.F. Kaiser. 1982. The private forest-land owners of the United States. Resource Bulletin WO-1. USDA Forest Service, Washington DC.

Birdsey, R.A. 1992b. Changes in forest carbon storage from increasing forest area and timber growth. In Forests and Global Change, eds. R.N. Sampson and D. Hair, American Forests, Washington, DC, pp 23-40.

Birdsey, R.A., A.J. Plantingam, and L.S. Heath. 1993. Past and prospective carbon storage in United States forests. Forest Ecology and Management 58 (1993), pp. 33-40.

Birdsey, R.A. 1992. Carbon storage and accumulation in United States forest ecosystems. USDA Forest Service General Technical Report, Northeastern Forest Experiment Station, pp. 1-51.

Cubbage, F.W., J. O'Laughlin, and S.S. Bullock. 1993. Forest Resource Policy. John Wiley and Sons, New York.

Dixon, R.K., K.J. Andrasko, F.G. Sussman, M.A. Lavinson, M.C. Trexler, and T.S. Vinson. 1993. Forest sector carbon offset projects: near-term opportunities to mitigate greenhouse gas emissions. Water, Air, and Soil Pollution, July-August, pp. 1-17.

Graham, R.L. and L.L. Wright. 1992. The potential for short-rotation woody crops to reduce U.S. $\mathrm{CO}_{2}$ emissions. Climate Change 22:223-238. 
Huang, Y.J., H. Akbari, and H. Taha. 1989. The wind-shielding and shading effects of trees on residential heating and cooling requirements. In American Society for Heating, Refrigeration, and Airconditioning Engineers, January 1990.

Marland, G. and S. Marland. 1992. Should we store carbon in trees? Water, Air and Soil Pollution 64 (1992). pp. 181-195.

McPherson, E.G., P. Sacamano, and S. Wensman. 1993. Modeling benefits and costs of community tree plantings. USDA Forest Service, Northeastern Forest Experiment Station, pp. 1-169.

Moulton, R.J. and K.R. Richards. 1990. Costs of sequestering carbon through tree planting and forest management in the United States. USDA General Technical Report WO-58, USDA, Washington, DC, pp. 1-44.

Plantinga, A.J. and R.A. Birdsey. 1993. Carbon fluxes resulting from U.S. private timberland management. Climatic Change 23 (1993), pp. 37-53.

Ranney, J.W., L.L. Wright, C.P. Mitchell. 1991. "Carbon Storage and Recycling in Short-Rotation Energy Crops." In Proceedings, International Energy Agency, Bioenergy Agreement, Task 5, Executive Committee Meeting, July 1991, Uppsala, Sweden. Swedish University of Agricultural Sciences.

Richards, K.R., R.J. Moulton, and R.A. Birdsey. 1993. "Costs of creating carbon sinks in the U.S." Chapter in Proceedings of the International Energy Agency Carbon Dioxide Disposal Symposium, ed. P. Riemer, pp. 905-912. Pergamon Press, Oxford.

Sampson, R.N. and D. Hair. 1992. Forests and global change. Volume One: Opportunities for Increasing Forest Cover. American Forests, Washington, DC, pp. 23-39 and appendices.

Sampson, R.N., G.A. Moll, and J.J. Kielbaso. 1992. Increasing tree numbers and canopy cover in urban and community forests. In Forests and Global Change, eds. R.N. Sampson and D. Hair, pp. 51-72. American Forests, Washington, DC.

Wright, L.L., R.L. Graham, A.F. Turhollow, and B.C. English. 1992. "The Potential Impacts of Short-Rotation Woody Crops on Carbon Conservation." In Forests and Global Changes, eds., R.N. Sampson and D. Hair, pp. 123-156. American Forests, Washington, DC. 
Appendix 5.A

Tables for Standard Tree Planting Procedures 


\section{Appendix 5.A: Tables for Standard Tree Planting Procedures}

The tables presented in this appendix were developed using general methods described in Birdsey (1992, p. 255-257). Carbon storage was estimated for each of the four forest ecosystem components defined in Section 5.4.3: trees, soil, forest flow, and understory vegetation. Tree carbon was estimated using timber volume yields for the United States derived from national forest inventories conducted by the U.S. Forest Service. Volumes were converted to carbon storage using ratios that account for tops, branches, foliage, and other material not included in timber volume estimates. These ratios also account for differences in tree sizes and differences among tree species and regions.

Carbon storage estimates for the non-tree components of the forest ecosystem were developed using methods and data available in several published studies. These estimates account for important regional differences owing mainly to differences in precipitation and temperature. For details on all of these methods, refer to Birdsey (1992). 
List of Tables:

\begin{tabular}{|c|c|c|c|c|c|}
\hline $\begin{array}{c}\text { Table } \\
\text { no. }\end{array}$ & Region & Species & $\begin{array}{c}\text { Site } \\
\text { Quality }\end{array}$ & Land Status & Access Code \\
\hline 1. & Southeast & Planted Pine & High & Clearcut forest & 1111 \\
\hline 2. & Southeast & Planted Pine & High & Cropland & 1112 \\
\hline 3. & Southeast & Planted Pine & Medium & Clearcut Forest & 1121 \\
\hline 4. & Southeast & Planted Pine & Medium & Pasture & 1123 \\
\hline 5. & South Central & Planted Pine & High & Clearcut forest & 2111 \\
\hline 6. & South Central & Planted Pine & High & Cropland & 2112 \\
\hline 7. & South Central & Planted Pine & Medium & Clearcut forest & 2121 \\
\hline 8. & South Central & Planted Pine & Medium & Pasture & 2123 \\
\hline 9. & Northeast & White/red Pine & All & Clearcut forest & $3111 ; 3121$ \\
\hline 10. & Northeast & White/red Pine & All & Cropland & $3112 ; 3122$ \\
\hline 11. & Northeast & White/red Pine & All & Pasture & $3113 ; 3123$ \\
\hline 12. & Northeast & Spruce-Fir & All & Clearcut forest & $3211 ; 3221$ \\
\hline 13. & Northeast & Spruce-Fir & All & Cropland & $3212 ; 3222$ \\
\hline 14. & Northeast & Spruce-Fir & All & Pasture & $3213 ; 3223$ \\
\hline 15. & Lake States & White/red Pine & All & Clearcut forest & $5111 ; 5121$ \\
\hline 16. & Lake States & White/red Pine & All & Cropland & $5112 ; 5122$ \\
\hline 17. & Lake States & White/red Pine & All & Pasture & $5113 ; 5123$ \\
\hline 18. & Lake States & Spruce-Fir & All & Clearcut forest & $5211 ; 5221$ \\
\hline 19. & Lake States & Spruce-Fir & All & Cropland & $5212 ; 5222$ \\
\hline 20. & Lake States & Spruce-Fir & All & Pasture & $5213 ; 5223$ \\
\hline 21. & Central States & White/red Pine & All & Clearcut forest & $6111 ; 6121$ \\
\hline 22. & Central States & White/red Pine & All & Cropland & $6112 ; 6122$ \\
\hline 23. & Central States & White/red Pine & All & Pasture & $6113 ; 6123$ \\
\hline 24. & Central States & Oak-Hickory & All & Clearcut forest & $6211 ; 6221$ \\
\hline 25. & Central States & Oak-Hickory & All & Cropland & $6212 ; 6222$ \\
\hline 26. & Central States & Oak-Hickory & All & Pasture & $6213 ; 6223$ \\
\hline 27. & Rocky Mtn-North & Ponderosa Pine & All & Clearcut forest & $7111 ; 7121$ \\
\hline
\end{tabular}

Tables for Standard Projects-Page A.2 


\begin{tabular}{||c|l|l|l|l|l||}
\hline $\begin{array}{c}\text { Table } \\
\text { no. }\end{array}$ & \multicolumn{1}{|c|}{ Region } & \multicolumn{1}{|c|}{ Species } & \multicolumn{1}{c|}{$\begin{array}{c}\text { Site } \\
\text { Quality }\end{array}$} & \multicolumn{1}{c|}{ Land Status } & \multicolumn{1}{c|}{ Access Code } \\
\hline 28. & Rocky Mtn-North & Ponderosa Pine & All & Cropland & $7112 ; 7122$ \\
\hline 29. & Rocky Mtn-North & Ponderosa Pine & All & Pasture & $7113 ; 7123$ \\
\hline 30. & Rocky Mtn-South & Ponderosa Pine & All & Clearcut forest & $8111 ; 8121$ \\
\hline 31. & Rocky Mtn-South & Ponderosa Pine & All & Cropland & $8112 ; 8122$ \\
\hline 32. & Rocky Mtn-South & Ponderosa Pine & All & Pasture & $8113 ; 8123$ \\
\hline 33. & Pacific Northwest & Douglas Fir & High & Clearcut Forest & 9111 \\
\hline 34. & Pacific Northwest & Douglas Fir & Medium & Clearcut Forest & 9121 \\
\hline 35. & Pacific Northwest & Douglas Fir & High & Cropland & 9112 \\
\hline 36. & Pacific Northwest & Douglas Fir & Medium & Pasture & 9123 \\
\hline 37. & Pacific Northwest & Ponderosa Pine & All & Clearcut Forest & $9211 ; 9221$ \\
\hline 38. & Pacific Northwest & Ponderosa Pine & All & Cropland & $9212 ; 9222$ \\
\hline 39. & Pacific Northwest & Ponderosa Pine & All & Pasture & $9213 ; 9223$ \\
\hline \hline
\end{tabular}

Tables for Standard Projects-Page A.3 


\begin{tabular}{|c|c|c|c|c|c|c|c|}
\hline \multicolumn{7}{|c|}{ 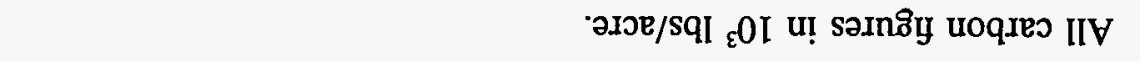 } & \multirow{2}{*}{$\frac{\text { :GLON }}{\text { OOI }}$} \\
\hline$\varepsilon$ & $6 \oplus \tau$ & 9I & $9 \varepsilon Z$ & $82^{-}$ & 082 & ZSZ & \\
\hline$\varepsilon$ & $8 \triangleright 2$ & $\angle I$ & $\downarrow \varepsilon Z$ & $\angle Z^{-}$ & $8 L Z$ & ISZ & 06 \\
\hline 9 & $t \nabla \tau$ & $\tau Z$ & $8 z 2$ & $0 z^{-}$ & $0<Z$ & $0 S Z$ & 08 \\
\hline 6 & $\triangleright \varepsilon \mathcal{Z}$ & $\tau \varepsilon$ & IIZ & s- & $8 \nabla z$ & $\varepsilon \triangleright \tau$ & $0 L$ \\
\hline $6 \mathrm{I}$ & tIZ & $8 \varepsilon$ & S6I & 8 & $\$ Z Z$ & $\varepsilon \varepsilon Z$ & 09 \\
\hline 62 & I6I & 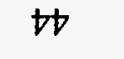 & $9 L I$ & 02 & $00 Z$ & $0 z 2$ & $0 S$ \\
\hline$\varsigma \varepsilon$ & $\angle 9 I$ & $9 t$ & $9 S I$ & $\varepsilon \varepsilon$ & $69 I$ & 202 & $0 t$ \\
\hline It & $8 \varepsilon \mathrm{I}$ & St & $\downarrow \varepsilon I$ & $t$ & SEI & $6 L I$ & $0 \varepsilon$ \\
\hline$s t$ & $\varepsilon 6$ & $\varepsilon \varepsilon$ & SOI & $L \varepsilon$ & IOI & $8 \varepsilon I$ & $0 z$ \\
\hline OI & t9 & OI & t9 & $z$ & $Z L$ & $\nabla L$ & OI \\
\hline$\varepsilon$ & $\angle 9$ & $\varepsilon$ & $\angle 9$ & $I$ & 69 & $0 L$ & $S$ \\
\hline 0 & 69 & 0 & 69 & 0 & 69 & 69 & 0 \\
\hline 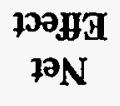 & $\begin{array}{l}\text { parots } \\
\text { uoqux }\end{array}$ & 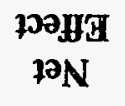 & $\begin{array}{c}\text { paxols } \\
\text { uoq.re }\end{array}$ & 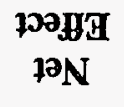 & $\begin{array}{l}\text { parois } \\
\text { uoqxeD }\end{array}$ & 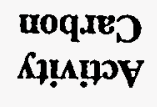 & ว8ี \\
\hline \multicolumn{2}{|c|}{ АлоҮग!Н ХеО } & \multicolumn{2}{|c|}{ әu!d YEO } & \multicolumn{2}{|c|}{ әu!d [exme } & & \\
\hline \multicolumn{6}{|c|}{ 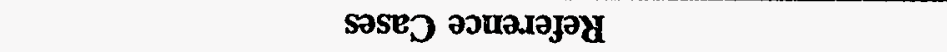 } & & \\
\hline
\end{tabular}


Table 5.E.2. Region: Southeast; Site: High; Access Code: 1112; Species: Southern Pines-Planted; Land Status: Cropland

\begin{tabular}{|c|c|c|c|}
\hline \multirow[b]{3}{*}{ Age } & \multirow[b]{3}{*}{$\begin{array}{l}\text { Activity } \\
\text { Carbon }\end{array}$} & \multirow{2}{*}{\multicolumn{2}{|c|}{$\frac{\text { Reference Cases }}{\text { Cropland }}$}} \\
\hline & & & \\
\hline & & $\begin{array}{l}\text { Carbon } \\
\text { Stored }\end{array}$ & $\begin{array}{c}\text { Net } \\
\text { Effect }\end{array}$ \\
\hline 0 & 35 & 35 & 0 \\
\hline 5 & 45 & 35 & 10 \\
\hline 10 & 57 & 35 & 22 \\
\hline 20 & 109 & 35 & 74 \\
\hline 30 & 142 & 35 & 107 \\
\hline 40 & 169 & 35 & 134 \\
\hline 50 & 193 & 35 & 158 \\
\hline 60 & 217 & 35 & 182 \\
\hline 70 & 238 & 35 & 203 \\
\hline 80 & 247 & 35 & 212 \\
\hline 90 & 249 & 35 & 214 \\
\hline 100 & 249 & 35 & 214 \\
\hline
\end{tabular}


Table 5.E.3. Region: Southeast; Site: Medium; Access Code: 1121; Species: Southern Pines-Planted; Land Status: Clearcut Forest

\begin{tabular}{|c|c|c|c|c|c|c|c|c|c|}
\hline \multirow[b]{3}{*}{ Age } & \multirow[b]{3}{*}{$\begin{array}{l}\text { Activity } \\
\text { Carbon }\end{array}$} & \multicolumn{8}{|c|}{ Reference Cases } \\
\hline & & \multicolumn{2}{|c|}{ Natural Pine } & \multicolumn{2}{|c|}{ Oak Pine } & \multicolumn{2}{|c|}{ Oak Hickory } & \multicolumn{2}{|c|}{$\begin{array}{l}\text { Bottomland } \\
\text { Hardwd }\end{array}$} \\
\hline & & $\begin{array}{l}\text { Carbon } \\
\text { Stored }\end{array}$ & $\begin{array}{c}\text { Net } \\
\text { Effect }\end{array}$ & $\begin{array}{l}\text { Carbon } \\
\text { Stored }\end{array}$ & $\begin{array}{c}\text { Net } \\
\text { Effect }\end{array}$ & $\begin{array}{l}\text { Carbon } \\
\text { Stored }\end{array}$ & $\begin{array}{c}\text { Net } \\
\text { Effect }\end{array}$ & $\begin{array}{l}\text { Carbon } \\
\text { Stored }\end{array}$ & $\begin{array}{c}\text { Net } \\
\text { Effect }\end{array}$ \\
\hline 0 & 69 & 69 & 0 & 69 & 0 & 69 & 0 & 69 & 0 \\
\hline 5 & 69 & 68 & 1 & 67 & 2 & 67 & 2 & 65 & 4 \\
\hline 10 & 68 & 68 & 0 & 63 & 5 & 63 & 5 & 60 & 8 \\
\hline 20 & 116 & 88 & 28 & 90 & 26 & 83 & 33 & 81 & 35 \\
\hline 30 & 153 & 112 & 41 & 114 & 39 & 118 & 35 & 121 & 32 \\
\hline 40 & 175 & 135 & 40 & 132 & 43 & 141 & 34 & 144 & 31 \\
\hline 50 & 191 & 157 & 34 & 145 & 46 & 159 & 32 & 162 & 29 \\
\hline 60 & 201 & 179 & 22 & 159 & 42 & 176 & 25 & 177 & 24 \\
\hline 70 & 210 & 198 & 12 & 169 & 41 & 192 & 18 & 190 & 20 \\
\hline 80 & 215 & 212 & 3 & 178 & 37 & 202 & 13 & 200 & 15 \\
\hline 90 & 217 & 217 & 0 & 181 & 36 & 206 & 11 & 204 & 13 \\
\hline 100 & 218 & 218 & 0 & 182 & 36 & 206 & 12 & 205 & 13 \\
\hline
\end{tabular}


Table 5.E.4. Region: Southeast; Site: High; Access Code: 1123; Species: Southern Pines-Planted; Land Status: Pasture

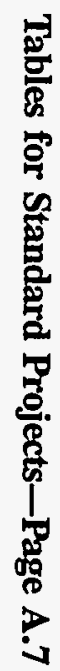

\begin{tabular}{|c|c|c|c|}
\hline \multirow[b]{3}{*}{ Age } & \multirow[b]{3}{*}{$\begin{array}{l}\text { Activity } \\
\text { Carbon }\end{array}$} & \multicolumn{2}{|c|}{ Reference Cases } \\
\hline & & \multicolumn{2}{|c|}{ Pasture } \\
\hline & & $\begin{array}{l}\text { Carbon } \\
\text { Stored }\end{array}$ & $\begin{array}{c}\text { Net } \\
\text { Effect }\end{array}$ \\
\hline 0 & 46 & 46 & 0 \\
\hline 5 & 54 & 46 & 8 \\
\hline 10 & 59 & 46 & 13 \\
\hline 20 & 97 & 46 & 51 \\
\hline 30 & 127 & 46 & 81 \\
\hline 40 & 151 & 46 & 105 \\
\hline 50 & 174 & 46 & 128 \\
\hline 60 & 192 & 46 & 146 \\
\hline 70 & 208 & 46 & 162 \\
\hline 80 & 212 & 46 & 166 \\
\hline 90 & 214 & 46 & 168 \\
\hline 100 & 214 & 46 & 168 \\
\hline
\end{tabular}


Table 5.E.5. Region: South Central; Site: High; Access Code: 1111; Species: Southern Pines-Planted; Land Status: Clearcut Forest

\begin{tabular}{|c|c|c|c|c|c|c|c|c|c|}
\hline \multirow[b]{3}{*}{ Age } & \multirow[b]{3}{*}{$\begin{array}{l}\text { Activity } \\
\text { Carbon }\end{array}$} & \multicolumn{8}{|c|}{ Reference Cases } \\
\hline & & \multicolumn{2}{|c|}{ Natural Pine } & \multicolumn{2}{|c|}{ Oak Pine } & \multicolumn{2}{|c|}{ Oak Hickory } & \multicolumn{2}{|c|}{$\begin{array}{l}\text { Bottomland } \\
\text { Hdwd }\end{array}$} \\
\hline & & $\begin{array}{l}\text { Carbon } \\
\text { Stored }\end{array}$ & $\begin{array}{l}\text { Net } \\
\text { Effect }\end{array}$ & $\begin{array}{l}\text { Carbon } \\
\text { Stored }\end{array}$ & $\begin{array}{c}\text { Net } \\
\text { Effect }\end{array}$ & $\begin{array}{l}\text { Carbon } \\
\text { Stored }\end{array}$ & $\begin{array}{c}\text { Net } \\
\text { Effect }\end{array}$ & $\begin{array}{l}\text { Carbon } \\
\text { Stored }\end{array}$ & $\begin{array}{l}\text { Net } \\
\text { Effect }\end{array}$ \\
\hline 0 & 68 & 68 & 0 & 68 & 0 & 68 & 0 & 68 & 0 \\
\hline 5 & 69 & 69 & 0 & 66 & 3 & 66 & 3 & 64 & 5 \\
\hline 10 & 77 & 75 & 2 & 65 & 12 & 64 & 13 & 65 & 12 \\
\hline 20 & 144 & 110 & 34 & 112 & 32 & 95 & 49 & 119 & 25 \\
\hline 30 & 187 & 150 & 37 & 148 & 39 & 143 & 44 & 164 & 23 \\
\hline 40 & 213 & 184 & 29 & 174 & 39 & 172 & 41 & 194 & 19 \\
\hline 50 & 233 & 212 & 21 & 197 & 36 & 194 & 39 & 218 & 15 \\
\hline 60 & 244 & 240 & 4 & 220 & 24 & 212 & 32 & 240 & 4 \\
\hline 70 & 250 & 262 & -12 & 239 & 11 & 226 & 24 & 261 & -11 \\
\hline 80 & 254 & 285 & -31 & 257 & -3 & 238 & 16 & 280 & -26 \\
\hline 90 & 255 & 293 & -38 & 264 & -9 & 242 & 13 & 287 & -32 \\
\hline 100 & 255 & 295 & -40 & 265 & -10 & 243 & 12 & 288 & -33 \\
\hline
\end{tabular}


Table 5.E.6. Region: South Central; Site: High; Access Code: 1112; Species: Southern Pines-Planted; Land Status: Cropland

\begin{tabular}{|c|c|c|c|}
\hline \multirow[b]{3}{*}{ Age } & \multirow[b]{3}{*}{$\begin{array}{l}\text { Activity } \\
\text { Carbon }\end{array}$} & \multirow{2}{*}{\multicolumn{2}{|c|}{$\frac{\text { Reference Cases }}{\text { Cropland }}$}} \\
\hline & & & \\
\hline & & $\begin{array}{l}\text { Carbon } \\
\text { Stored }\end{array}$ & $\begin{array}{c}\text { Net } \\
\text { Effect }\end{array}$ \\
\hline 0 & 34 & 34 & 0 \\
\hline 5 & 44 & 34 & 10 \\
\hline 10 & 59 & 34 & 25 \\
\hline 20 & 116 & 34 & 82 \\
\hline 30 & 150 & 34 & 116 \\
\hline 40 & 179 & 34 & 145 \\
\hline 50 & 204 & 34 & 170 \\
\hline 60 & 222 & 34 & 188 \\
\hline 70 & 229 & 34 & 195 \\
\hline 80 & 233 & 34 & 199 \\
\hline 90 & 234 & 34 & 200 \\
\hline 100 & 235 & 34 & 201 \\
\hline NOTE: & All carbo & es in 10 & /acre. \\
\hline
\end{tabular}


Table 5.E.7. Region: South Central; Site: Medium; Access Code: 2121; Species: Southern Pines-Planted; Land Status: Clearcut Forest

\begin{tabular}{|c|c|c|c|c|c|c|c|c|c|}
\hline \multirow[b]{3}{*}{ Age } & \multirow[b]{3}{*}{$\begin{array}{l}\text { Activity } \\
\text { Carbon }\end{array}$} & \multicolumn{8}{|c|}{ Reference Cases } \\
\hline & & \multicolumn{2}{|c|}{ Natural Pine } & \multicolumn{2}{|c|}{ Oak Pine } & \multicolumn{2}{|c|}{ Oak Hickory } & \multicolumn{2}{|c|}{$\begin{array}{c}\text { Bottomland } \\
\text { Hdwd }\end{array}$} \\
\hline & & $\begin{array}{l}\text { Carbon } \\
\text { Stored }\end{array}$ & $\begin{array}{c}\text { Net } \\
\text { Effect }\end{array}$ & $\begin{array}{l}\text { Carbon } \\
\text { Stored }\end{array}$ & $\begin{array}{c}\text { Net } \\
\text { Effect }\end{array}$ & $\begin{array}{l}\text { Carbon } \\
\text { Stored }\end{array}$ & $\begin{array}{c}\text { Net } \\
\text { Effect }\end{array}$ & $\begin{array}{l}\text { Carbon } \\
\text { Stored }\end{array}$ & $\begin{array}{c}\text { Net } \\
\text { Effect }\end{array}$ \\
\hline 0 & 68 & 68 & 0 & 68 & 0 & 68 & 0 & & 68 \\
\hline 5 & 67 & 67 & 0 & 66 & 1 & 66 & 1 & & 67 \\
\hline 10 & 68 & 70 & -2 & 63 & 5 & 63 & 5 & & 68 \\
\hline 20 & 121 & 92 & 29 & 93 & 28 & 90 & 31 & & 121 \\
\hline 30 & 160 & 119 & 41 & 122 & 38 & 125 & 35 & & 160 \\
\hline 40 & 185 & 142 & 43 & 144 & 41 & 150 & 35 & & 185 \\
\hline 50 & 201 & 164 & 37 & 158 & 43 & 169 & 32 & & 201 \\
\hline 60 & 211 & 187 & 24 & 172 & 39 & 184 & 27 & & 211 \\
\hline 70 & 217 & 204 & 13 & 183 & 34 & 197 & 20 & & 217 \\
\hline 80 & 221 & 215 & 6 & 193 & 28 & 207 & 14 & & 221 \\
\hline 90 & 223 & 219 & 4 & 197 & 26 & 211 & 12 & & 223 \\
\hline 100 & 223 & 220 & 3 & 198 & 25 & 212 & 11 & & 223 \\
\hline
\end{tabular}


Table 5.E.8. Region: South Central; Site: Medium; Access Code: 2123; Species: Southern Pines-Planted; Land Status: Pasture

\begin{tabular}{|c|c|c|c|}
\hline \multirow[b]{3}{*}{ Age } & \multirow[b]{3}{*}{$\begin{array}{l}\text { Activity } \\
\text { Carbon }\end{array}$} & \multirow{2}{*}{\multicolumn{2}{|c|}{$\frac{\text { Reference Cases }}{\text { Pasture }}$}} \\
\hline & & & \\
\hline & & $\begin{array}{l}\text { Carbon } \\
\text { Stored }\end{array}$ & $\begin{array}{c}\text { Net } \\
\text { Effect }\end{array}$ \\
\hline 0 & 45 & 45 & 0 \\
\hline 5 & 53 & 45 & 8 \\
\hline 10 & 59 & 45 & 14 \\
\hline 20 & 100 & 45 & 55 \\
\hline 30 & 133 & 45 & 88 \\
\hline 40 & 159 & 45 & 114 \\
\hline 50 & 181 & 45 & 136 \\
\hline 60 & 195 & 45 & 150 \\
\hline 70 & 201 & 45 & 156 \\
\hline 80 & 204 & 45 & 159 \\
\hline 90 & 205 & 45 & 160 \\
\hline 100 & 205 & 45 & 160 \\
\hline \multicolumn{4}{|c|}{ NOTE: All carbon figures in $10^{3} \mathrm{lbs} /$ acre. } \\
\hline
\end{tabular}


Table 5.E.9. Region: Northeast; Site: All; Access Code: 3111, 3121; Species: White/Red Pine; Land Status: Clearcut Forest

\begin{tabular}{|rr|cc|cc||}
\hline \multirow{2}{*}{} & & \multicolumn{4}{|c|}{ Reference Cases } \\
\cline { 3 - 6 } Age & Activity & Carbon & Spruce - Fir & Maple-Beech-Birch \\
\cline { 3 - 6 } & Ctored & $\begin{array}{c}\text { Net } \\
\text { Effect }\end{array}$ & $\begin{array}{c}\text { Carbon } \\
\text { Stored }\end{array}$ & $\begin{array}{c}\text { Net } \\
\text { Effect }\end{array}$ \\
\hline 0 & 152 & 152 & 0 & 150 & 2 \\
5 & 149 & 147 & 2 & 146 & 3 \\
10 & 147 & 140 & 7 & 142 & 5 \\
20 & 155 & 142 & 13 & 150 & 5 \\
30 & 177 & 160 & 17 & 173 & 4 \\
40 & 197 & 179 & 18 & 197 & 0 \\
50 & 217 & 198 & 19 & 220 & -3 \\
60 & 236 & 217 & 19 & 241 & -5 \\
70 & 253 & 234 & 19 & 262 & -9 \\
80 & 269 & 249 & 20 & 280 & -11 \\
90 & 284 & 263 & 21 & 297 & -13 \\
100 & 297 & 276 & 21 & 312 & -15 \\
\hline NOTE: & All carbon figures in 103 lbs/acre. & \\
\hline
\end{tabular}


Table 5.E.10. Region: Northeast; Site: All; Access Code: 3112, 3122; Species: White/Red Pine; Land Status: Cropland

\begin{tabular}{|c|c|c|c|}
\hline \multirow[b]{3}{*}{ Age } & \multirow[b]{3}{*}{$\begin{array}{l}\text { Activity } \\
\text { Carbon }\end{array}$} & \multirow{2}{*}{\multicolumn{2}{|c|}{$\begin{array}{c}\text { Reference Cases } \\
\text { Cropland }\end{array}$}} \\
\hline & & & \\
\hline & & $\begin{array}{l}\text { Carbon } \\
\text { Stored }\end{array}$ & $\begin{array}{c}\text { Net } \\
\text { Effect }\end{array}$ \\
\hline 0 & 72 & 72 & 0 \\
\hline 5 & 85 & 72 & 13 \\
\hline 10 & 99 & 72 & 27 \\
\hline 20 & 126 & 72 & 54 \\
\hline 30 & 152 & 72 & 80 \\
\hline 40 & 178 & 72 & 106 \\
\hline 50 & 203 & 72 & 131 \\
\hline 60 & 227 & 72 & 155 \\
\hline 70 & 249 & 72 & 177 \\
\hline 80 & 268 & 72 & 196 \\
\hline 90 & 284 & 72 & 212 \\
\hline 100 & 298 & 72 & 226 \\
\hline
\end{tabular}


Table 5.E.11. Region: Northeast; Site: All; Access Code: 3123; 3113; Species: White/Red Pine; Land Status: Pasture

\begin{tabular}{|rr|cc||}
\hline \multirow{2}{*}{} & & \multicolumn{2}{|c|}{ Reference Cases } \\
\cline { 3 - 4 } Age & Activity & \multicolumn{2}{|c|}{ Pasture } \\
\cline { 3 - 4 } 0 & 96 & $\begin{array}{c}\text { Carbon } \\
\text { Stored }\end{array}$ & $\begin{array}{c}\text { Net } \\
\text { Effect }\end{array}$ \\
\hline 5 & 108 & 96 & 0 \\
10 & 121 & 96 & 12 \\
20 & 145 & 96 & 25 \\
30 & 169 & 96 & 49 \\
40 & 193 & 96 & 97 \\
50 & 215 & 96 & 119 \\
60 & 237 & 96 & 141 \\
70 & 255 & 96 & 159 \\
80 & 270 & 96 & 174 \\
90 & 284 & 96 & 188 \\
100 & 296 & 96 & 200 \\
\hline NOTE: & All carbon figures in 10 & \\
\hline
\end{tabular}


Table 5.E.12. Region: Northeast; Site: All; Access Code: 3211, 3221; Species: Spruce-Fir; Land Status: Clearcut Forest

\begin{tabular}{|c|c|c|c|c|c|}
\hline \multirow[b]{3}{*}{ Age } & \multirow[b]{3}{*}{$\begin{array}{l}\text { Activity } \\
\text { Carbon }\end{array}$} & \multicolumn{4}{|c|}{ Reference Cases } \\
\hline & & \multicolumn{2}{|c|}{ White/red Pine } & \multicolumn{2}{|c|}{ Maple-Beech-Birch } \\
\hline & & $\begin{array}{l}\text { Carbon } \\
\text { Stored }\end{array}$ & $\begin{array}{c}\text { Net } \\
\text { Effect }\end{array}$ & $\begin{array}{l}\text { Carbon } \\
\text { Stored } \\
\end{array}$ & $\begin{array}{c}\text { Net } \\
\text { Effect }\end{array}$ \\
\hline 0 & 152 & 152 & 0 & 150 & 2 \\
\hline 5 & 147 & 149 & -2 & 146 & 1 \\
\hline 10 & 140 & 147 & -7 & 142 & -2 \\
\hline 20 & 142 & 155 & -13 & 150 & -8 \\
\hline 30 & 160 & 177 & -17 & 173 & -13 \\
\hline 40 & 179 & 197 & -18 & 197 & -18 \\
\hline 50 & 198 & 217 & -19 & 220 & -22 \\
\hline 60 & 217 & 236 & -19 & 241 & -24 \\
\hline 70 & 234 & 253 & -19 & 262 & -28 \\
\hline 80 & 249 & 269 & -20 & 280 & -31 \\
\hline 90 & 263 & 284 & -21 & 297 & -34 \\
\hline 100 & 276 & 297 & -21 & 312 & -36 \\
\hline
\end{tabular}


Table 5.E.13. Region: Northeast; Site: All; Access Code: 3212, 3222; Species: Spruce-Fir; Land Status: Cropland

\begin{tabular}{|rc|cc||}
\hline \multirow{2}{*}{} & & \multicolumn{2}{|c|}{ Reference Cases } \\
\cline { 3 - 4 } Age & Activity & \multicolumn{2}{|c|}{ Cropland } \\
\cline { 3 - 4 } & Carbon & $\begin{array}{c}\text { Carbon } \\
\text { Stored }\end{array}$ & $\begin{array}{c}\text { Net } \\
\text { Effect }\end{array}$ \\
\hline 0 & 72 & 72 & 0 \\
5 & 83 & 72 & 11 \\
10 & 92 & 72 & 20 \\
20 & 113 & 72 & 41 \\
30 & 136 & 72 & 64 \\
40 & 160 & 72 & 88 \\
50 & 185 & 72 & 113 \\
60 & 209 & 72 & 137 \\
70 & 230 & 72 & 158 \\
80 & 248 & 72 & 176 \\
90 & 262 & 72 & 190 \\
100 & 275 & 72 & 203 \\
\hline NOTE: & All carbon figures in $10^{3}$ lbs/acre. \\
\hline
\end{tabular}


Table 5.E.14. Region: Northeast; Site: All; Access Code: 3223; 3213; Species: Spruce-Fir; Land Status: Pasture

\begin{tabular}{|c|c|c|c|}
\hline \multirow[b]{3}{*}{ Age } & \multirow[b]{3}{*}{$\begin{array}{l}\text { Activity } \\
\text { Carbon }\end{array}$} & \multirow{2}{*}{\multicolumn{2}{|c|}{$\frac{\text { Reference Cases }}{\text { Pasture }}$}} \\
\hline & & & \\
\hline & & $\begin{array}{l}\text { Carbon } \\
\text { Stored }\end{array}$ & $\begin{array}{l}\text { Net } \\
\text { Effect }\end{array}$ \\
\hline 0 & 96 & 96 & 0 \\
\hline 5 & 106 & 96 & 10 \\
\hline 10 & 114 & 96 & 18 \\
\hline 20 & 132 & 96 & 36 \\
\hline 30 & 153 & 96 & 57 \\
\hline 40 & 175 & 96 & 79 \\
\hline 50 & 197 & 96 & 101 \\
\hline 60 & 217 & 96 & 121 \\
\hline 70 & 234 & 96 & 138 \\
\hline 80 & 249 & 96 & 153 \\
\hline 90 & 262 & 96 & 166 \\
\hline 100 & 273 & 96 & 177 \\
\hline
\end{tabular}


Table 5.E.15. Region: Lake States; Site: All; Access Code: 5111, 5121; Species: White/Red Pine; Land Status: Clearcut Forest

\begin{tabular}{|c|c|c|c|c|c|c|c|c|c|}
\hline \multirow[b]{3}{*}{ Age } & \multirow[b]{3}{*}{$\begin{array}{l}\text { Activity } \\
\text { Carbon } \\
\end{array}$} & \multicolumn{8}{|c|}{ Reference Cases } \\
\hline & & \multicolumn{2}{|c|}{ Spruce - Fir } & \multicolumn{2}{|c|}{ Maple-Beech } & \multicolumn{2}{|c|}{ Aspen-Birch } & \multicolumn{2}{|c|}{$\begin{array}{l}\text { Bottomland } \\
\text { Hdwd }\end{array}$} \\
\hline & & $\begin{array}{l}\text { Carbon } \\
\text { Stored }\end{array}$ & $\begin{array}{c}\text { Net } \\
\text { Effect }\end{array}$ & $\begin{array}{l}\text { Carbon } \\
\text { Stored }\end{array}$ & $\begin{array}{c}\text { Net } \\
\text { Effect }\end{array}$ & $\begin{array}{l}\text { Carbon } \\
\text { Stored }\end{array}$ & $\begin{array}{c}\text { Net } \\
\text { Effect }\end{array}$ & $\begin{array}{l}\text { Carbon } \\
\text { Stored }\end{array}$ & $\begin{array}{c}\text { Net } \\
\text { Effect }\end{array}$ \\
\hline 0 & 124 & 124 & 0 & 122 & 2 & 122 & 2 & 122 & 2 \\
\hline 5 & 125 & 123 & 2 & 117 & 8 & 121 & 4 & 120 & 5 \\
\hline 10 & 127 & 121 & 6 & 111 & 16 & 121 & 6 & 119 & 8 \\
\hline 20 & 148 & 128 & 20 & 110 & 38 & 136 & 12 & 130 & 18 \\
\hline 30 & 188 & 145 & 43 & 125 & 63 & 168 & 20 & 155 & 33 \\
\hline 40 & 234 & 161 & 73 & 148 & 86 & 195 & 39 & 181 & 53 \\
\hline 50 & 281 & 175 & 106 & 175 & 106 & 217 & 64 & 207 & 74 \\
\hline 60 & 325 & 187 & 138 & 203 & 122 & 235 & 90 & 234 & 91 \\
\hline 70 & 362 & 197 & 165 & 229 & 133 & 248 & 114 & 259 & 103 \\
\hline 80 & 395 & 206 & 189 & 252 & 143 & 259 & 136 & 281 & 114 \\
\hline 90 & 421 & 215 & 206 & 270 & 151 & 267 & 154 & 300 & 121 \\
\hline 100 & 435 & 221 & 214 & 284 & 151 & 273 & 162 & 334 & 101 \\
\hline
\end{tabular}


Table 5.E.16. Region: Lake States; Site: All; Access Code: 5112, 5122; Species: White/Red Pine; Land Status: Cropland

\begin{tabular}{|c|c|c|c|}
\hline \multirow[b]{3}{*}{ Age } & \multirow[b]{3}{*}{$\begin{array}{l}\text { Activity } \\
\text { Carbon }\end{array}$} & \multirow{2}{*}{\multicolumn{2}{|c|}{$\frac{\text { Reference Cases }}{\text { Cropland }}$}} \\
\hline & & & \\
\hline & & $\begin{array}{l}\text { Carbon } \\
\text { Stored }\end{array}$ & $\begin{array}{c}\text { Net } \\
\text { Effect }\end{array}$ \\
\hline 0 & 58 & 58 & 0 \\
\hline 5 & 72 & 58 & 14 \\
\hline 10 & 87 & 58 & 29 \\
\hline 20 & 123 & 58 & 65 \\
\hline 30 & 168 & 58 & 110 \\
\hline 40 & 218 & 58 & 160 \\
\hline 50 & 269 & 58 & 211 \\
\hline 60 & 318 & 58 & 260 \\
\hline 70 & 359 & 58 & 301 \\
\hline 80 & 393 & 58 & 335 \\
\hline 90 & 419 & 58 & 361 \\
\hline 100 & 433 & 58 & 375 \\
\hline
\end{tabular}


Table 5.E.17. Region: Lake States; Site: All; Access Code: 5123, 5113; Species: White/Red Pine; Land Status: Pasture

\begin{tabular}{|c|c|c|c|}
\hline \multirow[b]{3}{*}{ Age } & \multirow[b]{3}{*}{$\begin{array}{l}\text { Activity } \\
\text { Carbon }\end{array}$} & \multirow{2}{*}{\multicolumn{2}{|c|}{$\begin{array}{c}\text { Reference Cases } \\
\text { Pasture }\end{array}$}} \\
\hline & & & \\
\hline & & $\begin{array}{l}\text { Carbon } \\
\text { Stored }\end{array}$ & $\begin{array}{c}\text { Net } \\
\text { Effect }\end{array}$ \\
\hline 0 & 78 & 78 & 0 \\
\hline 5 & 91 & 78 & 13 \\
\hline 10 & 105 & 78 & 27 \\
\hline 20 & 139 & 78 & 61 \\
\hline 30 & 182 & 78 & 104 \\
\hline 40 & 230 & 78 & 152 \\
\hline 50 & 279 & 78 & 201 \\
\hline 60 & 325 & 78 & 247 \\
\hline 70 & 363 & 78 & 285 \\
\hline 80 & 395 & 78 & 317 \\
\hline 90 & 420 & 78 & 342 \\
\hline 100 & 433 & 78 & 355 \\
\hline
\end{tabular}


Table 5.E.18. Region: Lake States; Site: All; Access Code: 5111, 5121; Species: Spruce-Fir; Land Status: Clearcut Forest

\begin{tabular}{|c|c|c|c|c|c|c|c|c|c|}
\hline \multirow[b]{3}{*}{ Age } & \multirow[b]{3}{*}{$\begin{array}{l}\text { Activity } \\
\text { Carbon }\end{array}$} & \multicolumn{8}{|c|}{ Reference Cases } \\
\hline & & \multicolumn{2}{|c|}{ White/red Pine } & \multicolumn{2}{|c|}{ Maple-Beech } & \multicolumn{2}{|c|}{ Aspen-Birch } & \multicolumn{2}{|c|}{$\begin{array}{c}\text { Bottomland } \\
\text { Hdwd }\end{array}$} \\
\hline & & $\begin{array}{l}\text { Carbon } \\
\text { Stored }\end{array}$ & $\begin{array}{c}\text { Net } \\
\text { Effect }\end{array}$ & $\begin{array}{l}\text { Carbon } \\
\text { Stored }\end{array}$ & $\begin{array}{c}\text { Net } \\
\text { Effect }\end{array}$ & $\begin{array}{l}\text { Carbon } \\
\text { Stored }\end{array}$ & $\begin{array}{c}\text { Net } \\
\text { Effect }\end{array}$ & $\begin{array}{c}\text { Carbon } \\
\text { Stored }\end{array}$ & $\begin{array}{c}\text { Net } \\
\text { Effect }\end{array}$ \\
\hline 0 & 124 & 124 & 0 & 122 & 2 & 122 & 2 & 122 & 2 \\
\hline 5 & 123 & 125 & -2 & 117 & 6 & 121 & 2 & 120 & 3 \\
\hline 10 & 121 & 127 & -6 & 111 & 10 & 121 & 0 & 119 & 2 \\
\hline 20 & 128 & 148 & -20 & 110 & 18 & 136 & -8 & 130 & -2 \\
\hline 30 & 145 & 188 & -43 & 125 & 20 & 168 & -23 & 155 & -10 \\
\hline 40 & 161 & 234 & -73 & 148 & 13 & 195 & -34 & 181 & -20 \\
\hline 50 & 175 & 281 & -106 & 175 & 0 & 217 & -42 & 207 & -32 \\
\hline 60 & 187 & 325 & -138 & 203 & -16 & 235 & -48 & 234 & -47 \\
\hline 70 & 197 & 362 & -165 & 229 & -32 & 248 & -51 & 259 & -62 \\
\hline 80 & 206 & 395 & -189 & 252 & -46 & 259 & -53 & 281 & -75 \\
\hline 90 & 215 & 421 & -206 & 270 & -55 & 267 & -52 & 300 & -85 \\
\hline 100 & 221 & 435 & -214 & 284 & -63 & 273 & -52 & 334 & -113 \\
\hline
\end{tabular}


Table 5.E.19. Region: Lake States; Site: All; Access Code: 5212, 5222; Species: Spruce-Fir; Land Status: Cropland

\begin{tabular}{|rc|cc||}
\hline \multirow{2}{*}{} & & \multicolumn{2}{|c|}{ Reference Cases } \\
\cline { 3 - 4 } Age & Activity & \multicolumn{2}{|c|}{ Caropland } \\
\cline { 3 - 4 } & Carbon & $\begin{array}{c}\text { Carbon } \\
\text { Stored }\end{array}$ & $\begin{array}{c}\text { Net } \\
\text { Effect }\end{array}$ \\
\hline 0 & 58 & 58 & 0 \\
5 & 70 & 58 & 12 \\
10 & 80 & 58 & 22 \\
20 & 103 & 58 & 45 \\
30 & 114 & 58 & 56 \\
40 & 124 & 58 & 66 \\
50 & 145 & 58 & 87 \\
60 & 164 & 58 & 106 \\
70 & 181 & 58 & 123 \\
80 & 194 & 58 & 136 \\
90 & 204 & 58 & 146 \\
100 & 213 & 58 & 155 \\
\hline NOTE: & All carbon figures in 1033 lbs/acre. \\
\hline
\end{tabular}


Table 5.E.20. Region: Lake States; Site: All; Access Code: 5213, 5223; Species: Spruce-Fir; Land Status: Pasture

\begin{tabular}{|c|c|c|c|}
\hline \multirow[b]{3}{*}{ Age } & \multirow[b]{3}{*}{$\begin{array}{l}\text { Activity } \\
\text { Carbon }\end{array}$} & \multicolumn{2}{|c|}{ Reference Cases } \\
\hline & & \multicolumn{2}{|c|}{ Pasture } \\
\hline & & $\begin{array}{l}\text { Carbon } \\
\text { Stored }\end{array}$ & $\begin{array}{c}\text { Net } \\
\text { Effect }\end{array}$ \\
\hline 0 & 78 & 78 & 0 \\
\hline 5 & 88 & 78 & 10 \\
\hline 10 & 98 & 78 & 20 \\
\hline 20 & 118 & 78 & 40 \\
\hline 30 & 138 & 78 & 60 \\
\hline 40 & 157 & 78 & 79 \\
\hline 50 & 174 & 78 & 96 \\
\hline 60 & 188 & 78 & 110 \\
\hline 70 & 198 & 78 & 120 \\
\hline 80 & 206 & 78 & 128 \\
\hline 90 & 214 & 78 & 136 \\
\hline 100 & 219 & 78 & 141 \\
\hline
\end{tabular}


Table 5.E.21. Region: Central States; Site: All; Access Code: 6111, 6121; Species: White/Red Pine; Land Status: Clearcut Forest

\begin{tabular}{|c|c|c|c|c|c|}
\hline \multirow[b]{3}{*}{ Age } & \multirow[b]{3}{*}{$\begin{array}{l}\text { Activity } \\
\text { Carbon }\end{array}$} & \multicolumn{4}{|c|}{ Reference Cases } \\
\hline & & \multicolumn{2}{|c|}{ Oak-Hickory } & \multicolumn{2}{|c|}{$\begin{array}{l}\text { Bottomland } \\
\text { Hardwoods }\end{array}$} \\
\hline & & $\begin{array}{l}\text { Carbon } \\
\text { Stored }\end{array}$ & $\begin{array}{c}\text { Net } \\
\text { Effect }\end{array}$ & $\begin{array}{r}\text { Carbon } \\
\text { Stored }\end{array}$ & $\begin{array}{l}\text { Net } \\
\text { Effect }\end{array}$ \\
\hline 0 & 78 & 78 & 0 & 78 & 0 \\
\hline 5 & 80 & 79 & 1 & 81 & -1 \\
\hline 10 & .82 & 82 & 0 & 89 & -7 \\
\hline 20 & 91 & 94 & -3 & 107 & -16 \\
\hline 30 & 105 & 112 & -7 & 126 & -21 \\
\hline 40 & 118 & 131 & -13 & 143 & -25 \\
\hline 50 & 132 & 148 & -16 & 158 & -26 \\
\hline 60 & 145 & 165 & -20 & 172 & -27 \\
\hline 70 & 158 & 181 & -23 & 184 & -26 \\
\hline 80 & 170 & 194 & -24 & 195 & -25 \\
\hline 90 & 181 & 207 & -26 & 205 & -24 \\
\hline 100 & 193 & 218 & -25 & 214 & -21 \\
\hline
\end{tabular}


Table 5.E.22. Region: Central States; Site: All; Access Code: 6112, 6122; Species: White/Red Pine; Land Status: Cropland

\begin{tabular}{|c|c|c|c|}
\hline \multirow[b]{3}{*}{ Age } & \multirow[b]{3}{*}{$\begin{array}{l}\text { Activity } \\
\text { Carbon }\end{array}$} & \multirow{2}{*}{\multicolumn{2}{|c|}{$\begin{array}{c}\text { Reference Cases } \\
\text { Cropland }\end{array}$}} \\
\hline & & & \\
\hline & & $\begin{array}{l}\text { Carbon } \\
\text { Stored }\end{array}$ & $\begin{array}{l}\text { Net } \\
\text { Effect }\end{array}$ \\
\hline 0 & 37 & 37 & 0 \\
\hline 5 & 47 & 37 & 10 \\
\hline 10 & 57 & 37 & 20 \\
\hline 20 & 76 & 37 & 39 \\
\hline 30 & 92 & 37 & 55 \\
\hline 40 & 108 & 37 & 71 \\
\hline 50 & 125 & 37 & 88 \\
\hline 60 & 141 & 37 & 104 \\
\hline 70 & 156 & 37 & 119 \\
\hline 80 & 169 & 37 & 132 \\
\hline 90 & 181 & 37 & 144 \\
\hline 100 & 192 & 37 & 155 \\
\hline
\end{tabular}


Table 5.E.23. Region: Central States; Site: All; Access Code: 6123, 6113; Species: White/Red Pine; Land Status: Pasture



\begin{tabular}{|c|c|c|c|}
\hline \multirow[b]{3}{*}{ Age } & \multirow[b]{3}{*}{$\begin{array}{l}\text { Activity } \\
\text { Carbon }\end{array}$} & \multirow{2}{*}{\multicolumn{2}{|c|}{$\begin{array}{c}\text { Reference Cases } \\
\text { Pasture } \\
\end{array}$}} \\
\hline & & & \\
\hline & & $\begin{array}{l}\text { Carbon } \\
\text { Stored }\end{array}$ & $\begin{array}{c}\text { Net } \\
\text { Effect }\end{array}$ \\
\hline 0 & 50 & 50 & 0 \\
\hline 5 & 59 & 50 & 9 \\
\hline 10 & 69 & 50 & 19 \\
\hline 20 & 86 & 50 & 36 \\
\hline 30 & 101 & 50 & 51 \\
\hline 40 & 116 & 50 & 66 \\
\hline 50 & 131 & 50 & 81 \\
\hline 60 & 145 & 50 & 95 \\
\hline 70 & 158 & 50 & 108 \\
\hline 80 & 170 & 50 & 120 \\
\hline 90 & 182 & 50 & 132 \\
\hline 100 & 193 & 50 & 143 \\
\hline
\end{tabular}


Table 5.E.24. Region: Central States; Site: All; Access Code: 6211, 6221; Species: Oak-Hickory; Land Status: Clearcut Forest

\begin{tabular}{|c|c|c|c|c|c|}
\hline \multirow[b]{3}{*}{ Age } & \multirow[b]{3}{*}{$\begin{array}{l}\text { Activity } \\
\text { Carbon }\end{array}$} & \multicolumn{4}{|c|}{ Reference Cases } \\
\hline & & \multicolumn{2}{|c|}{ White/red Pine } & \multicolumn{2}{|c|}{$\begin{array}{l}\text { Bottomland } \\
\text { Hardwoods }\end{array}$} \\
\hline & & $\begin{array}{l}\text { Carbon } \\
\text { Stored }\end{array}$ & $\begin{array}{c}\text { Net } \\
\text { Effect }\end{array}$ & $\begin{array}{c}\text { Carbon } \\
\text { Stored }\end{array}$ & $\begin{array}{c}\text { Net } \\
\text { Effect }\end{array}$ \\
\hline 0 & 78 & 78 & 0 & 78 & 0 \\
\hline 5 & 79 & 80 & -1 & 81 & -2 \\
\hline 10 & 82 & 82 & 0 & 89 & -7 \\
\hline 20 & 94 & 91 & 3 & 107 & -13 \\
\hline 30 & 112 & 105 & 7 & 126 & -14 \\
\hline 40 & 131 & 118 & 13 & 143 & -12 \\
\hline 50 & 148 & 132 & 16 & 158 & -10 \\
\hline 60 & 165 & 145 & 20 & 172 & -7 \\
\hline 70 & 181 & 158 & 23 & 184 & -3 \\
\hline 80 & 194 & 170 & 24 & 195 & -1 \\
\hline 90 & 207 & 181 & 26 & 205 & 2 \\
\hline 100 & 218 & 193 & 25 & 214 & 4 \\
\hline
\end{tabular}


Table 5.E.25. Region: Central States; Site: All; Access Code: 6212, 6222; Species: Oak-Hickory; Land Status: Cropland

\begin{tabular}{|c|c|c|c|}
\hline \multirow[b]{3}{*}{ Age } & \multirow[b]{3}{*}{$\begin{array}{l}\text { Activity } \\
\text { Carbon }\end{array}$} & \multirow{2}{*}{\multicolumn{2}{|c|}{$\frac{\text { Reference Cases }}{\text { Cropland }}$}} \\
\hline & & & \\
\hline & & $\begin{array}{l}\text { Carbon } \\
\text { Stored }\end{array}$ & $\begin{array}{c}\text { Net } \\
\text { Effect }\end{array}$ \\
\hline 0 & 37 & 37 & 0 \\
\hline 5 & 46 & 37 & 9 \\
\hline 10 & 57 & 37 & 20 \\
\hline 20 & 79 & 37 & 42 \\
\hline 30 & 100 & 37 & 63 \\
\hline 40 & 121 & 37 & 84 \\
\hline 50 & 141 & 37 & 104 \\
\hline 60 & 161 & 37 & 124 \\
\hline 70 & 178 & 37 & 141 \\
\hline 80 & 193 & 37 & 156 \\
\hline 90 & 205 & 37 & 168 \\
\hline 100 & 216 & 37 & 179 \\
\hline
\end{tabular}




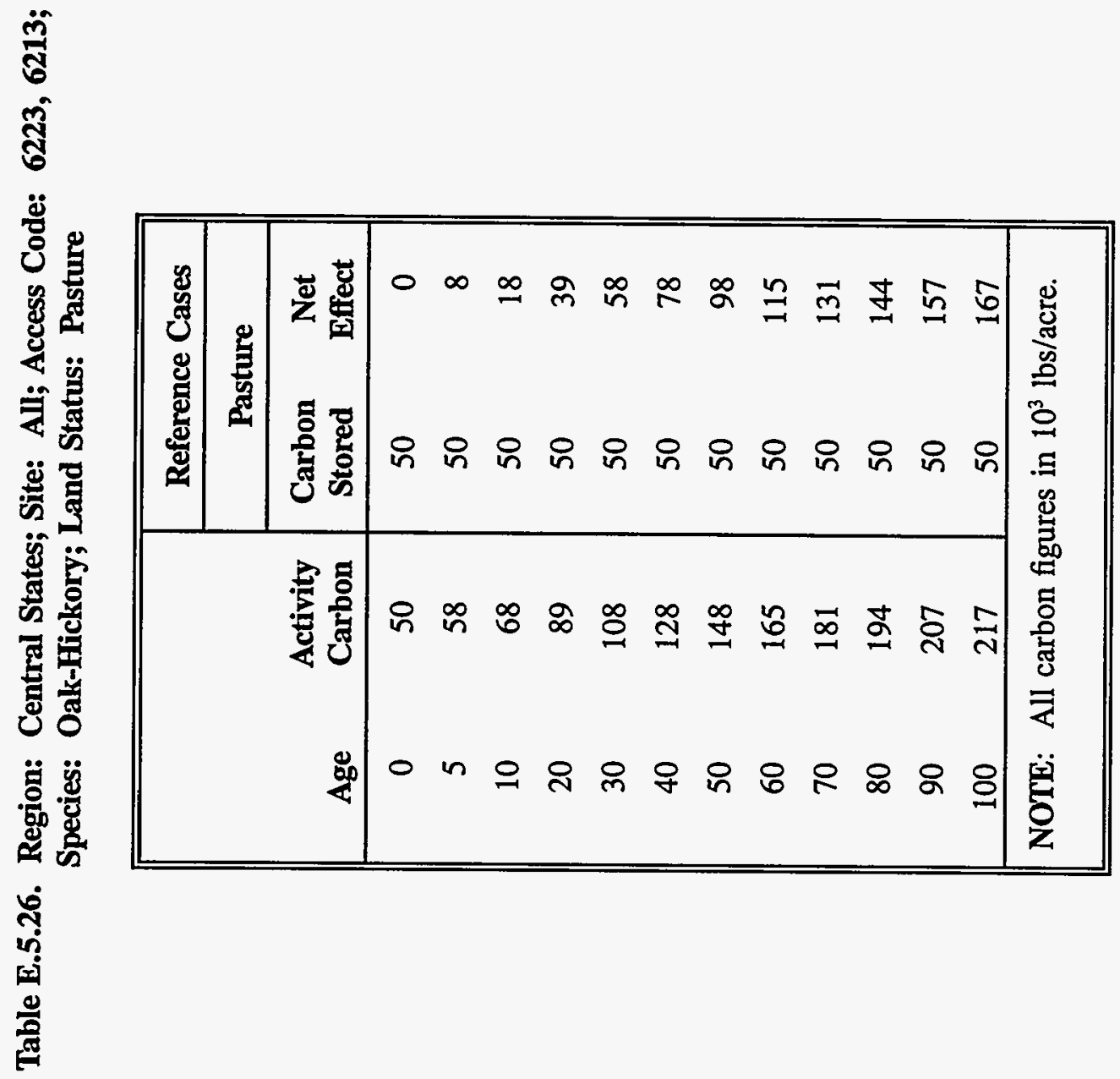

Tables for Standard Projects-Page A.29 
Table 5.E.27. Region: Rocky Mountains - North; Site: All; Access Code: 7111, 7121; Species: Ponderosa Pine; Land Status: Clearcut Forest

\begin{tabular}{|c|c|c|c|c|c|c|c|c|c|}
\hline \multirow[b]{3}{*}{ Age } & \multirow[b]{3}{*}{$\begin{array}{l}\text { Activity } \\
\text { Carbon }\end{array}$} & \multicolumn{8}{|c|}{ Reference Cases } \\
\hline & & \multicolumn{2}{|c|}{ Douglas fir } & \multicolumn{2}{|c|}{ Fir-Spruce } & \multicolumn{2}{|c|}{ Lodgepole Pine } & \multicolumn{2}{|c|}{ Larch } \\
\hline & & $\begin{array}{l}\text { Carbon } \\
\text { Stored }\end{array}$ & $\begin{array}{c}\text { Net } \\
\text { Effect }\end{array}$ & $\begin{array}{r}\text { Carbon } \\
\text { Stored }\end{array}$ & $\begin{array}{c}\text { Net } \\
\text { Effect }\end{array}$ & $\begin{array}{c}\text { Carbon } \\
\text { Stored }\end{array}$ & $\begin{array}{c}\text { Net } \\
\text { Effect }\end{array}$ & $\begin{array}{c}\text { Carbon } \\
\text { Stored }\end{array}$ & $\begin{array}{c}\text { Net } \\
\text { Effect }\end{array}$ \\
\hline 0 & 86 & 86 & 0 & 93 & -7 & 82 & 4 & 103 & -17 \\
\hline 5 & 86 & 86 & 0 & 95 & -9 & 83 & 3 & 110 & -24 \\
\hline 10 & 83 & 83 & 0 & 94 & -11 & 79 & 4 & 115 & -32 \\
\hline 20 & 86 & 86 & 0 & 98 & -12 & 81 & 5 & 131 & -45 \\
\hline 30 & 99 & 98 & 1 & 113 & -14 & 91 & 8 & 157 & -58 \\
\hline 40 & 117 & 119 & -2 & 134 & -17 & 107 & 10 & 190 & -73 \\
\hline 50 & 136 & 149 & -13 & 164 & -28 & 127 & 9 & 225 & -89 \\
\hline 60 & 155 & 182 & -27 & 197 & -42 & 146 & 9 & 260 & -105 \\
\hline 70 & 175 & 214 & -39 & 229 & -54 & 161 & 14 & 291 & -116 \\
\hline 80 & 193 & 245 & -52 & 257 & -64 & 176 & 17 & 319 & -126 \\
\hline 90 & 211 & 276 & -65 & 280 & -69 & 189 & 22 & 343 & -132 \\
\hline 100 & 227 & 304 & -77 & 299 & -72 & 201 & 26 & 360 & -133 \\
\hline
\end{tabular}


Table 5.E.28. Region: Rocky Mountains - North; Site: All; Access Code: 7112, 7122; Species: Ponderosa Pine; Land Status: Cropland

\begin{tabular}{|rc|cc||}
\hline \multirow{2}{*}{ Age } & & \multicolumn{2}{|c|}{ Reference Cases } \\
\cline { 3 - 4 } & Carbon & \multicolumn{2}{|c|}{ Cropland } \\
\cline { 3 - 4 } & Carbon & $\begin{array}{c}\text { Net } \\
\text { Stored }\end{array}$ & Effect \\
\hline 5 & 39 & 39 & 0 \\
10 & 49 & 39 & 10 \\
20 & 54 & 39 & 15 \\
30 & 67 & 39 & 28 \\
40 & 84 & 39 & 45 \\
50 & 106 & 39 & 67 \\
60 & 128 & 39 & 89 \\
70 & 151 & 39 & 112 \\
80 & 173 & 39 & 134 \\
90 & 193 & 39 & 154 \\
100 & 211 & 39 & 172 \\
\hline NOTE: & All carbon figures in 103 lbs/acre \\
\hline
\end{tabular}


Table 5.E.29. Region: Rocky Mountains - North; Site: All; Access Code: 7123, 7113; Species: Ponderosa Pine; Land Status: Pasture

\begin{tabular}{|c|c|c|c|}
\hline \multirow[b]{3}{*}{ Age } & \multirow[b]{3}{*}{$\begin{array}{l}\text { Activity } \\
\text { Carbon }\end{array}$} & \multirow{2}{*}{\multicolumn{2}{|c|}{$\frac{\text { Reference Cases }}{\text { Pasture }}$}} \\
\hline & & & \\
\hline & & $\begin{array}{c}\text { Carbon } \\
\text { Stored }\end{array}$ & $\begin{array}{c}\text { Net } \\
\text { Effect }\end{array}$ \\
\hline 0 & 52 & 52 & 0 \\
\hline 5 & 61 & 52 & 9 \\
\hline 10 & 71 & 52 & 19 \\
\hline 20 & 85 & 52 & 33 \\
\hline 30 & 103 & 52 & 51 \\
\hline 40 & 124 & 52 & 72 \\
\hline 50 & 146 & 52 & 94 \\
\hline 60 & 166 & 52 & 114 \\
\hline 70 & 185 & 52 & 133 \\
\hline 80 & 203 & 52 & 151 \\
\hline 90 & 219 & 52 & 167 \\
\hline 100 & 234 & 52 & 182 \\
\hline
\end{tabular}


Table 5.E.30. Region: Rocky Mountains - South; Site: All; Access Code: 8111, 8121; Species: Ponderosa Pine; Land Status: Clearcut Forest

\begin{tabular}{|c|c|c|c|c|c|c|c|c|c|}
\hline \multirow[b]{3}{*}{ Age } & \multirow[b]{3}{*}{$\begin{array}{c}\text { Activity } \\
\text { Carbon }\end{array}$} & \multicolumn{8}{|c|}{ Reference Cases } \\
\hline & & \multicolumn{2}{|c|}{ Douglas fir } & \multicolumn{2}{|c|}{ Fir-Spruce } & \multicolumn{2}{|c|}{ Lodgepole Pine } & \multicolumn{2}{|c|}{ Larch } \\
\hline & & $\begin{array}{l}\text { Carbon } \\
\text { Stored }\end{array}$ & $\begin{array}{c}\text { Net } \\
\text { Effect }\end{array}$ & $\begin{array}{l}\text { Carbon } \\
\text { Stored }\end{array}$ & $\begin{array}{c}\text { Net } \\
\text { Effect }\end{array}$ & $\begin{array}{l}\text { Carbon } \\
\text { Stored }\end{array}$ & $\begin{array}{c}\text { Net } \\
\text { Effect }\end{array}$ & $\begin{array}{l}\text { Carbon } \\
\text { Stored }\end{array}$ & $\begin{array}{c}\text { Net } \\
\text { Effect }\end{array}$ \\
\hline 0 & 74 & 74 & 0 & 82 & -8 & 71 & 3 & 103 & -29 \\
\hline 5 & 76 & 76 & 0 & 84 & -8 & 72 & 4 & 110 & -34 \\
\hline 10 & 75 & 74 & 1 & 83 & -8 & 66 & 9 & 115 & -40 \\
\hline 20 & 77 & 76 & 1 & 87 & -10 & 74 & 3 & 131 & -54 \\
\hline 30 & 85 & 84 & 1 & 100 & -15 & 85 & 0 & 157 & -72 \\
\hline 40 & 95 & 93 & 2 & 114 & -19 & 99 & -4 & 190 & -95 \\
\hline 50 & 107 & 104 & 3 & 128 & -21 & 115 & -8 & 225 & -118 \\
\hline 60 & 121 & 118 & 3 & 145 & -24 & 132 & -11 & 260 & -139 \\
\hline 70 & 135 & 133 & 2 & 162 & -27 & 149 & -14 & 291 & -156 \\
\hline 80 & 149 & 146 & 3 & 178 & -29 & 164 & -15 & 319 & -170 \\
\hline 90 & 162 & 158 & 4 & 193 & -31 & 177 & -15 & 343 & -181 \\
\hline 100 & 175 & 169 & 6 & 207 & -32 & 188 & -13 & 360 & -185 \\
\hline
\end{tabular}


Table 5.E.31. Region: Rocky Mountains - South; Site: All; Access Code: 8112, 8122; Species: Ponderosa Pine; Land Status: Cropland

\begin{tabular}{|rc|cc||}
\hline \multirow{2}{*}{} & & \multicolumn{2}{|c|}{ Reference Cases } \\
\cline { 3 - 4 } Age & Activity & \multicolumn{2}{|c|}{ Cropland } \\
\cline { 3 - 4 } & Carbon & $\begin{array}{c}\text { Carbon } \\
\text { Stored }\end{array}$ & $\begin{array}{c}\text { Net } \\
\text { Effect }\end{array}$ \\
\hline 0 & 33 & 33 & 0 \\
5 & 43 & 33 & 10 \\
10 & 49 & 33 & 16 \\
20 & 60 & 33 & 27 \\
30 & 72 & 33 & 39 \\
40 & 85 & 33 & 52 \\
50 & 100 & 33 & 67 \\
60 & 118 & 33 & 85 \\
70 & 135 & 33 & 102 \\
80 & 149 & 33 & 116 \\
90 & 162 & 33 & 129 \\
100 & 175 & 33 & 142 \\
\hline NOTE: & All carbon figures in $10^{3}$ lbs/acre. \\
\hline
\end{tabular}


Table 5.E.32. Region: Rocky Mountains - South; Site: All; Access Code: 8123; 8113; Species: Ponderosa Pine; Land Status: Pasture

\begin{tabular}{|c|c|c|c|}
\hline \multirow[b]{3}{*}{ Age } & \multirow[b]{3}{*}{$\begin{array}{l}\text { Activity } \\
\text { Carbon }\end{array}$} & \multicolumn{2}{|c|}{ Reference Cases } \\
\hline & & \multicolumn{2}{|c|}{ Pasture } \\
\hline & & $\begin{array}{l}\text { Carbon } \\
\text { Stored }\end{array}$ & Net Effect \\
\hline 0 & 44 & 44 & 0 \\
\hline 5 & 54 & 44 & 10 \\
\hline 10 & 59 & 44 & 15 \\
\hline 20 & 69 & 44 & 25 \\
\hline 30 & 79 & 44 & 35 \\
\hline 40 & 91 & 44 & 47 \\
\hline 50 & 106 & 44 & 62 \\
\hline 60 & 122 & 44 & 78 \\
\hline 70 & 136 & 44 & 92 \\
\hline 80 & 150 & 44 & 106 \\
\hline 90 & 162 & 44 & 118 \\
\hline 100 & 174 & 44 & 130 \\
\hline
\end{tabular}


Table 5.E.33. Region: Pacific Northwest; Site: High; Access Code: 9111; Species: Douglas Fir; Land Status: Clearcut Forest

\begin{tabular}{|c|c|c|c|c|c|c|c|}
\hline \multirow[b]{3}{*}{ Age } & \multirow[b]{3}{*}{$\begin{array}{l}\text { Activity } \\
\text { Carbon }\end{array}$} & \multicolumn{6}{|c|}{ Reference Cases } \\
\hline & & \multicolumn{2}{|c|}{$\begin{array}{l}\text { Hemlock-Sitka } \\
\text { Spruce }\end{array}$} & \multicolumn{2}{|c|}{ Hardwoods } & \multicolumn{2}{|c|}{ Redwoods } \\
\hline & & $\begin{array}{l}\text { Carbon } \\
\text { Stored }\end{array}$ & $\begin{array}{c}\text { Net } \\
\text { Effect }\end{array}$ & $\begin{array}{c}\text { Carbon } \\
\text { Stored }\end{array}$ & $\begin{array}{c}\text { Net } \\
\text { Effect }\end{array}$ & $\begin{array}{c}\text { Carbon } \\
\text { Stored }\end{array}$ & $\begin{array}{l}\text { Net } \\
\text { Effect }\end{array}$ \\
\hline 0 & 95 & 92 & 3 & 93 & 2 & 95 & 0 \\
\hline 5 & 96 & 93 & 3 & 98 & -2 & 99 & -3 \\
\hline 10 & 94 & 91 & 3 & 104 & -10 & 102 & -8 \\
\hline 20 & 120 & 103 & 17 & 122 & -2 & 119 & 1 \\
\hline 30 & 193 & 137 & 56 & 147 & 46 & 153 & 40 \\
\hline 40 & 285 & 185 & 100 & 175 & 110 & 196 & 89 \\
\hline 50 & 373 & 238 & 135 & 205 & 168 & 244 & 129 \\
\hline 60 & 449 & 288 & 161 & 234 & 215 & 291 & 158 \\
\hline 70 & 512 & 335 & 177 & 259 & 253 & 336 & 176 \\
\hline 80 & 564 & 377 & 187 & 276 & 288 & 374 & 190 \\
\hline 90 & 609 & 414 & 195 & 287 & 322 & 404 & 205 \\
\hline 100 & 649 & 446 & 203 & 296 & 353 & 431 & 218 \\
\hline
\end{tabular}


Table 5.E.34. Region: Pacific Northwest; Site: Medium; Access Code: 9121; Species: Douglas Fir; Land Status: Clearcut Forest

\begin{tabular}{|c|c|c|c|c|c|c|c|}
\hline \multirow[b]{3}{*}{ Age } & \multirow[b]{3}{*}{$\begin{array}{l}\text { Activity } \\
\text { Carbon }\end{array}$} & \multicolumn{6}{|c|}{ Reference Cases } \\
\hline & & \multicolumn{2}{|c|}{$\begin{array}{c}\text { Hemlock-Sitka } \\
\text { Spruce }\end{array}$} & \multicolumn{2}{|c|}{ Hardwoods } & \multicolumn{2}{|c|}{ Redwood } \\
\hline & & $\begin{array}{l}\text { Carbon } \\
\text { Stored }\end{array}$ & $\begin{array}{c}\text { Net } \\
\text { Effect }\end{array}$ & $\begin{array}{c}\text { Carbon } \\
\text { Stored }\end{array}$ & $\begin{array}{c}\text { Net } \\
\text { Effect }\end{array}$ & $\begin{array}{c}\text { Carbon } \\
\text { Stored }\end{array}$ & $\begin{array}{c}\text { Net } \\
\text { Effect }\end{array}$ \\
\hline 0 & 95 & 92 & 3 & 93 & 2 & 95 & 0 \\
\hline 5 & 97 & 93 & 4 & 98 & -1 & 99 & -2 \\
\hline 10 & 97 & 91 & 6 & 104 & -7 & 102 & -5 \\
\hline 20 & 109 & 103 & 6 & 122 & -13 & 119 & -10 \\
\hline 30 & 156 & 137 & 19 & 147 & 9 & 153 & 3 \\
\hline 40 & 228 & 185 & 43 & 175 & 53 & 196 & 32 \\
\hline 50 & 299 & 238 & 61 & 205 & 94 & 244 & 55 \\
\hline 60 & 366 & 288 & 78 & 234 & 132 & 291 & 75 \\
\hline 70 & 422 & 335 & 87 & 259 & 163 & 336 & 86 \\
\hline 80 & 468 & 377 & 91 & 276 & 192 & 374 & 94 \\
\hline 90 & 506 & 414 & 92 & 287 & 219 & 404 & 102 \\
\hline 100 & 538 & 446 & 92 & 296 & 242 & 431 & 107 \\
\hline
\end{tabular}




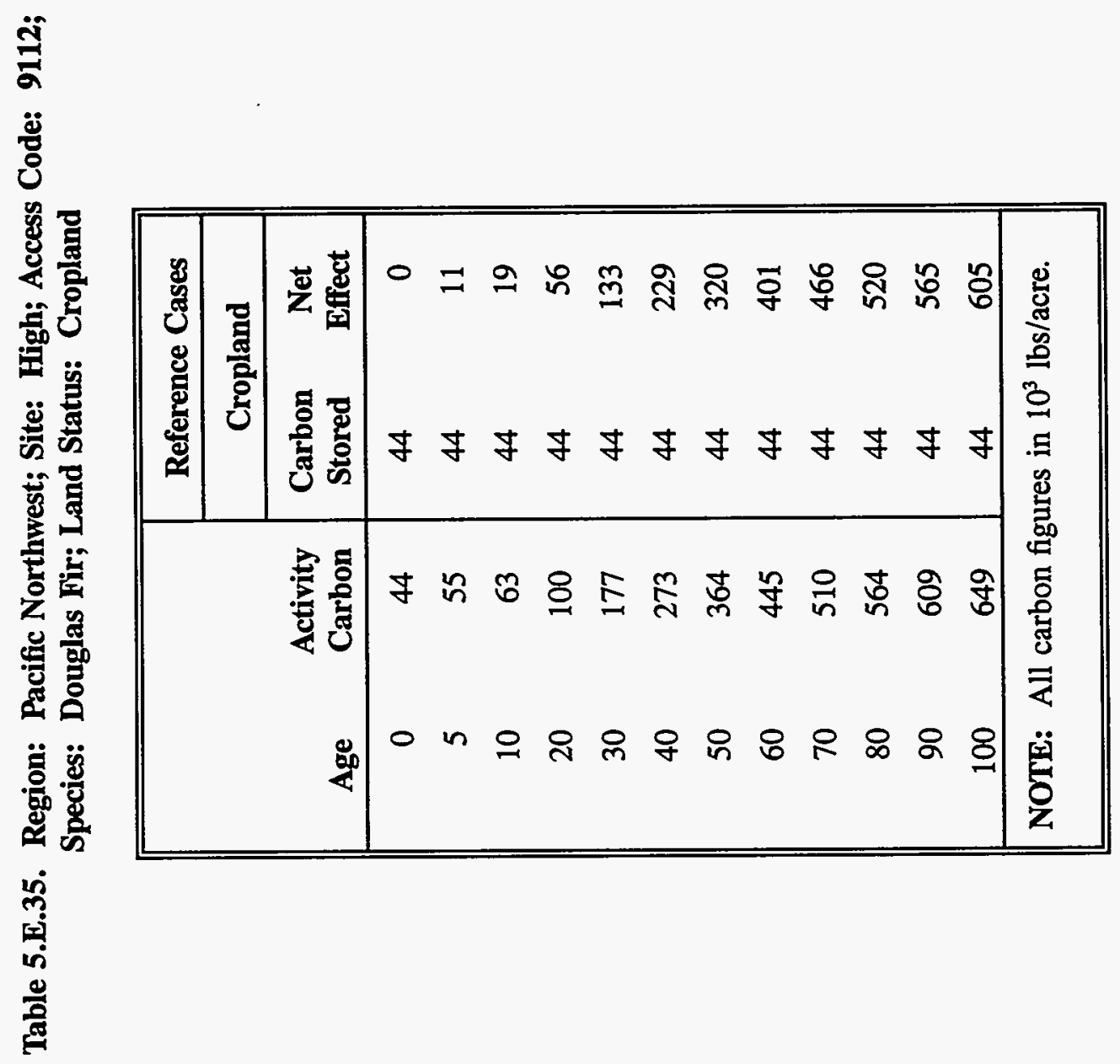


Table 5.E.36. Region: Pacific Northwest; Site: Medium; Access Code: 9123; Species: Douglas Fir; Land Status: Pasture

\begin{tabular}{|c|c|c|c|}
\hline \multirow[b]{3}{*}{ Age } & \multirow[b]{3}{*}{$\begin{array}{l}\text { Activity } \\
\text { Carbon }\end{array}$} & \multirow{2}{*}{\multicolumn{2}{|c|}{$\frac{\text { Reference Cases }}{\text { Pasture }}$}} \\
\hline & & & \\
\hline & & $\begin{array}{l}\text { Carbon } \\
\text { Stored }\end{array}$ & $\begin{array}{c}\text { Net } \\
\text { Effect }\end{array}$ \\
\hline 0 & 58 & 58 & 0 \\
\hline 5 & 70 & 58 & 12 \\
\hline 10 & 78 & 58 & 20 \\
\hline 20 & 100 & 58 & 42 \\
\hline 30 & 150 & 58 & 92 \\
\hline 40 & 224 & 58 & 166 \\
\hline 50 & 298 & 58 & 240 \\
\hline 60 & 366 & 58 & 308 \\
\hline 70 & 423 & 58 & 365 \\
\hline 80 & 468 & 58 & 410 \\
\hline 90 & 506 & 58 & 448 \\
\hline 100 & 538 & 58 & 480 \\
\hline
\end{tabular}


Table 5.E.37. Region: Pacific Northwest; Site: All; Access Code: 9211, 9221; Species: Ponderosa Pine; Land Status: Clearcut Forest

\begin{tabular}{|rc|cc||}
\hline \multirow{2}{*}{ Age } & & \multicolumn{2}{|c|}{ Reference Cases } \\
\cline { 3 - 4 } & Cartivity & \multicolumn{2}{|c|}{ Lodgepole Pine } \\
\cline { 3 - 4 } & Carbon & $\begin{array}{c}\text { Net } \\
\text { Stored }\end{array}$ & Effect \\
\hline 0 & 95 & 92 & 3 \\
5 & 96 & 92 & 4 \\
10 & 94 & 88 & 6 \\
20 & 98 & 89 & 9 \\
30 & 112 & 101 & 11 \\
40 & 129 & 120 & 9 \\
50 & 149 & 138 & 11 \\
60 & 168 & 153 & 15 \\
70 & 187 & 166 & 21 \\
80 & 204 & 177 & 27 \\
90 & 221 & 187 & 34 \\
100 & 237 & 194 & 43 \\
\hline NOTE: All carbon figures in $10^{3}$ lbs/acre. & & \\
\hline
\end{tabular}


Table 5.E.38. Region: Pacific Northwest; Site: High; Access Code: 9212, 9222; Species: Ponderosa Pine; Land Status: Cropland

\begin{tabular}{|c|c|c|c|}
\hline \multirow[b]{3}{*}{ Age } & \multirow[b]{3}{*}{$\begin{array}{l}\text { Activity } \\
\text { Carbon }\end{array}$} & \multirow{2}{*}{\multicolumn{2}{|c|}{$\frac{\text { Reference Cases }}{\text { Cropland }}$}} \\
\hline & & & \\
\hline & & $\begin{array}{l}\text { Carbon } \\
\text { Stored }\end{array}$ & $\begin{array}{l}\text { Net } \\
\text { Effect }\end{array}$ \\
\hline 0 & 44 & 44 & 0 \\
\hline 5 & 55 & 44 & 11 \\
\hline 10 & 62 & 44 & 18 \\
\hline 20 & 78 & 44 & 34 \\
\hline 30 & 96 & 44 & 52 \\
\hline 40 & 117 & 44 & 73 \\
\hline 50 & 140 & 44 & 96 \\
\hline 60 & 163 & 44 & 119 \\
\hline 70 & 185 & 44 & 141 \\
\hline 80 & 204 & 44 & 160 \\
\hline 90 & 221 & 44 & 177 \\
\hline 100 & 237 & 44 & 193 \\
\hline
\end{tabular}


Table 5.E.39. Region: Pacific Northwest; Site: Medium; Access Code: 9213, 9223; Species: Ponderosa Pine; Land Status: Pasture



\begin{tabular}{|c|c|c|c|}
\hline \multirow[b]{3}{*}{ Age } & \multirow[b]{3}{*}{$\begin{array}{r}\text { Activity } \\
\text { Carbon }\end{array}$} & \multirow{2}{*}{\multicolumn{2}{|c|}{$\begin{array}{c}\text { Reference Case } \\
\text { Pasture }\end{array}$}} \\
\hline & & & \\
\hline & & $\begin{array}{l}\text { Carbon } \\
\text { Stored }\end{array}$ & $\begin{array}{c}\text { Net } \\
\text { Effect }\end{array}$ \\
\hline 0 & 58 & 58 & 0 \\
\hline 5 & 68 & 58 & 10 \\
\hline 10 & 82 & 58 & 24 \\
\hline 20 & 97 & 58 & 39 \\
\hline 30 & 115 & 58 & 57 \\
\hline 40 & 136 & 58 & 78 \\
\hline 50 & 159 & 58 & 101 \\
\hline 60 & 179 & 58 & 121 \\
\hline 70 & 197 & 58 & 139 \\
\hline 80 & 213 & 58 & 155 \\
\hline 90 & 229 & 58 & 171 \\
\hline 100 & 244 & 58 & 186 \\
\hline NOTE: & carbon fi & $s$ in $10^{3}$ & acre. \\
\hline
\end{tabular}




\section{Agricultural Sector}

\section{Part 6 of 6 Supporting Documents}

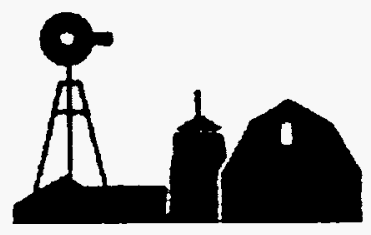

Sector-Specific Issues and Reporting Methodologies Supporting the General Guidelines for the Voluntary Reporting of Greenhouse Gases under Section 1605(b) of the Energy Policy Act of 1992 
.

. 


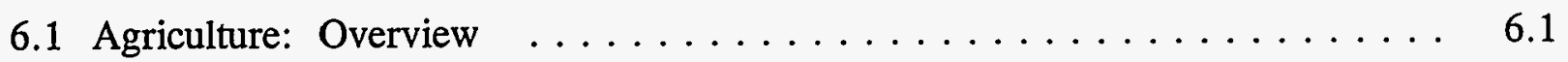

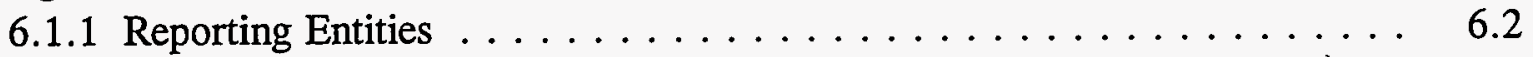

6.1 .2 Sector-Specific Issues $\ldots \ldots \ldots \ldots \ldots \ldots \ldots \ldots \ldots \ldots \ldots$

6.2 Reporting Greenhouse Gas Emissions $\ldots \ldots \ldots \ldots \ldots \ldots .4$

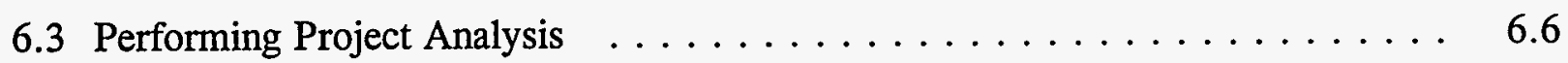

6.3.1 Define the Reference Case $\ldots \ldots \ldots \ldots \ldots \ldots \ldots . \ldots \ldots$

6.3 .2 Identify Effects of the Project $\ldots \ldots \ldots \ldots \ldots \ldots \ldots \ldots .6 .7$

6.3.3 Estimate Emissions for the Reference Case and the Project . . . . . . 6.8

6.3.4 Reporting by Conservation District $\ldots \ldots \ldots \ldots \ldots \ldots \ldots .6 .9$

6.4 Reportable Types of Projects in the Agriculture Sector . . . . . . . . . . . 6.11

6.4 .1 Cropland Management . . . . . . . . . . . . . . . 6.12

6.4 .2 Windbreaks and Shelterbelts $\ldots \ldots \ldots \ldots \ldots \ldots \ldots \ldots . \ldots \ldots$

6.4.3 Reduction and Recovery of Manure Methane Emissions . . . . . . . . 6.16

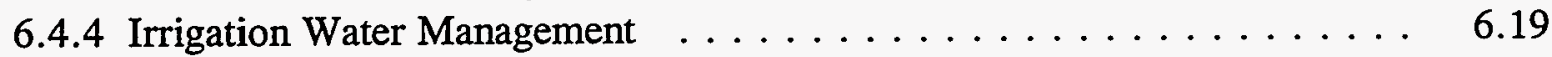

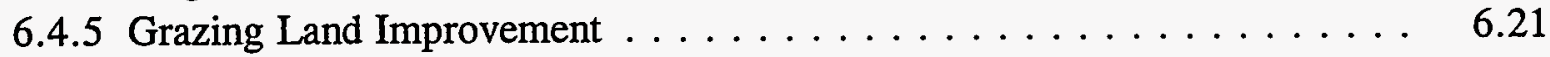

6.4.6 Efficient Nutrient Management for Crop Production $\ldots \ldots \ldots \ldots . . .6 .22$

6.4.7 Growth of Biomass as a Renewable Energy Source . . . . . . . . . 6.25

6.5 References $\ldots \ldots \ldots \ldots \ldots \ldots \ldots \ldots \ldots \ldots \ldots \ldots \ldots \ldots \ldots \ldots \ldots \ldots \ldots \ldots .28$ 


\section{Tables}

6.1 Typical State Technical Guide Index of Standards and Specifications $\ldots \ldots \ldots . \ldots$

6.2 Average Carbon Emitted from Energy Use Associated with Crop Production $\ldots . . .66 .14$

6.3 Livestock Manure Methane Emissions Factors $\ldots \ldots \ldots \ldots \ldots \ldots$

\section{Examples}

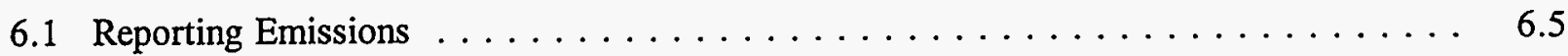

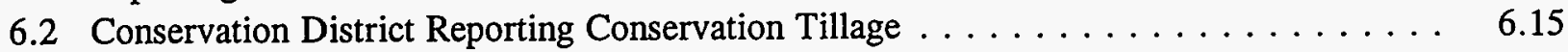

6.3 Reporting Methane Emissions Reductions $\ldots \ldots \ldots \ldots \ldots \ldots \ldots \ldots \ldots$

6.4 Association Report of a Nutrient Management Project . . . . . . . . . . . . . . . 6.24

6.5 Report of a Biomass Project $\ldots \ldots \ldots \ldots \ldots \ldots \ldots \ldots \ldots \ldots \ldots \ldots \ldots \ldots \ldots \ldots \ldots .27$ 


\subsection{Agricultural Sector}

This document supports and supplements the General Guidelines for reporting greenhouse gas information under Section 1605(b) of the Energy Policy Act (EPAct) of 1992. The General Guidelines provide the rationale for the voluntary reporting program and overall concepts and methods to be used in reporting. Before proceeding to the more specific discussion contained in this supporting document, you should read the General Guidelines. Then read this document, which has been developed in cooperation with the U.S. Department of Agriculture (USDA) and which relates the general guidance to the issues, methods, and data specific to the agricultural sector. Other supporting documents address the electricity supply sector, the residential and commercial buildings sector, the industrial sector, the transportation sector, and the forestry sector.

The General Guidelines and supporting documents describe the rationale and processes for estimating emissions and analyzing emissions-reducing and carbon sequestration projects. When you understand the approaches taken by the voluntary reporting program, you will have the background needed to complete the reporting forms.

The General Guidelines and supporting documents address four major greenhouse gases: carbon dioxide, methane, nitrous oxide, and halogenated substances. Although other radiatively enhancing gases are not generally discussed, you will be able to report nitrogen oxides $\left(\mathrm{NO}_{\mathrm{x}}\right)$, nonmethane volatile organic compounds (NMVOCs), and carbon monoxide (CO) after the second reporting cycle (that is, after 1996).

The Department of Energy (DOE) has designed this voluntary reporting program to be flexible and easy to use. For example, you are encouraged to use the same fuel consumption or energy savings data that you may already have compiled for existing programs or for your own internal tracking. In addition, you may use the default emissions factors and stipulated factors that this document provides for some types of projects to convert your existing data directly into estimated emissions reductions. The intent of the default emissions and stipulated factors is to simplify the reporting process, not to discourage you from developing your own emissions estimates.

Whether you report for your whole organization, only for one project, or at some level in between, you will find guidance and overall approaches that will help you in analyzing your projects and developing your reports. If you need reporting forms, contact the Energy Information Administration (EIA) of DOE, 1000 Independence Avenue, S.W., Washington, DC 20585.

\subsection{Agriculture: Overview}

Agriculture is a complex sector that deals with soil, water, plant, air, and animal resources in relation to economic considerations that affect the use of agricultural chemicals, fuels, and timing of operations. Rarely is an agricultural operation directed toward the production of only one commodity. Rather, the

\section{Agricultural Sector-Page 6.1}


operation is really a system geared to multiple-commodity production, depending on the global economy. Given the myriad of combinations that the inputs to production may take, collecting and reporting reliable data are challenges.

For agriculture, the risks of global climate change are considerable. Shifting precipitation patterns and increased variability of moderate to extreme climate events would require adaptation of management techniques, application of technologies, and perhaps strategies to compensate for or prevent lower yields. All of these risks make mitigation actions of interest to the agricultural sector.

The agricultural sector includes both activities that reduce greenhouse gas emissions and sequester carbon. In the context of the earth's carbon cycle, carbon sequestering is the capture and storage of carbon. Carbon sequestration is reversible, depending upon agricultural management. It is a two-step process; carbon dioxide is first withdrawn from the atmosphere through the photosynthetic process, then stored in organic materials and perhaps underground over a period of time. The sequestration process ends when the carbon is released back into the atmosphere, principally as carbon dioxide and other carbon compounds, because of either combustion or decay. In this sense, carbon sequestration is defined by flows of carbon among the atmosphere, plants, animals, and soil. Carbon sequestration in agriculture is increased when the amount of carbon flow from the atmosphere to plants exceeds the flow from plants to the atmosphere.

The complexities of agricultural systems may present challenges to knowledgeable reporters when assessing specific effects of individual conservation or agronomic applications. Even more important will be understanding the integration of these efforts in the context of ecosystems-based management as well as impacts upon the atmospheric natural resource.

\subsubsection{Reporting Entities}

This sector includes not only family farms, but also any individual or group involved in producing crops or animals. Reporting entities could be classified into three groups: individual farmers or ranchers; associations or third parties; and local bodies of government, such as soil conservation districts, that could be third-party reporters.

\section{Individual Agricultural Operation}

Individual farmers, ranchers, consultants, management firms, manufacturers of agricultural products (such as fertilizer), and food producers (for their agricultural operations) may wish to report how their activities or those of their clients have affected greenhouse gas emissions. Many changes in agricultural practices are originally motivated by the needs to conserve soil and water and to use resources more efficiently. However, these same changes may reduce emissions, sequester carbon, or both, and thus may be reported under the EPAct 1605(b) program.

Individual agricultural operations may use tools such as the Erosion Productivity Index Calculator (EPIC), a process simulation model that takes into account farm management practices over 8-10 years

\section{Agricultural Sector-Page 6.2}


and can show the effect of these practices on carbon sequestration. The model is very site-specific and data-intensive.

\section{Associations and Third Parties}

Agricultural operators often are members of groups, such as cooperatives, that share information and resources. These groups or associations may have the resources to collect, aggregate, and summarize the data to report under this program and may wish to report jointly, aggregating their data for greater impact and sharing the reporting burden. For example, an association of rangeland grazers could sequester carbon by increasing rangeland quality from poor/fair to good/excellent condition. Such an association might use the 1991 Simulation of Production and Utilization of Rangelands (SPUR) (USDA 1987) model to compare soil organic carbon (SOC) before and after the change in range conditions.

Third parties might also report under this program. Third-party reporters might include food production businesses that contract out to individual farmers and thus control many aspects of production on those farms. These reporters should identify the individual farms as other potential reporters. Another third-party reporter might be a farming consultant who reports practices initiated at client farms; again, the consultant should identify the clients as other potential reporters.

\section{Local Government (Conservation Districts)}

Conservation districts, usually at the county level, are in a unique position because they collect and report relevant data under a USDA voluntary reporting program. As part of their current function, they cooperate closely with the individual operations in their counties in order to gather data on agricultural management and conservation activities. The districts possess information on the majority of the farms/ranches in the United States. Since conservation district supervisors are elected officials of county governments, they are answerable to their constituents for the accuracy of the data.

These data are aggregated to the county level and could be used to calculate greenhouse emissions impacts, primarily relying on computer processing. Representative values for the majority of the agricultural operations in a county could be reduced by multiple runs of the models to produce order of magnitude multipliers. For example, using the Cost and Return Evaluator (CARE), a conservation district could calculate the reduction of energy use brought about by the improvement of irrigation water efficiency, or the reduction of fuel use caused by changes in tillage practices or residue management. This may be the most economical method to get a large representation of the agricultural sector. Data could be aggregated to the state or national level.

As the science of carbon sequestration improves, the physical data gathered by the districts can be reanalyzed to more precisely assess the impact over time of agriculture and varying agricultural practices on greenhouse gas emissions.

\section{Agricultural Sector-Page 6.3}




\subsubsection{Sector-Specific Issues}

The agricultural sector includes numerous, highly varied activities and many sources of information that can be reported under this program. The sector encompasses crops and animals. Some overlap may occur with the industrial sector in activities involving the food and agricultural chemical industries, and agricultural energy sources.

The sector is unique in the variety of activities that contribute both to greenhouse gas emissions and to carbon sequestration; in the range of possible reporters, from small individual farms to cooperatives and associations to governmental organizations at all levels; and in the understanding of interactions among activities in living organic systems, leading to complex project definitions and estimation methods.

You may encounter complexities in every step of your project analysis. In defining projects and determining effects, you may need to consider carefully what activities to include. An activity that has some straightforward, intended effects may lead to other effects in the life cycle of a crop, in off-site (downstream) impacts on resources surrounding your land, or in other practices that affect greenhouse gas emissions. Similarly, quantifying effects may be a challenge when so many elements need to be accounted for. Furthermore, some effects may interact with each other, either increasing or decreasing the overall effects.

\subsection{Reporting Greenhouse Gas Emissions}

The General Guidelines ("What is Involved in Reporting Emissions?") explain that reporting information on greenhouse gas emissions for the baseline period of 1987 through 1990 and for subsequent calendar years on an annual basis is considered an important element of this program. If you are able to report emissions for your entire agricultural operation, you should consider providing a comprehensive accounting so that your audience can gain a clear understanding of your overall activities.

You may report your emissions by either estimating emissions only (from fuel use, fertilizer use, manure lagoons, etc.) or by accounting for carbon flows to and from the atmosphere (capture of carbon, perhaps offsetting some portion of emissions to arrive at net amounts of emissions).

You may not be able to develop a comprehensive emissions report. However, you may be able to report one or more of the following emissions-related activities, which are arranged roughly in increasing order of complexity:

- Carbon emissions from fuel use. To report fuel-related emissions, you may determine the amount and type of energy consumed in the reporting year and, for each fuel, multiply the amount by the corresponding emissions factor in Appendix B. (Emission from fuel use are discussed more 
extensively in the supporting documents for the electricity supply, residential and commercial buildings, industrial, and transportation sectors.)

- Carbon dioxide emissions from electricity use. To calculate emissions resulting from electricity purchases, you may use the state-level default emissions factors in Appendix C. (Emissions from electricity use are discussed more extensively in the supporting documents for electricity supply and residential and commercial buildings.)

- Methane emissions from manure. These may be measured from a covered lagoon or estimated using the procedure and default factors in Section 6.4.3.

- Nitrous oxide emissions from fertilizer and nitrogen use. Although the application of nitrogen leads to emissions of nitrous oxide, these emissions are difficult to quantify.

- Adjustments to carbon dioxide emissions from calculations of carbon flows. To accomplish this, you may estimate carbon captured by and released from the soil, above- and below-ground biomass, and windbreaks and shelterbelts. Your estimates of carbon flows should include negative flows (capture of carbon from the atmosphere) and positive flows (release of carbon to the atmosphere). That estimate of carbon must be multiplied by 3.67 in order to convert carbon to carbon dioxide. (See Appendix D.) If your activities are capturing more carbon than they are releasing, your carbon dioxide emissions will be lowered. (A more detailed discussion of calculating carbon flows is contained in Section 5.2 of the supporting document for the forestry sector.)

The following example illustrates the decision-making process for determining categories of emissions to report under the voluntary reporting program.

Example 6.1 - Reporting Emissions

Grundvig Chickens, Inc., operated several chicken farms that delivered poultry to a local processing plant. GC had made several improvements to its operations since 1990 in order to become more competitive. As results of these efficiency improvements, the farms were using less fuel for heating and transportation, and less electricity. The farms were also managing the chicken manure to capture methane for on-farm use.

Although reducing greenhouse gas emissions had not been a goal of these activities, GC realized that reporting emissions under the EPAct 1605(b) program would be good public relations for the organization-and lay the basis for reports of emissions reductions.

Since the company had records of fuel use and electricity use, GC decided to report emissions from these activities, using the default emissions factors for natural gas and gasoline, and an emissions factor developed by the local rural electric company. In addition, GC could estimate the amount of natural gas displaced by using recovered methane, since only one heating system was involved. The company had no way to determine actual methane emissions for their reporting years; however, these emissions must have been more than the amount recovered. Therefore, GC decided to report methane emissions at the level that could be substantiated, that is, the amount recovered in a subsequent project. GC reported

Agricultural Sector-Page 6.5 
Example 6.1 - (cont'd)

emissions of carbon dioxide and methane for 1987-1990 and carbon dioxide for each year thereafter. (Since the company was now recovering methane and did not measure the amount that was not recovered, methane could not be included in the emissions report.)

GC also reported data on tillage practice and crop management to the local conservation district, which aggregated data and determined flows for all cooperators in the district. This became the basis for an emissions report from the conservation district to ELA under the EPAct 1605 (b) program.

The primary process of estimation must be documented and be based upon acceptable science from industry, academia, or other research and development sources. The process can include direct measurements, or the method may be based upon simulations of the appropriate resource management models (carbon sequestered from the SPUR or EPIC models, or fuel use from the CARE model), or engineering computations based upon average or normal conditions.

\subsection{Performing Project Analysis}

The analysis of emission reductions and carbon flow reductions in the agriculture sector follows the process described in the General Guidelines ("How Should I Analyze Projects I Wish to Report?"):

- Establish the reference case.

- Identify the effects of the project.

- Estimate carbon flows for the reference case and the project.

You have considerable freedom in selecting activities to report and deciding how to estimate their effects. At a minimum, however, you must meet the reporting requirements described in the General Guidelines ("What Are the Minimum Reporting Requirements?"). You need to provide information on a reference case-carbon flows and greenhouse gas emissions had the project not been undertaken-and the project-the carbon flows and greenhouse gas emissions with the project in place. You must identify the effects of the project. Finally, you must estimate the emissions associated with the reference case and the project, and calculate the difference between them as an estimate of your project accomplishment.

The starting point for any reporting will be gathering the physical data about the operators' activities on any piece of land over time. Science will provide acceptable methods to compute effects of such activities on atmospheric greenhouse gases. As science evolves, new techniques can be applied directly to these physical data. DOE expects that database users will have the opportunity to use the reported information to reevaluate estimated effects in the future, as better data or estimation methods become available. 
Well-documented procedures are required to illustrate how the data can show the impact of agriculture on the atmosphere. Integrated applications can be summarized and reported in terms of tons of greenhouse gases sequestered or not emitted within the time frame and spatial extent, depending upon how you define a specific project.

\subsubsection{Define the Reference Case}

Defining the effects of the agricultural activity starts with defining a reference case. This reference case describes the physical parameters of the activity and the emission effects without the activity. Once you have established the reference case, it serves as the basis for evaluating the effects of the reported activity (the project). In simple terms, the net effects of the activity are defined by the emission levels or carbon flows for the reference case minus the emission levels or carbon flows for the project case.

If you can develop a basic (historic) reference case specific to your operation, that case will probably be the most credible for your audiences. In some situations, your farming operation may be stable, including over the baseline years (1987-1990). Even where your operation has changed from year to year, identifying a typical year or using the year just prior to your project may well be both convenient and credible.

For other situations, you may have difficulty in defining a reference case because no record of historic farm/ranch operations exists, because you have no data or no reliable data, or because you have good reason to believe that greenhouse gas emissions even without the project would have been different from historic emissions. For example, agricultural practices may change rapidly in response to market and other conditions, and your farm's production may change completely within several years. Your range of choices for a reference case might include regional averages, alternative scenarios available in models (for example, in the EPIC program), or projections of trends (such as additional carbon sequestration in the soil, projected as a continuation of past years' activity). For a few well-defined projects, you may wish to use default factors, documenting the source for any such factors. Similarly, you may be able to find data on land similar to yours and refine that information to develop a reference case.

If you use such a reference case, called a modified reference case, keep in mind that your audiences may need to be convinced of the comparability of your reference and project cases. In this situation, the construction of a reference case can involve considerable analysis and the best estimate of knowledgeable technical people. You will need to state both the methods and assumptions that you used to arrive at the reference case. For example, if you use modeled data or regional averages, you should exercise care in applying the data to your specific site(s).

\subsubsection{Identify Effects of the Project}

In developing your project analysis, you should strive to include all relevant effects of the activity as described in the General Guidelines ("What Effects Did the Project Have?"). The complexities of

\section{Agricultural Sector-Page 6.7}


natural resource systems do not lend themselves well to well-defined project boundaries, and you may need to account for a wide range of possible effects. Actions taken to reduce carbon dioxide emissions may increase emissions of other greenhouse gases. For example, the life-cycle effects of growing biomass include energy and chemical inputs that may partially offset the beneficial effects of alternative fuels made from the biomass crop.

The guidance for analysis of specific activities in Section 6.4 provides some description of likely effects of each type of project. However, actual effects will be site-specific. You should carefully attempt to identify all effects, and where possible, quantify those effects.

\subsubsection{Estimate Emissions for the Reference Case and Project}

Your report must include an estimation of emissions effects and carbon sequestration associated with your project. Although this supporting document provides a few default factors, you generally must develop your own estimation process for agricultural projects. Remember that your report will be less credible if you do not use acceptable analytical practices. You may want to review the guidance provided in Section 6.4 that discusses some acceptable procedures for estimating the carbon flow effects for some types of agricultural projects.

\section{Default Factors}

For this sector, as for all sectors, you can use default factors to estimate emissions from fuel use (multiply the quantity of each fuel by the relevant factor-see Appendix B) and electricity use (multiply the megawatt hours by your state's emissions factor-see Appendix C).

However, very few default factors exist for uniquely agricultural activities, since, for the most part, emissions from any activity depend upon specific characteristics such as type and condition of the site, management practices, and weather. Field measurements or site-specific estimates are almost always preferred to default factors. Nevertheless, this guidance draws from research some default factors for a few projects, such as methane emissions from livestock manure and carbon dioxide emissions from tillage systems. As the scientific understanding of atmospheric greenhouse gases increases, more default factors will become available for use in specific situations. These default factors may allow you to report projects easily, but they will be less precise than your own data from actual field measurements.

\section{Field Measurements}

When appropriately designed and executed, site-specific field studies will provide the highest quality data and thus the highest credibility with users of the database. If you use field measurements, your report should briefly describe the sampling plan and the associated levels of confidence. 


\section{Models}

Many of the estimation techniques discussed in this supporting document for specific projects rely on the use of models. You should carefully consider the suitability of any model that you use. For example, some models are designed for farm-scale use; to apply them on a district-wide basis may reduce their accuracy. Moreover, the models discussed earlier (EPIC, SPUR, and CARE) were developed originally for different purposes than estimating greenhouse gas emissions and, therefore, may not adequately address issues of many effects, integrated effects, or multiple gases. Finally, the model that is otherwise suitable for your situation may not provide a credible reference case. For example, you could use EPIC to estimate emissions from tillage systems, but if your site's historic use does not fit any of the model's simulation categories, your report may lose credibility because your reference case may then be considered arbitrary.

\subsubsection{Reporting by Conservation District}

Local communities create soil and water conservation districts (SWCDs) that are in a unique position to be able to collect and aggregate data that may be used to report under the EPAct 1605(b) program. These districts, which often follow county boundaries, can receive funds from the state or may have the power to tax land in their jurisdictions to provide citizens a means of determining which soil and water conservation problems should be addressed and how. District employees work closely with staff from the USDA's Soil Conservation Service (SCS).

These linkages among national, state, and local levels allow conservation districts to use computer databases that are common across the United States. The districts enter data based on their knowledge of local practices and programs for which they assist landowners. A typical district office provides assistance to the extent requested by the landowners in the district and participates in special projects, such as erosion and sediment control work, conservation education, soil survey efforts, and the Small Watershed Protection Program. An important task has been overseeing the implementation of the 1985 and 1990 Farm Bills, which require that farmers develop and apply a conservation plan on their land in order to remain eligible for USDA program benefits.

The data currently gathered and entered into computer databases by both SCS and SWCD personnel at the district level provide most, if not all, the information required to track agricultural practices related to global climate change. The database system records changes to the landscape that SCS or district employees observe and/or initiate with the cooperation of the land users. Projects for EPAct 1605(b) reports can be identified using the district progress reporting codes, shown in Table 6.1. Each of these project codes is associated with a multi-page definition of the activity. For example, the description of Code 328, Conservation Cropping Sequence, begins, "An adapted sequence of crops designed to provide adequate organic residue for maintenance or improvement of soil tilth." This is followed by definitions of the elements of such a practice (including planning) and 32 possible variations. 
Table 6.1 Typical State Technical Guide Index of Standards and Specifications

\begin{tabular}{|c|c|c|c|c|c|}
\hline Code & Project & Code & Project & Code & Project. \\
\hline 310 & Bedding & 460 & Land Clearing & 586 & Stripcropping, Field \\
\hline 324 & Chiseling and Subsoiling & 451 & $\begin{array}{l}\text { Land Reclamation, Fire } \\
\text { Control }\end{array}$ & 589 & Stripcropping, Wind \\
\hline 326 & Clearing and Snagging & 456 & Land Reclamation, & 587 & Structure for Water Control \\
\hline 327 & Conservation Cover & 453 & $\begin{array}{l}\text { Land Reclamation, Landslide } \\
\text { Treatment }\end{array}$ & 606 & Subsurface Drain \\
\hline 328 & $\begin{array}{l}\text { Conservation Cropping } \\
\text { Sequence }\end{array}$ & 452 & $\begin{array}{l}\text { Land Reclamation, Shaft and } \\
\text { Adit Closing }\end{array}$ & 607 & Surface Drainage, Field Ditch \\
\hline 329 & Conservation Tillage & 454 & $\begin{array}{l}\text { Land Reclamation, } \\
\text { Subsidence Treatment }\end{array}$ & 608 & $\begin{array}{l}\text { Surface Drainage, Main or } \\
\text { Lateral }\end{array}$ \\
\hline 330 & Contour Farming & 453 & $\begin{array}{l}\text { Land Reconstruction, } \\
\text { Abandoned Mined Land }\end{array}$ & 600 & Terrace \\
\hline 340 & $\begin{array}{l}\text { Cover and Green Manure } \\
\text { Crop }\end{array}$ & 544 & $\begin{array}{l}\text { Land Reconstruction, } \\
\text { Currently Mined Land }\end{array}$ & 612 & Tree Planting \\
\hline 342 & Critical Area Planting & 466 & Land Smoothing & 614 & Trough or Tank \\
\hline 344 & Crop Residue Use & 468 & Lined Waterway or Outlet & 620 & Underground Outlet \\
\hline 349 & Dam, Multiple Uses & 472 & Livestock Exclusion & 312 & Waste Management System \\
\hline 356 & Dike & 484 & Mulching & 425 & Waste Storage Pond \\
\hline 362 & Diversion & 590 & Nutrient Management & 313 & Waste Storage Structure \\
\hline 380 & $\begin{array}{l}\text { Farmstead and Feedlot } \\
\text { Windbreak }\end{array}$ & 500 & Obstruction Removal & 359 & Waste Treatment Lagoon \\
\hline 382 & Fencing & 582 & Open Channel & 633 & Waste Utilization \\
\hline 386 & Field Border & 510 & $\begin{array}{l}\text { Pasture and Hayland } \\
\text { Management }\end{array}$ & 638 & $\begin{array}{l}\text { Water and Sediment Control } \\
\text { Basin }\end{array}$ \\
\hline 392 & Field Windbreak & 512 & Pasture and Hayland Planting & 641 & Water Table Control \\
\hline 393 & Filter Strip & 595 & Pest Management & 642 & Well \\
\hline 394 & Firebreak & 516 & Pipeline & 990 & Well Testing \\
\hline 399 & Fishpond Management & 556 & Planned Grazing Systems & 657 & $\begin{array}{l}\text { Wetland Development or } \\
\text { Restoration }\end{array}$ \\
\hline 402 & Dam, Flood Water Retarding & 378 & Pond & 645 & $\begin{array}{l}\text { Wildlife Upland Habitat } \\
\text { Management }\end{array}$ \\
\hline 408 & $\begin{array}{l}\text { Forest Land Erosion Control } \\
\text { System }\end{array}$ & $521 \mathrm{~A}$ & $\begin{array}{l}\text { Pond Sealing and Lining - } \\
\text { Flexible Membrane }\end{array}$ & 644 & $\begin{array}{l}\text { Wildlife Wetland Habitat } \\
\text { Management }\end{array}$ \\
\hline 409 & Forest Land Management & $521 \mathrm{~B}$ & $\begin{array}{l}\text { Pond Sealing and Lining - } \\
\text { Soil Dispersant }\end{array}$ & 652 & Woodland Direct Seeding \\
\hline 410 & Grade Stabilization Structure & $521 \mathrm{C}$ & Pond Sealing, Bentonite & 654 & $\begin{array}{l}\text { Woodland Improved } \\
\text { Harvesting }\end{array}$ \\
\hline 412 & Grassed Waterway & 338 & Prescribed Burning & 666 & Woodland Improvement \\
\hline
\end{tabular}


Table 6.1 (cont'd)

\begin{tabular}{|c|l|c|l|c|c||}
\hline Code & \multicolumn{1}{|c|}{ Project } & Code & \multicolumn{1}{c|}{ Project } & Code & \multicolumn{1}{c|}{ Project } \\
\hline 411 & $\begin{array}{l}\text { Grasses and Legumes in } \\
\text { Rotation }\end{array}$ & 991 & Record Keeping & 660 & Woodland Pruning \\
\hline 560 & Access Road & 566 & $\begin{array}{l}\text { Recreation Land Grading and } \\
\text { Shaping }\end{array}$ & 490 & Woodland Site Preparation \\
\hline 422 & Hedgerow Planting & 568 & $\begin{array}{l}\text { Recreation Trail and } \\
\text { Walkway }\end{array}$ & 990 & Well Testing \\
\hline $522 \mathrm{~A}$ & Irrigation Pit & 558 & Roof Runoff Management & 991 & Record Keeping \\
\hline 436 & Irrigation Storage Reservoir & 350 & Sediment Basin & 333 & Cross Slope Farming \\
\hline 442 & Irrigation System, Sprinkler & 574 & Spring Development & 342 & Critical Area Planting \\
\hline 441 & Irrigation System, Trickle & 584 & Stream Channel Stabilization & 3311 & Cross Slope Farming \\
\hline 430 & $\begin{array}{l}\text { Irrigation System Conveyance } \\
\text { - Pipeline }\end{array}$ & 580 & $\begin{array}{l}\text { Streambank and Shoreline } \\
\text { Protection }\end{array}$ & $318 \mathrm{I}$ & Dead Poultry Composting \\
\hline 449 & Irrigation Water Management & $585 B$ & Stripcropping, Buffer & & \\
\hline 561 & Heavy Use Protection Area & 585 & Stripcropping, Contour & & \\
\hline Source: & Virginia State Technical Guide & & & & \\
\hline
\end{tabular}

These data are shared with the USDA's Agriculture Stabilization and Conservation Service who collect and share data on crop yield and field boundary changes. However, both of these data sets are only the physical data for projects, not the emissions effects of the projects. In order to report under EPAct 1605(b), the district offices would have to apply methods and factors to estimate emissions from both a reference case and a project case.

A reference case could be constructed from data already being collected by the districts. Every five years (for example, 1987 and 1992) the districts, using statistical sampling methods, inventory all the land they have information about. Data for the intervening years represent changes from the previous inventory, for example, acreage that has been taken from conventional tillage and put into conservation tillage during the preceding year. Data can be retrieved from any year and compared to the inventory year.

\subsection{Reportable Types of Projects in the Agricultural Sector}

If you report emissions for your entire operation (see Section 6.2), you may wish to define your emissions reductions project at that level also. You would then simply report emissions in a reference case year (say, 1990) and emissions in the project year; if the project year emissions are less, you have emissions reductions to report. 
This section addresses activities that may be analyzed using either a basic or modified reference case-cropland management (for carbon sequestration or reduced fuel consumption), grazing land improvement, windbreaks and shelterbelts, reduction of manure methane emissions, irrigation water management, efficient nutrient management for crop production, and growing biomass. The objective is to provide an overview of anticipated effects and to suggest published studies that may be useful for framing your estimates. However, reference to a particular study should not be construed as an endorsement of its contents by DOE.

Also, these are only some of the types of projects that could be reported in the agricultural sector. Others could include (but are not limited to) changing the diets or diet supplements of animals, changing the types or amounts of fertilizer used, using more energy-efficient equipment, removing land from production, and switching to less energy-intensive crops. For example, in a large rowcrop operation, the primary activity might be sequestering carbon and reducing the release of nitrous oxide into the atmosphere.

Some projects may be most appropriately analyzed using approaches and data found in other supporting documents. Windbreaks and shelterbelts, for example; can capture carbon in the trees and shrubs themselves and also reduce energy use in buildings; these functions of trees are covered in the supporting document for the forestry sector. (However, because of the mix of vegetation and the species of trees normally used for windbreaks and shelterbelts, these projects would need to be treated as reporter-designed projects, not estimated using default factors found in that document.) Similarly, the forestry sector document discusses establishing short-rotation woody biomass plantations (but not grasses) for biomass energy and agroforestry, the combination of agriculture and silvaculture on the same tract of land. The use of fuels such as ethanol made from biomass is discussed in the transportation sector. Projects that report reductions associated with energy use (fuel reductions) can be analyzed using the approach outlined in the supporting document for the industrial sector, along with the default factors in Appendixes B and C.

\title{
6.4.1 Cropland Management
}

No-till practices appear to increase the amount of organic carbon in the top 4 to 6 inches of the soil profile. Limited research on conservation tillage indicates that this system maintains the existing organic matter equilibrium. Although conventional tillage has been shown in long-term plots to reach an equilibrium, smaller losses have been noted after the initial decline (Kern and Johnson 1993). Based on this study of the impacts of conservation tillage on national soil and organic carbon levels, you may assume that conventional tillage continues to reduce SOC, conservation tillage prevents further loss, and no-till increases SOC. However, different soil types (with different texture, drainage, and erosion status) will respond differently to the same management regimes.

You may report increases in carbon sequestration accomplished through adoption of no-till systems, through the establishment of permanent vegetative cover, and through residue management. You may test any number of fields with applicable soil mapping units or one representative field and its soil mapping units.

\author{
Agricultural Sector-Page 6.12
}


You may also report estimated accomplishments from an ecosystem-based management approach to the entire farm to account for areas that are cumbersome to track individually, such as grassed waterways and permanent buffers between fields and streams. You may report the total but specify each practice.

\section{Reference case}

For projects involving changing tillage practices, the basic reference case would be the tillage practices in the year(s) before you began no till or conservation till. If you have no site-specific data and you use a model such as EPIC, you can run the model for conventional or conservation tillage, if that is the appropriate reference case.

\section{Effects of the project}

The major effect should be to sequester organic carbon in the A soil horizon (the top 4 to 6 inches). Other effects would include increasing the release of nitrous oxide, since residue on the soil surface will increase soil moisture and carbon. (The residue will have other conservation benefits, including reducing soil temperatures, increasing infiltration, and increasing the water-holding capacity of the soil.) If you maintain vegetative cover, carbon sequestration in the soil should increase.

Based on data compiled by the Conservation Technology Information Center, ${ }^{(a)}$ fuel use is reduced by adopting conservation tillage and greatly reduced by using no-till. Producers have also reduced their fuel use by combining pesticide, fertilizer, and planting operations, thereby reducing the number of trips across a field.

\section{Estimation of effects for the reference case and project}

The Soil Conservation Service (SCS) Technical Guides, developed by individual states, provide guidance for an appropriate estimation system. The conservation plan that documents the applied resource management system will show the data about how and how often nutrients are applied. You may use this information to calculate the total tons of carbon sequestered.

Soil organic matter content testing could be used to document carbon sequestration in areas of no-till and permanent cover. Your soil carbon testing program would require an initial soil test reading to show the present carbon level or the level before the field was planted to permanent cover or converted to a no-till operation. Then, on a periodic basis (for example, every five years), another test on the same field would be taken and the results input into a soil carbon sequestration database. To control variability in the soil sampling procedure, you should follow your state's SCS technical guidelines.

EPIC, an SCS computer program that models farm management practices (Williams et al. 1984) plus a two-equation model (Kern and Johnson 1993) that estimates organic carbon may be used to quantify the

(a) Conservation Technology Information Center, 1220 Potter Drive, Room 170, Purdue Research Park, West Lafayette, IN 47906-1334.

Agricultural Sector-Page 6.13 
organic carbon level in the soil as a reference case at the beginning of the sequestration process. This same approach can be used to estimate the carbon level in the soil after application of no-till or permanent vegetative cover is implemented. EPIC is a multi-year simulation with daily time-step accounting that considers weather, soils, cropping rotations, planting dates, cultivation dates, fertility dates, herbicide applications, all types of tillage and management practices, and natural wind or water erosion process. It monitors soil fertility, soil organic content, soil moisture, and soil erosion. It has the capability to provide very accurate accounting of "before and after" sequestered soil carbon-the basic reference case and the project case.

Estimates of emission reductions for fuel use could be based upon historical fuel consumption on a per acre basis and then tracked with reports of current use. This information would include tillage reduction figures as well as figures for reducing the number of trips across a field. The total gallons of fuel saved on a farm would be converted to total carbon emission reductions. The SCS CARE computer program or another farm budget program can be used to estimate fuel savings.

If you collect information on total benefits of no-till, then emission reductions could be reported specifically for the type of tillage system used on a farm (See Table 6.2). This approach has the advantage of making reporting relatively easy and providing a standard estimate of emission reductions. Example 6.2 illustrates one project analysis for a conservation tillage project.

Table 6.2. Average Carbon Emitted from Energy Use Associated with Crop Production ${ }^{(a)}$

\begin{tabular}{||l|c|}
\hline \multicolumn{1}{|c|}{ Tillage Method } & Carbon Emitted $(\mathrm{kgC} / \mathrm{ha} / \mathrm{yr})^{(\mathrm{b})}$ \\
\hline Conventional & 52.8 \\
\hline Minimum tillage & 45.1 \\
\hline No tillage & 29.0 \\
\hline $\begin{array}{l}\text { (a) Includes carbon for herbicide manufacturing and for machinery and repair. Based upon the } \\
\text { energy estimates in liters of diesel fuel per hectare. }\end{array}$ \\
(b) kg C/hectare/year, using typical density of \#2 diesel fuel of $852 \mathrm{~g} /$ liter and a carbon content of \\
$873 \mathrm{~g} \mathrm{C/kg.}$ \\
Source: Frye 1984.
\end{tabular}


Example 6.2 - Conservation District Reporting Conservation Tillage

The John Marshall Soil and Water Conservation District encompasses Fauquier County, an area of 660 square miles (422,400 acres) in Virginia. In 1993, this office assisted 372 landowners and participated in a number of special projects. The office collected data on conservation projects using CAMPS, microcomputer software developed by the Soil Conservation Service (SCS).

This district wished to report under the EPAct $1605(\mathrm{~b})$ program to link its local efforts to national initiatives in a way that would be visible to the local landowners. In order to report, the district obtained agreement from over 300 of the landowners to report their data. The district reported the remaining landowners as other potential reporters. Staff members realized that, because appropriate emissions factors were not available for all their activities, only a limited subset could be reported. Further, they wished to keep the costs of reporting to an absolute minimum. Therefore, they decided to report conservation tillage only for the reporting year, 1993.

Conservation tillage data (code 329) showed three reports during 1993, for a total of 1,339 acres that came under conservation tillage. Using a reference case of conventional tillage, the district staff calculated an annual reduction per hectare of $7.7 \mathrm{~kg}$ carbon emitted from energy use associated with crop production (see Table 6.2; $52.8-45.1=7.7 \mathrm{kgC} / \mathrm{ha} / \mathrm{yr}$ ).

They then computed the emissions reductions by multiplying acres by the carbon savings $(1,339$ acres $\bullet 1$ hectare/ 2.47 acres $\bullet 7.7 \mathrm{kgC} /$ hectare $/ \mathrm{yr}=4,174.2 \mathrm{~kg} \mathrm{C}$ ), then multiplying the carbon reduction by 3.67 to obtain the annual carbon dioxide emissions reductions (see Appendix D):

$$
4,174.2 \cdot 3.67=15,319 \mathrm{~kg} \mathrm{CO}
$$

For the report, the kilograms may be converted to metric tons, using the tables in Appendix A.

\subsubsection{Windbreaks and Shelterbelts}

Windbreaks are composed of rows of progressively taller vegetation established perpendicular to the predominate wind flow. The lowest vegetation is on the windward side and the tallest on the downstream, leeward, side of the flow. This vegetation is a mixture of low-to mid-level brush and low- to tall-growing trees. As these plantings mature, they offer significant resistance to wind flow and reduce greenhouse gas emissions as discussed below. Windbreaks and shelterbelts are grown mostly to slow winds during the growing season, thus stopping wind erosion and plant desiccation. They can also be used to shelter the farmstead, thus reducing fuel required to heat and cool the buildings.

Windbreaks and shelterbelts are usually a small component of a larger modern farm operation when computed on a per-acre basis, and they use different species from the trees for which the forestry sector document gives default values (Appendix 5.A). For these two reasons, windbreaks and shelterbelts cannot be estimated as standard forestry projects.

\section{Reference case}

The simplest basic reference case is the land without windbreaks and shelterbelts. Your reference case may include the land use without the project and fuel and electricity use by the farmstead before your windbreak project. If you are replacing an existing shelterbelt, computations will prove more difficult.

\section{Agricultural Sector-Page 6.15}




\section{Effects of the project}

The effects of windbreaks and shelterbelts on greenhouse gas emissions have two components: the capture of carbon in the vegetation itself and the reduction in energy requirements for cooling and heating the farmstead.

\section{Estimation of effects for the reference case and project}

To estimate carbon storage, the most credible method is field measurement. Although research literature (for example, Brandle, Wardle, and Bratton 1992) may provide carbon storage factors by type of vegetation, your site-specific project may yield quite different results. Although you may report using factors derived from research, you should also use measured data if you can.

Shelterbelts may reduce winter fuel consumption at the farmstead by 10 to 30 percent (USDA 1978). To estimate your reduced energy requirements, you may use fuel and energy bills for both the reference case and project cases, corrected for differences in weather between the two cases. If you have reduced electricity use, you may use your state's default emissions factors (Appendix C) if you do not have data from your electricity supplier about its specific emissions. You may find further guidance on how to estimate emissions reductions for the farm buildings in Part 2 of these supporting documents (Residential and Commercial Buildings Sector).

\subsubsection{Reduction and Recovery of Manure Methane Emissions}

Methane is produced during the anaerobic decomposition of the organic material in livestock and poultry manure. Large livestock facilities store and treat livestock manure in anaerobic lagoons and pits to comply with the limitations on the legal discharge of manure into surface waters. These lagoons and pits are conducive to the production of methane, which can be captured for energy production. Recovered methane can be used to produce electricity or to fuel gas-fired equipment such as boilers or chillers.

The major approaches for recovering and using livestock manure methane are as follows:

- Covered Anaerobic Lagoon: Anaerobic lagoons are among the simplest manure storage and treatment systems in current use. Methane is produced in the lagoon by the biological process that stabilizes the manure. Covering the lagoon allows the recovery of methane, which then can be used as an on-farm energy source.

- Plug Flow and Complete Mix Digesters: Digesters have been used for many years to produce energy from livestock manure. The digesters are commonly built as tanks (complete mix) or trenches (plug flow). As the manure decomposes in the digester, the methane is recovered and used for fuel. 
Alternative manure management systems that reduce methane emissions involve handling manure under aerobic conditions. These include land application, composting, and incineration of the manure.

You may report reductions of methane emissions from manure for your individual operating units or you may combine all your projects into a single report, taking care to account for potential effects within and outside of your organization. (See Example 6.3.)

\section{Reference case}

The most credible reference case would be the emissions from manure before the management system was implemented. However, no reliable method exists to estimate these emissions. Therefore, you should estimate your emissions reductions directly as the amount of methane you recover.

\section{Effects of the project}

The major effect is to reduce emissions of methane. Possible other effects include substitution of methane for fossil fuels, which reduces emissions from fossil fuel use.

\section{Estimation of effects for the reference case and project}

Estimating emissions reductions using actual measurements is possible in the particular case of an existing, covered lagoon from which you recover methane. Emissions reductions in that case equal the amount of methane recovered.

Under other circumstances emissions reductions cannot be estimated from the amount of gas recovered under a new manure management system. Emissions reductions equal the change in emissions resulting from the manure that is handled by the new management system. For example, if half the manure from an animal feeding/holding area (drylot) is transferred to a covered lagoon to recover gas, emissions from this area will also be reduced by half.

Measuring is difficult, but you may estimate emissions in one of two ways:

- If your existing lagoon is covered and the methane is recovered, reference case emissions may be estimated as the amount of methane recovered.

- You may use the set of emissions factors in Table 6.3 to estimate reference case emissions. To use these factors, first calculate total excretion of volatile solids and the amount of volatile solids handled in each manure management system. Next, select a climate region from those in the table, and multiply the amount of volatile solids in each system by the appropriate emissions factor.

Agricultural Sector-Page 6.17 
Table 6.3. Livestock Manure Methane Emissions Factors ${ }^{(a)}$

\begin{tabular}{|c|c|c|c|c|c|}
\hline Type of Manure Management & Dairy & $\begin{array}{l}\text { Beef in } \\
\text { Feedlots }\end{array}$ & Beef Grazing & $\begin{array}{l}\text { Swine- } \\
\text { Breeder }\end{array}$ & $\begin{array}{l}\text { Swine- } \\
\text { Fattening }\end{array}$ \\
\hline Anaerobic lagoons-all climates & 146 & 201 & 104 & 220 & 287 \\
\hline Pasture/range and solid storage-cool & 1.6 & 2.2 & 1.2 & 2.4 & 3.2 \\
\hline $\begin{array}{l}\text { Pasture/range and solid storage- } \\
\text { temperate }\end{array}$ & 2.4 & 3.4 & 1.7 & 3.7 & 4.8 \\
\hline Pasture/range and solid storage-warm & 3.3 & 4.5 & 2.3 & 4.9 & 6.4 \\
\hline Drylot-cool & 1.6 & 2.2 & 1.2 & 2.4 & 3.2 \\
\hline Drylot-temperate & 2.4 & 3.4 & 1.7 & 3.7 & 4.8 \\
\hline Drylot-warm & 8.1 & 11.2 & 5.8 & 12.2 & 15.9 \\
\hline Daily spread-cool & 0.2 & 0.2 & 0.1 & 0.2 & 0.3 \\
\hline Daily spread-temperate & 0.8 & 1.1 & 0.6 & 1.2 & 1.6 \\
\hline Daily spread-warm & 1.6 & 2.2 & 1.2 & 2.4 & 3.2 \\
\hline Liquid/slurry-cool & 16 & 22 & 12 & 24 & 32 \\
\hline Liquid/slurry-temperate & 57 & 78 & 40 & 85 & 112 \\
\hline Liquid/slurry-warm & 106 & 145 & 75 & 159 & 207 \\
\hline Pit storage $<30$ days - cool & 8 & 11 & 6 & 12 & 16 \\
\hline Pit storage $<30$ days-temperate & 29 & 40 & 21 & 44 & 57 \\
\hline Pit storage $<30$ days-warm & 54 & 74 & 38 & 81 & 105 \\
\hline Pit storage $>30$ days $-\mathrm{cool}$ & 16 & 22 & 12 & 24 & 32 \\
\hline Pit storage $>30$ days-temperate & 57 & 78 & 40 & 85 & 112 \\
\hline Pit storage $>30$ days - warm & 106 & 145 & 75 & 159 & 207 \\
\hline \multicolumn{6}{|c|}{ (a) in $\mathrm{kgs}$ of methane $/ 1000 \mathrm{kgs}$ of volatile solids } \\
\hline
\end{tabular}


Example 6.3 - Reporting Methane Emissions Reductions

In 1989 Robert Link began systematically making improvements to his farm to increase the overall economic efficiency of his operation. As one aspect of his efforts, he hired a farm management consultant, Gordon Stillwell, who analyzed energy inputs and recommended several changes that resulted in reducing fuel and electricity use on the farm. During the same year, Link followed the example of a neighbor and covered his manure lagoon so he could use the methane he recovered as on-farm fuel. The methane recovery project was operational by January 1991 .

When the EPAct 1605(b) program was implemented, Link was encouraged by a local conservation district employee to submit a report out of his belief in the contribution agriculture could make to solving the problem of increasing greenhouse gas emissions. The conservation district, said the employee, was going to submit a report on changes in cropping and tillage practices. "But you've made other changes," he said, "and you should get all of them on record."

Link wanted to report and wanted his report to be accurate. However, he also wanted to spend as little of his time and energy as possible on reporting. He therefore called Gordon Stillwell to ask if the consultant still had data from his analysis readily available. When he called Stillwell, however, the consultant said that he wished to report the data himself in order to be able to tell his clients that his accomplishments were on the federal record. Link agreed to let Stillwell report the reductions in fuel and electricity use, knowing that he could still report the methane recovered from his covered manure lagoon.

Link had metered his recovered methane, so he could estimate the amount of recovered methane directly as the emissions reduction, following the technical guidance in the EPAct $1605(\mathrm{~b})$ program.

\subsubsection{Irrigation Water Management}

Only about 3 percent of the nation's energy is used in agriculture and only 23 percent of this quantity (or less than 0.7 percent of the nation's energy use) powers the irrigation pumping plants. However, in those areas where irrigation allows continuous agricultural production, the energy use for irrigation remains a much larger percentage of the on-farm energy requirement, often exceeding two-thirds. Further, in some locations, the peak electrical power generating capacity is often driven by irrigation pumping (ASAE 1990).

Although the energy savings from accelerated irrigation water management is relatively small on a national scale, the savings in selected portions of the 17 western states could be significant, especially in the states of California, Texas, and Nebraska. In recent years, these three states have accounted for one-half the on-farm energy used for irrigation (ASAE 1990).

Energy savings from irrigation may be achieved through any of the following actions:

- Reduced pumping volume which may be achieved through

- $\quad$ runoff reuse

- improved application efficiencies and irrigation scheduling

- improved irrigation systems

low energy precision application (LEPA)

low-pressure center pivot

surge 


\section{trickle}

- $\quad$ moisture stress-limited

- Reduced pumping head

- $\quad$ reduced pipeline friction losses

- $\quad$ substitution of surface water for groundwater

- $\quad$ improved irrigation systems (see above)

- Improved pumping plant efficiency

- Alternative energy sources

Of these, those offering the greatest potential for substantial savings are reduced pumping volume and improved pumping plant efficiency. Agricultural irrigation efficiencies are often 10 to 20 percent less than that reasonably achievable. On-farm pump plant efficiencies are often found to be far below the 75 percent that can be attained with good design, installation, operation and maintenance. In several studies, half the pump plant efficiencies were found to be less than 75 percent, with some plants as low as 40 percent (ASAE 1990).

\section{Reference case}

A basic reference case would be an existing system for which the efficiencies and fuel use are known. These data would likely have been gathered in order to determine the costs and benefits of improving the system. A modified reference case is more problematic, for example, the installation of a new system or of equipment that is more energy-efficient or uses alternative fuel. In this situation, you will need to carefully consider what emissions would have been in the absence of the new system. In order to have a credible emissions reductions report, your reference case must be acceptable to your audiences.

\section{Effects of the project}

The effect of your irrigation project is likely to be reduction in energy use and/or use of energy sources that have lower emissions. These effects may be increased by improved operation and maintenance procedures.

\section{Estimation of effects for the reference case and project}

You may quantify emission reductions from improved irrigation management in the following ways:

- Reductions in energy use could be based on fuel and utility cost reductions and the resultant savings in fuel. 
- Where energy is saved by another entity (for example, the Central Arizona Project has nine pumping stations on its canals) because the farmer reduced water volume, estimates of reductions would be based on the equivalent carbon dioxide reduction from the energy saved.

\subsubsection{Grazing Land Improvement}

Grazing lands worldwide provide a significant opportunity to reduce net emissions of greenhouse gases by capturing carbon in soils and below-ground biomass and by reducing the need for more energyintensive processed feed for livestock. In the United States, grazing land resources represent 45 percent of non-federal rural lands, including rangelands (63 percent), pasturelands ( 21 percent), haylands (10 percent) and grazed forestlands ( 6 percent)-a total area of 634 million acres (USDA,SCS 1987).

The potential for increased carbon sequestration through the improvement of grazing land conditions is supported by numerous studies. Globally, rangeland soils have been determined to contain $150-$ 300 percent as much carbon as does above-ground biomass (Kinsman and Trexler 1993). In U.S. studies at the Jornada Experimental Range (Texas), soil organic carbon (SOC) in rangelands is twice that in croplands (Johnson et al. 1992). Lands in the Conservation Reserve Program (CRP) that were managed for carbon sequestration over five years showed a 5 to 16 percent improvement in the amount of SOC (Gebhart et al. 1992).

A permanent grassland environment stores more SOC than does cropland agriculture, and grazing land stimulates more below-ground biomass that stores more carbon. Grasses, forbs, and shrubs represent the primary vegetative components found on rangelands. Grazed rangelands convert six times more energy to below-ground biomass compared to above-ground biomass. Ungrazed rangelands deliver only three times as much energy to below-ground biomass than was allocated for above-ground biomass (Sims and Singh 1978).

Generally greater above-ground biomass indicates greater below-ground biomass on rangeland sites. Rangelands in good and excellent condition will typically have greater above-ground biomass than these sites in poor or fair condition. Blue grama rangelands were found to correlate to higher organic carbon in near climax or excellent range condition (Spaeth 1990). Studies using the Simulation of Production and Utilization of Rangelands (SPUR) model, 1991 version, on data collected by the SCS/ARS Range Study Team, have shown a definitive trend toward higher organic carbon values on tallgrass sites compared to shortgrass sites.

Improvement of conditions in grazing lands will generally offer effective energy savings to livestock producers. Livestock producers who have integrated state-of-the-art grazing systems in New York have reduced the cost of dairy production by 19 percent (Sweetland 1993). Most of this savings has been achieved though the reduction of feeding harvested or processed feeds. Reducing processed feed in livestock operations places more reliance on low energy pastures from grazing lands, thereby significantly reducing fossil fuel expenditure directly by reducing fuels expended during harvesting, 
processing of livestock feeds, and spreading manure. Fossil fuels are saved indirectly by a reduction in the use of mineral fertilizers needed in the production of high-yielding grain and silage crops.

Although potential biomass production levels are generaily considered least in arid and semiarid environments, long-term sequestration is at a high level because of the low level of natural oxidation that occurs. Annual dry biomass of irrigated halophytes (saline-tolerant plants) has been shown to store large quantities of carbon per hectare (Glenn 1993).

\section{Reference case}

The reference case could be cropland, or unmanaged rangeland or grassland, with appropriate measurements or estimates of SOC and perhaps other carbon sequestration data.

\section{Effects of the project}

The major effect of improving grazing land conditions (even though it is a slow, 10 to $20+$ year process) will be an increase in the sequestration of atmospheric carbon, partitioned in above- and below-ground sectors of grazing land ecosystems. Other effects might be increasing the efficiency of large ruminant livestock production, thereby reducing (per unit of production) methane emissions from livestock and reducing the need for processed feed, thus eliminating or reducing the energy inputs involved in the production of processed feed.

\section{Estimation of effects for the reference case and the project}

As an alternative to using direct measurement and/or engineering methodologies to estimate the carbon levels associated with your activities before and after implementing a change in farming operations, you may wish to use a process simulation model such as SPUR (USDA 1987), a comprehensive rangeland ecosystem model that was developed as a tool for both research and management. The SPUR model has five components: climate, hydrology, plant, animal (both domestic and wildlife), and economics. In the plant component, net photosynthesis is the basis for predicting total above-ground biomass. Carbon and nitrogen levels are estimated and tracked by the model through the life-cycle process, including standing green, standing dead, live roots, dead roots, seeds, litter, and soil organic matter.

This model can be used to predict accumulation of SOC in range and grasslands of the United States. Inputs required by the model are initial biomass content, and parameters that describe the species, photosynthesis level, transpiration rate, and nitrogen utilization.

\subsubsection{Efficient Nutrient Management for Crop Production}

High-yield production agriculture can be sustainable agriculture. They are not mutually exclusive. As conservation and agronomic practices are adapted, nutrient use efficiency increases, erosion is slowed, the potential for nonpoint source water pollution drops, and crop yields go up. More productive plants 
will require more nutrients-perhaps twice the demand of current plants. As that happens, less land is needed, so more fragile land can be converted to permanent ground cover, set aside for wildlife protection and used for recreational purposes.

Plant nutrients from all sources, including commercial fertilizers, animal manures, human wastes, legumes, native soil fertility, and plant residues can contribute to the total yield of crops. Once in the soil, all nutrient sources undergo various transformations that result in crop uptake and use. These transformations are all subject to other processes, such as potential leaching of nitrate- $\mathrm{N}$ into groundwater, denitrification, $\mathrm{N}$ volatilization, release of nitrous oxide into the atmosphere, nutrient loss by erosion, and so on.

Adding nitrogen to the soil results in some nitrous oxide emissions, a very effective greenhouse gas. But how much is emitted depends upon many factors, including the quantity, the acreage, the form in which nitrogen is added, the manner of application, and the frequency of application.

Efficient nutrient management helps to maximize the sum of all benefits-economic and environmental. Appropriate trade-offs must be made between using nutrient sources in a manner that results in the greatest economic and agronomic benefit to the farmer, while conserving energy and otherwise protecting the environment. While energy requirements for the production of commercial fertilizers are high, so are energy needs for the use of animal manures, human wastes, and the production of legumes. Other factors must be considered as well.

- Nutrient contents of manures are low compared to commercial fertilizers, so large quantities must be applied to each acre. This requires significant amounts of fuel and is usually labor intensive. Economics prevent the efficient hauling of manure more than about 10 miles from the source.

- Legumes provide nitrogen, but they also require larger amounts of phosphorus, potassium, and other nutrients to be effective nitrogen producers. Each ton of alfalfa, for example, removes more than 60 pounds of potassium oxide per acre if the crop is harvested.

- All forms of nitrogen added to the soil result in the formation of nitrous oxide.

The efficiency of nutrient use in agriculture is greatly improving as a result of farmer implementation of science-based technologies, including conservation tillage practices to reduce erosion, hold more nutrients in the soil, and improve infiltration. Some of the ways farmers can ensure that applied nutrients get into the plant are through testing and plant analysis. Precise application equipment, timing and placement of nutrients also help, by matching nutrient levels to crop needs. In addition, encapsulating fertilizer to slow the release of nitrogen and using nitrification inhibitors will reduce nitrous oxide emissions.

All nutrient sources that are valuable to the farmer can be managed in ways that help to reduce erosion, to reduce nitrate- $\mathrm{N}$ in groundwater, and to control emissions of greenhouse gases such as nitrous oxide. Further, as nutrient use and crop yields increase, more carbon can be sequestered.

\section{Agricultural Sector-Page 6.23}




\section{Reference case}

In developing your reference case for nutrient management, you need to list the practices that would have been used, except for the project. For example-

- Crop rotation

- Nutrients in the soil (soil test)

- Seeding rate

- Nitrogen management (number and type of applications)

- Pest control (methods and restrictions).

Changes in any or all of these practices can result in environmental advantages, including soil carbon sequestration.

\section{Effects of the project}

If, through good management practices, you apply the needed nitrogen and increase crop productivity, you may decrease nitrous oxide emissions in two ways: (1) you can allow some land to remain uncultivated (because your cropland will be more productive) and (2) the nitrogen you apply will be used more efficiently by the plants if you apply the amount they need where they need it in the root zone. In addition, you will reduce carbon dioxide emissions because less land is under cultivation.

\section{Estimation of effects for the reference case and project}

The emissions effects of best nutrient management practices are difficult to estimate. No standard method exists to perform field measurements of nitrous oxide, and factors derived from research literature may be problematic. The reductions in carbon dioxide emissions can be derived from the emissions factors associated with cultivation of certain crops. If you convert the noncultivated land to permanent vegetative cover (grazing land, for example), you may also determine the amount of carbon sequestered by that activity. Example 6.4 illustrates some of the aspects of reporting a nutrient management project.

\section{Example 6.4 - Association Report of a Nutrient Management Project}

A group of farmers in central Virginia formed the Best Rural Management Practices Club in order to demonstrate and . quantify the benefits of conservation and energy efficiency in nutrient management. They began by calling on university extension service scientists to measure several parameters over one growing season and to work with them in designing and implementing best management practices (BMPs) over the next growing season. Thus, they had the data to develop a historic reference case.

The activities that became defined for basic and project cases included the following: 


\begin{tabular}{|l|l|l|}
\hline Example 6.4 - (cont'd) & \multicolumn{2}{|l|}{} \\
\hline Practice & $\begin{array}{l}\text { Previous Management } \\
\text { (Reference Case) }\end{array}$ & BMP Management \\
& (Project Case) \\
Rotation & Sometimes & Always \\
Soil test & Unbalanced nutrients & Balanced nutrients \\
Seeding rate & 1.5 bu/A & 22 seeds/ft row \\
N management & Single application & Tissue test; split applications \\
Pest control & No integrated pest management or scouting & Use integrated pest management and scouting \\
\hline
\end{tabular}

Beyond their expectations, they achieved the following results:

- Higher yields: $85 \mathrm{bu} / \mathrm{A}$ with BMP vs. $50 \mathrm{bu} / \mathrm{A}$

- Higher $\mathrm{N}$ use efficiency: $0.65 \mathrm{bu} / \mathrm{lb}$ with BMP vs. $0.50 \mathrm{bu} / \mathrm{lb}$

- Lower production costs: $\$ 2.44 / \mathrm{bu}$ with BMP vs. $\$ 3.20 / \mathrm{bu}$

- Less $\mathrm{N}$ left in the soil from BMP: $34 \mathrm{lb} / \mathrm{A}$ vs $40 \mathrm{lb} / \mathrm{A}$

- More $\mathrm{CO}_{2}$ captured: 3.8 more tons in total with BMP.

Although their primary purpose was to increase crop productivity relative to nutrient inputs, the club members noted that they had achieved an increase in carbon sequestration. However, they realized that the increase was part of the carbon flow and would be lost as the plants were used after harvest. As part of their efforts to publicize and extend the use of BMPs, they wanted to submit a report under the EPAct 1605(b) program, but they were puzzled about the relationship between their crop-related accomplishments and possible emissions reductions.

They knew, for example, that applying nitrogen means that nitrous oxide is emitted from the agricultural operation. However, John Johnston, a scientist from the university extension service, informed them that scientists do not know how to measure these emissions in the field and that no default factors existed. Thus, even though the group felt that their more efficient use of nitrogen actually resulted in fewer nitrous oxide emissions, they had no basis on which to estimate the reductions.

They decided that the only effect they could estimate with any confidence was less fuel use because they were more efficient about applying nutrients and controlling pests. For the hundred acres, the difference between the reference case and the project case was about the same difference between conventional till and minimum till, as they read the definitions from the conservation district. Using Table 6.2 from the technical support document for agriculture, they estimated 7.7 kilograms of carbon per hectare saved $(52.8-45.1=7.7)$. One hundred acres was converted to 40 hectares, then multiplied by 7.7 kilograms for a total of 308 kilograms of carbon saved. Multiplying the kilograms of carbon saved by 3.67 (the conversion factor from Appendix D), they estimated an emissions reduction of 1,131 kilograms of carbon dioxide.

After some discussion, the club members agreed to report the carbon sequestration and note separately in the club's report that there were nitrous oxide emissions in both the reference and project cases, but that changes in emissions could not be quantified. They agreed that their report next year would reflect land converted to grass cover and again mention the nitrous oxide. If methods were developed to quantify the nitrous oxide reductions, they could amend their reports in later years.

\subsubsection{Growth of Biomass as a Renewable Energy Source}

Biomass is currently being used to produce liquid fuels such as ethanol, methanol, and biodiesel as well as a fuel to produce electricity. In order to meet clean air standards in many cities across the nation, the Clean Air Act Amendments require the use of alternative fuels for motor vehicles. The Electric

\section{Agricultural Sector-Page 6.25}


Power Research Institute (EPRI) is promoting the use of biomass as an alternative, renewable source of energy that will reduce the net emissions of greenhouse gasses.

DOE is promoting research to ioientify a variety of efficient, high-yielding plants as a source of biomass and cost effective technologies to convert biomass to liquid fuels and/or electricity. USDA is supporting research to convert grains and vegetable oils to biofuels. Biomass crops can be woody (trees or short rotation woody biomass), herbaceous perennial (for example, switch grass), or herbaceous annual (such as corn or sorghum).

The production of biomass has an impact on carbon emissions in three different ways. First, it can substitute for fossil fuels. The conversion of biomass to energy releases $\mathrm{CO}_{2}$ into the atmosphere. The photosynthesis process recycles $\mathrm{CO}_{2}$ from the air and converts it into biomass. Therefore, any quantity of biomass substituted for fossils fuels will reduce the net increase of $\mathrm{CO}_{2}$ in the atmosphere that would occur from combustion of the fossil fuel.

Second, the difference in fuel and agricultural chemical requirements to produce biomass versus other crops will have an impact on carbon emissions to the atmosphere.

The third impact of producing biomass is the sequestration of carbon in the soil. On the average, there is less soil disturbance in the production and harvesting of biomass crops than for annual crops. This should reduce oxidation and release of carbon to the atmosphere and help sequester carbon in the soil (except if the biomass crop is an annual such as energy sorghum).

\section{Reference case}

The most credible reference case may be what the land was used for in the year before you initiated the biomass project. If you change crops (for example, from a food crop to switch grass), the energy inputs in terms of equipment, fertilizer use, and processing would constitute the major portions of the reference case.

\section{Effects of the project}

When examining biofuel projects, you must consider life cycle effects. For example, DeLuchi (1991) states that the growth of corn for biofuels actually increase greenhouse gas emissions because corn production is extremely fuel- and chemical-intensive, though other research analysis (for example, Graham et al. 1992) indicates that life cycle analysis yields emissions reductions.

\section{Estimation of effects for the reference case and project}

Estimating project effects, especially on a life cycle basis, is a complex, perhaps time-consuming process. For example, you should take into account fossil fuel requirements for the production of the crop and the production of nitrogenous fertilizers for both the reference and project cases. You need to know the conversion efficiencies to liquid fud or electricity and the energy substitution properties of

\section{Agricultural Sector-Page 6.26}


various fuels (Graham et al. 1992). The following example illustrates the process of estimating carbon dioxide reductions from growing biomass and using fuels made from that biomass.

\section{Example 6.5 - Report of a Biomass Project}

Don Marshall, a Midwestern farmer, harvested his hybrid poplars (a short rotation woody crop) in 1993 and wished to report the resulting emissions reductions under the EPAct 1605 (b) program. He had followed management practices reported in the research literature (Turhollow and Perlack 1991) and so felt he could use the assumptions and factors from an associated research article (Graham et al. 1992).

Marshall's yield was $11.3 \mathrm{Mg} / \mathrm{ha}$, or a total of approximately $1500 \mathrm{Mg}$ of biomass that would be converted to ethanol to displace gasoline. The ethanol yield from each megagram of biomass is 344 liters; Marshall's $1500 \mathrm{Mg}$ would thus yield

$$
1500 \mathrm{Mg} \bullet 344 \mathrm{~L} / \mathrm{Mg}=516,000 \text { liters }
$$

The current wood-to-ethanol technology produces a surplus of $184 \mathrm{kWh}$ of electricity per dry megagram of wood (taking into account that some electricity is used in processing the feedstock). Marshall's electricity yield was

$$
1500 \mathrm{Mg} \bullet 184 \mathrm{kWh} / \mathrm{Mg}=276,000 \mathrm{kWh}=276 \mathrm{MWh}
$$

To calculate the emissions saved from substituting ethanol for gasoline, Marshall (following Graham et al. 1992) assumed that the carbon content of gasoline is $0.723 \mathrm{~kg} / \mathrm{L}$ and one liter of ethanol can substitute for $0.8 \mathrm{~L}$ of gasoline; therefore, the carbon offset by the fuel substitution is

$$
516,000 \mathrm{~L} \cdot 0.8=412,800 \mathrm{~L} \text { gasoline }
$$

$412,800 \mathrm{~L}$ gasoline $\bullet 0.723 \mathrm{kgC} / \mathrm{L}=298,454 \mathrm{~kg} \mathrm{C}$

This figure must be adjusted for the carbon emissions involved in producing the woody crops; again, following Graham et al. (1992), Marshall used the carbon emissions calculated for his management regime $(0.29 \mathrm{Mg} / \mathrm{ha})$, multiplying that by his 133 hectares:

$$
133 \mathrm{ha} \bullet 0.29 \mathrm{MgC} / \mathrm{ha}=38.57 \mathrm{Mg} \mathrm{C}=38,570 \mathrm{~kg} \mathrm{C}
$$

The final carbon offset figure is thus $298,454-38,570=259,884 \mathrm{~kg} \mathrm{C}$. This figure would be converted to carbon dioxide emissions using the conversion figure in Appendix D:

$$
259,884 \mathrm{~kg} \mathrm{C} \cdot 3.67=953,774 \mathrm{~kg} \mathrm{CO}
$$

To determine the emissions saved from the electricity generated by the biomass, Marshall used the default emissions factor for his state (Illinois) from Appendix C. The carbon dioxide emissions factor for Illinois is $1137.6 \mathrm{lb} / \mathrm{MWh}$, so the emissions reduction from $276 \mathrm{MWh}$ generated by Marshall's biomass is

$$
276 \mathrm{MWh} \bullet 1137.6 \mathrm{lb} / \mathrm{MWh}=313,978 \mathrm{lb}=142,394 \mathrm{~kg} \mathrm{CO}
$$

Adding the figures for carbon dioxide reductions resulting from fuel substitution and the figure for electricity generation, Marshall arrived at the following total, which he reported under the EPAct 1605(b) program:

$$
953,774 \mathrm{~kg} \mathrm{CO}+142,394 \mathrm{~kg} \mathrm{CO}=1,096,168 \mathrm{~kg} \mathrm{CO}=1,096 \text { metric tons } \mathrm{CO}_{2}
$$

In his report, Marshall identified his local utility and the transport company that bought the ethanol as other potential reporters.

\section{Agricultural Sector-Page 6.27}




\subsection{References}

American Society of Agricultural Engineers (ASAE). 1990. Management of the Farm Irrigation Systems. Monograph, ASAE, St. Joseph, MI.

Brandle, J.R., T.D. Wardle, and G.F. Bratton. 1992. "Opportunities to Increase Tree Planting in Shelterbelts and the Potential Impacts on Carbon Storage and Conservation." In Forests and Global Change, Volume 1: Opportunities for Increasing Forest Cover, eds. R.N. Sampson and D. Hair. American Forests, Washington, DC.

Frye, W.W. 1984. "Energy Requirements in No-Tillage." In No Tillage Agriculture, Principles and Practices, ed. R.E. Phillips, S.H. Phillips, pp. 127-151. Van Nostrand Reinhold, New York, NY.

Gebhart, D.L., H.B. Johnson, M.S. Mayeux, and H.W. Polley. 1992. "Conservation Reserve Program Increases Soil Organic Carbon Content." Strategic Plan Issue, Grassland, Soil, and Water Research Laboratory, Temple, Texas. Unpublished.

Graham, R.L., L.L. Wright, and T.F. Turhollow. 1992. "The Potential for Short-Rotation Woody Crops to Reduce U.S. $\mathrm{CO}_{2}$ Emissions." Climatic Change 22:223-238.

Glenn, E., V. Squires, M. Olsen, and R. Frye. 1993. "Potential for Carbon Sequestration in the Drylands." Water, Air and Soil Pollution 70.

Johnson, H.B., H.W. Polley, D.L. Gebhart, H.S. Mayeux, and W.A. Dugas. 1992. Sequestration and Release of Carbon in the Terrestrial Carbon Cycle and its Interaction with the Atmosphere. Strategic Plan Issue, Grassland, Soil, and Water Research Laboratory, Temple, TX.

Kern, J.S., and M.G. Johnson. 1993. "Conservation Tillage Impacts on National Soil and Atmospheric Carbon Levels." Soil Sci. Soc. Am. J. 57:200-210.

Kinsman, J.D., and M.C. Trexler. 1993. "Terrestrial Carbon Management and Electric Utilities." In Water, Air and Soil Pollution 70.

Sims, P.L., and J.L. Singh. 1978. The Structure and Function of Ten Western North American Grasslands, Compartmental Transfer and Energy Flow Within the Ecosystem. Blackwell Scientific Publications.

Spaeth, K.E., Jr. 1990. Hydrological and Ecological Assessments of a Discrete Range Site on the Southern High Plains. Dissertation in Agriculture, Texas Tech University, TX.

Sweetland, A. 1993. Personal communication between Al Sweetland, a dairy farmer in Fabius, New York, and Greg Hendricks, a resources conservationist with the U.S. Department of Agriculture, Soil Conservation Service, Washington, DC.

Turhollow, A.F., and Perlack, R.D. 1991. "Emissions of $\mathrm{CO}_{2}$ from Energy Crop Production." Biomass and Bioenergy 1:129-135. 
U.S. Department of Agriculture (USDA), Agricultural Research Service. 1987. SPUR, Simulation of Production and Utilization of Rangelands, Documentation and Users Guide. ARS-63, USDA, Washington, DC.

U.S. Department of Agriculture, Soil Conservation Service (SCS). Field Office Technical. Guides.

U.S. Department of Agriculture, Soil Conservation Service (SCS). 1987. National Resources Inventory. Washington, DC.

U.S. Environmental Protection Agency (EPA). 1993. Anthropogenic Methane Emissions in the United States: Estimates for 1990. EPA 430-R-93-003, Washington, DC.

Williams, J.R., C.A. Jones, and P.T. Dyke. 1984. "The EPIC model and its application." In Proceedings ICRISAT-IBSNAT-SYSS Symposium on Minimum Data Sets for Agrotechnology Transfer, March 1983, Hyderabad, India. 


\section{Appendix A}

\section{Conversion Factors for Standard Units}


This appendix has been prepared in consistent metric units based on the Le Systeme International d'Unités (SI). Some important features of the SI are summarized in this appendix along with a summary of factors to enable readers to convert to English units.

Table A.1. SI Derived Units

\begin{tabular}{||l|l|c||}
\hline \multicolumn{1}{|c|}{ Quantity } & \multicolumn{1}{|c|}{ Unit } & Symbol \\
\hline Energy, work, heat ${ }^{(a)}$ & joule & $\mathrm{J}$ \\
\hline Power, radiant fiux & watt & $\mathrm{W}$ \\
\hline Electric potential & volt & $\mathrm{V}$ \\
\hline Electric resistance & ohm & $\mathrm{R}$ \\
\hline Conductance & siemans & $\mathrm{S}$ \\
\hline $\begin{array}{l}\text { (a) An energy unit accepted for limited use is the kilowatthour }(\mathrm{kWh}) . \\
1 \mathrm{kWh}=1,000 \mathrm{Wh}=3.6 \mathrm{MJ} .\end{array}$ \\
\hline
\end{tabular}

Table A.2. SI Prefixes

\begin{tabular}{||c|c|c||}
\hline Prefix & Symbol & Multiplication Factor \\
\hline exa & E & $10^{18}$ \\
\hline peta & P & $10^{15}$ \\
\hline tera & T & $10^{12}$ \\
\hline giga & G & $10^{9}$ \\
\hline mega & M & $10^{6}$ \\
\hline kilo & k & $10^{3}$ \\
\hline
\end{tabular}

Conversion Factors for Standard Units-Page A.1 
Table A.3. SI Area and Mass Units

\begin{tabular}{||l|r|r||}
\hline \multicolumn{1}{|c|}{ Quantity } & \multicolumn{1}{c|}{ Unit } & \multicolumn{1}{c|}{ Symbol } \\
\hline Area & $\cdot$ & \\
\hline Square meter & $1 \mathrm{~m}^{2}$ & $\mathrm{~m}^{2}$ \\
\hline Hectare & $10,000 \mathrm{~m}^{2}$ & ha \\
\hline Million hectares & $10^{6} \mathrm{ha}$ & Mha \\
\hline Mass & & \\
\hline Metric ton & $10^{3} \mathrm{~kg}$ & $\mathrm{t}$ \\
\hline Gigagram & $10^{9} \mathrm{~g}$ & $\mathrm{Gg}$ \\
\hline Million metric tons & $10^{6} \mathrm{t}$ & $\mathrm{Mt}$ \\
\hline Giga ton & $10^{9} \mathrm{t}$ & $\mathrm{Gt}$ \\
\hline \multicolumn{2}{|l}{} \\
\hline
\end{tabular}


Table A.4. Conversion of Metric Units to English Units

\begin{tabular}{|c|c|c|}
\hline To convert from & to & multiply by \\
\hline \multicolumn{3}{|l|}{ Basic units } \\
\hline \multicolumn{3}{|l|}{ Area } \\
\hline hectares (ha) & acres & 2.471 \\
\hline \multicolumn{3}{|l|}{ Mass } \\
\hline kilograms (kg) & pounds (mass) & 2.205 \\
\hline metric tons (t) & short ton $(2,000 \mathrm{lb})$ & 1.102 \\
\hline gigagrams $(\mathrm{Gg})$ & short ton $(2,000 \mathrm{lb})$ & $1.102 \times 10^{3}$ \\
\hline \multicolumn{3}{|l|}{ Energy } \\
\hline kilojoules (kJ) & British thermal units (Btus) & 0.9478 \\
\hline exajoules (EJ) & quad (10 ${ }^{15}$ Btus) & 0.9478 \\
\hline petajoules (PJ) & quad (10 15 Btus) & $0.9478 \times 10^{-3}$ \\
\hline \multicolumn{3}{|l|}{ Special Units } \\
\hline \multicolumn{3}{|l|}{ Carbon } \\
\hline kg carbon (kg C) & $\mathrm{lb} \mathrm{CO}_{2}$ & 8.084 \\
\hline \multicolumn{3}{|l|}{ Crop production } \\
\hline metric $t$ (corn) & bushel (56 lb) & 39.37 \\
\hline metric t (soybeans) & bushel (60 lb) & 36.74 \\
\hline metric $t$ (wheat) & bushel (60 lb) & 36.74 \\
\hline \multicolumn{3}{|l|}{ Crop yield } \\
\hline $\mathrm{kg} / \mathrm{ha}$ & lb/acre & 0.8922 \\
\hline metric $\mathrm{t} / \mathrm{ha}$ & short ton/acre & 0.4461 \\
\hline metric tha (corn) & bushels $(56 \mathrm{lb}) /$ acre & 15.93 \\
\hline metric tha (soybeans) & bushels $(60 \mathrm{lb}) / \mathrm{acre}$ & 14.87 \\
\hline metric tha (wheat) & bushels $(60 \mathrm{lb}) / \mathrm{acre}$ & 14.87 \\
\hline
\end{tabular}

Conversion Factors for Standard Units-Page A.3 
Appendix B

\section{Emissions Factors}


Table B.1. Factors: Carbon Coefficients and Assumptions

\begin{tabular}{|c|c|c|}
\hline Fuel Type & $\begin{array}{l}\text { Million Short Tons } \\
\text { Carbon Dioxide per } \\
\text { Quadrillion Btu }\end{array}$ & $\begin{array}{l}\text { Million Metric Tons } \\
\text { Carbon Dioxide per } \\
\text { Quadrillion Btu } \\
\text { (u) }\end{array}$ \\
\hline \multicolumn{3}{|l|}{ Petroleum } \\
\hline Motor Gasoline & 77.7 & 70.5 \\
\hline LPG & 69.1 & 62.7 \\
\hline Jet Fuel & 77.9 & 70.7 \\
\hline Distillate Fuel & 79.9 & 72.5 \\
\hline Residual Fuel & 86.6 & 78.6 \\
\hline Asphalt and Road $\mathrm{Oil}^{(\mathrm{b})}$ & 84.2 & 76.4 \\
\hline Lubricants $^{(\mathrm{b})}$ & 84.9 & 77.0 \\
\hline Petrochemical Feed & 77.8 & 70.6 \\
\hline Aviation Gas $^{(\mathfrak{B})}$ & 77.7 & 70.5 \\
\hline Kerosene & 77.9 & 70.7 \\
\hline Petroleum Coke ${ }^{(\mathrm{b})}$ & 109.2 & 99.1 \\
\hline Special Naphtha ${ }^{(b)}$ & 77.7 & 70.5 \\
\hline Other: Waxes and Miscellaneous ${ }^{(b)}$ & 84.2 & 76.4 \\
\hline \multicolumn{3}{|l|}{$\mathrm{Coal}^{(\mathrm{c})}$} \\
\hline Anthracite Coal & 112.5 & 102.1 \\
\hline Bituminous Coal & 101.5 & 92.1 \\
\hline Subbituminous Coal & 105.0 & 95.3 \\
\hline Lignite & 106.5 & 96.6 \\
\hline \multicolumn{3}{|l|}{ Natural Gas } \\
\hline Flare Gas $^{(\mathrm{b})}$ & 60.8 & 55.2 \\
\hline Natural Gas & 58.2 & 52.8 \\
\hline \multicolumn{3}{|c|}{$\begin{array}{l}\text { (a) Assumes conversion of } 1 \text { quadrillion Btu }=1.0551 \text { exajoules and fraction combusted }=99 \text { percent. } \\
\text { (b) Emissions coefficients are ELA estimates based on underlying chemical composition of the product. } \\
\text { (c) Coal emissions factor is for } 1990 \text { : varies by } \pm 0.2 \text { percent in other years. } \\
\text { NA = not available. }\end{array}$} \\
\hline
\end{tabular}

Emissions Factors-Page B.1 



\section{Appendix C}

Adjusted Electricity Emissions Factors by State 


\section{Use of the State-Level Electricity Emissions Factors}

The default emissions factors contained in this appendix are the simplest to use relative to other methods of calculating emissions. However, you should realize that these default factors will either underestimate or overestimate the actual emissions characteristics of any given power-generating equipment, as they represent the average emissions characteristics over a state. If available, you are encouraged to use emissions factors specific to your reported project, for example, a utility-specific factor that has incorporated actual fuel mix and dispatching modes.

For the purposes of the voluntary reporting program, and to retain flexibility and ease-of-use, Appendix $\mathrm{C}$ provides default state-level electrical emissions factors for carbon dioxide $\left(\mathrm{CO}_{2}\right)$, methane $\left(\mathrm{CH}_{4}\right)$, and nitrous oxide $\left(\mathrm{N}_{2} \mathrm{O}\right)$. Three factors are given for each state: one for emissions from utility generation, one for emissions from nonutility generation, and one combined utility/nonutility. If you know the source for your electricity (that is, utility or nonutility), you may use the appropriate factor. If you do not know or if you use both utility and nonutility sources, you should use the combined factors for your state.

Adjusted Electricity Emissions Factors by State-C.1 
Table C.1. Adjusted Electricity Emissions Factors by State

\begin{tabular}{|c|c|c|c|c|c|c|c|c|c|c|c|c|c|c|}
\hline \multirow[b]{2}{*}{ REGION } & \multirow[b]{2}{*}{ STATE } & \multicolumn{2}{|c|}{ UTILITY } & \multicolumn{2}{|c|}{ NUG } & \multicolumn{3}{|c|}{ COMBINED } & \multirow{2}{*}{\begin{tabular}{|c|} 
UTILITY \\
Weighted N20 \\
Emissions \\
Factor \\
(lbs/MWn) \\
\end{tabular}} & \multirow{2}{*}{$\begin{array}{c}\text { NUG } \\
\text { Weighted N20 } \\
\text { Emissions } \\
\text { Factor } \\
\text { (lbs/MWh) }\end{array}$} & \multirow{2}{*}{\begin{tabular}{|c|} 
UTILITY \\
Wolghted CH4 \\
Emissions \\
Factor \\
(lbs/MWh)
\end{tabular}} & \multirow{2}{*}{$\begin{array}{c}\text { NUG } \\
\text { Wolghtod CH4 } \\
\text { Emissions } \\
\text { Factor } \\
\text { (lbs/MWn) }\end{array}$} & \multicolumn{2}{|c|}{ COMBINED } \\
\hline & & \begin{tabular}{|c|}
$\mathrm{CO2}$ \\
Emissions \\
Factor \\
(short ton/MWn)
\end{tabular} & $\begin{array}{c}\mathrm{CO2} \\
\text { Emissions } \\
\text { Factor } \\
\text { (Ibs/MWh) }\end{array}$ & $\begin{array}{c}\text { Welghted CO2 } \\
\text { Emissions } \\
\text { Factor } \\
\text { (short ton/MWh) }\end{array}$ & $\begin{array}{c}\text { Woightod CO2 } \\
\text { Emissions } \\
\text { Factor } \\
\text { (Ibs/MWh) }\end{array}$ & $\begin{array}{c}\mathrm{CO2} \\
\text { Emissions } \\
\text { Factor } \\
\text { (short ton/MWm) }\end{array}$ & \begin{tabular}{|c|}
$\mathrm{CO} 2$ \\
Emissions \\
Factor \\
(bs/MWM)
\end{tabular} & $\begin{array}{c}\mathrm{CO} 2 \\
\text { Emissions } \\
\text { Factor } \\
\text { (metric ton } / \mathrm{MW} \text { ) }\end{array}$ & & & & & $\begin{array}{l}\text { Weighted N20 } \\
\text { Emissions } \\
\text { Factor } \\
\text { (lbs/MWM) }\end{array}$ & $\begin{array}{l}\text { Woighted CHA } \\
\text { Emissions } \\
\text { Factor } \\
\text { (lbs/MWh) }\end{array}$ \\
\hline \multirow{6}{*}{$\begin{array}{c}\text { New } \\
\text { England }\end{array}$} & Connocticut & 0.262 & 523 & 1.005 & 2010 & 0.358 & 715 & 0.324 & 0.037 & 0.290 & 0.005 & 0.052 & 0.0683 & 0.0104 \\
\hline & Maine & 0.126 & 251 & 1.157 & 2314 & 0.483 & 966 & 0.438 & 0.000 & 0.351 & 0.000 & 0.054 & 0.1170 & 0.0180 \\
\hline & Massachusetts & 0.711 & 1,422 & 0.824 & 1647 & 0.729 & 1459 & 0.662 & 0.118 & 0.184 & 0.021 & 0.056 & 0.1281 & 0.0266 \\
\hline & Now Hampshire & 0.340 & 680 & 1.283 & 2567 & 0.426 & 852 & 0.386 & 0.081 & 0.395 & 0.010 & 0.063 & 0.1077 & 0.0145 \\
\hline & Rhode lalend & 0.917 & 1,835 & 0.537 & 1074 & 0.546 & 1091 & 0.495 & 0.020 & 0.066 & 0.019 & 0.049 & 0.0644 & 0.0487 \\
\hline & Vermont & 0.066 & 131 & 0.586 & 1173 & 0.080 & 159 & 0.072 & 0.011 & 0.182 & 0.003 & 0.030 & 0.0152 & 0.0041 \\
\hline \multirow{3}{*}{$\begin{array}{c}\text { Mid } \\
\text { Atlantic }\end{array}$} & New Jersey & 0.302 & 605 & 0.616 & 1232 & 0.387 & 774 & 0.351 & 0.065 & 0.097 & 0.015 & 0.051 & 0.0731 & 0.0241 \\
\hline & Now York & 0.493 & 986 & 0.763 & 1527 & 0.518 & 1036 & 0.470 & 0.076 & 0.186 & 0.018 & 0.048 & 0.0859 & 0.0208 \\
\hline & Penneyivanla & 0.627 & 1,254 & 0.917 & 1835 & 0.643 & 1286 & 0.583 & 0.209 & 0.274 & 0.025 & 0.046 & 0.2128 & 0.0259 \\
\hline \multirow{5}{*}{$\begin{array}{l}\text { East-North } \\
\text { Contral }\end{array}$} & itinole & 0.432 & 865 & 0.814 & 1628 & 0.433 & 866 & 0.393 & 0.136 & 0.227 & 0.016 & 0.046 & 0.1360 & 0.0164 \\
\hline & Indiana & 1.086 & 2,171 & 0.633 & 1267 & 1.086 & 2171 & 0.985 & 0.335 & 0.126 & 0.040 & 0.044 & 0.3346 & 0.0398 \\
\hline & Michlgan & 0.792 & 1,584 & 0.756 & 1511 & 0.788 & 1576 & 0.715 & 0.253 & 0.168 & 0.031 & 0.052 & 0.2450 & 0.0327 \\
\hline & Ohlo & 0.903 & 1,807 & 1.111 & 2222 & 0.904 & 1807 & 0.820 & 0.302 & 0.344 & 0.036 & 0.053 & 0.3020 & 0.0355 \\
\hline & Wisconain & 0.664 & 1,329 & 1.063 & 2125 & 0.671 & 1343 & 0.609 & 0.241 & 0.336 & 0.029 & 0.049 & 0.2430 & 0.0292 \\
\hline \multirow{7}{*}{$\begin{array}{l}\text { West-North } \\
\text { Central }\end{array}$} & lown & 0.842 & 1,685 & 0.943 & 1885 & 0.843 & 1686 & 0.765 & 0.288 & 0.319 & 0.034 & 0.040 & 0.2878 & 0.0342 \\
\hline & Kaneas & 0.852 & 1,703 & 0.513 & 1027 & 0.852 & 1703 & 0.773 & 0.239 & 0.055 & 0.030 & 0.047 & 0.2386 & 0.0302 \\
\hline & Minnesota & 0.810 & 1,619 & 1.018 & 2035 & 0.814 & 1627 & 0.738 & 0.226 & 0.322 & 0.027 & 0.049 & 0.2278 & 0.0276 \\
\hline & Missount & 0.891 & 1,783 & 0.907 & 1815 & 0.891 & 1783 & 0.809 & 0.281 & 0.293 & 0.033 & 0.041 & 0.2814 & 0.0334 \\
\hline & Nobraska & 0.644 & 1,288 & N/A & N/A & 0.644 & 1288 & 0.580 & 0.189 & N/A & 0.023 & N/A & 0.189 & 0.023 \\
\hline & North Dakoth & 1.152 & 2,303 & 0.794 & 1589 & 1.151 & 2303 & 1.045 & 0.319 & 0.222 & 0.038 & 0.041 & 0.3194 & 0.0376 \\
\hline & South Dakote & 0.456 & 912 & N/A & N/A & 0.456 & 912 & 0.410 & 0.143 & N/A & 0.017 & N/A & 0.143 & 0.017 \\
\hline \multirow{9}{*}{$\begin{array}{c}\text { South } \\
\text { Atlantic }\end{array}$} & Detaware & 0.933 & 1,865 & 0.735 & 1470 & 0.928 & 1855 & 0.842 & 0.217 & 0.171 & 0.034 & 0.029 & 0.2161 & 0.0344 \\
\hline & Dintrict of Columbla & 1.324 & 2,649 & N/A & N/A & 1.324 & 2649 & 1.192 & 0.048 & N/A & 0.005 & N/A & 0.048 & 0.005 \\
\hline & Florlda & 0.633 & 1,266 & 1.144 & 2288 & 0.647 & 1294 & 0.587 & 0.159 & 0.340 & 0.027 & 0.058 & 0.1640 & 0.0275 \\
\hline & Georgin & 0.609 & 1,218 & 1.333 & 2665 & 0.610 & 1220 & 0.553 & 0.216 & 0.395 & 0.025 & 0.066 & 0.2160 & 0.0255 \\
\hline & Maryland & 0.675 & 1,350 & 1.005 & 2011 & 0.678 & 1356 & 0.615 & 0.205 & 0.263 & 0.026 & 0.057 & 0.2051 & 0.0260 \\
\hline & North Carollna & 0.650 & 1,300 & 1.138 & 2276 & 0.675 & 1350 & 0.612 & 0.222 & 0.371 & 0.026 & 0.050 & 0.2290 & 0.0276 \\
\hline & South Carolina & 0.332 & 665 & 1.439 & 2878 & 0.344 & 688 & 0.312 & 0.110 & 0.447 & 0.013 & 0.070 & 0.1130 & 0.0136 \\
\hline & Virginla & 0.488 & 977 & 1.101 & 2202 & 0.554 & 1107 & 0.502 & 0.163 & 0.336 & 0.022 & 0.053 & 0.1805 & 0.0253 \\
\hline & Wost Virginla & 1.007 & 2,013 & 0.645 & 1290 & 1.003 & 2005 & 0.909 & 0.337 & 0.208 & 0.040 & 0.029 & 0.3356 & 0.0396 \\
\hline
\end{tabular}

Adjusted Electricity Emissions Factors by State-C.2 
Table C.1. Adjusted Electricity Emissions Factors by State

\begin{tabular}{|c|c|c|c|c|c|c|c|c|c|c|c|c|c|c|}
\hline \multirow[b]{2}{*}{ REGION } & \multirow[b]{2}{*}{ STATE } & \multicolumn{2}{|c|}{ UTILITY } & \multicolumn{2}{|c|}{ NUG } & \multicolumn{3}{|c|}{ COMBINED } & \multirow{2}{*}{\begin{tabular}{|c|} 
UTILITY \\
Weighted N20 \\
Emissions \\
Factor \\
(lbs/MWh)
\end{tabular}} & \multirow{2}{*}{$\begin{array}{c}\text { NUG } \\
\text { Weighted N20 } \\
\text { Emissions } \\
\text { Factor } \\
\text { (lbs/MMh) }\end{array}$} & \multirow{2}{*}{\begin{tabular}{|c|} 
UTILITYY \\
Weighted CH4 \\
Emissions \\
Factor \\
(bs/MWh)
\end{tabular}} & \multirow{2}{*}{$\begin{array}{c}\text { NUG } \\
\text { Weighted CH4 } \\
\text { Emissions } \\
\text { Factor } \\
\text { (bs } / \text { MWh })\end{array}$} & \multicolumn{2}{|c|}{ COMBINED } \\
\hline & & \begin{tabular}{|c|}
$\mathrm{CO2}$ \\
Emissions \\
Factor \\
(short tonMMWh) \\
\end{tabular} & \begin{tabular}{|c|}
$\mathrm{CO2}$ \\
Emissions \\
Factor \\
(lbs $/ \mathrm{MW}$ ) \\
\end{tabular} & $\begin{array}{c}\text { Weighted } \mathrm{CO} 2 \\
\text { Emissions } \\
\text { Factor } \\
\text { (short ton/MWn) }\end{array}$ & $\begin{array}{c}\text { Weighted CO2 } \\
\text { Emissions } \\
\text { Factor } \\
\text { (Ibs/MMn) }\end{array}$ & $\begin{array}{c}\mathrm{CO2} \\
\text { Emissions } \\
\text { Factor } \\
\text { (short ton } / \mathrm{MW} \text { ) } \\
\end{array}$ & \begin{tabular}{|c|}
$\mathrm{CO2}$ \\
Emissions \\
Factor \\
(Ibs $\mathrm{MWWn})$ \\
\end{tabular} & \begin{tabular}{|c|}
$\mathrm{CO} 2$ \\
Emissions \\
Factor \\
(metric ton $M W$ W) \\
\end{tabular} & & & & & $\begin{array}{l}\text { Weighted N20 } \\
\text { Emissions } \\
\text { Factor } \\
\text { (bss/MWh) }\end{array}$ & $\begin{array}{l}\text { Weighted CH4 } \\
\text { Emissions } \\
\text { Factor } \\
\text { (lbs/MWh) }\end{array}$ \\
\hline \multirow{4}{*}{$\begin{array}{c}\text { East-South } \\
\text { Central }\end{array}$} & Alabama & 0.683 & 1,367 & 1.258 & 2515 & 0.684 & 1369 & 0.621 & 0.227 & 0.358 & 0.027 & 0.068 & 0.2277 & 0.0271 \\
\hline & Kontucky & 0.965 & 1,930 & N/A & N/A & 0.965 & 1930 & 0.869 & 0.323 & N/A & 0.038 & N/A & 0.323 & 0.038 \\
\hline & Mississippi & 0.533 & 1,066 & 1.487 & 2973 & 0.537 & 1075 & 0.487 & 0.137 & 0.439 & 0.029 & 0.079 & 0.1382 & 0.0290 \\
\hline & Tennessee & 0.667 & 1,334 & 1.066 & 2131 & 0.668 & 1335 & 0.606 & 0.226 & 0.342 & 0.027 & 0.050 & 0.2259 & 0.0266 \\
\hline \multirow{4}{*}{$\begin{array}{c}\text { West-South } \\
\text { Central }\end{array}$} & Arkanses & 0.642 & 1,284 & 1.293 & 2586 & 0.643 & 1286 & 0.584 & 0.182 & 0.364 & 0.025 & 0.073 & 0.1825 & 0.0250 \\
\hline & Loulsiana & 0.695 & 1,390 & 0.674 & 1348 & 0.694 & 1388 & 0.629 & 0.125 & 0.129 & 0.038 & 0.050 & 0.1248 & 0.0385 \\
\hline & Oklahoma & 0.834 & 1,667 & 0.867 & 1735 & 0.836 & 1672 & 0.758 & 0.219 & 0.252 & 0.047 & 0.046 & 0.2211 & 0.0470 \\
\hline & Texas & 0.798 & 1,596 & 0.576 & 1151 & 0.776 & 1552 & 0.704 & 0.172 & 0.087 & 0.041 & 0.048 & 0.1637 & 0.0413 \\
\hline \multirow{8}{*}{ Mountain } & Arizona & 0.399 & 797 & 1.140 & 2281 & 0.399 & 798 & 0.362 & 0.171 & 0.349 & 0.023 & 0.054 & 0.1709 & 0.0232 \\
\hline & Colorado & 1.015 & 2,030 & 0.582 & 1164 & 1.000 & 2001 & 0.908 & 0.320 & 0.114 & 0.038 & 0.044 & 0.3137 & 0.0385 \\
\hline & Idaho & 0.000 & 0 & 0.874 & 1748 & 0.134 & 269 & 0.122 & 0.000 & 0.261 & 0.000 & 0.046 & 0.0382 & 0.0067 \\
\hline & Montana & 0.774 & 1,548 & 0.950 & 1899 & 0.777 & 1553 & 0.704 & 0.230 & 0.319 & 0.027 & 0.041 & 0.2317 & 0.0276 \\
\hline & Novada & 1.011 & 2,021 & 0.257 & 515 & 0.937 & 1875 & 0.850 & 0.268 & 0.029 & 0.037 & 0.024 & 0.2457 & 0.0360 \\
\hline & New Maxico & 0.703 & 1,405 & 0.587 & 1174 & 0.703 & 1405 & 0.637 & 0.311 & 0.087 & 0.040 & 0.054 & 0.3111 & 0.0404 \\
\hline & Utah & 0.996 & 1,991 & 0.494 & 988 & 0.995 & 1990 & 0.903 & 0.329 & 0.062 & 0.040 & 0.047 & 0.3283 & 0.0399 \\
\hline & Wyoming & 1.097 & 2,194 & 0.633 & 1267 & 1.097 & 2194 & 0.995 & 0.334 & 0.149 & 0.039 & 0.043 & 0.3343 & 0.0393 \\
\hline \multirow{3}{*}{$\begin{array}{c}\text { Pacific } \\
\text { Contiguous }\end{array}$} & Callfomia & 0.287 & 573 & 0.593 & 1186 & 0.378 & 756 & 0.343 & 0.004 & 0.123 & 0.027 & 0.042 & 0.0392 & 0.0315 \\
\hline & Oregon & 0.097 & 195 & 1.309 & 2618 & 0.118 & 235 & 0.107 & 0.039 & 0.400 & 0.009 & 0.066 & 0.0448 & 0.0102 \\
\hline & Washington & 0.138 & 276 & 0.915 & 1831 & 0.153 & 306 & 0.139 & 0.043 & 0.241 & 0.006 & 0.055 & 0.0461 & 0.0069 \\
\hline \multirow{3}{*}{$\begin{array}{c}\text { Pacific } \\
\text { Non-contiguous } \\
\end{array}$} & Ataska & 0.000 & 1 & 0.834 & 1667 & 0.016 & 31 & 0.014 & 0.173 & 0.201 & 0.091 & 0.049 & 0.1732 & 0.0907 \\
\hline & Hawali & 0.700 & 1,399 & 0.943 & 1886 & 0.757 & 1514 & 0.687 & 0.042 & 0.248 & 0.005 & 0.036 & 0.0888 & 0.0120 \\
\hline & U.S. Moan & 0.648 & 1,296 & 0.896 & 1792 & 0.646 & 1291 & 0.586 & 0.179 & 0.245 & 0.026 & 0.050 & 0.1872 & 0.0291 \\
\hline
\end{tabular}

Adjusted Electricity Emissions Factors by State-C.3 


\section{Methodology Used to Develop Electricity Emissions Factors by State}

\section{C.1 Utility $\mathrm{CO}_{2}$ Emissions Factors}

To arrive at the carbon dioxide emissions factors in pounds per megawatt hour (lb/MWh), for each state, carbon dioxide emissions for 1992 in thousand short tons were converted to pounds (short tons multiplied by 2,000 pounds), then divided by 1992 net generation in million kilowatt hours $\left(10^{6}\right.$ $\mathrm{kWh}$ ). (Since these factors are principally for use by consumers of electricity, gross generation is not used.) The resultant value was then multiplied by 1,000 to convert pounds per kilowatt hour to pounds per megawatt hour. Because transmission and distribution losses have not been included, the emissions factors are considered conservative.

Example: State of Wisconsin

$\mathrm{CO}_{2}$ Emissions $\quad=30,867 \times 10^{3}$ short tons

$$
=30,867 \times 10^{3} \text { short tons } \bullet 2,000 \mathrm{lb}=61,734 \times 10^{6} \mathrm{lb}
$$

Net Generation $\quad=46,464 \times 10^{6} \mathrm{kWh}$

$\mathrm{CO}_{2}$ Emission Factor $=61,734 \times 10^{6} \mathrm{lb} / 46,464 \times 10^{6} \mathrm{kWh}=1,329 \mathrm{lbs} / \mathrm{MWh}$

Source: DOE/EIA 1994, Table 46, third column, Electric Utility $\mathrm{CO}_{2}$ Emissions in thousand short tons and Table 12, first column, Electric Utility Net Generation in million kilowatthours.

\section{C.2 Utility Methane and Nitrous Oxide Emissions Factors}

The utility weighted non- $\mathrm{CO}_{2}$ emissions factors were calculated by assigning representative technologies to each energy source. These representative technologies for each energy source were compiled from 1992 information collected by the Energy Information Administration. The emissions factors (in pounds per megawatt hour), developed by NREL (1993), DOE (1991), WAPA (1994), and IPCC (1991), for these technologies were multiplied by the 1992 net generation (in millions of kilowatt hours) to give pounds of methane and nitrous oxide emissions. Finally, the pounds of methane and nitrous oxide emissions from each energy source were added and the sum divided by the total net generation. (See the example below, computing the nitrous oxide emissions factor for the state of Wisconsin.) 
Example: Weighted $\mathrm{N}_{2} \mathrm{O}$ Emissions Factor for the State of Wisconsin for 1992

\begin{tabular}{|c|c|c|c|}
\hline Technology & $\begin{array}{l}\text { Net Generation } \\
\left(10^{3} \mathrm{MWh}\right)\end{array}$ & $\begin{array}{l}\mathrm{N}_{2} \mathrm{O} \text { Emissions } \\
\text { Pactor } \\
\text { (lbs/MWh) }\end{array}$ & $\begin{array}{l}\text { Estimated } \mathrm{N}_{2} \mathrm{O} \\
\text { Emissions } \\
\text { (thousand lbs) }\end{array}$ \\
\hline Coal - Pulverized & 32,741 & 0.34 & $11,131.94$ \\
\hline Nuclear/Other & 11,207 & 0.00 & 0.00 \\
\hline Hydroelectric & 2,123 & 0.00 & 0.00 \\
\hline Wood - Steam Turbine & 133 & 0.55 & 73.15 \\
\hline $\begin{array}{l}\text { Municipal Solid Waste - } \\
\text { Steam Turbine }\end{array}$ & 16 & 0.55 & 8.80 \\
\hline Gas - Steam Turbine & 173 & 0.00 & 0.00 \\
\hline Gas - Combustion Turbine & 15 & 0.24 & 3.6 \\
\hline Oil - Steam Turbine & 53 & 0.00 & 0.00 \\
\hline Oil - Combustion Turbine & 2 & 0.276 & 0.55 \\
\hline Total & 46,464 & . & $11,218.04$ \\
\hline \multicolumn{4}{|c|}{$\begin{array}{l}\text { Weighted } \mathrm{N}_{2} \mathrm{O} \text { Emissions Factor for State of Wisconsin for } 1992 \text { : } \\
{\left[\left(11,218.04 \times 10^{3} \mathrm{lbs} \text { of } \mathrm{N}_{2} 0\right) /\left(46,464 \times 10^{6} \mathrm{kWh}\right)\right] \bullet 10^{3} \mathrm{kWh} / \mathrm{MWh}=\underline{0.241 \mathrm{lbs} / \mathrm{MWh}}}\end{array}$} \\
\hline
\end{tabular}

Adjusted Electricity Emissions Factors by State-C.5 


\section{C.3 Nonutility $\mathrm{CO}_{2}$ and Non- $\mathrm{CO}_{2}$ Weighted Emissions Factors Calculation}

The weighted emissions factors for nonutility generators were calculated as outlined above for utility non-carbon dioxide emission factors, based on "bottom-up" (technology) methodology. The emissions factors for each technology are listed in the Emissions Factors for Selected Technologies table below.

Deliveries data in millions of kilowatt hours were used to account for sales, interchanges, and exchanges of electric energy with utilities and other nonutilities.

Source: DOE/EIA 1994, Tables 79 and 82.

\section{Emissions Factors for Selected Technologies}

\begin{tabular}{|c|c|c|c|}
\hline Technology & $\begin{array}{l}\mathrm{CO}_{2} \text { Emissions } \\
\text { Factor (lbs/MWh) }\end{array}$ & $\begin{array}{c}\mathrm{N}_{2} \mathrm{O} \text { Emissions Factor } \\
\text { (lbs/MWh) }\end{array}$ & $\begin{array}{c}\mathrm{CH}_{4} \text { Emissions Factor } \\
\text { (lbs/MWh) }\end{array}$ \\
\hline Coal - Pulverized & 1,970 & 0.34 & 0.04 \\
\hline Nuclear/Other & 0.00 & 0.00 & 0.00 \\
\hline Hydroelectric & 0.00 & 0.00 & 0.00 \\
\hline Wood Waste Biomass Boiler & 3,400 & 0.55 & 0.14 \\
\hline Municipal Solid Waste Boiler & 3,747 & 0.55 & 0.02 \\
\hline Gas - Steam Turbine & 968 & 0.00 & 0.05 \\
\hline Gas - Combustion Turbine & 1,560 & 0.24 & 0.16 \\
\hline Gas- Combined Cycle & 952 & 0.063 & 0.015 \\
\hline Oil - Steam Turbine & 1,452 & 0.00 & 0.002 \\
\hline Oil - Combustion Turbine & 2,150 & 0.276 & 0.021 \\
\hline Oil- Combined Cycle & 1,330 & 0.268 & 0.013 \\
\hline Renewables & 0.00 & 0.00 & 0.00 \\
\hline
\end{tabular}

Adjusted Electricity Emissions Factors by State-C.6 


\section{C.4 Combined Emissions Factors}

To calculate combined $\mathrm{CO}_{2}, \mathrm{~N}_{2} \mathrm{O}$, and $\mathrm{CH}_{4}$ utility/nonutility factors, the sum of utility and non-utility $\mathrm{CO}_{2}$ emissions was divided by the sum of utility and nonutility generation.

\section{C.5 References}

Intergovernmental Panel on Climate Change (IPCC). 1991. Estimation of Greenhouse Gas Emissions and Sinks, Geneva.

National Renewable Energy Laboratory (NREL). 1993. Environmental Characterization Data Phase II: Utility and Transportation Data. NREL, Golden CO.

United States Department of Energy (DOE). 1991. Limiting Net Greenhouse Gas Emissions in the United States Vblume I: Energy Technologies. USDOE, Washington, DC.

United States Department of Energy (DOE) Energy Information Administration (EIA). 1992. Electric Power Annual 1992. DOE/EIA-0348. DOE/EIA, Washington, DC.

United States Environmental Protection Agency (EPA). 1990. Estimation of Greenhouse Gas Emissions and Sinks for the United States 1990. EPA Office of Policy Planning and Evaluation, Washington, DC.

Western Area Power Administration (WAPA). 1994. Energy Planning and Management Program Draft Environmental Impact Statement. WAPA, Golden, CO. 


\section{Appendix D}

\section{Conversion of Carbon to Carbon Dioxide Emissions}




\section{Conversion of Carbon to Carbon Dioxide Emissions}

Many times project analysis starts with data on the carbon content of fuels or the release of carbon from sinks. This means that the analysis may end with a result expressed in terms of carbon emissions or carbon capture. However, the EPAct 1605(b) voluntary reporting program requires that reports be expressed in terms of greenhouse gases-that is, carbon dioxide.

The conversion of quantities of carbon to quantities of carbon dioxide is simple. The atomic weight of carbon is 12 . The atomic weight of oxygen is 16 . Hence, the molecular weight of carbon dioxide (carbon dioxide) is 44 (one atom of carbon, 12, plus two atoms of oxygen, 32). This means that 12 grams (or pounds or tons) of carbon released as carbon dioxide is associated with 44 grams (or pounds or tons) of carbon dioxide. Therefore, the conversion from carbon released to carbon dioxide emissions can be expressed as follows:

Weight of $\mathrm{CO}_{2}=44 / 12$ weight of carbon $=3.67$ weight of carbon 
Appendix E

\section{Reportable Greenhouse Gases for Which Global Warming Potentials} Have Been Developed 


\section{Reportable Greenhouse Gases for Which Global Warming Potentials Have Been Developed}

A Global Warming Potential (GWP) is a measure, or index, of the impact that each gas has on global warming relative to the effect that carbon dioxide has. So, for example, if a kilogram of a certain gas has a GWP of 2, that kilogram of that gas is expected to have twice as much effect on global warming as a kilogram of carbon dioxide. Using GWPs helps decision-makers (for example, in utilities or industry) and policymakers put different greenhouse gases on an equivalent scale to perform a wide variety of analyses:

- performing cost-benefit analyses of various candidate projects to reduce greenhouse gas emissions

- assessing the relative contributions of the many human activities contributing to greenhouse gas emissions

- comparing (and ranking) climate effects from competing technologies and energy uses, including consideration of different energy policies

- developing approaches to minimize the impact of human activities on the climate system

- comparing the global climate change contributions of various countries

- functioning as a signal to policymakers for encouraging some activities and discouraging others

- determining approaches most appropriate for industries and governments to meet commitments to help reduce the radiative forcing on climate from increasing concentrations and emissions of greenhouse gases.

Several factors affect the GWP value for any particular gas. Gases that have large immediate warming effects (instantaneous radiative forcing) will generally have higher GWPs. However, the effects of greenhouse gases are realized over a period of time, so the second important factor in calculating a GWP is the length of time the gas stays in the atmosphere (atmospheric lifetime). Generally, gases with longer atmospheric lifetimes will have higher GWPs than gases with shorter lifetimes. Finally, some gases interact with other gases in the atmosphere (indirect effects) to either increase or decrease the impact of the gases.

The GWPs listed in Table E.1 were developed recently for the Intergovernmental Panel on Climate Change (IPCC 1994). This list will replace GWPs developed previously (IPCC 1990, 1992); as the science continues to evolve, the gases and the values will likely be revised again. Because of the difficulty in modeling the interactions of the various gases, these GWPs do not include indirect effects except where noted. (See, for example, methane.)

Table E.1 actually contains three sets of GWPs, each set calculated over a different time period. The GWP calculated for 20 years provides a comparison of the effects of gases in the relatively near

\section{Reportable Greenhouse Gases for Which Global Warming Potentials Have Been Developed-Page E.1}


future. In contrast, the 500-year index will give a relatively higher GWP values to long-lived gases than the 20-year GWP values.

As you use these GWPs, remember the limitations of such a measure. First, for most gases the GWPs do not account for indirect effects. So, for example, while CFC-11 appears to be 5,000 times as potent a greenhouse gas as carbon dioxide over the short term, its indirect effects may entirely negate its direct effects. This possibility is not reflected in the GWP index. Second, the modeling of atmospheric chemistry is rapidly changing. These GWPs are significantly different from those used by the IPCC two years ago, and they will probably be revised again. Third, these GWPs rest on an assumption that the background concentration of carbon dioxide is stable and that the atmospheric system is in equilibrium. This assumption is clearly unrealistic, though it helps to provide consistency in making assessments. 
Table E.1. Direct Global Warming Potentials ${ }^{(a)}$

\begin{tabular}{|c|c|c|c|c|c|}
\hline \multirow[b]{2}{*}{ Species } & \multirow{2}{*}{$\begin{array}{l}\text { Chemical } \\
\text { Formula }\end{array}$} & \multirow{2}{*}{$\begin{array}{l}\text { Atmospheric } \\
\text { Lifetime } \\
\text { (years) }\end{array}$} & \multicolumn{3}{|c|}{$\begin{array}{c}\text { Global Warming Potential } \\
\text { (Time Horizon) }\end{array}$} \\
\hline & & & 20 years & 100 years & 500 years \\
\hline $\mathrm{CO}_{2}$ & $\mathrm{CO}_{2}$ & (b) & 1 & 1 & 1 \\
\hline \multicolumn{6}{|l|}{ CFCs } \\
\hline CFC-11 & $\mathrm{CFCl}_{3}$ & $50 \pm 5$ & 5000 & 3900 & 1400 \\
\hline CFC-12 & $\mathrm{CF}_{2} \mathrm{Cl}_{2}$ & 102 & 8000 & 8300 & 4000 \\
\hline CFC-13 & $\mathrm{CClF}_{3}$ & 640 & 8700 & 12100 & 13800 \\
\hline CFC-113 & $\mathrm{C}_{2} \mathrm{~F}_{3} \mathrm{Cl}_{3}$ & 85 & 5100 & 4900 & 2200 \\
\hline CFC-114 & $\mathrm{C}_{2} \mathrm{~F}_{4} \mathrm{Cl}_{2}$ & 300 & 7000 & 9100 & 7900 \\
\hline$\overline{C F C}-115$ & $\mathrm{C}_{2} \mathrm{~F}_{5} \mathrm{Cl}$ & 1700 & 6300 & 9100 & 12400 \\
\hline \multicolumn{6}{|l|}{ HCFCS, etc. } \\
\hline HCFC-22 & $\mathrm{CF}_{2} \mathrm{HCl}$ & 13.3 & 4300 & 1600 & 500 \\
\hline HCFC-123 & $\mathrm{C}_{2} \mathrm{~F}_{3} \mathrm{HCl}_{2}$ & 1.4 & 310 & 90 & 30 \\
\hline HCFC-124 & $\mathrm{C}_{2} \mathrm{~F}_{4} \mathrm{HCl}$ & 5.9 & 1500 & 470 & 140 \\
\hline HCFC-141b & $\mathrm{C}_{2} \mathrm{FH}_{2} \mathrm{Cl}_{3}$ & 9.4 & 1800 & 620 & 190 \\
\hline HCFC-142b & $\mathrm{C}_{2} \mathrm{~F}_{2} \mathrm{H}_{3} \mathrm{Cl}$ & 19.5 & 4300 & 2000 & 600 \\
\hline HCFC-225CA & $\mathrm{C}_{3} \mathrm{~F}_{5} \mathrm{HCl}_{2}$ & 2.5 & 590 & 180 & 50 \\
\hline HCFC-225CB & $\mathrm{C}_{3} \mathrm{~F}_{5} \mathrm{HCl}_{2}$ & 6.6 & 1800 & 570 & 170 \\
\hline Carbon Tetrachloride & $\mathrm{CCl}_{4}$ & 42 & 2000 & 1400 & 480 \\
\hline Methyl Chloroform & $\mathrm{CH}_{3} \mathrm{CCl}_{3}$ & $5.4 \pm 0.4$ & 360 & 110 & 30 \\
\hline \multicolumn{6}{|l|}{ Bromocarbons ${ }^{(i)}$} \\
\hline $\mathrm{H}-1301$ & $\mathrm{CF}_{3} \mathrm{Br}$ & 65 & 6300 & 5500 & 2100 \\
\hline \multicolumn{6}{|l|}{ Other } \\
\hline HFC-23 & $\mathrm{CHF}_{3}$ & 390 & 9500 & 12700 & 12400 \\
\hline HFC-32 & $\mathrm{CH}_{2} \mathrm{~F}_{2}$ & 6 & 1900 & 570 & 180 \\
\hline HFC-43-10mee & & 20.8 & 3400 & 1600 & 490 \\
\hline HFC- 125 & $\mathrm{C}_{2} \mathrm{HF}_{5}$ & 36.0 & 5000 & 3200 & 1100 \\
\hline HFC-134 & $\mathrm{C}_{2} \mathrm{H}_{2} \mathrm{~F}_{4}$ & 11.9 & 3200 & 1160 & 350 \\
\hline HFC-134a & $\mathrm{CH}_{2} \mathrm{FCF}_{3}$ & 17.7 & 3800 & 1700 & 510 \\
\hline HFC-152a & $\mathrm{C}_{2} \mathrm{H}_{4} \mathrm{~F}_{2}$ & 1.5 & 440 & 130 & 40 \\
\hline HFC-143a & $\mathrm{C}_{2} \mathrm{H}_{3} \mathrm{~F}_{3}$ & 55 & 5300 & 4300 & 1600 \\
\hline
\end{tabular}

Reportable Greenhouse Gases for Which Global Warming Potentials Have Been Developed-Page E.3 
Table E.1. (cont'd)

\begin{tabular}{|c|c|c|c|c|c|}
\hline \multirow[b]{2}{*}{ Species } & \multirow{2}{*}{$\begin{array}{l}\text { Chemical } \\
\text { Formula }\end{array}$} & \multirow{2}{*}{$\begin{array}{l}\text { Atmospheric } \\
\text { Lifetime } \\
\text { (years) }\end{array}$} & \multicolumn{3}{|c|}{$\begin{array}{c}\text { Global Warming Potential } \\
\text { (Time Horizon) }\end{array}$} \\
\hline & & & 20 years & 100 years & 500 years \\
\hline HFC-227ea & $\mathrm{C}_{3} \mathrm{HF}_{7}$ & 43.0 & 4800 & 3300 & 1100 \\
\hline HFC-236fa & $\mathrm{C}_{3} \mathrm{H}_{2} \mathrm{~F}_{6}$ & 265 & 6200 & 7900 & 6500 \\
\hline HFC-245ca & $\mathrm{C}_{3} \mathrm{H}_{3} \mathrm{~F}_{5}$ & 1.0 & 300 & 90 & 30 \\
\hline HFC-245ca & $\mathrm{C}_{3} \mathrm{H}_{3} \mathrm{~F}_{5}$ & 9.2 & 2400 & 790 & 240 \\
\hline Chloroform & $\mathrm{CHCl}_{3}$ & 0.55 & 20 & 5 & 1 \\
\hline Methylene chloride & $\mathrm{CH}_{2} \mathrm{Cl}_{2}$ & 0.41 & 30 & 10 & 3 \\
\hline Sulfur hexafluoride & $\mathrm{SF}_{6}$ & 3200 & 9300 & 13600 & 19500 \\
\hline Perfluoromethane & $\mathrm{CF}_{4}$ & 50000 & 2700 & 4000 & 6100 \\
\hline Perfluoroethane & $\mathrm{C}_{2} \mathrm{~F}_{6}$ & 10000 & 6100 & 9000 & 13500 \\
\hline $\begin{array}{l}\text { Perfluorocyclo- } \\
\text { butane }\end{array}$ & $\mathrm{c}-\mathrm{C}_{4} \mathrm{~F}_{8}$ & 3200 & 6100 & 8900 & 12800 \\
\hline Perfluorohexane & $\mathrm{C}_{6} \mathrm{~F}_{14}$ & 3200 & 5600 & 8900 & 17800 \\
\hline Methane $^{(c)}$ & $\mathrm{CH}_{4}$ & $12-18^{(d)}$ & $56-110$ & $19-43$ & $9-16$ \\
\hline Nitrous oxide & $\mathrm{N}_{2} \mathrm{O}$ & 121 & 290 & 320 & 170 \\
\hline $\begin{array}{l}\text { Trifluoroiodo- } \\
\text { methane }\end{array}$ & $\mathrm{CF}_{3} \mathrm{I}$ & $<0.005$ & $<6$ & $<<1$ & $<<<1$ \\
\hline Carbon monoxide $e^{(e)}$ & $\mathrm{CO}$ & months & + & + & + \\
\hline $\begin{array}{l}\text { Nonmethane } \\
\text { hydrocarbons }{ }^{(e)}\end{array}$ & NMHCs & days to months & + & + & + \\
\hline Nitrous oxides ${ }^{(e)}$ & $\mathrm{NO}_{x}$ & days & + & + & + \\
\hline \multicolumn{6}{|c|}{$\begin{array}{l}\text { (a) Referenced to the AGWP for the Bern carbon cycle model } \mathrm{CO}_{2} \text { decay response and future } \mathrm{CO}_{2} \\
\text { atmospheric concentrations held constant at current levels (based on IPCC } 1994 \text { and WMO } \\
\text { 1994). } \\
\text { (b) Decay of } \mathrm{CO}_{2} \text { is a complex function of the carbon cycle. } \\
\text { (c) Includes direct and indirect components. } \\
\text { (d) Includes the dependence of the residence time on } \mathrm{CH}_{4} \text { abundance. } \\
\text { (e) GWPs for indirect effects involving emissions from short-lived gases are particularly difficult to } \\
\text { evaluate, though the sign of these three types is expected to be positive. } \\
\text { (f) You may report other halogenated substances, such as } \mathrm{H}-1211 \text { and } \mathrm{H}-2402 \text {, that are not listed in } \\
\text { this table and for which the IPCC has not developed an estimate of global warming potential. }\end{array}$} \\
\hline
\end{tabular}

Reportable Greenhouse Gases for Which Global Warming Potentials Have Been Developed-Page E.4 